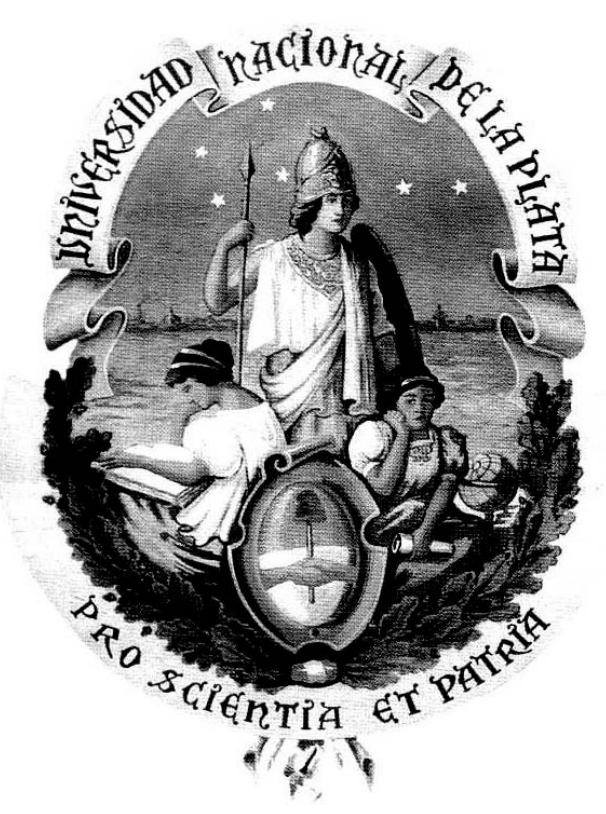

Universidad Nacional de La Plata

Facultad de Ciencias Astronómicas y Geofísicas

\title{
Tesis doctoral \\ INVESTIGACIÓN DE GALAXIAS LOCALES DE BAJA LUMINOSIDAD MEDIANTE PERFILES DE HIDRÓGENO NEUTRO
}

Lic. Juliana Saponara

\author{
Directora: Dra. Paula Benaglia \\ Co-Directora: Dra. Bärbel S. Koribalski
}

La Plata, Argentina 


\section{Declaración}

Esta tesis es la presentación de mi trabajo de investigación original para obtener el Doctorado en Astronomía en la Universidad Nacional de La Plata, Argentina. Donde sea que haya contribución de otros, se hace todo lo posible para indicar esto claramente, con la debida referencia a la literatura y el reconocimiento de la investigación y las discusiones de colaboración.

El trabajo se realizó bajo la dirección de la Dra. P. Benaglia y la codirección de la Dra. B. S. Koribalski, en el Instituto Argentino de Radioastronomía (IAR CONICETCIC), Buenos Aires, Argentina. 


\section{Resumen}

En general, los procesos que conducen a la evolución de las galaxias se pueden dividir en: internos, por ejemplo, eventos de formación estelar, supernovas y externos, por ejemplo, interacciónes de marea, barrido por presión cinética, fusiones. Las observaciones de hidrógeno neutro ( $\mathrm{HI}$ ) son una excelente herramienta para estudiar las interacciones entre galaxias o entre galaxias y su entorno. La línea de $21 \mathrm{~cm}$ (H I) proporciona información espacial y cinemática del gas. Nos permite derivar la masa total del H I gas en una galaxia, estudiar las fases fría y tibia del medio interestelar y, además, señalar las ubicaciones de posibles regiones de formación estelar.

Usando las observaciones de archivo del Autralia Telescope Compact Array y nuevas obtenidas con el Giant Metrewave Radio Telescope, analizamos galaxias que pertenecen a diferentes entornos. Estudiamos, en primer lugar, la región central del grupo de galaxias IC 1459. El grupo contiene alrededor de diez galaxias; la mayoría de ellas son galaxias de tipo tardío, pero la central, la cual da nombre al grupo, es una galaxia elíptica de tipo temprano. Nuestra búsqueda de emisión extendida de H I utilizando datos de archivo de ATCA reveló la presencia de un complejo de nubes cerca de la galaxia IC 1459. También, se observa en este grupo la distribución de morfología-densidad, siendo las galaxias NGC 5264 y NGC 7418A deficientes en H I. Proponemos entonces, que el complejo de nubes de $\mathrm{H}$ I se originó principalmente por las interacciones de mareas entre las galaxias IC 1459, NGC 5264 y NGC 7418A.

Continuamos nuestra investigación estudiando la galaxia enana KK 69. Esta galaxia es parte de un pequeño grupo ubicado cerca de la región de baja densidad, Gemini-Leo. Encontramos un desplazamiento entre la región de alta densidad estelar observada en las imágenes ópticas, y la región de alta densidad del gas H i detectada con el GMRT. Propusimos que KK 69 es una galaxia enana de transición, que evoluciona de una galaxia enana rica en gas (enana irregular) a una enana pobre en gas (enana esferoidal). Por primera vez, en esta galaxia, se pudo llevar a cabo la descomposición del medio interestelar en las fases fría y tibia del gas neutro. Aproximadamente el $19 \%$ de la masa total del H i se encontró en la fase de fría; este valor excepcional es una característica común con la galaxia enana Leo T perteneciente al Grupo Local. Aunque la componente fría del gas es el combustible principal para el proceso de formación de estrellas, la galaxia no está formando estrellas en la actualidad.

Terminamos nuestro proyecto estudiando la galaxia Fourcade-Figueroa, una galaxia espiral vista de canto, situada detrás del lóbulo sur de la galaxia Cen A. Combinamos los datos ATCA disponibles con las nuevas observaciones dedicadas en GMRT en el plano de visibilidades, definidas por las proyecciones de las líneas de conexión entre pares de antenas. El disco de la galaxia está deformado en la región noroeste de la galaxia. Modelamos la distribución de masa de la galaxia a partir de la curva de rotación obtenida con nuestros datos y encontramos que el halo de materia oscura que mejor 
ajusta es el de Navarro, Frenk y White. 


\section{Índice general}

1. Introducción $\quad 1$

1.1. Formación de galaxias . . . . . . . . . . . . . . . . . . 1

1.2. Clasificación de galaxias . . . . . . . . . . . . . . . . . . . . . . . . . . . . . . . . .

1.2.1. Galaxias enanas . . . . . . . . . . . . . . . . 6

1.3. Interacción entre galaxias . . . . . . . . . . . . . . . 8

2. El hidrógeno neutro $\quad 11$

2.1. Origen de la emisión del $\mathrm{H}$ I . . . . . . . . . . . . . . . . . . . . 12

2.2. Reducción de los datos y construcción de las imágenes . . . . . . . . . . 12

2.3. Parámetros obtenidos del H I . . . . . . . . . . . . . . . . . 15

2.3.1. Mapas de momentos . . . . . . . . . . . . . . . . . . . . 15

2.3.2. Momento de orden 0 . . . . . . . . . . . . . 15

2.3.3. Momento de orden 1 . . . . . . . . . . . . . . . 15

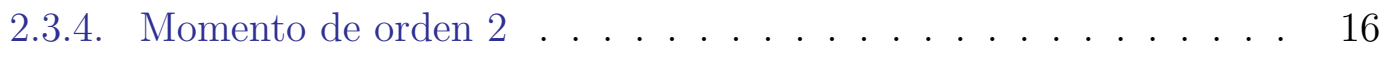

2.3.5. Distribución global del espectro de $\mathrm{H}$ I $\ldots . . . . .16$

2.3.6. Curva de rotación . . . . . . . . . . . . . . . . . . 17

2.4. Mediciones complementarias . . . . . . . . . . . . . . . . . 19

2.5. Efectos ambientales en la evolución de las galaxias . . . . . . . . . . . 19

3. Muestra seleccionada 21

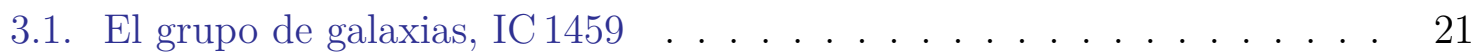

3.2. La galaxia enana KK $69 \ldots \ldots$. . . . . . . . . . . . . . . . . . . . . . . . . . . . . . . . . . . . . . . . . 22

3.3. La galaxia Fourcade-Figueroa . . . . . . . . . . . . . . . . . . 22

3.4. Parkes, ATCA y GMRT . . . . . . . . . . . . . 23

4. Escombros de HI en el grupo de galaxias IC $1459 \quad 25$

4.1. El grupo de galaxias IC 1459 galaxy . . . . . . . . . . . . . . 25

4.2. Observaciones y reducción de los datos . . . . . . . . . . . . . . . . . . . . 30

4.3. Resultados . . . . . . . . . . . . . . . . . . 32

4.3.1. Escombros de H I en los alrededores de IC 1459 . . . . . . . . . 34

4.3.2. Emisión continua y línea de absorción . . . . . . . . . . . . . . . 39

4.3.3. H i en las galaxias miembro del grupo IC 1459 . . . . . . . . . . 39

4.4. Discusión . . . . . . . . . . . . . . . . . . 45

4.5. Resumen . . . . . . . . . . . . . . . . . 46 
5. KK 69, una galaxia enana en transición $\quad 49$

5.1. KK69 y el ambiente donde se encuentra . . . . . . . . . . . . . . . . 49

5.2. Observaciones y reducción de los datos . . . . . . . . . . . . . 53

5.3. Resultados . . . . . . . . . . . . . . . . . 55

5.3.1. Distribución y cinemática del H I . . . . . . . . . . . . . 55

5.3.2. Identificación de la component fría y tibia del medio interestelar de la galaxia KK69 . . . . . . . . . . . . . . . . . . 60

5.4. Discusión . . . . . . . . . . . . . . . . . . 64

5.4.1. El medio interestelar de la galaxia KK 69 . . . . . . . . . . . . 64

5.4.2. Clasificando morfológicamente a KK 69 . . . . . . . . . . . 65

5.5. Resumen . . . . . . . . . . . . . . . . . 66

$\begin{array}{ll}\text { 6. La galaxia Fourcade-Figueroa } & \mathbf{6 9}\end{array}$

6.1. Introducción . . . . . . . . . . . . . . . . . . . . . 69

6.1.1. La galaxia Fourcade-Figueroa . . . . . . . . . . . . . . 70

6.2. Observaciones y reducción de los datos . . . . . . . . . . . . . . 71

6.2.1. Datos de archivo del "Australia Telescope Compact Array" . . . 73

6.2.2. Datos obtenidos con el "Giant Metrewave Radio Telescope" . . 78

6.3. Combinación de los datos de ATCA con los de GMRT. . . . . . . . . . 82

6.4. Resultados y Discusión . . . . . . . . . . . . . . . 85

6.4.1. Distribución del HI . . . . . . . . . . . . . . . . . . . . 88

6.4.2. Cinemática, modelado 3D de la curva de rotación utilizando FAT 88

6.4.3. Distribución de luminosidad de la galaxia FF . . . . . . . . . 90

6.5. Modelado de la distribución de masa . . . . . . . . . . . . . . . . . . . 92

6.5.1. Halo de materia oscura . . . . . . . . . . . . . . . . 93

6.6. Resumen . . . . . . . . . . . . . . . . . . . . 95

$\begin{array}{ll}\text { 7. Conclusiones generales } & 97\end{array}$

A. Catálogo de Parámetros del HI en galaxias (CHIPA) 99

A.1. Introducción . . . . . . . . . . . . . . . . . . . . . 99

A.2. Breve descripción de los relevamientos . . . . . . . . . . . . . . . 101

A.3. Parámetros disponibles . . . . . . . . . . . . . . . . . . . 101

$\begin{array}{ll}\text { B. Tutoriales } & 103\end{array}$

$\begin{array}{ll}\text { References } & 118\end{array}$ 


\section{Índice de figuras}

1.1. Red conceptual del modelo de formación de galaxias de acuerdo al modelo $\Lambda$ CDM . . . . . . . . . . . . . . . . . . 2

1.2. Esquema de la evolución de una galaxia de acuerdo al modelo $\Lambda$ CDM . 3

1.3. Diagrama de Hubble ... . . . . . . . . . . . . . . . . . 4

1.4. Galaxias de distintos tipos morfológicos . . . . . . . . . . . . . . 5

1.5. Sistema de clasificación de galaxias propuesto por van den Bergh . . . . 6

1.6. Comparación entre galaxias dE y dIrr . . . . . . . . . . . . . . . . . . . 7

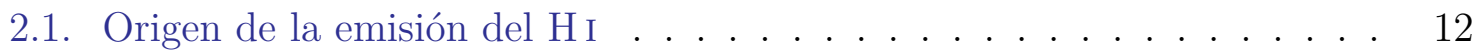

2.2. Plano $u v \ldots \ldots \ldots \ldots$

2.3. Curva de rotación . . . . . . . . . . . . . . . . . . . . . . 18

3.1. Imágenes de los instrumentos Parkes, Australia Telescope Compact Array y Giant Metrewave Radio Telescope . . . . . . . . . . . . . . . . . . 23

4.1. Distribución del H i en el grupo IC 1459 . . . . . . . . . . . . . . . . . 31

4.2. ATCA H I - Mapas de momento de escombros al sureste de la galaxia elíptica gigante IC 1459 . . . . . . . . . . . . . . . . . . 35

4.3. ATCA H I - Mapas de canales del complejo de nubes alrededor de IC 145936

4.4. Mapas de momento HIPASS del grupo IC 1459 . . . . . . . . . . . . 37

4.5. Mapa de continuo y detección de una línea de absorción en dirección a la fuente PKS 2254-367 . . . . . . . . . . . . . . . . . . . 39

4.6. Distribución de H Ien las galaxias próximas a IC 1459 . . . . . . . . . . 40

4.7. Campos de velocidad del H Ien las galaxias próximas a IC 1459 . . . . . 41

4.8. Campo de dispersión de velocidades del H I en las galaxias próximas a IC $1459 \ldots \ldots \ldots$. . . . . . . . . . . . . . . . . . 42

4.9. Diagrama posición velocidad $(p v) \ldots \ldots . \ldots . \ldots . . \ldots 44$

5.1. La galaxia espiral NGC 2683 y sus galaxias compañeras . . . . . . . . . 50

5.2. Imagen sin la resta del continuo . . . . . . . . . . . . . . . . 54

5.3. Flujo integrado del espectro de H I de la galaxia KK 69 . . . . . . . . . 56

5.4. Mapa de H i por canales de velocidad de la galaxia KK 69 . . . . . . . . 57

5.5. La galaxia enana KK 69 . . . . . . . . . . . . . . . . . . 58

5.6. Mapas de momento de H I de la galaxia enana KK 69 . . . . . . . . . . 59

5.7. Identificación de la component fría y tibia del medio interestelar de la

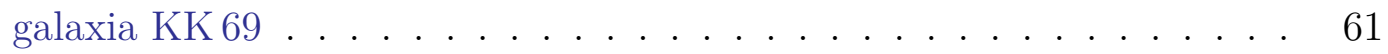

5.8. Componente fría del H i en KK 69 . . . . . . . . . . . . . . . 62 
6.1. El grupo de galaxias Cen A . . . . . . . . . . . . . . . . 70

6.2. Los haces primarios de ATCA y GMRT . . . . . . . . . . . . . . 72

6.3. Mapas de momentos ATCA con diferentes resoluciones angulares de la galaxia Fourcade-Figueroa (ATCA) . . . . . . . . . . . . . . 74

6.4. Mapas de Hi por canales de baja resolución de la galaxia FourcadeFigueroa $(\mathrm{ATCA}) \ldots \ldots \ldots \ldots \ldots$

6.5. Mapas de H i por canales con una resolución angular intermedia de la galaxia Fourcade-Figueroa (ATCA) . . . . . . . . . . . . . .

6.6. Mapas de H I por canales de alta resolución de la galaxia FourcadeFigueroa $($ ATCA) . . . . . . . . . . . . . . . .

6.7. Mapas de momento de H r realizadas con diferentes resoluciones angulares de la galaxia Fourcade-Figueroa $($ GMRT) . . . . . . . . . . . . .

6.8. Mapas de H I por canales de baja resolución de la galaxia FourcadeFigueroa $($ GMRT) . . . . . . . . . . . . . . . .

6.9. Mapas de H I por canales de alta resolución de la galaxia FourcadeFigueroa $($ GMRT) . . . . . . . . . . . . . . . . . . . 81

6.10. Comparación de las correcciones de haz primario . . . . . . . . . . . . 83

6.11. Comparaciónn del perfil global de H i de la galaxia FF obtenido con los distintos intrumentos . . . . . . . . . . . . . . . 84

6.12. ATCA + GMRT mapas de H i por canales de alta resolución de la galaxia Fourcade-Figueroa . . . . . . . . . . . . . . . .

6.13. ATCA + GMRT mapas de momentos de Hi de la galaxia FourcadeFigueroa . . . . . . . . . . . . . . . . 87

6.14. El diagrama posición-velocidad del H I $(p v) \ldots \ldots . . . . .88$

6.15. La curva de rotación de la galaxia Fourcade-Figueroa obtenida utilizando

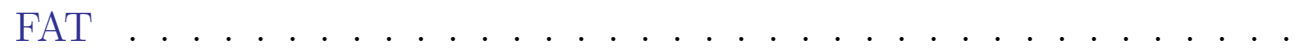

6.16. Distribución de luminosidad de FF obtenida considerando el modelo de un disco visto de canto . . . . . . . . . . . . . . . . . . . 92

6.17. Modelado de la curva de rotación de la galaxia Fourcade-Figueroa . . . 94

6.18. Perfiles de distribución de masa . . . . . . . . . . . . . . . . . 95

A.1. Página web . . . . . . . . . . . . . . . . . . . . 100

A.2. Ejemplo de búsqueda . . . . . . . . . . . . . . . . . . . . 102 


\section{Índice de tablas}

4.1. Propiedades ópticas de las galaxias dentro del área observada . . . . . . 28

4.2. HIPASS - propiedades de las galaxias dentro del área observada . . . . 29

4.3. Observaciones realizadas con ATCA del grupo de galaxias IC 1459 . . . 30

4.4. ATCA H I - Propiedades individuales de las nubes próximas a IC 1459 . 33

4.5. Deficiencia en el contenido de H I . . . . . . . . . . . . . . . . . 38

4.6. ATCA H i propiedades de las galaxias estudiadas . . . . . . . . . . 43

5.1. Propiedades ópticas de KK 69 y de las galaxias que forman parte del grupo 51

5.2. Parámetros de observación de GMRT . . . . . . . . . . . . . . 54

5.3. Flujos de las calibradoras . . . . . . . . . . . . . . . 54

5.4. Propiedades en H I de KK 69 y del resto de las galaxias del grupo . . . 60

5.5. Propiedades de las fases CNM y WNM en la galaxia KK 69 . . . . . . . 64

6.1. Propiedades ópticas de la galaxia Fourcade-Figueroa . . . . . . . . . . . 71

6.2. Parámetros de las observaciones realizadas con ATCA y GMRT . . . . 72

6.3. Calibradoras - valores coincidentes con un error del $10 \%$. . . . . . . . 73

6.4. Resumen de las propiedades de los cubos de imagen obtenidos con los datos de ATCA y de GMRT . . . . . . . . . . . . . . . 84

6.5. Comparación de los resultados obtenidos utilizando los diferentes modelos 91

6.6. Resultados del modelado de distribución de masa utilizando los perfiles de halo de materia oscura pseudo-isotérmica (PI) y NFW . . . . . . . . 94 
ÍNDICE DE TABLAS 


\section{Capítulo 1}

\section{Introducción}

En este capítulo, presentamos el marco teórico relacionado con la formación y evolución de las galaxias, la clasificación de las mismas haciendo foco en las galaxias enanas y describimos algunos de los mecanismos de interacción entre las galaxias, siendo éstos la base del modelo jerárquico de formación de galaxias.

\subsection{Formación de galaxias}

Para establecer el contexto de trabajo de esta tesis, primero presentamos brevemente una visión general del marco teórico subyacente con respecto a la formación y evolución de las galaxias (ver Fig. 1.1). El modelo cosmológico es el que establece las condiciones iniciales y de contorno para la formación de galaxias. Hasta la fecha, el más aceptado es el modelo "Lambda Cold Dark Matter" ( $\Lambda \mathrm{CDM}$, modelo de materia oscura fría, Blumenthal et al. [1984]) ${ }^{1}$. Este modelo considera que el Universo tuvo primero una expansión desacelerada y luego una expansión acelerada donde las principales componentes del Universo son la energía oscura (70\%), la materia oscura (25\%) y átomos y bariones ( $5 \%$, materia de la cual están conformadas las estrellas y las galaxias). $\Lambda$ es la constante cosmológica asociada con la energía oscura, y se utiliza para describir la expansión acelerada del espacio contemporáneo contra los efectos de atracción de la gravedad. La materia oscura fría se presenta para explicar los efectos gravitacionales observados en estructuras a gran escala (para más detalles, ver Mo et al. [2010]).

Una vez que se especifican las condiciones iniciales y el marco cosmológico, es el momento de explicar la inestabilidad gravitacional: una región cuya densidad inicial es ligeramente más alta que la media atraerá a su entorno algo más fuertemente que el promedio. En consecuencia, las regiones excesivamente densas se vuelven más densas y las áreas menos densas se vuelven aún menos densas. Cada perturbación inicial contiene gas bariónico y materia oscura (no colisional). Cuando un objeto colapsa, la materia oscura se relaja para formar un halo de materia oscura, mientras que el gas puede asentarse en equilibrio hidrostático en el pozo de potencial del halo de materia oscura si el proceso de enfriamiento es lento.

Los procesos posteriores son el enfriamiento del gas y la retroalimentación. El efecto neto del enfriamiento es que el material bariónico se separa de la materia oscura y se

\footnotetext{
${ }^{1}$ Otro modelo, por ejemplo, es "Modified Newtonian Dynamics" (MOND, por sus siglas en inglés) [Milgrom, 1983]
} 


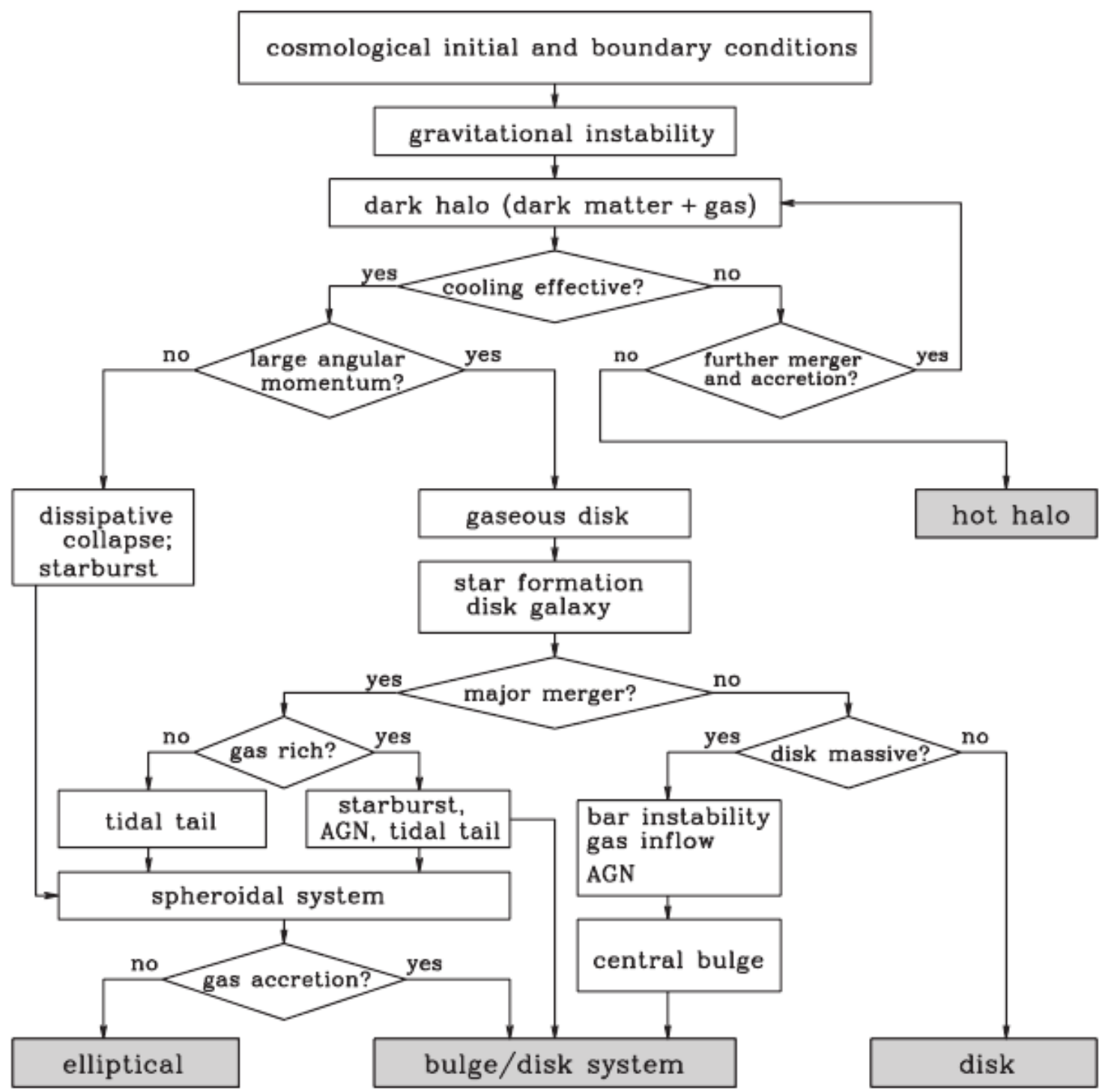

Figura 1.1: Red conceptual del modelo de formación de galaxias de acuerdo al modelo $\Lambda$ CDM; este diagrama fue tomado de Mo et al. [2010]. 


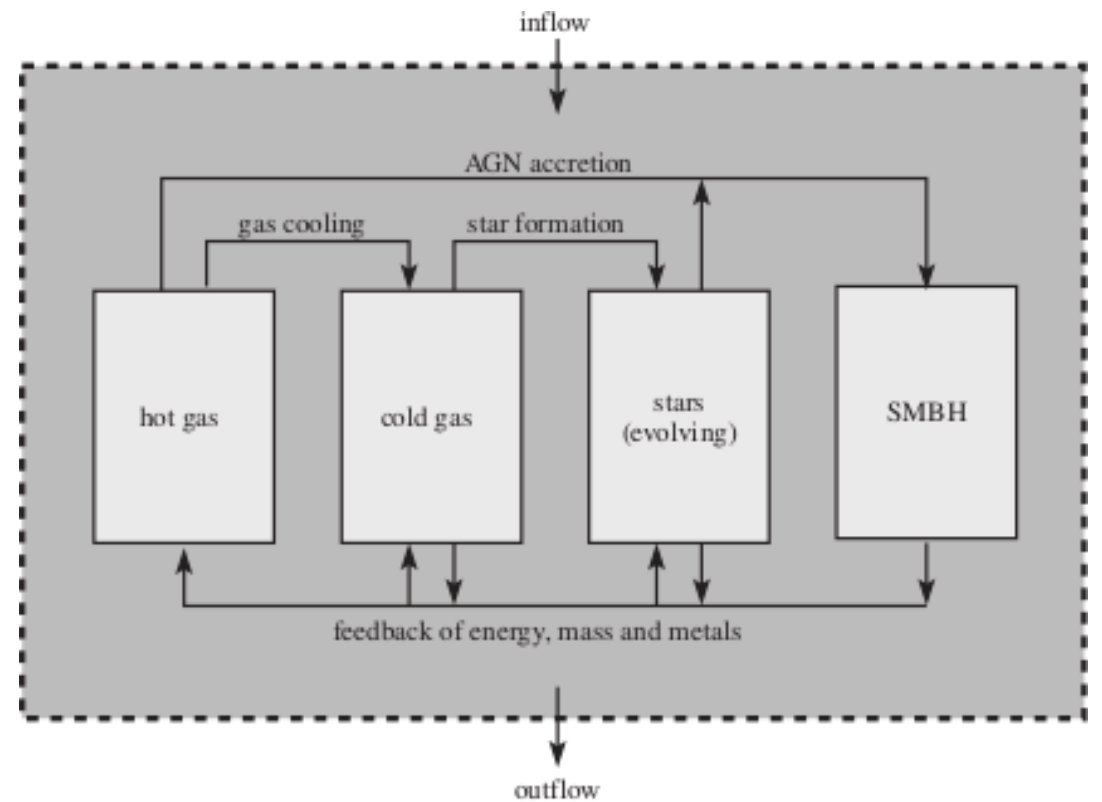

Figura 1.2: Esquema de la evolución de una galaxia de acuerdo al modelo $\Lambda$ CDM; el gráfico fue tomado de Mo et al. [2010].

acumula como un gas frío denso en el centro del halo de la materia oscura, comenzando a formarse una protogalaxia. Eventualmente, este gas denso frío podría colapsarse bajo su gravedad. La nube de gas puede fragmentarse en pequeños núcleos de alta densidad y formar estrellas. Pero, de manera observable, solo una pequeña fracción de todos los bariones se encuentran en gas frío o en estrellas. Esto significa que algún proceso físico debe evitar que el gas se enfríe, o recalentarlo después de que se haya enfriado. De ahora en adelante, los procesos de retroalimentación como eventos de supernova o la fase de acreción activa de agujeros negros súper masivos (SMBH) en núcleos galácticos activos (AGN), toman un papel activo (ver Fig. 1.2).

Hasta ahora, hemos descrito lo que sucede con un sistema único y aislado de materia oscura, gas y estrellas. Sin embargo, las galaxias y los halos de materia oscura no están aislados. El tipo de galaxia resultante -elíptica, bulbo/disco, disco-dependerá de si las galaxias y los halos están alojados en un entorno de alta densidad o baja densidad, si sufren fusiones, si continúan acumulando gas frío y si el momento angular es grande o no. El tema de la formación y evolución de las galaxias es de gran complejidad. En particular, a lo largo de esta tesis, nos centraremos en el papel que desempeña el entorno en la evolución de las galaxias.

\subsection{Clasificación de galaxias}

En 1936, Edwin Hubble ordenó a las galaxias en una secuencia morfológica basada en sus perfiles de luminosidad, la presencia o ausencia de brazos espirales y bulbo, y su forma irregular. El esquema clasifica a las galaxias en cuatro tipos morfológicos: elípticas (E), espirales (S), lenticulares (S0) e irregulares (Irr) (ver Figs. 1.3 y 1.4). 


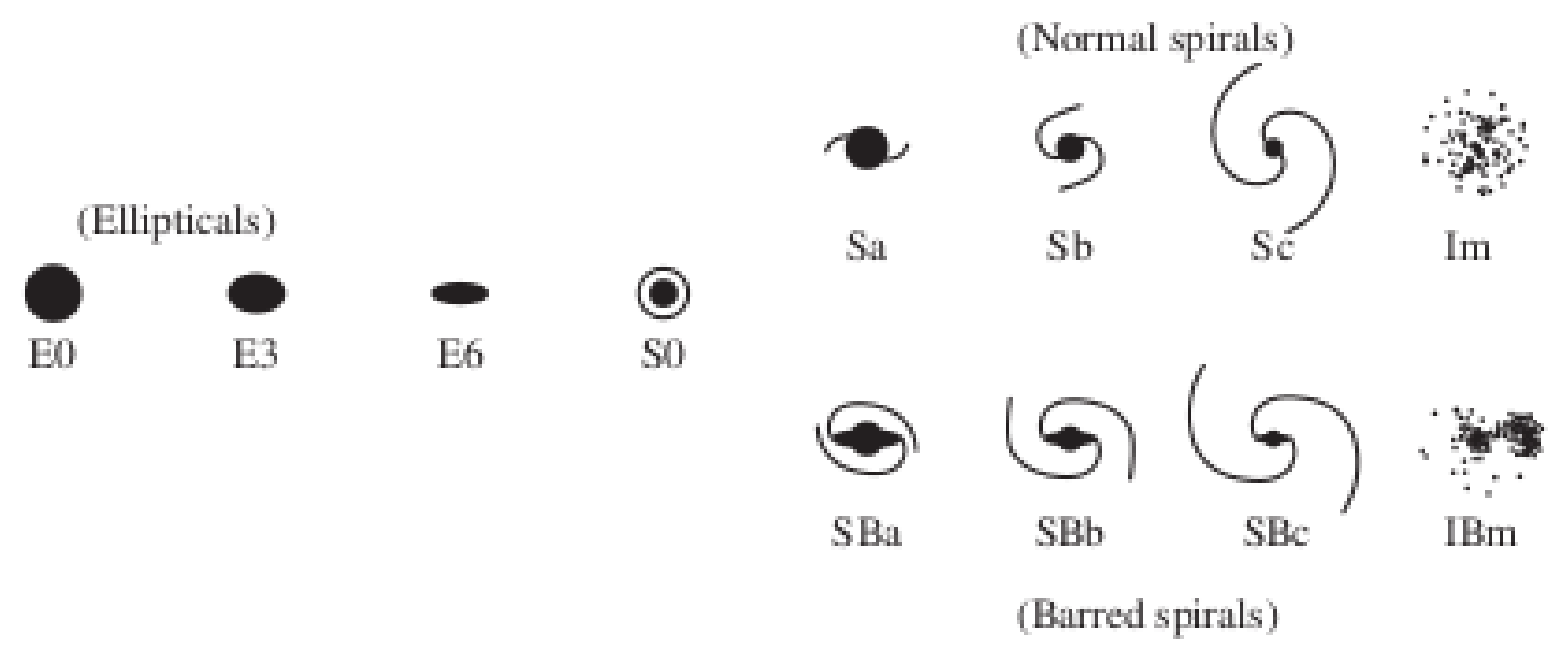

Figura 1.3: Diagrama de Hubble. Las galaxias elípticas y las S0 también son conocidas como de tipo temprano mientras que las galaxias espirales e irregulares, de tipo tardío, [Sparke and Gallagher, 2007].

- Galaxias elípticas: estas galaxias están bien descritas por isofotas que pueden ser del tipo "boxy" o "disky". Además, pueden subclasificarse en los tipos E0, E1, ..., E7, dependiendo de los tamaños de los semiejes mayor y menor.

- Galaxias lenticulares o S0: estas galaxias se describen como una clase intermedia entre elípticas y espirales. Las galaxias S0 podrían presentar una distribución de luminosidad suave, un disco grueso y un bulbo. Si la galaxia tiene una barra central, se clasifica como SB0.

- Galaxias espirales: estas galaxias están bien descritas por un disco con estructuras de brazos espirales y también se pueden dividir en barradas o normales. La subclase está determinada por la presencia de una estructura en forma de barra en la parte central de la galaxia. Cada rama de las galaxias espirales se divide adicionalmente en tres clases, a, b y c, dependiendo de la fracción de la luminosidad del bulbo y la tensión de los brazos espirales.

- Galaxias irregulares: estas galaxias muestran un aspecto irregular, dominado por unas pocas regiones HII. Originalmente, Hubble no incluyó las galaxias irregulares en su secuencia; hoy en día se suelen ubicar como una extensión a las galaxias espirales [Sparke and Gallagher, 2007].

Los primeros dos tipos de galaxias, elípticas y lenticulares son también conocidas como galaxias de tipo temprano mientras que los últimos dos, espirales e irregulares, son conocidas como galaxias de tipo tardío.

Cincuenta años después, van den Bergh [1976] propuso una alternativa en la clasificación. El autor organizó a las galaxias S0 en una secuencia S0a-S0b-S0c paralela a la secuencia Sa-Sb-Sc de galaxias espirales. Argumentó que la falta de estructura espiral, gas H I y formación de estrellas se atribuyen a procesos ambientales. 

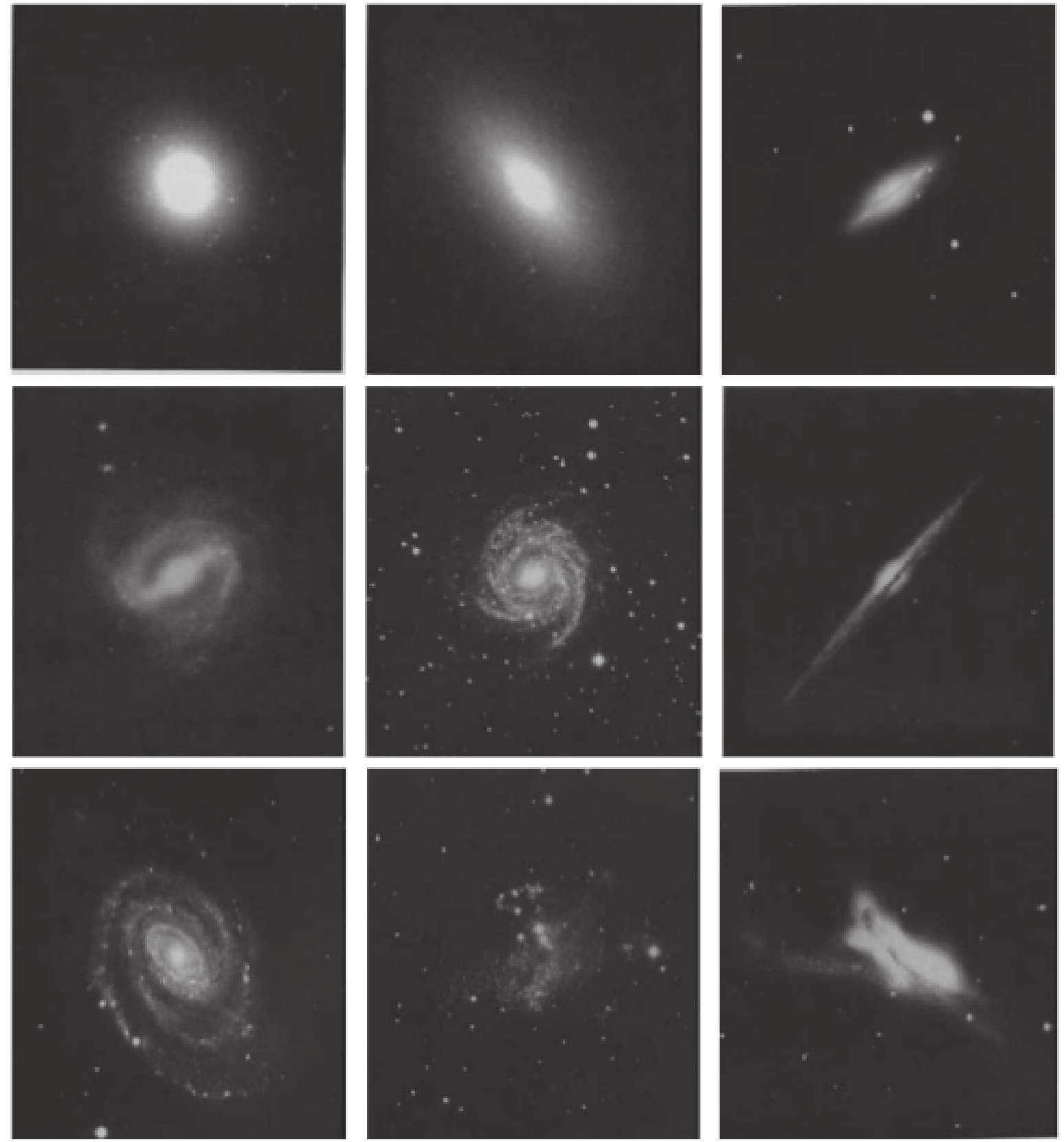

Figura 1.4: Galaxias de distintos tipos morfológicos; la imágen fue tomada de Mo et al. [2010]. 


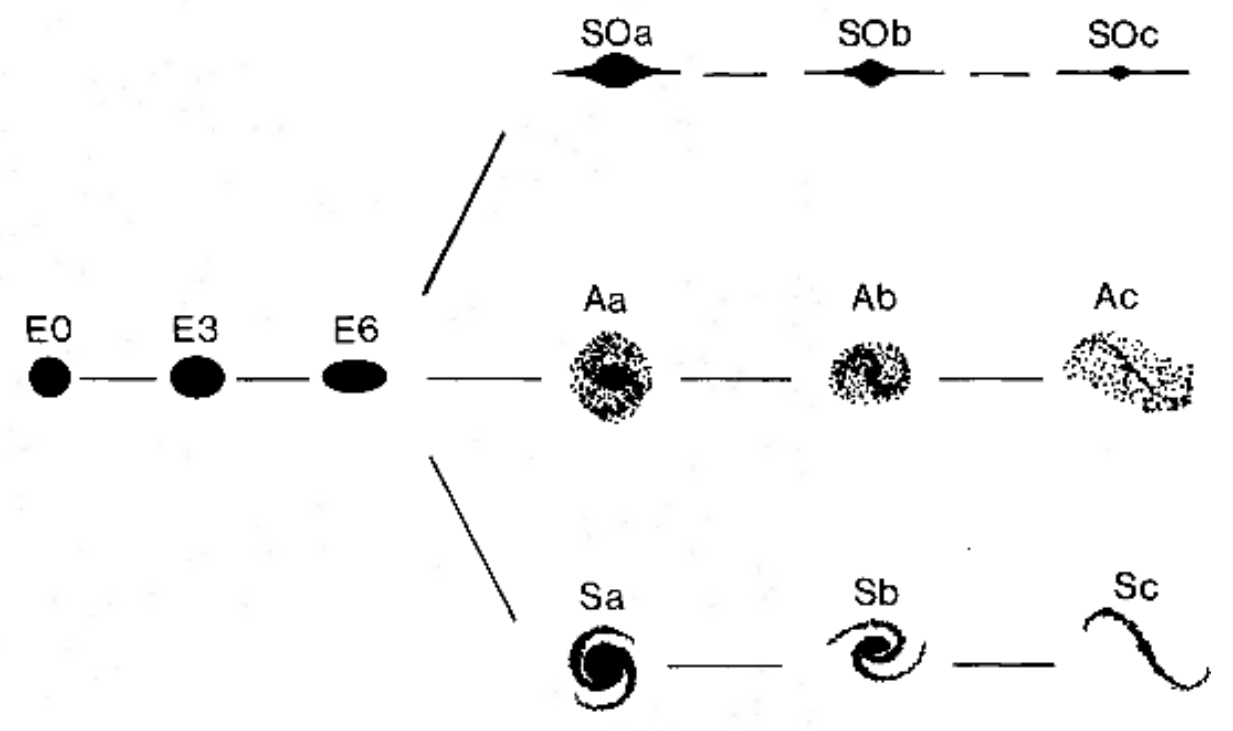

Figura 1.5: Sistema de clasificación de galaxias propuesto por van den Bergh [van den Bergh, 1976]. El sistema comprende secuencias paralelas de espirales normales (Sa-Sb$\mathrm{Sc}$ ), espirales anémicas (Aa-Ab-Ac, intermedio entre las espirales normales ricas en gas y los sistemas pobres en gas de tipo S0) y lenticulares sin gas (S0a-S0b-S0c).

\subsubsection{Galaxias enanas}

Si bien no existe una definición precisa, se consideran galaxias enanas a aquellas galaxias con magnitudes en el azul $M_{\mathrm{B}}>-18$ mag (o luminosidades inferiores a $\left.2,5 \times 10^{9} \mathrm{~L}_{\mathrm{B}, \odot}\right)$ [Tammann, 1980, Staveley-Smith et al., 1992, Tammann, 1994]. En el rango $-18<M_{\mathrm{B}}<-16 \mathrm{mag}$ las galaxias de tipo temprano reciben el nombre de galaxias enanas elípticas (dE) o galaxias enanas lenticulares (dS0), dependiendo de su morfología, mientras que las galaxias de tipo tardío son denominadas galaxias enanas irregulares (dI) (ver Fig. 1.6). En el extremo débil de la función de luminosidad, las galaxias enanas pueden llegar a luminosidades típicas de los cúmulos globulares (CG). La principal diferencia entre las galaxias enanas y los CG es que estos últimos son más compactos y la dinámica no está dominada por la materia oscura.

Se podría hacer una clasificación aproximada en galaxias enanas sin gas H I, sin actividad de formación de estrellas y galaxias enanas con una gran cantidad de gas H I y eventos recientes de formación de estrellas. Pero esto es una simplificación excesiva. La existencia de una gran variedad de galaxias enanas está relacionada con los diferentes orígenes e historias evolutivas. A continuación describimos algunos de ellas.

- Galaxias elípticas enanas (dE): fue Shapley en 1938 quien descubrió las primeras galaxias dE en los alrededores de la Vía Láctea: Fornax y Sculptor. Las galaxias dE podrían dividirse en difusas, con un bajo brillo superficial en el centro de la galaxia (por ejemplo, NGC 205, $\mu_{B} \sim 20 \mathrm{mag} \operatorname{arcsec}^{-2}$ ) y compactas, con un brillo superficial alto en el centro de la galaxia (por ejemplo, M 32, $\mu_{B} \sim 17$ mag $\operatorname{arcsec}^{-2}$ ) [Choi et al., 2002]. Si la galaxia es difusa y tiene un brillo superficial extremadamente bajo, se considerará como una galaxia esferoidal enana (dSph). En general, las galaxias dE tienen una población de estrellas viejas (> 5 Gyr) 

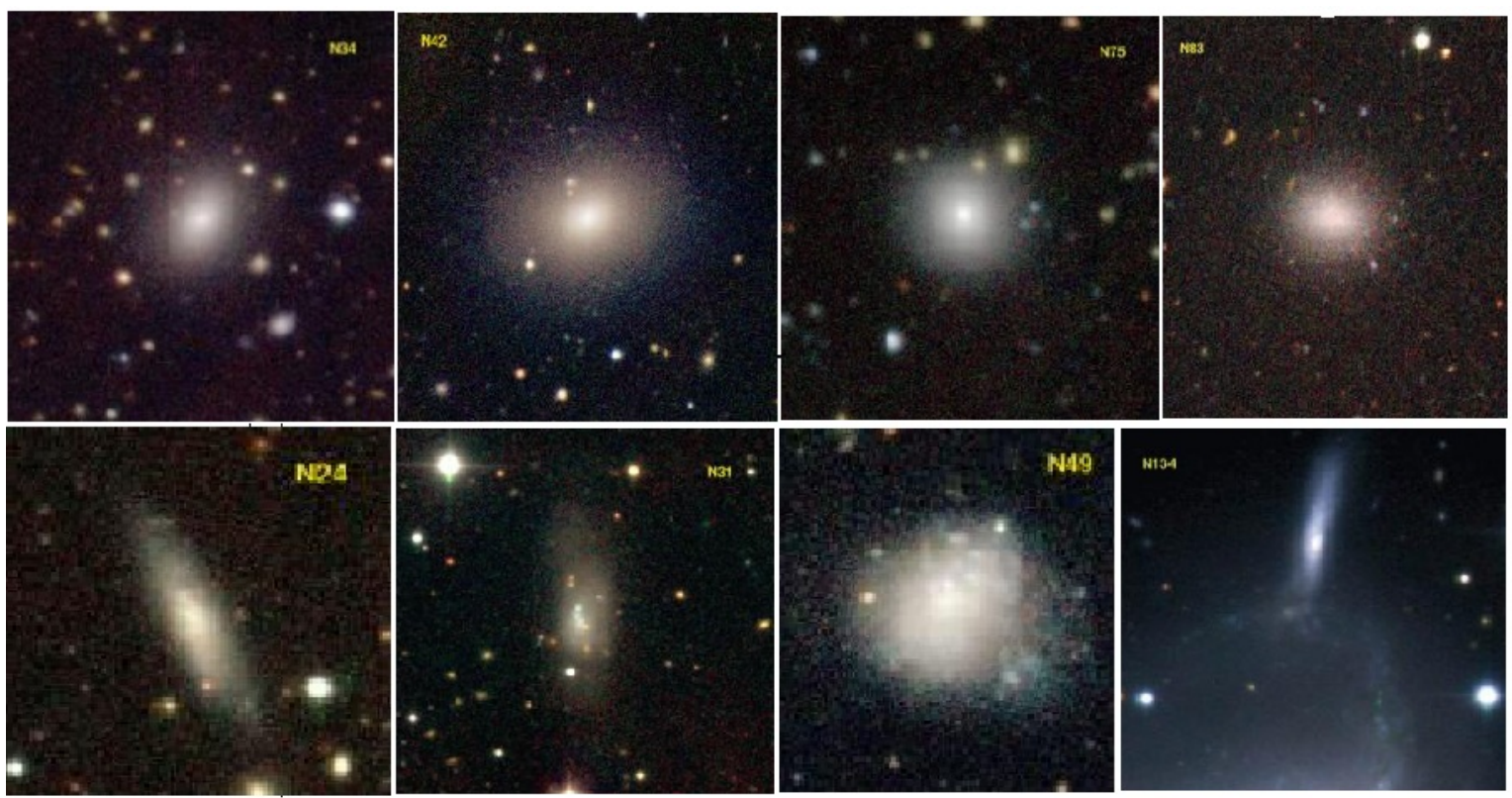

Figura 1.6: Comparación entre galaxias dE y dIrr. Primer fila: dE, de izquierda a derecha, N 34, N 42, N 75, N 83. Segunda fila: dIrr N 24, N 31, N 49, N 134. Todas las galaxias son miembros del grupo NGC 5044 [Cellone and Buzzoni, 2005].

con metalicidades sub-solares. La falta de gas neutro y la baja tasa de formación estelar sugiere que estos son objetos evolucionados. Se observa que las enanas elípticas sin la presencia de un núcleo claro están ubicadas en medios de baja densidad, las de discos se encuentran en entornos de densidad intermedia y las enanas elípticas con núcleos están en entornos de alta densidad. Para más información ver Sparke and Gallagher [2007] y Tolstoy et al. [2009].

- Galaxias enanas Irregulares (dIrr): estas galaxias están formando estrellas, y las regiones de formación estelar se pueden rastrear usando observaciones en las bandas ópticas $\mathrm{U}, \mathrm{B}, \mathrm{V}$ y $H_{\alpha}$. Las observaciones infrarrojas se utilizan para mapear la ubicación de la población de estrellas más viejas. Comúnmente, la emisión del gas H I es más extendida que la contraparte óptica. Para más información ver Sparke and Gallagher [2007] y Tolstoy et al. [2009].

- Galaxias enanas de marea (TDG, por sus siglas en inglés): el origen de estas galaxias es el resultado de la interacción entre galaxias. Las TDG se clasifican en dos tipos: las que son especialmente jóvenes, posiblemente formando estrellas por primera vez y las dominadas por una vieja población de estrellas recolectadas de las galaxias que interactúan. Las metalicidades son altas considerando sus magnitudes. Es posible que los progenitores los vuelvan a acretar en $\sim 1$ Gyr o que los efectos de las mareas puedan destruirlas por completo. Para más información ver por ejemplo Duc and Mirabel [1999], Duc et al. [2000].

- Galaxias enanas en transición (dT): este tipo de galaxias comparten características comunes con las galaxias dIrr y dSph/dE. Actualmente, el origen de estas 
galaxias no se entiende completamente. Algunos autores contemplan la idea de que las dIrr podría ser las precursores de dSph [Kormendy and Bender, 2012, Grcevich and Putman, 2009]. Phoenix y NGC 5237 son galaxias enanas en transición donde el Hidrógeno neutro (H I) está desplazado de la componente estelar, pero el origen del desplazamiento en cada caso parece ser diferente. En Phoenix, el desplazamiento es una evidencia de la actividad de formación de estrellas [Young et al., 2007]. Sin embargo, en NG 5237, se sospecha que los efectos ambientales son el motivo dominante del desplazamiento [Koribalski et al., 2018b].

\subsection{Interacción entre galaxias}

El escenario jerárquico de la formación de estructuras se basa en las interacciones frecuentes entre las galaxias y sus halos de materia oscura. Además, las interacciones gravitacionales entre las galaxias y su entorno desempeñan un papel importante y continuo en la evolución de las galaxias, afectando sus propiedades locales y globales, como el contenido de gas, la cinemática y la velocidad de formación de estrellas.

Estudios de la naturaleza y de la frecuencia de las interacciónes son esenciales para comprender la formación y evolución de la galaxia. A continuación, describiremos encuentros de alta velocidad, interacciones de marea, proceso de barrido por presión cinética y fusiones, que son algunos de los procesos de interacción que ocurren en cúmulos y grupos de galaxias.

- Los encuentros de alta velocidad juegan un papel esencial en los cúmulos de galaxias. Se llama encuentro de alta velocidad cuando la velocidad del encuentro, entre dos sistemas, es mucho mayor que la dispersión de velocidades interna de los miembros individuales de la galaxia $\left(\sigma_{\text {cluster }} \sim 1000 \mathrm{~km} \mathrm{~s}^{-1}\right)$. Este proceso puede llevar a modificaciones en la estructura interna de los sistemas que interactúan [Mo et al., 2010].

- Las interacciones de mareas se pueden dividir en dos casos específicos: la interacción de un satélite relativamente pequeño que orbita en un sistema anfitrión más grande, y el efecto de mareas que acompaña a la fusión entre dos galaxias de disco de masas comparables, [Mo et al., 2010]. El ejemplo más conocido del primer caso es la corriente de Magallanes, que es una corriente de H I despojado de las nubes de Magallanes, que se extiende más de 100 grados en el cielo [Putman et al., 1998]. Otros ejemplos de interacciones de mareas se encuentran en pares cercanos [por ejemplo, Gordon et al., 2001, Koribalski and Dickey, 2004, Koribalski and López-Sánchez, 2009, Sengupta et al., 2015], grupos compactos [Gordon et al., 2003, Koribalski et al., 2003, Serra et al., 2012], grupos compactos de Hickson [Hickson, 1982, Verdes-Montenegro et al., 2001], grupos sueltos [Kilborn et al., 2009, Pisano et al., 2011] y en cúmulos [Chung et al., 2009].

- La extracción de gas originada por el proceso de barrido por presión cinética $P_{\text {ram }}$, es el efecto producido en la componente gaseosa de una galaxia que se está moviendo a través del medio intracúmlo o intragrupo con una velocidad dada. Si el proceso es lo suficientemente fuerte, puede despojar el gas inicialmente asociado 
con la galaxia. El mecanismo de barrido por presión cinética fue propuesto por primera vez por Gunn and Gott [1972]. Cuantitativamente,

$$
P_{\text {ram }}=\rho_{\text {IGM }} v_{\text {gal }}^{2}>2 \pi G \sigma_{\text {star }}(r) \sigma_{\text {gas }}(r),
$$

donde $\rho_{\text {IGM }}$ es la densidad del gas del medio intragaláctico, $v_{\text {gal }}$ es la velocidad de la galaxia a través del medio intragrupo, $\sigma_{\text {star }}(r)$ es la densidad superficial estelar, y $\sigma_{\text {gas }}$ la densidad de masa superficial del gas galáctico.

En el siguiente capítulo, explicaremos y daremos algunos ejemplos de por qué y cómo el hidrógeno neutro es un indicador de los procesos de interacción antes mencionados. 
1. Introducción 


\section{Capítulo 2}

\section{El hidrógeno neutro}

El espacio que existe entre las estrellas de las galaxias no está vacío. Contiene gas en forma iónica, atómica y molecular, y también presenta polvo y partículas cargadas dando lugar al medio interestelar (MIE). La principal componente es el H I. Por ejemplo, se estima que la Vía Láctea contiene alrededor de $4,8 \times 10^{9} \mathrm{M}_{\odot}$ de $\mathrm{H} \mathrm{I}$ donde el H I galáctico constituye aproximadamente el $4,4 \%$ de la masa total visible [Verschuur and Kellermann, 1988] y al comprender entre el $20 \%$ y el $90 \%$ del espacio ocupado por la componente interestelar, es la componente del MIE que más afecta a la cinemática y a la evolución del mismo. Si bien el MIE representa una pequeña fracción de la masa en las galaxias, esta fracción es dependiente del tipo, lo que convierte al MIE en una característica esencial en el proceso de clasificación de las galaxias.

El gas neutro H i es también una componente clave del universo ya que rige la formación estelar y por ende afecta la evolución de las galaxias de manera significativa. En el MIE galáctico, el H I se puede encontrar en un rango de temperaturas de $100 \mathrm{~K}$ a $10000 \mathrm{~K}$. Las teorías sugieren que el gas se debe asentar en alguna de las dos fases estables, estas son, el Medio Neutro Frío (CNM, por sus siglas en inglés) o el Medio Neutro Cálido (WNM, por sus siglas en inglés) bajo equilibrio térmico local [Field et al., 1969, McKee and Ostriker, 1977, Wolfire et al., 1995, 2003]. El CNM tendría una temperatura de $\leq 300 \mathrm{~K}$ con alta densidad de partículas $\left(\sim 1-100 \mathrm{~cm}^{-3}\right)$ mientras que el WNM tendría una temperatura mucho más alta $\sim 500-8000 \mathrm{~K}$ con baja densidad de partículas $\left(\sim 0,1-1 \mathrm{~cm}^{-3}\right)$ [eg Dickey et al., 1978, Payne et al., 1983, Heiles and Troland, 2003, Roy et al., 2006]. Cualquier gas con temperatura intermedia se movería rápidamente a una de estas fases estables por procesos térmicos.

A lo largo de esta tesis, nuestra herramienta principal fueron las observaciones de H I con el fin de estudiar las interacciones entre galaxias y entre galaxias y su entorno. En este capítulo, mencionamos el origen de la emisión H I, explicamos las mediciones que se pueden realizar y describimos brevemente el medio interestelar. Además, describimos la forma en la que el $\mathrm{H}$ I puede ser utilizado como un indicador de los efectos ambientales sobre las galaxias. 

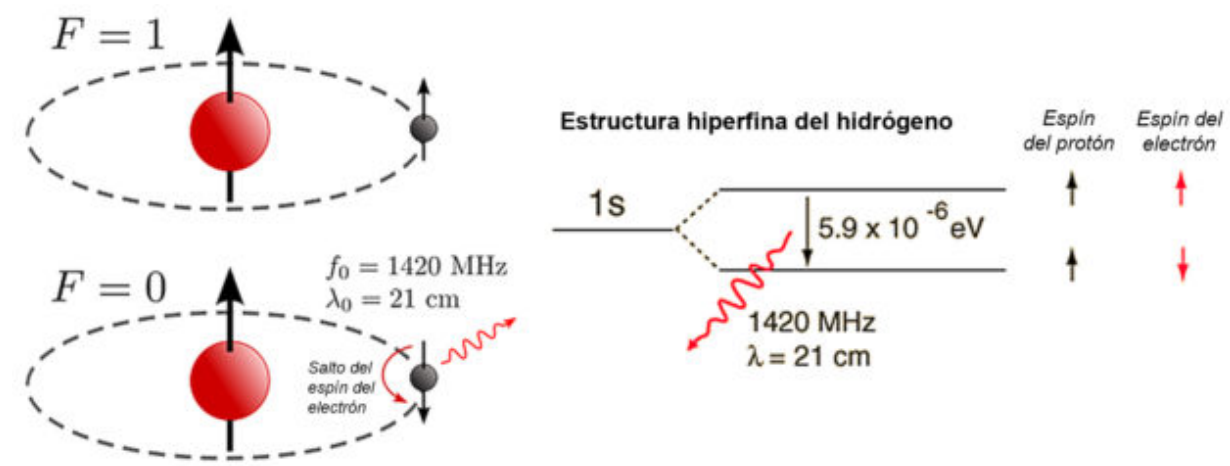

Figura 2.1: Origen de la emisión del H i. En el panel izquierdo se muestra una representación gráfica del salto del electrón. En el panel derecho se muestra una representación gráfica de la transición hiperfina del átomo de hidrógeno.

\section{1. $\quad$ Origen de la emisión del $\mathrm{H}$ I}

En el átomo de hidrógeno, el momento magnético de un protón interactúa con el campo magnético generado por el electrón en su órbita; esta interacción resulta en una separación de los niveles de energía dando lugar a la llamada estructura hiperfina. La línea de $21 \mathrm{~cm}$ de $\mathrm{H}$ I es el resultado del desdoblamiento del estado base $\left(1^{2} S_{1 / 2}\right)$ del átomo de hidrógeno. Luego de ser excitado, el decaimiento espontáneo sucede 12 millones de años después mientras que por procesos colisionales el tiempo se reduce a 400 años. Esto también es conocido como salto del espín del electrón.

Esta transición fue predicha por Van de Hulst en 1945 y fue confirmada observacionalmente en 1951 por Ewen and Purcell [1951] en los Estados Unidos de América y Muller and Oort [1951] en Holanda.

La frecuencia precisa de esta transición es 1420405751,7667 Hz (ver Fig. $2.1^{1}$ ). La energía del fotón emitida es tan baja que se determinó una unidad de medida específica. Esta unidad de medida es el Jansky en honor a Karl Jansky², donde 1 Jy equivale a $10^{-23} \mathrm{erg} \mathrm{s}^{-1} \mathrm{~cm}^{-1} \mathrm{~Hz}^{-1}$.

\subsection{Reducción de los datos y construcción de las imágenes}

Se le llama reducción de los datos al proceso de transformar los datos tal como los graba el telescopio al momento de la observación, en datos útiles (por ejemplo, con los que se pueden hacer imágenes). Este procedimiento puede ser llevado a cabo utilizan-

\footnotetext{
${ }^{1}$ https://culturacientifica.com/2017/01/20/hidrogeno-universo-i-la-emision-del-hidrogeno-neutro$21-\mathrm{cm} /$

${ }^{2}$ Karl Guthe Jansky fue un físco e ingeniero electrónico estadounidense quien descrubrió la emisión en radioondas proveniente del centro de la Vía Láctea
} 


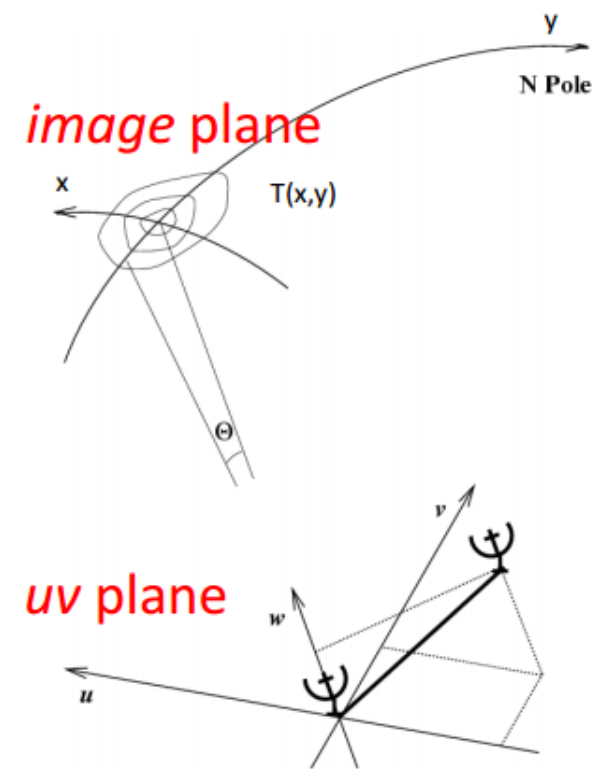

Figura 2.2: Representación gráfica del sistema cartesiano sobre el plano del cielo y del sistema dado por la distribución de las antenas, conocido como plano uv. Imagen tomada de la charla "Interferometry Basics", Andrea Isella, Caltech CASA Radio Analysis Workshop.

do diferentes software. Durante la realización de esta tesis se hizo uso de los software MIRIAD [Sault et al., 1995] y AIPS ${ }^{3}$.

Haciendo un breve resumen, la señal recibida por el receptor de cada antena de un arreglo interferométrico es combinada con la de cada una del resto de las antenas, en un dispositivo llamado correlador. A la salida del correlador se obtiene la llamada función de visibilidad, que mide la correlación entre las señales de pares de antenas. La función de visibilidad es una función compleja cuya expresión es:

$$
V(u, v, w)=\int P_{n}(x, y) I(x, y) e^{-i 2 \pi \nu_{o} \vec{B} \vec{\sigma} / c} \mathrm{~d} \omega .
$$

Las coordenadas $x$ e $y$ están definidas según un nuevo sistema cartesiano, que se ubica sobre el plano del cielo, centrado en la fuente. El vector $\vec{\sigma}$ tiene origen en este sistema de coordenadas, y recorre punto a punto la fuente. $P_{n}(x, y)$ es el patrón de interferencia, $I(x, y)$ la intensidad, $\nu_{0}$ es la frecuencia central y $\vec{B}$ la línea de base. La integral se realiza sobre el ángulo sólido que subtiende la fuente (ver Fig 2.2).

En el camino desde la fuente radioastronómica hasta la salida del correlador, hay muchos factores que afectan y modifican la señal. Se denomina 'ganancia' del equipo al factor por el que se multiplica la señal real, para obtener la señal medida. En su forma más general entendemos por equipo toda la cadena de medios físicos (medio intergaláctico, dispositivos, etc.) colocada entre la fuente emisora y la salida del correlador. En

\footnotetext{
${ }^{3}$ www.aips.nrao.edu
} 
particular, se trata a las ganancias por línea de base (esto es, un par de antenas). Algunos de los agentes que contribuyen a afectar la ganancia son: la rotación Faraday en la ionosfera, el vapor de agua en la tropósfera, pérdidas en los polarímetros, variaciones de ganancia en los amplificadores, ruido del correlador (interferencias), promedios de la señal, etc.

Las observaciones hacia fuentes de calibración permiten determinar esas correcciones a las ganancias, ya que para las fuentes de calibración se conocen de antemano los valores de la función de visibilidad verdaderos (no afectados por ningún agente). El proceso de calibrar consiste en la búsqueda de soluciones para las ganancias por línea de base.

Los pasos seguidos para la calibración de los datos medidos hacia las fuentes bajo estudio fueron:

- Identificación de datos malos. Durante una observación parte del equipamiento puede tener fallas. Esto producirá la grabación de datos fuera de los estándares, o datos malos. En el caso de la función de visibilidad, por ejemplo pueden aparecer valores con amplitudes inusualmente altas (hasta miles de veces lo esperado) o fases cambiantes en tiempos menores a los de registro de la señal. En esos casos es necesario identificar los datos malos y marcarlos (tarea de MIRIAD uvflag, tareas de AIPS UVFLG, TVFLAG).

- Determinar las ganancias a aplicar a cada canal. Se crea una tabla con las correcciones, que se agrega a los datos de la fuente calibradora. Se utiliza una calibradora llamada de flujo, fuente que es observada generalmente al principio y al final (tareas de MIRIAD mfcal, gpcal, tareas de AIPS CLCAL, SETJY, CALIB).

- Se aplican estas correcciones al resto de las fuentes (tarea de MIRIAD gpcopy, tarea de AIPS TACOP).

- Las ganancias complejas de las visibilidades cambian con el tiempo, debido a condiciones atmosféricas, variaciones de temperatura del sistema, elevación de la antena, etc. Esta es la razón por la que se observa intermitentemente la fuente calibradora de fase, durante toda la observación. Como con el resto de las calibradoras, la respuesta del instrumento es conocida para la calibradora de fase. Se calculan las correcciones de ganancia a aplicar a las fases. Para esto se utiliza una calibradora secundaria, generalmente llamada calibradora de fase (tarea de MIRIAD gpcal, tareas de AIPS CLCAL),

- Se copian las tablas de correcciones de ganancias construidas antes, a la fuente en estudio (tarea de MIRIAD gpboot, tarea de AIPS TACOP).

- Como trabajamos con datos de línea se resta la contribución del continuo (tarea de MIRIAD uvlin, tareas de AIPS, UVLIN, IMLIN).

De lo anterior se obtuvo un conjunto de visibilidades, o datos $u v$, calibrados. 
Una vez calibrados los datos se procede a la construcción de las imágenes. Como ya se mencionó, el interferómetro mide el patrón de interferencia producido por pares de antenas y el patrón de interferencia está directamente relacionado con el brillo de la fuente. En particular, para pequeños campos de visión, la función compleja de visibilidad, $V(u, v, w)$ es la transformada de Fourier del brillo en el cielo. La transformada de Fourier relaciona el patrón de interferencia con la intensidad. Es por esto que, para despejar la componente que representa la distribución de brillo en el cielo de la fuente es que se hace una interpolación (para regularizar la grilla de datos), se le aplica una transformada de Fourier y posteriormente se hace una deconvolución. Cada software le otorga un nombre diferente a cada uno de estos procesos. Por ejemplo esta secuencia es realizada utilizando las tareas de MIRIAD invert, clean/mossdi, restor mientras que en AIPS son IMAGR, APCLN entre otras opciones. Para ver más en detalle la función de cada tarea consultar el manual de usuario de MIRIAD ${ }^{4}$ y AIPS $^{5}$.

Trabajar con observaciones de línea implica que el proceso mencionado se repite para cada canal, dando origen a un cubo de imágenes. Cada canal representa una velocidad y es por esto que las observaciones de línea de H i no sólo brindan información sobre la distribución del material si no también sobre la cinemática del mismo.

\subsection{Parámetros obtenidos del $\mathrm{H}_{\mathrm{I}}$}

Presentamos aquí las herramientas que se utilizarán en los estudios de H I en galaxias.

\subsubsection{Mapas de momentos}

Se define el momento de orden $\mathrm{n}$, evaluado para cada pixel espacial (x,y) (o por beam) a lo largo del eje de velocidad, como:

$$
M_{n}=\int I(v) v^{n} \mathrm{~d} v
$$

donde $v$ es la velocidad e $I(v)$ es la intensidad para una dada velocidad en Jy beam ${ }^{-1}$.

\subsubsection{Momento de orden 0}

Es la integral de la intensidad en velocidad; las unidades son Jy $\mathrm{km} \mathrm{s}^{-1} \mathrm{haz}^{-1}$. A partir de éste se puede observar cómo es la distribución del H I en la galaxia.

$$
M_{0}=\int I(v) \mathrm{d} v
$$

\subsubsection{Momento de orden 1}

Corresponde a la integral de la intensidad pesada por la velocidad; las unidades son $\mathrm{km} \mathrm{s}^{-1}$.

\footnotetext{
${ }^{4}$ www.atnf.csiro.au

${ }^{5}$ www.aips.nrao.edu
} 


$$
M_{1}=\frac{\int I(v) v \mathrm{~d} v}{\int I(v) \mathrm{d} v} .
$$

Este mapa nos indica cómo es la cinemática del material.

\subsection{4. $\quad$ Momento de orden 2}

Es la integral de la intensidad pesada por el cuadrado de las velocidades. Nos dice cómo es la dispersión de velocidades:

$$
M_{2}=\sqrt{\frac{\int I(v)\left(v-M_{1}\right)^{2} \mathrm{~d} v}{\int I(v) \mathrm{d} v}} .
$$

\subsubsection{Distribución global del espectro de $\mathrm{H}_{\mathrm{I}}$}

El espectro global es la distribución global de la intensidad de la galaxia a lo largo de la velocidad del gas. A partir de ella podemos estimar tres parámetros fundamentales de la región emisora:

El flujo total, como la integral de la intensidad medida en el rango de velocidad de detección.

$$
F_{\mathrm{HI}}=\int_{v_{1}}^{v_{2}} F(\nu) \mathrm{d} \nu \quad\left[\mathrm{Jy} \mathrm{km} \mathrm{s}^{-1}\right] .
$$

La densidad columnar, se define como

$$
N_{\mathrm{HI}}=\int_{v_{1}}^{v_{2}} a T_{s} \tau_{v} \mathrm{~d} v \quad\left[\mathrm{~cm}^{-2}\right]
$$

donde $v_{1}$ y $v_{2}$ son los límites del rango de velocidad, $T_{s}$ es la temperatura de spin, $\tau_{v}$ es la profundidad óptica y $a$ es constante.

La ecuación de transferencia radiativa está dada por la siguiente expresión,

$$
\frac{d I_{\nu}}{d \tau_{\nu}}=S_{\nu}-I_{\nu}
$$

donde $S_{\nu}$ e $I_{\nu}$ representan la función fuente (relación entre los coeficientes de emisión y absorción) y la intensidad en cada frecuencia.

Usando la aproximación de Rayleigh-Jeans para $I_{\nu}$, que es válida a lo largo del rango de radio, la solución de la transferencia radiativa es:

$$
T_{b}(v)=T_{s}\left(1-e^{-\tau_{v}}\right),
$$

donde $T_{b}(v)$ es la temperatura de brillo. Por lo tanto, considerando una baja opacidad $\left(\tau_{v} \ll 1\right)$, podemos usar la aproximación de primer orden del polinomio de Taylor y expresar la ecuación como $T_{b}(v)=T_{s} \tau_{v}$. Se puede demostrar que:

$$
T_{b} \Delta v=\frac{F_{\mathrm{HI}} c^{2}}{2 k \Omega_{\text {fuente }} \nu^{2}},
$$


donde, $\mathrm{c} \sim 300.000 \mathrm{~km} \mathrm{~s}^{-1}$ es la velocidad de la luz, $\mathrm{k}=1,3803 \times 10^{-23} \mathrm{~J} \mathrm{~K}^{-1}$ es la constante de Boltzmann, $\Omega_{\text {fuente }}$ es el ángulo sólido que subtiende a la fuente, $\nu=$ $1,420 \times 10^{9} \mathrm{~Hz}$.

Y con los reemplazos apropiados, obtenemos

$$
N_{\mathrm{HI}}=1,82310^{18} \int_{v_{1}}^{v_{2}} T_{b} \mathrm{~d} v=1,82310^{18} \Delta T_{b} \Delta v \quad\left[\mathrm{~cm}^{-2}\right] .
$$

El contenido de $\mathrm{H}_{\mathrm{I}}\left(M_{\mathrm{HI}}\right)$

La masa total de hidrógeno atómico de una galaxia se puede calcular a partir de la emisión de línea integrada de $21 \mathrm{~cm}$ como:

$$
M_{\mathrm{HI}}=2,35610^{5} D^{2} F_{\mathrm{HI}}\left[\mathrm{M}_{\odot}\right],
$$

donde la distancia está en Mpc y el flujo de línea integrado de $21 \mathrm{~cm}$ en Jy $\mathrm{km} \mathrm{s}^{-1}$.

Masa dinámica:, para estimar la masa dinámica dentro de un radio $r$, se propone un equilibrio entre la fuerza gravitacional y la fuerza centrífuga. De este procedimiento se llega a la siguiente expresión:

$$
M_{\text {dyn }}(r)=2,3310^{5} r V(r)^{2} \quad\left[\mathrm{M}_{\odot}\right]
$$

donde la velocidad se encuentra en unidades de $\mathrm{km} \mathrm{s}^{-1}$ y $r$ en $\mathrm{kpc}$.

\subsubsection{Curva de rotación}

En las galaxias de disco, se puede suponer que todo el H i está confinado en el plano, ya que las velocidades aleatorias del H I son típicamente de 8 a $10 \mathrm{~km} \mathrm{~s}^{-1}$. Por lo tanto, el modelo más simple de movimiento de gas en galaxias de disco es el modelo de rotación. En un radio $r$, una nube de gas sigue una trayectoria casi circular con velocidad $V_{\text {rot }}(r)$. Observacionalmente, a partir de la detección de la emisión de la línea de $\mathrm{HI}$, podemos detectar la velocidad de la componente radial hacia o alejándose de nosotros, lo que depende del radio y la inclinación $\left(V_{\text {rad }}(r, i)\right)$. El valor de la velocidad radial en el centro de la galaxia es la velocidad sistémica $\left(V_{\text {sys }}\right)$. Si consideramos un disco de rotación circular pura, inclinado en un ángulo $i$, como en la Fig. 2.3, podemos especificar la posición de una estrella o nube de gas por su radio $r \mathrm{y}$ azimut $\phi$, medidos en el disco desde el diámetro AB que se encuentran perpendiculares a nuestras direcciones de visualización. La velocidad radial está dada por esta expresión,

$$
V_{\text {rad }}(r, i)=V_{\text {sys }}+V_{\text {rot }} \sin (i) \cos (\phi)
$$

Podemos parametrizar esta geometría y cinemática haciendo uso del modelo propuesto por Rogstad et al. [1974]. El modelo consiste en la descripción de la galaxia por un conjunto de anillos concéntricos. Cada anillo tiene un conjunto de parámetros cinemáticos, una coordenada central $\left(x_{c}, y_{c}\right)$, una velocidad sistémica $V_{\text {sys }}$, una inclinación $i$, un ángulo de posición $P A$ y la velocidad de rotación $V_{\text {rot }}$. Con el valor de $V_{\text {rot }}$ en un radio diferente $r$ se puede realizar el trazado de la curva de rotación, así como el diagrama de araña (ver Fig. 2.3). 

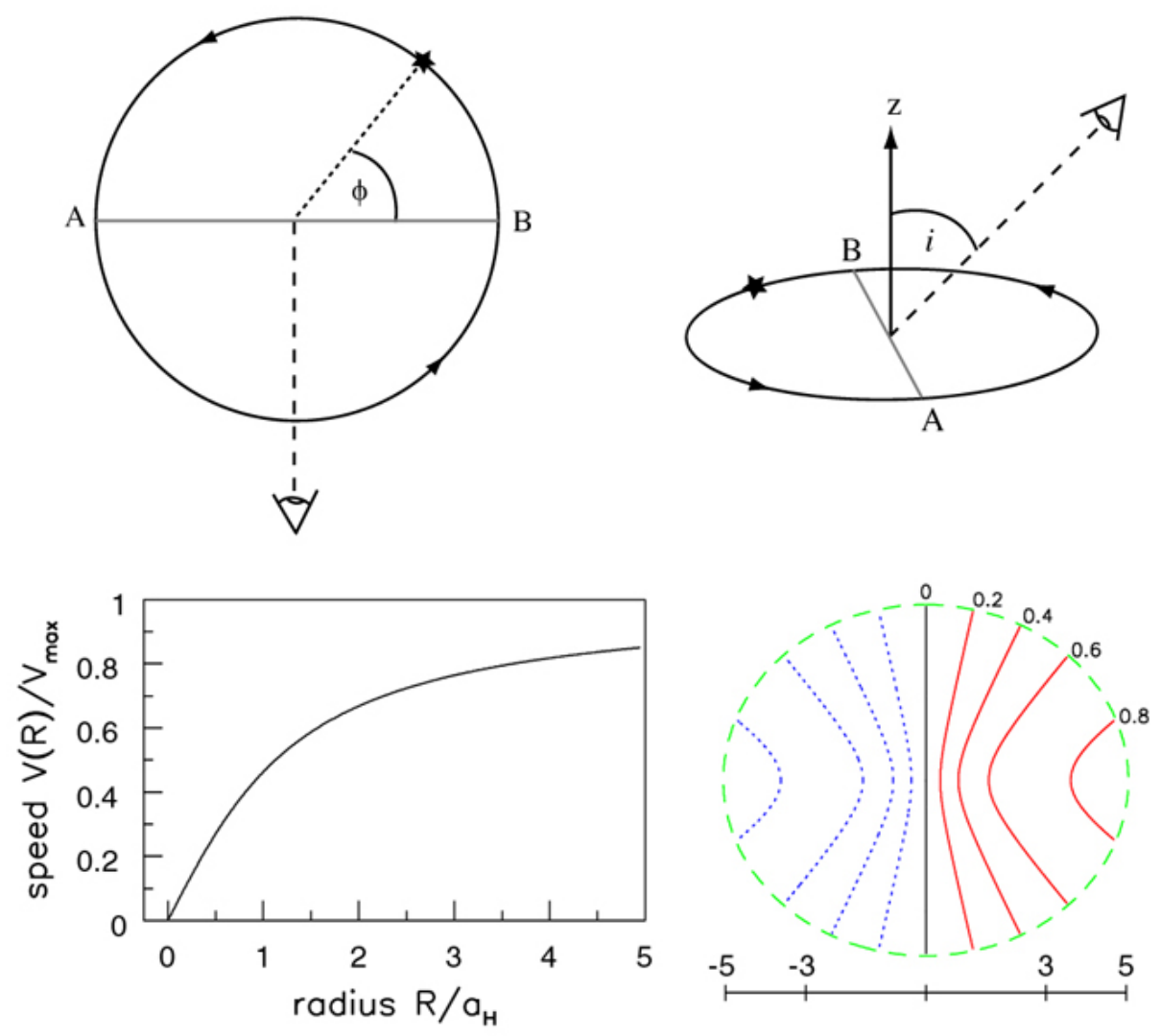

Figura 2.3: Panel Superior: A la izquierda, un disco giratorio visto desde arriba. El azimut $\phi$, medido en el plano del disco, da la posición de una estrella en su órbita; un observador mira desde arriba del disco, perpendicular al diámetro AB. A la derecha, la línea de visual del observador forma el ángulo $i$ con la rotación del disco. Panel Inferior: A la izquierda, la curva de rotación para un potencial de halo oscuro $\mathrm{V}(\mathrm{r})$, en unidades de $V_{\mathrm{H}}=V_{\max }$ y la distancia al centro en función del tamaño de la galaxia $a_{\mathrm{H}}$. A la derecha, el diagrama de araña de $V_{r}-V_{\text {sys }}$ para un disco de frente observado a $30^{\circ}$; los contornos están marcados en unidades de $V_{\mathrm{H}} \sin \left(30^{\circ}\right)$, con las velocidades negativas mostradas utilizando puntos [Sparke and Gallagher, 2007]. 


\subsection{Mediciones complementarias}

Junto con las observaciones de la línea de emisión del H i también se puede recopilar información sobre la emisión continua. Los mecanismos que generan la emisión continua en $\lambda=20 \mathrm{~cm}$ son el Bremsstrahlung térmico y el sincrotrón. La radiación de Bremsstrahlung se produce por la desaceleración de una partícula cargada cuando es desviada por otra partícula cargada, típicamente un electrón por un núcleo atómico (libre-libre), o cuando el electrón es capturado y neutraliza el átomo (unido libremente). La radiación de sincrotrón es producida por una partícula relativista cargada que se mueve en un campo magnético. En las galaxias, el primer mecanismo generalmente se produce en las regiones $\mathrm{H}$ II, mientras que el segundo involucra electrones relativistas (AGN).

Midiendo la emisión continua de una galaxia podemos obtener la tasa de formación de estrellas usando la siguiente expresión:

$$
S F R=0,14 D^{2} F_{20 \mathrm{~cm}}\left[\mathrm{M}_{\odot} \mathrm{yr}^{-1}\right],
$$

donde $D$ es la distancia en $M p c$ y $F_{20 \mathrm{~cm}}$ es la densidad de flujo del continuo de radio (a $20 \mathrm{~cm}$ ) en Janskys [Condon, 1992].

\subsection{Efectos ambientales en la evolución de las ga- laxias}

La línea de $21 \mathrm{~cm}$ del H i proporciona información espacial y cinemática del gas. Por lo tanto, la cinemática del H I asociado con galaxias y/o residuos de marea puede resaltar las órbitas pasadas de sus interacciones. Los resultados compilados a continuación proporcionan buenos ejemplos de tales investigaciones.

En Virgo y en la región de la Osa mayor, se han detectado y mapeado la presencia de filamentos de H i [Oosterloo and van Gorkom, 2005, Boselli and Gavazzi, 2006, Verheijen and Zwaan, 2001, Wolfinger et al., 2013], que son indicios de procesos perturbadores en curso, al tiempo que proporcionan combustible para la formación de nuevas galaxias enanas a partir de los desechos de las mareas [Duc et al., 2004, Lee-Waddell et al., 2016]. Por lo general, los residuos de H i se detectan cerca de galaxias masivas, a menudo de tipo temprano [Schneider, 1989, Ryder et al., 2001, Bekki et al., 2005b,a, Chung et al., 2009, English et al., 2010, Struve et al., 2010]. También se observa cerca del centro del cúmulo la presencia de galaxias deficientes en $\mathrm{H}$ I, donde se eliminó H I de los discos externos de espirales ricas en gas [Chung et al., 2007, 2009]. La eficiencia de extracción se estima por la diferencia entre la masa observada de H I y la esperada para una galaxia aislada con el mismo tipo morfológico [Haynes et al., 1984].

A pesar de que inicialmente los estudios de interacciones de galaxias y los efectos del medio ambiente estaban relacionados en su mayoría con grupos de galaxias, actualmente también son convencionales en grupos de galaxias [Verdes-Montenegro et al., 2001, Bekki et al., 2005b,a, Chung et al., 2009, English et al., 2010, Serra et al., 2012, 


\section{El hidrógeno neutro}

Wolfinger et al., 2013, Serra et al., 2015a].

Sin embargo, para los grupos cercanos, las investigaciones presentan desafíos especiales. Por un lado puede darse que se requieran diferentes apuntamientos ya que a menudo el tamaño del grupo es más grande que el campo de visión, y por el otro lado se necesita mucho tiempo de observación ya que en general, estas estructuras extendidas de H I pueden ser difíciles de detectar por los interferómetros. Es por eso que también son importantes las observaciones realizadas con antenas de disco simple. 


\section{Capítulo 3}

\section{Muestra seleccionada}

En este capítulo presentamos la muestra de galaxias bajo estudio. Gracias a las características intrínsecas de estas galaxias y del ambiente donde se encuentran inmersas, pudimos estudiar la distribución y cinemática del H y y la presencia de restos intergalácticos de H i en el grupo compacto IC 1459, las fases fría y caliente del medio interestelar en KK69, y la distribución de materia oscura en la Fourcade-Figueroa.

\subsection{El grupo de galaxias, IC 1459}

El grupo de galaxias IC 1459 es una asociación de unas $\sim 10$ galaxias ubicado a una distancia aproximada de $29 \mathrm{Mpc}$. La galaxia central, que da nombre al grupo, es una galaxia masiva elíptica de tipo temprano. Los escombros de H I más importantes se detectan, generalmente, cerca de galaxias masivas, a menudo de tipo temprano. También se observa cerca del centro del cúmulo la presencia de galaxias deficientes en H I [Gordon et al., 2003, Koribalski et al., 2003, Serra et al., 2012]. El grupo IC 1459 proporciona un entorno particularmente atractivo para estudiar el desplazamiento de H I producido tanto por las interacciones de las mareas como por barrido por presión cinética.

Este grupo fue observado recientemente por el equipo de WALLABY [Serra et al., 2015a] usando seis antenas de ASKAP (Australian Square Kilometer Array Pathfinder). Este instrumento consta de unas 36 antenas de $12 \mathrm{~m}$ de diámetro con líneas de base de hasta $6 \mathrm{~km}$. WALLABY es un relevamiento que será realizado con ASKAP y cubrirá el cielo sur hasta una declinación de $\delta=30^{\circ}$ y hasta un redshift de $z=0,26$ [Koribalski et al., 2012].

En el Capítulo 4, exploramos el área alrededor de IC 1459 mediante el uso de los datos de archivo de la línea de $21 \mathrm{~cm}$ de ATCA (Australia Telescope Compact Array) y los resultados de las observaciones del radiotelescopio de disco simple Parkes. 


\subsection{La galaxia enana KK 69}

El grupo de galaxias NGC 2683 está ubicado a $\sim 9$ Mpc y está cerca de la región de muy baja densidad llamada Leo-Gemini void. El grupo está conformado por la galaxia espiral NGC 2683 y las galaxias enanas KK 69, KK 70, AGC 182595, N2683dw1 y N2683dw2 [Karachentsev et al., 2015b, Vollmer et al., 2016]. Nuestro objetivo es contribuir a la comprensión de la distribución del gas, la cinemática y la formación de estrellas en galaxias enanas débiles. En particular, nos interesa distinguir las fases fría y cálida neutra del ISM y buscar evidencias de interacciones de la galaxia ya sea con otras galaxias o con su entorno en esta región específica de baja densidad.

En el Capítulo 5, investigamos a la enana KK 69, miembro del pequeño grupo mencionado. Para lograr nuestros objetivos de investigación utilizamos nuevas observaciones dedicadas de H i (J. Saponara, P. Benaglia y B. Koribalski; C29-067) obtenidas con el radiotelescopio Giant Metrewave Radio Telescope (GMRT).

\subsection{La galaxia Fourcade-Figueroa}

Centaurus A (NGC 5128) es la radio-galaxia más cercana a la Vía Láctea, ubicada a una distancia de $\sim 3,8 \mathrm{Mpc}$. Es la galaxia central de un grupo de galaxias que consta de 28 miembros [Karachentsev et al., 2004]. NGC 5128 tiene una morfología peculiar generalmente reconocida como resultado de una fusión de galaxias. A pesar de que la galaxia Fourcade-Figueroa (FF) se proyecta en la parte sur de Centauros A, su distancia de $\sim 6,9 \mathrm{Mpc}$ sugiere que está ubicada muy por detrás, en las afueras del grupo.

En el caso de galaxias vistas de canto o muy inclinadas, tanto la velocidad de rotación H i como la altura de escala del H i pueden determinarse por medio de observaciones de H I. La velocidad de rotación del disco de H i se pueden usar para restringir el perfil de densidad de los halos de materia oscura [Begum and Chengalur, 2004, Banerjee et al., 2010, Banerjee and Jog, 2008, 2011]. La galaxia FF es una galaxia vista de canto cuyo tamaño angular es menor que el campo de visión de GMRT, lo que nos permite observarla con un sólo apuntamiento. Además, el hecho de ser una galaxia cercana y al ser observada con muy buena resolución angular nos garantiza una buena resolución lineal. Todo esto la convierte en una buena candidata a ser empleada para aprender acerca de la distribución de materia oscura.

En el Capítulo 6, describimos la investigación llevada a cabo sobre la galaxia FF. Para este proyecto, combinamos nuevas observaciones dedicadas de H I (P. Benaglia, J. Saponara, B. Koribalski y A. Banerjee, C28-081) realizadas con el GMRT, con datos previos obtenidos con el ATCA. Hicimos uso también de las observaciones en H I obtenidas con el telescopio de disco simple Parkes. 


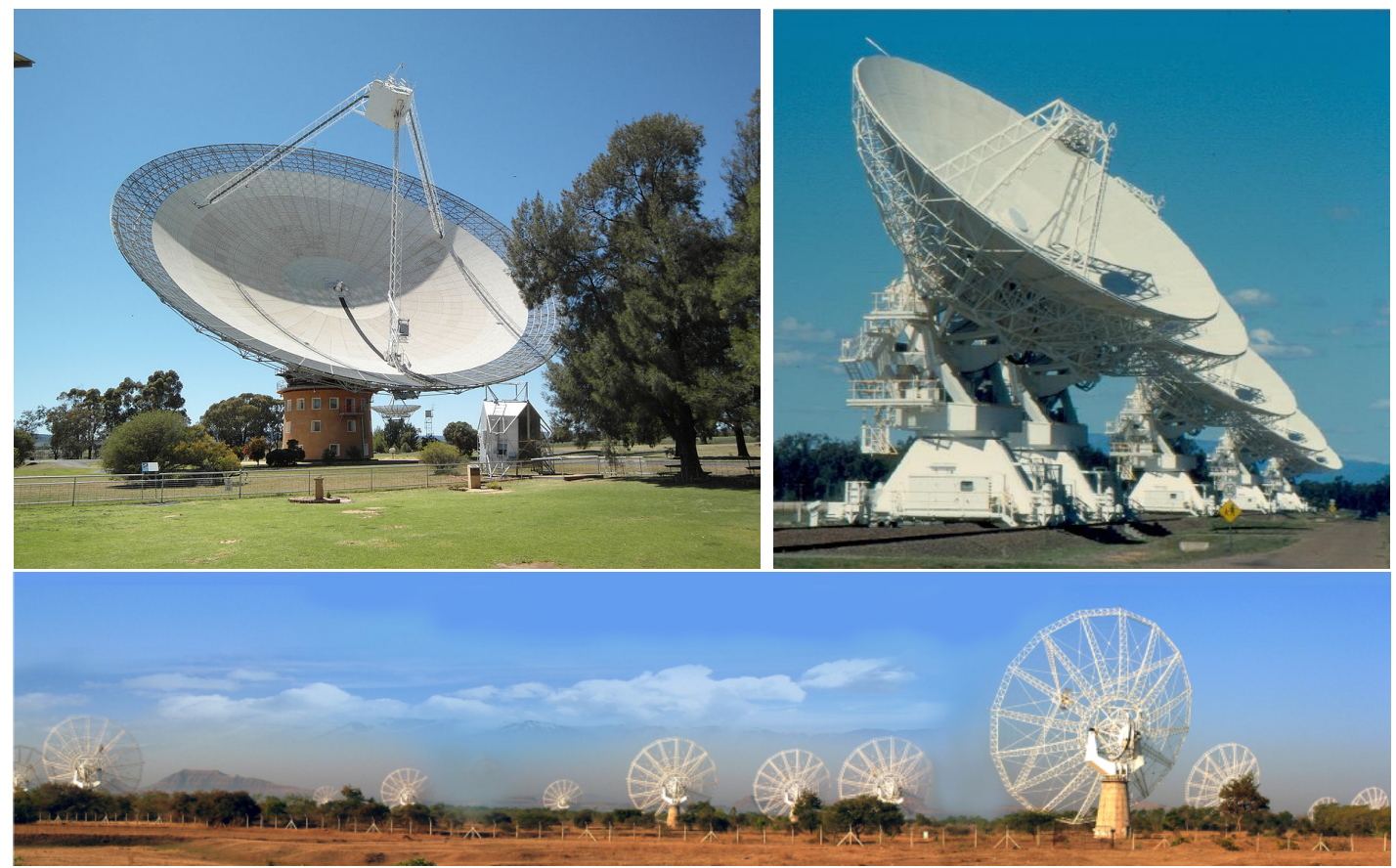

Figura 3.1: Imágenes de los instrumentos Parkes (primer fila a la izquierda), Australia Telescope Compact Array (ATCA, primer fila a la derecha) y Giant Metrewave Radio Telescope (GMRT, segunda fila). Los créditos de las imágenes de Parkes y ATCA son de CSIRO-ATNF y la de GMRT es NCRA-TIRF.

\subsection{Parkes, ATCA y GMRT}

El telescopio de $64 \mathrm{~m}$ Parkes está ubicado a $20 \mathrm{~km}$ al norte de la ciudad de Parkes en Nueva Gales del Sur, Australia. Fue una de las antenas que se utilizó para recibir imágenes del Apollo 11 cuando aterrizó en la Luna, el 20 de julio de 1969. El campo de visión a $1420 \mathrm{MHz}$ es de 14,5'. En el rango de frecuencia de 1,22 a 1,53 Ghz opera un receptor multihaz. Consiste en receptores de $21 \mathrm{~cm}$ de 13 haces que se colocan en el foco principal del disco. La instalación se desarrolló especialmente para realizar el relevamiento HIPASS ("HI" Parkes All-sky Survey) y ZOA (Zone of Avoidance) H i. Los diferentes receptores y sus propiedades se describen en la página web del telescopio de Parkes ${ }^{1}$. Parkes es operado por "The Commonwealth Scientific and Industrial Research Organisation (CSIRO), part of the Australia Telescope National Facility (ATNF)".

El Australia Telescope Compact Array (ATCA) consta de seis antenas de $22 \mathrm{~m}$ de diámetro, ubicadas cerca de la ciudad de Narrabri, Australia. Las antenas se pueden disponer en 17 configuraciones diferentes; cinco de ellas pueden moverse a lo largo de una pista de $3 \mathrm{~km}$ de este a oeste y en un ramal corto norte-sur, mientras que la antena seis (CAO6) está fija en su posición. Desde 2010, el backend de banda ancha de matriz compacta (CABB) está disponible y ofrece una banda inferior que cubre de 1 a $105 \mathrm{Ghz}$ [Wilson et al., 2011]. El campo de visión a 1,4 Ghz es $\sim 34^{\prime}$. El haz sintetizado dependerá de la matriz de configuración y la declinación de la fuente

\footnotetext{
${ }^{1}$ www.narrabri.atnf.csiro.au/observing/users_guide/html/atug.html
} 
de observación, pero en la banda L/S se puede alcanzar un haz sintetizado de 9" a $3^{\prime \prime}$. La resolución de velocidad más alta que se puede lograr actualmente a $21 \mathrm{~cm}$ es $\sim 0,1 \mathrm{~km} \mathrm{~s}^{-1}$. ATCA es operado por CSIRO-ATNF.

El Giant Metrewave Radio Telescope (GMRT), está ubicado a unos $80 \mathrm{~km}$ al norte de Pune, India. GMRT consta de 30 antenas de $45 \mathrm{~m}$ de diámetro cada una distribuidas en distancias de hasta $25 \mathrm{~km}$. El número de las antenas y la configuración se optimizaron para lograr los principales objetivos astrofísicos que requieren alta sensibilidad y una gran resolución angular, así como la capacidad de generar imágenes de emisiones de radio de regiones extendidas difusas. 14 de las treinta antenas se distribuyen al azar en un arreglo central compacto en una región de aproximadamente un kilómetro cuadrado. Las 16 antenas restantes están ubicadas a lo largo de tres brazos, siguiendo una distribución aproximada en forma de ' $\mathrm{Y}$ '. La línea base interferométrica más extendida es de $25 \mathrm{~km}$. La cobertura de declinación es de -53 grados a +90 grados. La matriz opera en bandas de frecuencia de hasta 1420Mhz; algunos frecuencias centrales utilizadas habitualmente son 50, 153, 233, 325, 610 y 1420 MHz. La resolución angular máxima que se puede alcanzar en la banda L es $2^{\prime \prime}$ y la resolución de velocidad es $1,8 \mathrm{~km} \mathrm{~s}^{-1}$. El campo de visión en la banda L es de $26^{\prime}$. GMRT es operado por "The National Centre for Radio Astrophysics, Tata Institute of Fundamental Research (NCRA-TIRF)".

Parkes, ATCA y GMRT son retratados en la Fig. 3.1. 


\section{Capítulo 4}

\section{Escombros de HI en el grupo de galaxias IC 1459}

En este capítulo, presentamos el estudio realizado sobre la región central del grupo de galaxias IC 1459, a partir de observaciones de H I utilizando la técnica de síntesis de apertura. Nuestra búsqueda de emisión de H I extendida reveló la presencia de un gran complejo de nubes de H I cerca de IC 1459, probablemente los escombros resulten de la interacción de mareas con las galaxias vecinas. La masa total de $\mathrm{H}$ I es de $\sim 10^{9} \mathrm{M}_{\odot}$; las nubes detectadas abarcan en extensión $250 \mathrm{kpc}$ yendo desde el noreste de la espiral rica en gas, NGC 7418A, al sureste de la galaxia IC 1459. La morfología y la cinemática de estos escombros son similares a los que se observan en otros grupos de galaxias cercanos. Este descubrimiento junto con las nubes de H r recientemente detectadas cerca de otros dos miembros, IC 5270 y NGC 7418, usando "The Australia Square Kilometer Array Pathfinder (ASKAP)", implica que los escombros detectados constituyen una fracción significativa del medio intergaláctico del grupo.

Los resultados presentados en este capítulo se publicaron en "H I debris in the IC 1459 galaxy group " [Saponara et al., 2018].

\subsection{El grupo de galaxias IC 1459 galaxy}

IC 1459 es una galaxia elíptica, ubicada en el centro de un grupo pequeño de galaxias y se encuentra a una distancia aproximada de 29 Mpc [Blakeslee et al., 2001, Tonry et al., 2001]; consideremos esta distancia como la distancia para todo el grupo [ver también Serra et al., 2015a]. El grupo de galaxias IC 1459 contiene diez galaxias, en su mayoría de tipo tardío [Brough et al., 2006, Kilborn et al., 2009], que a su vez forman parte del grupo de Grus a gran escala [Aaronson et al., 1981, Huchra and Geller, 1982]. Además, dos galaxias elípticas enanas (denotadas como dE1 y dE2) han sido catalogadas por Vader and Chaboyer [1994] como miembros del grupo, ambos ubicadas al sureste de IC 5264. Ambas galaxias, la enana nucleada dE2 y dE1, son visibles en imágenes del "Digital Survey Sky Survey (DSS2)" de segunda generación. La Tabla 4.1 resume las propiedades ópticas de los miembros del grupo de galaxias IC 1459 bajo nuestro estudio mientras que la Tabla 4.2 enumera las propiedades de H I obtenidas con "H I Parkes All Sky survey" [Koribalski et al., 2004, HIPASS]. 
Imágenes ópticas con gran sensibilidad del grupo de galaxias IC 1459 fueron publicadas por Malin [1985] y Forbes et al. [1995]. Estas imágenes revelan estructuras de brazos, plumas y cáscaras muy tenues en las afueras de la componente estelar de IC 1459 y son indicadores de fenómenos como acreción y fusión. Las cáscaras más débiles parecen abarcar a la galaxia espiral vecina IC 5264. La distancia media de la cáscara más grande desde el centro de IC 1459 es 3'8. Forbes et al. [1995] encontró que las cáscaras, que están orientadas a lo largo del eje mayor de la galaxia, tienen colores rojos similares a la galaxia principal.

Un mapa de H I de baja sensibilidad de IC 1459 y sus alrededores, realizado con datos de VLA, fue presentado por Walsh et al. [1990], quien detectó a tres miembros del grupo (IC 5269B, NGC 7418A e IC 5264) y dio un límite superior de $3 \mathrm{Jy} \mathrm{km} \mathrm{s}^{-1}$ para el flujo H I en las inmediaciones de IC 1459 (es decir, $M_{\mathrm{HI}}<6 \times 10^{8} \mathrm{M}_{\odot}$ ). Sus mapas de canales del H I mostraron pistas de escombros al este de IC $5264 \mathrm{a} \sim 1800 \mathrm{~km} \mathrm{~s}^{-1}$. Un mapa preliminar de ATCA H I de la misma área fue mostrado por Oosterloo et al. [1999]; en este se observan los residuos de H I alrededor de IC 1459. En ese trabajo, se discutió brevemente su morfología irregular, sugiriendo que el gas H i fue extraído de los miembros del grupo ricos en gas a través de interacciones con IC 1459.

Las observaciones de rayos X de ROSAT realizadas por Osmond and Ponman [2004] revelaron la presencia de emisión extendida de baja intensidad cerca de IC 1459 y estimaron una luminosidad total para el grupo de $L_{\mathrm{X}}\left(r_{500}{ }^{1}\right)=41,51 \mathrm{erg} \mathrm{s}^{-1}$. Kilborn et al. [2009] realizó observaciones de H i con Parkes de 16 grupos de galaxias y comparó sus propiedades en H I y en rayos X. Para el grupo IC 1459 derivaron un masa total de $\mathrm{H}$ I de al menos de $2,5 \times 10^{10} \mathrm{M}_{\odot}$. Basándose en la masa dinámica inferida por el agujero negro en IC 1459 de $3-12 \times 10^{8} \mathrm{M}_{\odot}$, Verdoes Kleijn et al. [2000] estimó una masa total de $\sim 3 \times 10^{11} \quad \mathrm{M}_{\odot}$ para esta galaxia (todas las estimaciones en masa citadas se ajustan a nuestra distancia adoptada). Usando el modelado dinámico de los datos de HST, los mismos autores midieron una velocidad sistémica de $v_{\text {sys }}=1783 \pm 10$ $\mathrm{km} \mathrm{s}^{-1}$, del gas ionizado en IC 1459, $90 \mathrm{~km} \mathrm{~s}^{-1}$ más alto que la velocidad óptica de IC 1459 de $1691 \pm 18 \mathrm{kms}^{-1}$ [de Vaucouleurs et al., 1991]. La emisión de una línea estrecha $\left(35 \mathrm{~km} \mathrm{~s}^{-1}\right){ }^{12} \mathrm{CO}(1-0)$ hacia IC 1459 en $v_{\text {sys }}=1782 \mathrm{~km} \mathrm{~s}^{-1}$ fue detectada por Bettoni et al. [2001]. Además, estimaron un límite de masa molecular de $2 \times 10^{7}$ $\mathrm{M}_{\odot}$ y sugirieron que la emisión se origina a partir de una asociación molecular gigante, posiblemente residual del proceso de fusión.

La galaxia IC 1459 muestra una serie de características peculiares que sugieren ser alteraciones debidas a procesos de interacciones y/o fusión con otras galaxias, como por ejemplo: las isofotas distorsionadas primero observadas por Williams and Schwarzschild [1979] y Franx et al. [1989], un núcleo estelar en contra-rotación [Franx and Illingworth, 1988], cáscaras estelares débiles [Malin, 1985] y la línea de emisión de $\mathrm{H}+\mathrm{N}$ [II] que muestra un estructura espiral débil [Goudfrooij et al., 1990]. Además, IC 1459 alberga una fuente de radio brillante, PKS 2254-367, caracterizada por dos jets de radio simétricos, cuya actividad puede haber sido generada por los mismos eventos que

\footnotetext{
${ }^{1} r_{500}$ es un radio proyectado determinado por los autores a partir de la temperatura, ver la Sección 4.2 del trabajo Osmond and Ponman [2004]
} 
le dieron a la galaxia su peculiar morfología y cinemática. Los jets se extienden a solo 8 pc, bien dentro del núcleo de la galaxia, lo que indica que el AGN es muy joven [Tingay and Edwards, 2015]. 
Tabla 4.1: Propiedades ópticas de las galaxias dentro del área observada.

\begin{tabular}{lccccccccc}
\hline \hline Nombre & tipo & $\begin{array}{c}\text { posición central } \\
\alpha, \delta(\mathrm{J} 2000)\end{array}$ & $\begin{array}{c}v_{\mathrm{opt}} \\
{\left[\mathrm{km} \mathrm{s}^{-1}\right]}\end{array}$ & $\begin{array}{c}m_{\mathrm{B}} \\
{[\mathrm{mag}]}\end{array}$ & $\begin{array}{c}M_{\mathrm{B}} \\
{[\mathrm{mag}]}\end{array}$ & $\begin{array}{c}D_{\mathrm{B} 25} \\
{[\mathrm{arcmin}]}\end{array}$ & $\begin{array}{c}i \\
{[\mathrm{deg}]}\end{array}$ & $\begin{array}{c}P A \\
{[\mathrm{deg}]}\end{array}$ & $\begin{array}{c}\text { distancia a IC 1459 } \\
{[\operatorname{arcmin}]}\end{array}$ \\
\hline IC 5269B & SBcd & $22: 56: 36.5,-36: 14: 57$ & 1659 & 13.2 & -18.9 & 4.1 & 78 & 96 & 14.5 \\
IC 5269A & SBm & $22: 55: 55.7,-36: 20: 52$ & 2870 & 13.9 & -18.9 & 1.3 & 41 & 35 & 16.5 \\
IC 1459 & E3 & $22: 57: 11.5,-36: 27: 44$ & 1691 & 11.0 & -21.3 & 4.9 & 42 & 47 & - \\
dE1 & dE0/Im & $22: 57: 07.6,-36: 37: 15$ & - & 15.5 & -16.8 & 0.04 & - & - & 9.5 \\
dE2 & dE0,N & $22: 57: 10.6,-36: 40: 09$ & 1838 & 17.3 & -15.0 & 0.32 & - & - & 12.4 \\
IC 5264 & Sab & $22: 56: 52.6,-36: 33: 15$ & 2043 & 13.7 & -18.6 & 2.5 & 77 & 82 & 6.5 \\
NGC 7418A & SAd & $22: 56: 41.8,-36: 46: 21$ & 2102 & 13.8 & -18.8 & 1.8 & 56 & 83 & 19.5 \\
\hline
\end{tabular}

Notas: Cols. (2-8), clasificación morfológica de la galaxia, coordendas del centro [h $\left.\mathrm{m} \mathrm{s}{ }^{\circ}{ }^{\prime}{ }^{\prime \prime}\right]$, velocidad óptica $\left(v_{\text {opt }}\right)$, magnitud en el azul $\left(m_{\mathrm{B}}\right)$, magnitud absoluta en el azul $\left(M_{\mathrm{B}}\right)$ diámetro medido hasta 25th magnitud en el azul $\left(D_{\mathrm{B} 25}\right)$, ángulo de inclinación $(i)$ y ángulo de posición (PA). - Referencias: ESO LV Lauberts and Valentijn [1989], de Vaucouleurs et al. [1991], da Costa et al. [1991], and Vader and Chaboyer [1994]. 
Tabla 4.2: HIPASS - propiedades de las galaxias dentro del área observada.

\begin{tabular}{lccccccc}
\hline \hline Nombre & Nombre en HIPASS & $\begin{array}{c}v_{\text {sys }} \\
{\left[\mathrm{km} \mathrm{s}^{-1}\right]}\end{array}$ & $\begin{array}{c}w_{50} \\
{\left[\mathrm{~km} \mathrm{~s}^{-1}\right]}\end{array}$ & $\begin{array}{c}w_{20} \\
{\left[\mathrm{~km} \mathrm{~s}^{-1}\right]}\end{array}$ & $\begin{array}{c}F_{\mathrm{HI}} \\
{\left[\mathrm{Jy} \mathrm{km} \mathrm{s}^{-1}\right]}\end{array}$ & Referencia & $\begin{array}{c}\text { separación } \\
\text { coordendas ópticas }\end{array}$ \\
\hline IC 5269B & HIPASS J2256-36b & $1667 \pm 4$ & 226 & 242 & $21,5 \pm 3,3$ & $(1)$ & $10^{\prime} 5$ \\
IC 1459 debris & HIPASS J2257-36* & $1802 \pm 12$ & 80 & 111 & 3.0 & $(2)$ & 3.5 \\
IC 5269A & HIPASS J2255-36 & $2872 \pm 8$ & 124 & 147 & 6.0 & $(2)$ & 1.3 \\
IC 5264 & - & $\sim 1950$ & & $\sim 300$ & & here & $(1)$ \\
NGC 7418A & HIPASS J2256-36a & $2115 \pm 5$ & 173 & 209 & $23,5 \pm 3,3$ & $(1)$ & 1.0 \\
\hline
\end{tabular}

Notas: Cols. (3-6), velocidad sistémica del H I $\left(v_{\mathrm{sys}}\right), 50 \%$ y $20 \%$ del ancho en velocidad $\left(w_{50}, w_{20}\right)$ y el flujo integrado $\left(F_{\mathrm{HI}}\right)$. * HIPASS J2257-36 abarca parte de los escombros detectados en H i cerca de IC 1459. — Referenciass: (1) Koribalski et al. [2004] (HIPASS BGC); (2) Meyer et al. [2004] (HICAT). 
Tabla 4.3: Observaciones realizadas con ATCA del grupo de galaxias IC 1459.

\begin{tabular}{|c|c|c|c|c|}
\hline ATCA (configuración) & $\mathrm{H} 214$ & 375 & $750 \mathrm{~A}$ & $6 \mathrm{~A}$ \\
\hline Proyecto & $\mathrm{C} 1154$ & C530 & C1027 & C689 \\
\hline Fecha & 04-03-05 & $19-09-96$ & 08-01-02 & 03-02-98 \\
\hline & & $23-09-97$ & & 08-02-98 \\
\hline Tiempo sobre la fuente [min] & 87 & 396 & 5543 & $\begin{array}{c}09-02-98 \\
1635\end{array}$ \\
\hline & & 651 & & 40 \\
\hline & & & & 80 \\
\hline Calibradora primaria & \multicolumn{4}{|c|}{ PKS 1934-638 (14.95 Jy) } \\
\hline Calibradora de fase & $0008-421$ & $0008-421$ & $2259-375$ & $2259-375$ \\
\hline Frecuencia central $[\mathrm{MHz}]$ & 1412 & 1412 & 1413 & 1413 \\
\hline Ancho de banda $[\mathrm{MHz}]$ & 8 & 16 & 8 & 8 \\
\hline Nro. de canales & 512 & 512 & 1024 & 512 \\
\hline Ancho de canales $\left[\mathrm{km} \mathrm{s}^{-1}\right]$ & 3.3 & 6.6 & 1.6 & 3.3 \\
\hline Resolución en velocidad $\left[\mathrm{km} \mathrm{s}^{-1}\right]$ & 4 & 8 & 2 & 4 \\
\hline
\end{tabular}

\subsection{Observaciones y reducción de los datos}

Las observaciones de la línea H I y de continuo en $20 \mathrm{~cm}$ de IC 1459 se obtuvieron con ATCA en las configuraciones H214, 375, 750A y 6A entre septiembre de 1996 y marzo de 2005. Los datos fueron descargados de "Australia Telescope Online Archive 2(ATOA)". Los parámetros observacionales se resumen en la Tabla 6.2; el tiempo total empleado sobre la fuente es de 32.8 horas.

Realizamos la reducción de datos y el análisis con el software MIRIAD [Sault et al., 1995] usando procedimientos estandarizados. Adicionalmente, utilizamos KVIS, parte del KARMA package [Gooch, 1996], para la visualización de nuestros cubos de imágenes e imágenes de diferentes longitudes de onda. Calibramos cada conjunto de datos por separado, utilizando PKS 1934-638 como calibrador de flujo primario y calibrador de pasa banda, excepto para el caso de la configuración 375, donde se utilizó PKS 2259375 para la calibración de pasa banda. El último conjunto de datos se vio afectado por la interferencia solar. Las fuentes PKS 2259-375 y PKS 0008-421 sirvieron como calibradores de fase. Usando una densidad de flujo de 14.95 Jy para PKS 1934-638, obtuvimos 2.6 Jy para PKS 2259-375 y 4.3 Jy para PKS 0008-421. La substracción del continuo se realizó utilizando la tarea UVLIN; las opciones sun y twofit se implementaron para restar la emisión continua del Sol. Con un ancho de banda de al menos $8 \mathrm{MHz}$ (consulte la Tabla 6.2), pudimos seleccionar canales sin líneas en cada lado de la emisión H I detectada dentro del grupo de galaxias IC 1459. A los datos de la línea espectral H I se les aplica la transformada de Fourier utilizando una ponderación natural en un caso y otra robusta. Las líneas de base más largas, las cuales se corresponden con la antena distante seis (CA06), se excluyeron al realizar los cubos de $\mathrm{H}$ I de baja resolución con el fin de mejorar la sensibilidad y así poder detectar la emisión difusa y extendida del H I.

\footnotetext{
${ }^{2}$ http://atoa.atnf.csiro.au/
} 


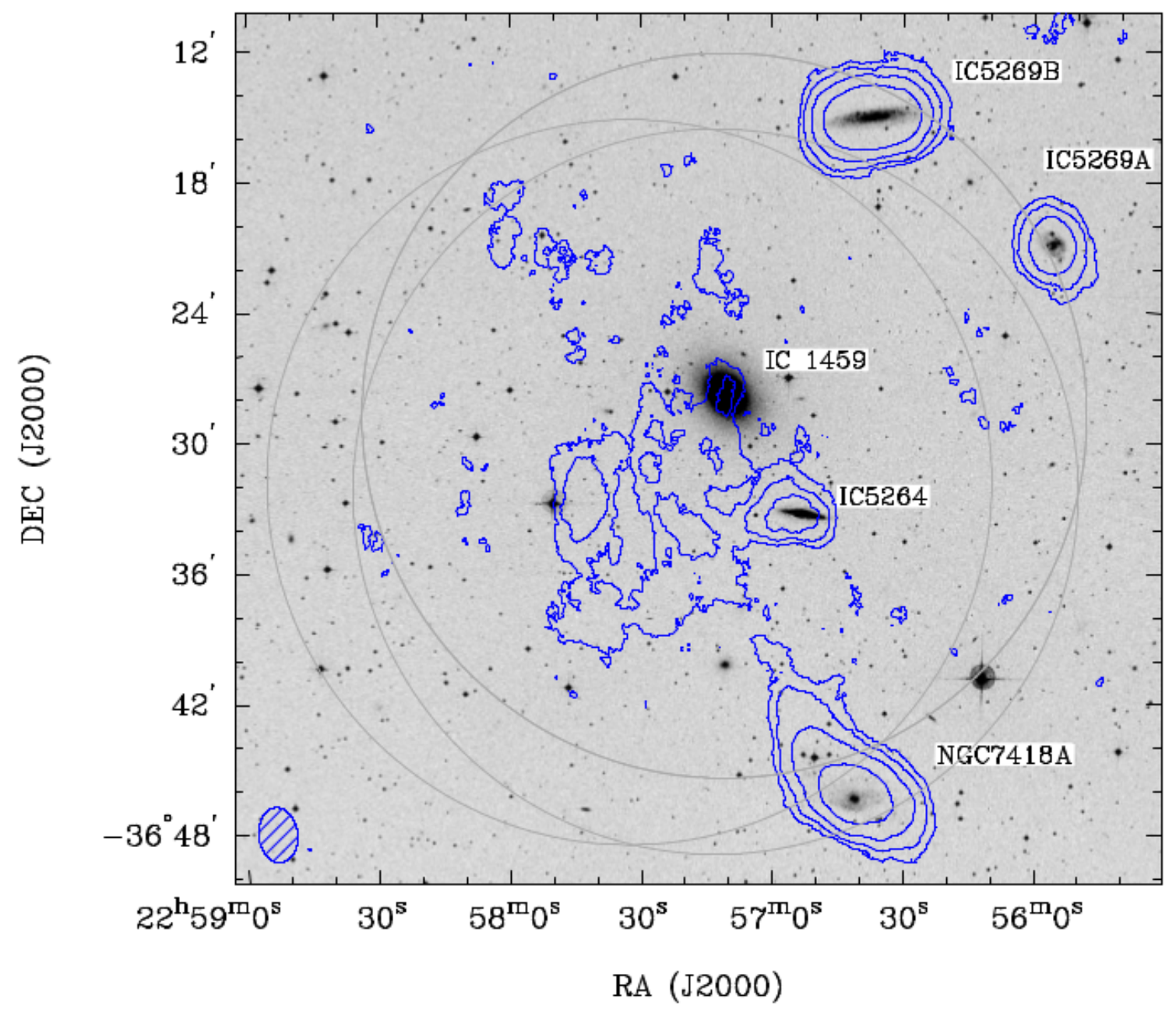

Figura 4.1: Distribución del H i en el grupo IC 1459 en el rango de velocidad de 1200 a $2950 \mathrm{~km} \mathrm{~s}^{-1}$, superpuesta sobre una imagen en el filtro $B$ del DSS2. Grandes cantidades de residuos de H i se detectan alrededor de la galaxia elíptica gigante IC 1459, así como la emisión de $\mathrm{H}$ I en cuatro galaxias (todos los miembros del grupo conocidos están etiquetados). Los niveles de contorno son 0,$25 ; 0,5 ; 1 ; 2 \mathrm{Jy} \mathrm{haz}^{-1} \mathrm{~km} \mathrm{~s}^{-1}$. El haz sintetizado $\left(151^{\prime \prime} .9 \times 108^{\prime \prime} .7\right)$ se muestra en la esquina inferior izquierda; los círculos grises marcan las tres ubicaciones diferentes del haz primario ATCA. Esta imagen no es de haz primario corregida. 
Como los cuatro conjuntos de datos tienen centro de apuntado diferentes, marcados en la Fig. 4.1, se produjo una imagen de mosaico que luego se limpió y se restauró. El haz sintetizado en el mapa de H I de baja resolución es $152^{\prime \prime} \times 107^{\prime \prime}$, el r.m.s. medido es de $\sim 1,7 \mathrm{mJy} \mathrm{haz}^{-1}$ en el centro del campo de cada canal $\left(8 \mathrm{~km} \mathrm{~s}^{-1}\right.$ cada canal). El valor de $N_{\mathrm{HI}}$ y de $M_{\mathrm{HI}}$ considerando $5 \sigma$, promediado cada tres canales, resulta en $\sim 6 \times 10^{17} \mathrm{~cm}^{-2} \mathrm{y} \sim 4 \times 10^{7} \mathrm{M}_{\odot}$. En el cubo con mayor resolución angular $\left(30^{\prime \prime} \times 30^{\prime \prime}\right)$, el cual fue utilizado para identificar las nubes con mayor densidad, medimos un r.m.s. de $\sim 0,8 \mathrm{mJy} \mathrm{haz}^{-1}$ por canal. Por lo tanto, el valor de $N_{\mathrm{HI}}$ y de $M_{\mathrm{HI}}$ considerando $5 \sigma$, promediado cada tres canales, resulta en $\sim 5 \times 10^{18} \mathrm{~cm}^{-2}$ y $\sim 0,2 \times 10^{7} \mathrm{M}_{\odot}$.

\subsection{Resultados}

En la Fig. 4.1, se muestra la distribución de H i dentro de la región central del grupo de galaxias IC 1459, observado con el interferómetro ATCA. Detectamos la emisión H I en cuatro galaxias espirales; estas son (de norte a sur) IC 5269B, IC 5269A, IC 5264 y NGC 7418A. Sus propiedades ópticas y observacionales publicadas en HIPASS se enumeran en las Tablas 4.1 y 4.2, respectivamente. Además, encontramos un complejo de nubes de H I cerca de la galaxia elíptica IC 1459, así como también nubes individuales de H i presentes al noreste de NGC 7418A y al este de IC 5264. A pesar de que el grupo IC 1459 contiene un medio difuso caliente/cálido intragrupo, el cual probablemente provenga de la separación del gas de las galaxias dado por el fenómeno de barrido por presión cinética, encontramos evidencia relevante que apunta a las interacciones de marea entre los miembros del grupo. Las propiedades de las nubes medidas a partir de los datos de ATCA H i aquí presentados, se resumen en la Tabla 4.4. Estas nubes de H I son adicionales a las descubiertas con datos de ASKAP Serra et al. [2015a] cerca de las galaxias espirales IC 5270 y NGC 7418, las cuales se encuentran fuera del área observada en esta tesis. El contorno más bajo en la Fig. 4.1 corresponde a una densidad columnar del H i de $N_{\mathrm{HI}}=1,7 \times 10^{19} \mathrm{~cm}^{-2}$ (asumiendo que el H I llena el haz). 
Tabla 4.4: ATCA H I - Propiedades individuales de las nubes próximas a IC 1459.

\begin{tabular}{|c|c|c|c|c|c|c|c|}
\hline H I nube & $\begin{array}{c}\text { pisición central } \\
\alpha, \delta(\mathrm{J} 2000)\end{array}$ & $\begin{array}{l}\text { rango de velocidades } \\
\qquad\left[\mathrm{km} \mathrm{s}^{-1}\right]\end{array}$ & \multicolumn{2}{|c|}{$\begin{array}{c}F_{\mathrm{HI}} \\
{\left[\mathrm{Jy} \mathrm{km} \mathrm{s}^{-1}\right]}\end{array}$} & \multicolumn{2}{|c|}{$\begin{array}{c}M_{\mathrm{HI}} \\
{\left[10^{8} \mathrm{M}_{\odot}\right]}\end{array}$} & galaxia más cercana \\
\hline $\mathrm{C} 1$ & $22: 57: 44,-36: 33: 13$ & $1780-1844$ & $0.81 \pm 0.16$ & $0.55 \pm 0.02$ & 1.61 & 1.09 & IC 5264 \\
\hline $\mathrm{C} 2$ & $22: 57: 42,-36: 38: 08$ & $1752-1792$ & $0.35 \pm 0.10$ & $0.18 \pm 0.02$ & 0.70 & 0.35 & NGC $7418 \mathrm{~A}$ \\
\hline C3 & $22: 57: 27,-36: 37: 13$ & $1776-1800$ & $0.18 \pm 0.05$ & - & 0.36 & - & NGC 7418A \\
\hline $\mathrm{C} 4$ & $22: 57: 17,-36: 34: 09$ & $1744-1808$ & $0.83 \pm 0.10$ & $0.15 \pm 0.01$ & 1.66 & 0.29 & IC 5264 \\
\hline C5 & $22: 57: 13,-36: 30: 10$ & $1759-1828$ & $0.43 \pm 0.10$ & $0.14 \pm 0.02$ & 0.85 & 0.27 & IC 1459 \\
\hline $\mathrm{C} 6$ & $22: 57: 04,-36: 33: 35$ & $1480-1512$ & $0.22 \pm 0.05$ & - & 0.5 & - & IC 5264 \\
\hline $\mathrm{C} 7$ & $22: 56: 54,-36: 42: 09$ & $1680-1736$ & $0.7 \pm 0.1$ & - & 1.5 & - & NGC 7418A \\
\hline
\end{tabular}

Notas: Cols. (2-6), coordenadas del centro [h $\mathrm{m} \mathrm{s},{ }^{\circ}$ ' "] , rango de velocidades del H I, y los valores de la densidad de flujo $\left(F_{\mathrm{HI}}\right)$ y la masa $\left(M_{\mathrm{HI}}\right)$ para las nubes de H I identificadas, tanto a partir del mapa de baja resolución como de alta resolución, respectivamente (ver la sección 4.2). 


\subsubsection{Escombros de $\mathrm{H}$ I en los alrededores de IC 1459}

Los escombros de H i en los alrededores de la galaxia IC 1459 poseen un bajo brillo superficial y su distribución es extendida (ver Fig. 4.1), lo que los hace difícil de mapear por completo con un interferómetro. En la Fig. 4.2 nos centramos en el complejo de nubes de H I más brillantes, ubicados al sureste de IC 1459 e IC 5264. Abarcan un rango de velocidades estrecho de $\sim 1760$ a $1850 \mathrm{~km} \mathrm{~s}^{-1}$. Los mapas de canales ATCA H I de estas nubes de H I suavizados a una resolución de $16 \mathrm{~km} \mathrm{~s}^{-1}$ se muestran en la Fig. 4.3. El complejo de escombros de H i que se muestra en la Fig. 4.2 abarca $\sim 10^{\prime} \mathrm{u}$ $85 \mathrm{kpc}$ a la distancia supuesta de $29 \mathrm{Mpc}$. El campo de velocidad media del H i de los residuos muestra un gradiente de velocidad débil, generalmente disminuyendo de norte a sur. La dispersión media de la velocidad del H I es baja, en comparación con la que se encuentra en las galaxias, y es consistente con un complejo de nubes. La extensión total de los escombros de H i que se muestran en la Fig. 4.1 parece ser al menos $\sim 3$ veces más grande que lo observado, probablemente abarca más de $\sim 250 \mathrm{kpc}$ desde el extremo este de NGC 7418A a las nubes H I al noreste de IC 1459.

Los escombros de H I, en los alrededores de IC 1459, se detectaron por primera vez por Oosterloo et al. [1999] con ATCA y más tarde fue descubierto de forma independiente en HIPASS, catalogado como HIPASS J2257-36 [Meyer et al., 2004]. Se dan las propiedades HIPASS en la Tabla 4.2. Tomamos nota de que la posición HIPASS ajustada, $\alpha, \delta(\mathrm{J} 2000)=22^{h} 57^{m} 12,6^{s},-36^{\circ} 31^{\prime} 14^{\prime \prime}$ está $\sim 3.5$ desplazada desde el centro óptico de IC 1459 hacia el sureste y 4 '4 desde IC 5264 hacia el este, de acuerdo con el complejo de escombros de H i identificado aquí (ver Fig. 4.4 y Fig. 4.2). La velocidad central de HIPASS J2257-36 (1802 $\pm 12 \mathrm{~km} \mathrm{~s}^{-1}$ ) y sus anchos de velocidad (ver Tabla 4.2) también coinciden con los obtenidos aquí. Usando nuestros datos de ATCA medimos $F_{\mathrm{HI}}=2,6 \mathrm{Jy} \mathrm{km} \mathrm{s}^{-1}$ para el complejo de H I que se muestra en la Fig. 4.2, de acuerdo con HIPASS, y obtenemos una H I masa de 5,2 $\times 10^{8} \mathrm{M}_{\odot}$. Para IC 5264, ubicado al oeste del complejo $\mathrm{H}$ I de escombros, medimos $F_{\mathrm{HI}}=0,5 \pm 0,2 \mathrm{Jy} \mathrm{km} \mathrm{s}^{-1}$.

Identificamos cinco nubes de H I (C1-C5) dentro del complejo de escombros (ver Fig. 4.2). Sus propiedades se detallan en la Tabla 4.4. No se detectan contra partes ópticas o en el ultravioleta (GALEX) asociadas con estas nubes en los datos actualmente disponibles. Nuestros mapas de H I de alta resolución (30") (que no se muestran aquí) revelan los grupos más densos dentro de estas nubes. Cuatro de las cinco nubes H I muestran grupos compactos con masas de $\mathrm{H}$ I de $0,1-1,1 \times 10^{8} \mathrm{M}_{\odot}$. Dos nubes de $\mathrm{H}$ I adicionales, $\mathrm{C} 6$ y $\mathrm{C} 7$, se pueden diferenciar de sus galaxias más cercanas debido a sus distintas velocidades radiales, $\sim 1480 \mathrm{~km} \mathrm{~s}^{-1}$ y $1704 \mathrm{~km} \mathrm{~s}^{-1}$, respectivamente.

Los escombros de Hi próximos a IC 1459 detectados junto con las nubes de H I cerca de IC $5270\left(\sim 2100 \mathrm{~km} \mathrm{~s}^{-1}\right)$ y NGC $7418\left(\sim 1450 \mathrm{~km} \mathrm{~s}^{-1}\right)$, identificados por Serra et al. [2015a], constituyen una fracción significativa del medio interestelar frío de los grupos. La cantidad total de masa de $\mathrm{H}$ i contenida en las nubes $\left(7,2 \times 10^{8} \mathrm{M}_{\odot}\right)$ es casi 6 veces el contenido de H I de IC $5264\left(1,2 \times 10^{8} \mathrm{M}_{\odot}\right)$.

Dénes et al. [2014] propuso encontrar relaciones entre el contenido de H I y algunas propiedades estelares, como por ejemplo las magnitudes $M_{B}$ y $M_{r}$ y los tamaños. Una 

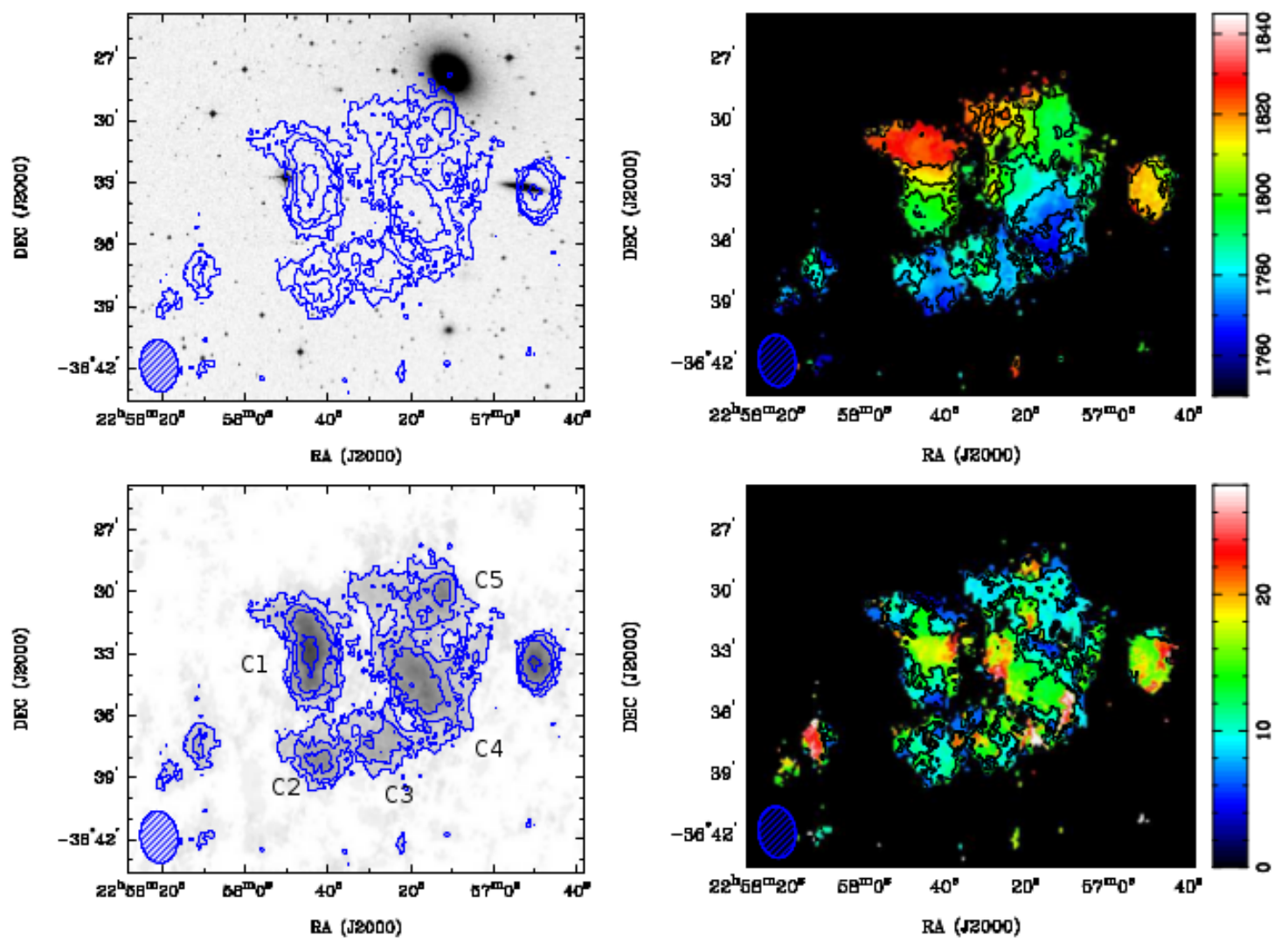

Figura 4.2: ATCA H I - Mapas de momento de escombros al sureste de la galaxia elíptica gigante IC 1459 en el rango de velocidad de 1750 a $1840 \mathrm{~km} \mathrm{~s}^{-1}$. Algunas emisiones de H I asociadas con la pequeña galaxia de borde IC 5264 también son visibles en este rango de velocidad. Panel superior izquierdo: Distribución de H I (contornos) superpuestos a una imagen del filtro B del DSS2; los niveles de contorno son 0,$7 ; 1,4 ; 2,1 ; 3,5 \times 10^{19}$ $\mathrm{cm}^{-2}$. Panel inferior izquierdo: Disitribución de H I (mismos contornos); Panel superior derecho: Campo medio de velocidades; los niveles de contorno van desde 1760 a $1820 \mathrm{~km} \mathrm{~s}^{-1}$ en pasos de $10 \mathrm{~km} \mathrm{~s}^{-1}$. Panel inferior derecho: Dispersión media de velocidades; los niveles de contorno son 4, 8 y $12 \mathrm{~km} \mathrm{~s}^{-1}$. El haz sintetizado $\left(151^{\prime \prime} .9 \times 108^{\prime \prime} .7\right)$ se muestra en la esquina inferior izquierda de cada panel. 


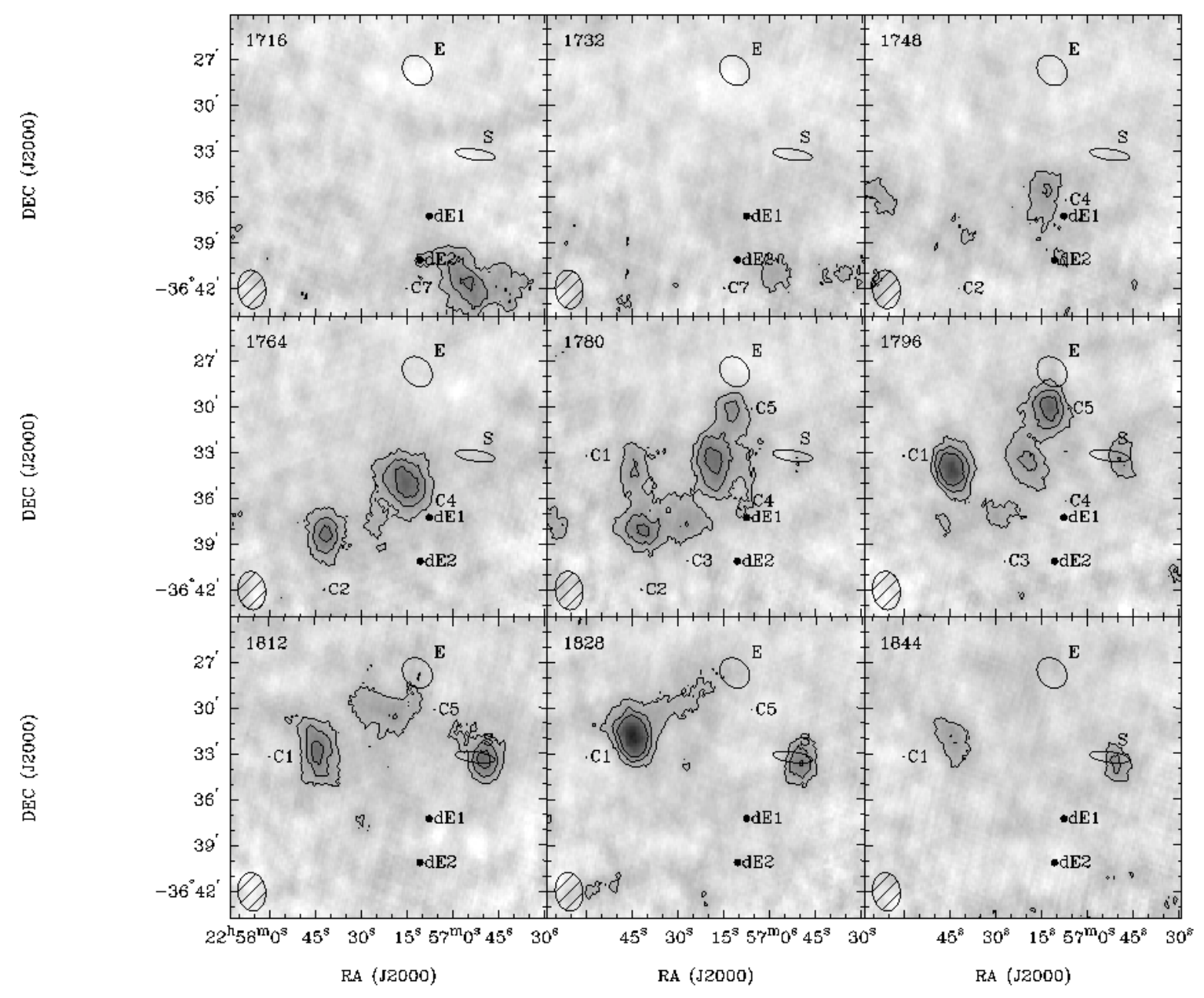

Figura 4.3: ATCA H I - Mapas de canales del complejo de nubes alrededor de IC 1459. La velocidad del canal se muestra en la esquina superior izquierda (en $\mathrm{km} \mathrm{s}^{-1}$ ) y el haz sintetizado en la esquina inferior izquierda de cada panel. Las posiciones de las galaxias IC 1459 (E) e IC 5264 (S), así como dE1, dE2 y las nubes están marcadas. Los niveles de contorno son 5,$1 ; 8,5 ; 11,9$ mJy beam $^{-1}$. 

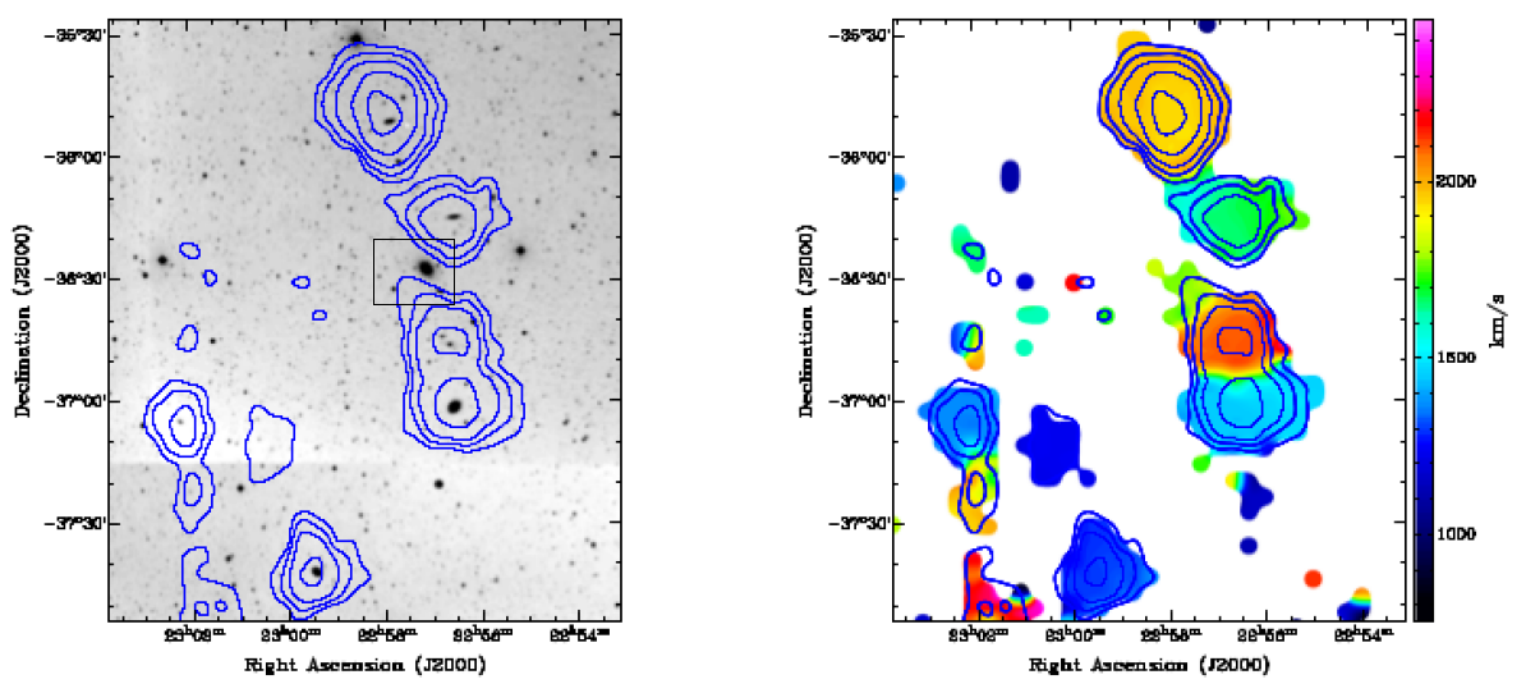

Figura 4.4: Mapas de momento HIPASS del grupo IC 1459 en el rango de velocidad de 1000 a $2400 \mathrm{~km} \mathrm{~s}^{-1}$. Panel izquierdo: Distribución del H I (contornos azules) superpuestos en una imagen óptica DSS2 $B$ de banda suavizada. Panel derecho: Campo de velocidades del H i. El campo de visión de Parkes es 15!5. Una comparación entre la distribución de H I detactada por ATCA y HIPASS (Parkes) permite determinar que la protuberancia vista aquí en $\alpha, \delta(\mathrm{J} 2000)=22^{\mathrm{h}} 57^{\mathrm{m}} 30^{\mathrm{s}},-36^{\circ} 30^{\prime} 00^{\prime \prime}$ (marcado con un recuadro en el panel derecho) corresponde a parte del complejo de escombros/nubes de H I mostrado en esta tesis.

galaxia se considera deficiente en $\mathrm{H}$ i si el parámetro $D E F$ es mayor que 0,6 (ver Dénes et al. [2014] para obtener más detalles). Encontramos que la galaxia IC 5264 es una galaxia deficiente en $\mathrm{H}$ I, lo que quiere decir que la cantidad de $\mathrm{H}$ I detectada no condice con la cantidad de H i esperada para este tipo de galaxia (ver la Tabla 4.5). El escenario se asemeja a las primeras etapas de un proceso que conlleva a la relación morfología-densidad, en el cual las galaxias se vuelven deficientes en H I. 
Tabla 4.5: Deficiencia en el contenido de H I.

\begin{tabular}{|c|c|c|c|c|c|c|}
\hline Galaxy & $M_{b}$ & Mass_Obs $\left(10^{8} \mathrm{M}_{\odot}\right)$ & Mass_expected Mag $\left(10^{8} \mathrm{M}_{\odot}\right)$ & $D E F$ & Mass_expected Diam $\left(10^{8} \mathrm{M}_{\odot}\right)$ & $D E F$ \\
\hline IC5269B & 13.2 & 40 & 25 & -0.19 & 25 & 0.56 \\
\hline IC5269A & 13.9 & 3.9 & 14 & 0.57 & 14 & 0.93 \\
\hline IC5264 & 13.7 & 1.6 & 17 & 1.03 & 17 & 1.69 \\
\hline NGC7418A & 13.8 & 30 & 15 & -0.27 & 15 & 0.23 \\
\hline Galaxy & $M_{r}$ & & Mass_expected Mag $\left(10^{8} \mathrm{M}_{\odot}\right)$ & $D E F$ & Mass_expected Diam $\left(10^{8} \mathrm{M}_{\odot}\right)$ & $D E F$ \\
\hline IC5269B & 12.48 & & 29 & -0.16 & 79 & 0.29 \\
\hline IC5269A & 13.94 & & 9 & 0.39 & 16 & 0.60 \\
\hline IC5264 & 12.08 & & 35 & 1.34 & 39 & 1.39 \\
\hline NGC7418A & 13.62 & & 12 & -0.38 & 25 & 0.07 \\
\hline
\end{tabular}

Notas: Mass_Obs es la H I masa estimada, Mass_expected Mag es la masa esperada usando la relación de escala de magnitud, Mass_expected Diam es la masa esperada usando la relación de escala de diámetro y $D E F$ se define como $\log \left[M_{\exp }\right]-\log \left[M_{\mathrm{HIobs}}\right]$. 

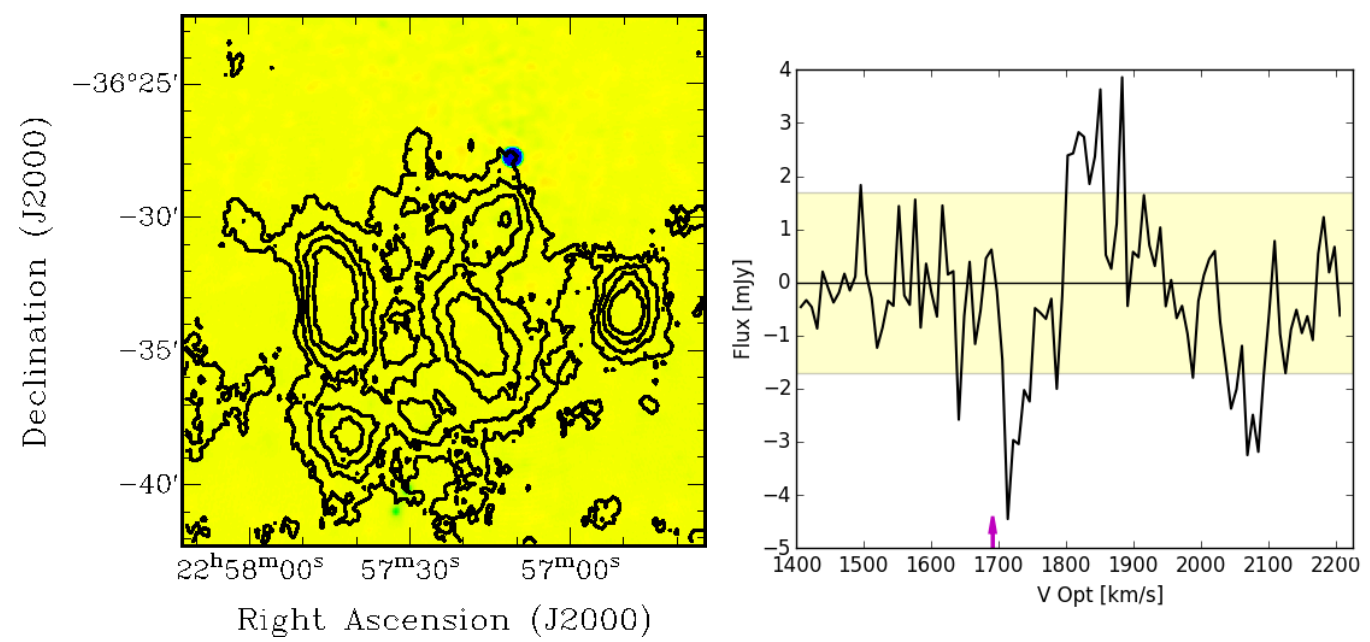

Figura 4.5: Mapa de continuo y detección de una línea de absorción en dirección a la fuente PKS 2254-367. Panel izquierdo: El mapa continuo obtenido siguiendo el procedimientos estándar; la fuente brillante de radio continuo PKS 2254-367 está en color azul. Los contornos negros muestran los escombros de H I. Panel derecho: La línea de absorción. La banda en amarillo claro indica los límites de $2 \sigma$. La flecha en color rosa marca la velocidad de la línea de emisión de CO.

\subsubsection{Emisión continua y línea de absorción}

El mapa de emisión continua se realizó con la tarea UVLIN del software MIRIAD, utilizando las opciones chan0 del parámetro mode. Como todos los conjuntos de datos tienen diferentes fases centrales, se implementó la tarea UVEDIT y se redefinieron las coordenadas centrales. Para mejorar la calidad del mapa final, se empleó el proceso de autocalibración. Tal como se esperaba, la fuente del continuo brillante, PKS 2254-367 ( 1.1 Jy a $21 \mathrm{~cm})$, se observa en el centro de la galaxia IC 1459 (ver Fig: 4.5).

Buscando la línea de absorción del H i contra la fuente de radio brillante continuo en el centro de la galaxia elíptica IC 1459 encontramos una línea débil (a $2.5 \sigma$ ) con una velocidad de $\sim 1714 \mathrm{~km} \mathrm{~s}^{-1}$ con un ancho de velocidad de $\sim 30 \mathrm{~km} \mathrm{~s}^{-1}$ (ver Fig. 4.5). El grumo de H I más cercano a IC 1459 dentro del complejo de escombros parece ser C5 (etiquetado en la Fig. 4.2), más prominente a velocidades de $1780-1800 \mathrm{~km} \mathrm{~s}^{-1}$ (ver Fig. 4.3). La emisión de CO (1-0) detectada en $1782 \mathrm{~km} \mathrm{~s}^{-1}$ por Bettoni et al. [2001] también cae dentro de este rango.

\subsubsection{H I en las galaxias miembro del grupo IC 1459}

Las propiedades de H I de las cuatro espirales cerca de IC 1459, obtenidas de nuestros cubos de datos de alta resolución angular (después de la corrección del haz primario), se resumen en la Tabla 4.6. Debido a la ubicación de tres galaxias cerca del $50 \%$ de sensibilidad del haz primario ATCA (ver Fig. 4.1), los flujos H i citados son algo inciertos. 

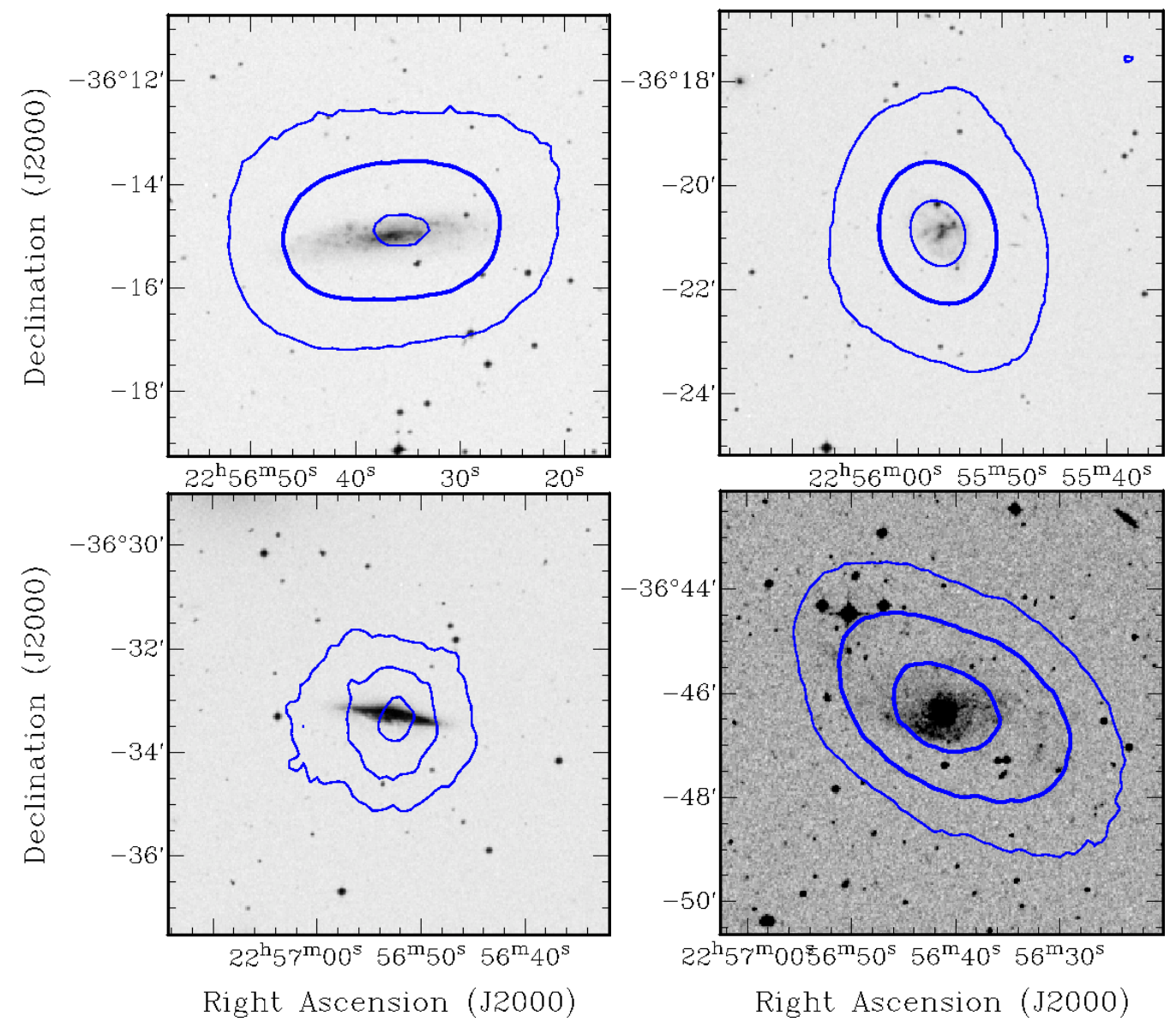

Right Ascension (J2000)

Figura 4.6: Distribución de H I, de baja resolución angular utlizando datos de ATCA en contornos azules, superpuesta en una imagen óptica DSS2 $B$-band suavizada. Se muestran las cuatro galaxias espirales en las proximidades de la gigante elíptica IC 1459. Panel superior izquierdo: IC 5269B, los niveles de contorno son 1, 4, 8,2 $\mathrm{Jy} \mathrm{haz}^{-1}$; Panel superior derecho: IC 5269A, los niveles de contorno son $0,2,1,1,8 \mathrm{Jy} \mathrm{haz}^{-1}$; Panel inferior izquierdo: IC 5264, los niveles de contorno son $0,5,1,1,1,7 \mathrm{Jy} \mathrm{haz}^{-1} \mathrm{y}$ Panel inferior derecho: NGC 7418A, los niveles de contorno son 1,4,3,5 $\mathrm{Jy} \mathrm{haz}^{-1}$. El haz sintetizado es $151^{\prime \prime} .9 \times 108^{\prime \prime} .7$. 

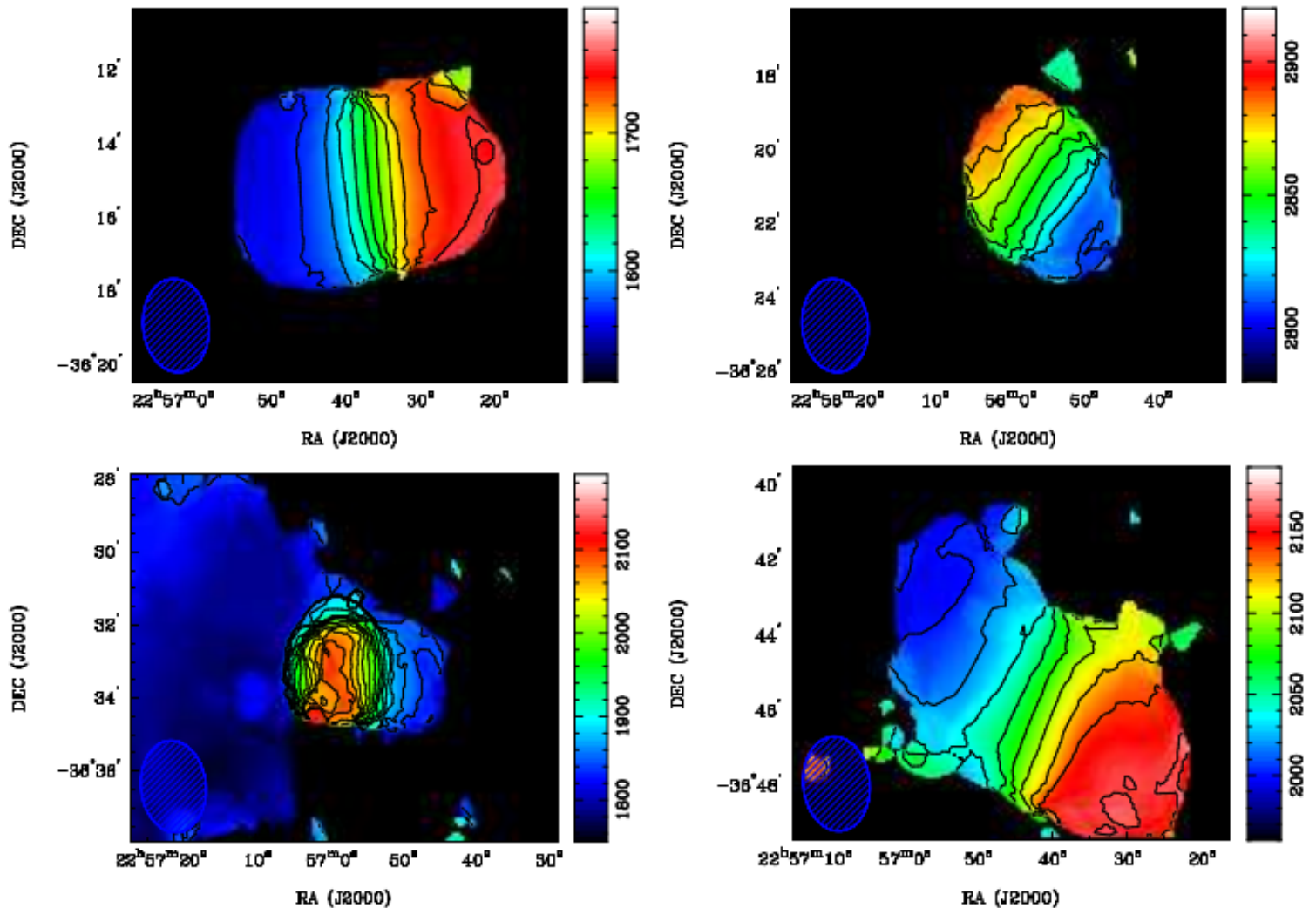

Figura 4.7: Campos de velocidad de Hi, de baja resolución, de las cuatro galaxias espirales en las proximidades de la galaxia elíptica gigante IC 1459. Panel superior izquierdo: IC 5269B $\left(1550-770 \mathrm{~km} \mathrm{~s}^{-1}, 20 \mathrm{~km} \mathrm{~s}^{-1}\right)$. Panel superior derecho: IC 5269A (2810 - 2880 $\left.\mathrm{km} \mathrm{s}^{-1}, 10 \mathrm{~km} \mathrm{~s}^{-1}\right)$. Panel inferior izquierdo: IC $5264\left(1840-2100 \mathrm{~km} \mathrm{~s}^{-1}, 20 \mathrm{~km} \mathrm{~s}^{-1}\right)$. Panel inferior derecho: NGC 7418A $\left(2000-2160 \mathrm{~km} \mathrm{~s}^{-1}, 20 \mathrm{kms}^{-1}\right)$. Los rangos de nivel de contorno y los tamaños de paso se dan entre paréntesis El haz sintetizado $\left(151^{\prime \prime} .9 \times 108^{\prime \prime} .7\right)$ se muestra en la esquina inferior izquierda de cada panel. Estos mapas no están corregidos por el haz primario. 

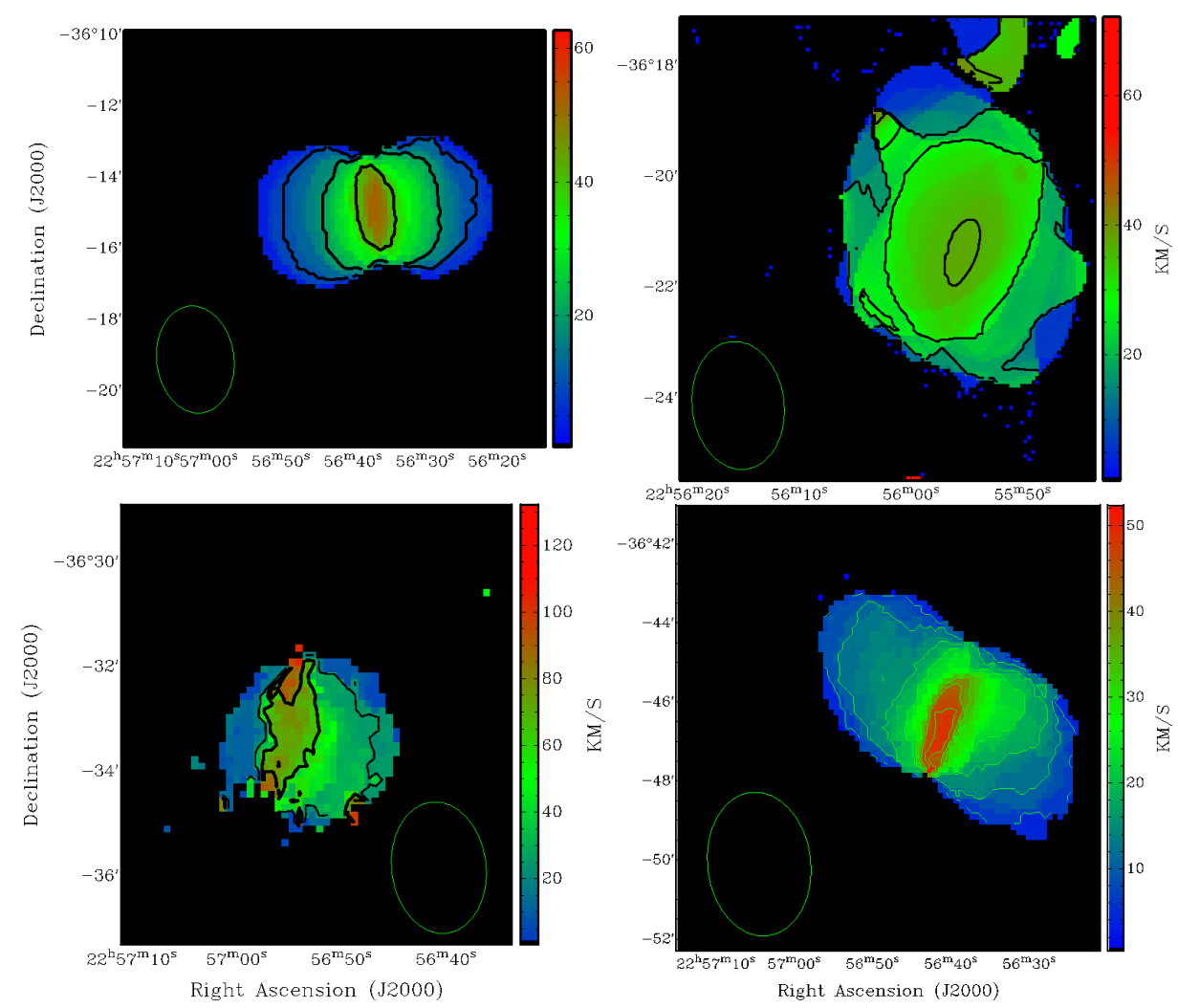

Figura 4.8: Campo de dispersión de velocidades del Hi, de baja resolución, de las cuatro galaxias espirales próximas a la galaxia elíptica gigante IC 1459. Panel superior izquierdo: IC 5269B (15-50 $\left.\mathrm{km} \mathrm{s}^{-1}, 35 \mathrm{~km} \mathrm{~s}^{-1}\right)$; Panel superior derecho: IC 5269A, $\left(15-40 \mathrm{~km} \mathrm{~s}^{-1}, 25 \mathrm{~km} \mathrm{~s}^{-1}\right)$; Panel inferior izquierdo: IC $5264\left(15-100 \mathrm{~km} \mathrm{~s}^{-1}\right.$, $\left.85 \mathrm{~km} \mathrm{~s}^{-1}\right)$ y Panel inferior derecho: NGC 7418A $\left(10-50 \mathrm{~km} \mathrm{~s}^{-1}, 40 \mathrm{~km} \mathrm{~s}^{-1}\right)$. El haz sintetizado es $151^{\prime \prime} .9 \times 108^{\prime \prime} .7$. 
Tabla 4.6: ATCA H I propiedades de las galaxias estudiadas.

\begin{tabular}{lccc}
\hline \hline Galaxia & $\begin{array}{c}\text { rango de velocidades } \\
{\left[\mathrm{km} \mathrm{s}^{-1}\right]}\end{array}$ & $\begin{array}{c}F_{\mathrm{HI}} \\
{\left[\mathrm{Jy} \mathrm{km} \mathrm{s}^{-1}\right]}\end{array}$ & $\begin{array}{c}M_{\mathrm{HI}} \\
{\left[10^{8} \mathrm{M}_{\odot}\right]}\end{array}$ \\
\hline IC 5269B & $1550-1780$ & $18 \pm 2,0$ & 40 \\
IC 5269A & $2770-2920$ & $1,6 \pm 0,4$ & 3,5 \\
IC 5264 & $1800-2150$ & $0,5 \pm 0,2$ & 1,2 \\
NGC 7418A & $2000-2200$ & $14 \pm 1,3$ & 31 \\
\hline
\end{tabular}

Los mapas de distribución del H I y de velocidad de IC 5269A y IC 5269B, ambos localizados al noroeste de IC 1459, parecen regulares y simétricos, mientras que NGC 7418A y IC 5264 muestran distribuciones H I ligeramente distorsionadas (ver Fig. 4.7). Los mapas de alta resolución de las galaxias, que se analizan a continuación, también se muestran en Serra et al. [2015a].

- IC 5269B (HIPASS J2256-36b) es una galaxia espiral de tipo tardío ubicada 14.5 al noroeste de IC 1459 y tiene una velocidad de sistema similar. Sengupta et al. [2007] y Serra et al. [2015a] mostraron datos de GMRT de alta resolución y mapas de ASKAP de H I de la galaxia IC 5269B, respectivamente, lo que indica un disco simétrico y en rotación. El $F_{\mathrm{HI}}$ medido es de al menos $18 \mathrm{Jy} \mathrm{km} \mathrm{s}^{-1}$, algo menos que lo detectado por ASKAP y Parkes [Serra et al., 2015a], y derivamos $M_{\mathrm{HI}}=4 \times 10^{9} \mathrm{M}_{\odot}$.

- IC 5269A (HIPASS J2255-36) es una galaxia espiral barrada de tipo Magallánica ubicada 16!5 al noroeste de IC 1459. Es una galaxia vista de frente, el disco estelar aparece muy irregular [Buat et al., 2007], mientras que los datos H I indican un disco que gira regularmente. Esta galaxia está en el campo de visión, pero es poco probable que sea un miembro del grupo. Su velocidad sistémica de $2845 \mathrm{~km} \mathrm{~s}^{-1}$ es más de $1000 \mathrm{~km} \mathrm{~s}^{-1}$ mayor que el de IC 1459. Obtuvimos $M_{\mathrm{HI}}$ $=3,5 \times 10^{8} \mathrm{M}_{\odot}$.

- IC $5264\left(v_{\text {opt }}=2048 \mathrm{~km} \mathrm{~s}^{-1}\right)$ es una pequeña galaxia espiral vista de canto, ubicada solo a 6.5 al sudoeste de IC $1459\left(v_{\text {opt }}=1692 \mathrm{~km} \mathrm{~s}^{-1}\right)$ y justo al oeste de el complejo de nubes de $\mathrm{H}$ I $\left(v_{\mathrm{HI}} \sim 1800 \mathrm{~km} \mathrm{~s}^{-1}\right)$. La presencia parcial de polvo le otorga una apariencia ligeramente peculiar en imágenes ópticas [Forbes et al., 1995]. La velocidad óptica de IC 5264 es $\sim 350 \mathrm{~km} \mathrm{~s}^{-1}$ más alta que la de IC 1459, sugiriendo una distancia mayor y/o movimientos peculiares significativos. El diagrama $p v$ (Fig. 4.9) muestra que la emisión de H I de IC 5264 cubre un rango de velocidades entre $\sim 1800$ y $2150 \mathrm{~km} \mathrm{~s}^{-1}$; el gradiente observado es un claro indicador de la rotación de la galaxia. La emisión de H I correspondiente al desplazamiento en el azul de IC 5264 en su lado oeste (ver Fig. 4.7) cae dentro del rango de velocidad del complejo $\mathrm{H}$ i debris extendido hacia el este. Estimamos su H I masa como $1,2 \times 10^{8} \mathrm{M}_{\odot}$. También identificamos una nube H I en la dirección de IC 5264, a una velocidad radial muy diferente (C6 en $v_{\text {sys }} \sim 1500 \mathrm{~km} \mathrm{~s}^{-1}$, consulte la Tabla 4.4). 


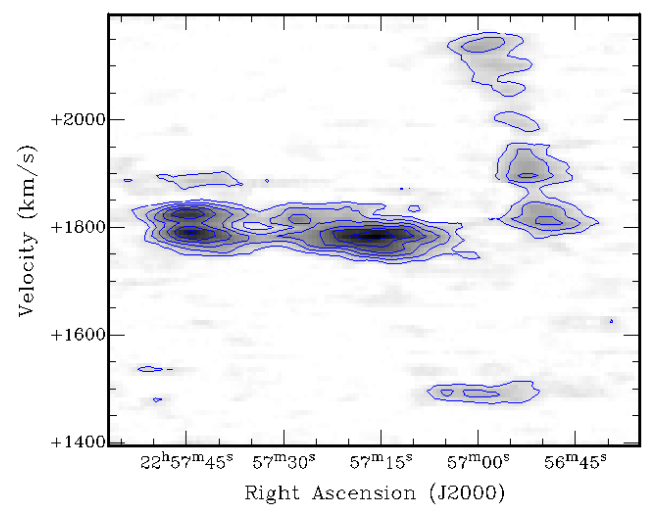

Figura 4.9: Diagrama posición velocidad $(p v)$. El diagrama corresponde al área próxima a IC 1459, la cual se muestra en la Figura 4.2. Incluye el complejo de nubes de H I (1750-1840 $\left.\mathrm{km} \mathrm{s}^{-1}\right)$, la galaxia IC $5264\left(\sim 1800-2150 \mathrm{~km} \mathrm{~s}^{-1}\right)$, y la nube de H I C6 $\left(\sim 1500 \mathrm{~km} \mathrm{~s}^{-1}\right)$. Se aplicó al cubo de imágenes para este gráfico un suavizado. Los niveles de contorno son 3, 6 y $10 \mathrm{mJy} \mathrm{haz}^{-1}$.

También fueron observadas dos enanas elípticas (dE), catalogadas por Vader and Chaboyer [1994], ubicadas al sureste de IC 5264 (ver Fig. 4.2) y probablemente sean miembros del groupo de galaxias IC 1459. Ambas son visibles en las imagenes del DSS, una de ellas es una enana con núcleo cuya $v_{\text {opt }}$ es $1838 \mathrm{~km} \mathrm{~s}^{-1}$.

- NGC 7418A (HIPASS J2256-36a) es una galaxia espiral de tipo tardío, que se encuentra a 19'5 al sur de IC 1459. Las imágenes de GALEX muestran emisión extendida en el ultravioleta (XUV) proveniente del disco [Thilker et al., 2007]. Las imágenes obtenidas con ATCA de NGC 7418A muestran que la distribución de H I se extiende un factor tres veces mayor que la del disco XUV y revela la presencia de una cola orientada al noreste, hacia el complejo principal de escombros

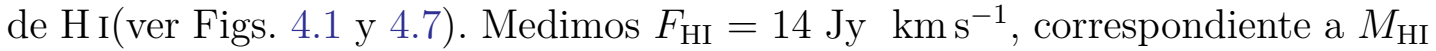
$=3,1 \times 10^{9} \quad \mathrm{M}_{\odot}$. Además, encontramos una nube de H I $\left(\mathrm{C} 7, \sim 1700 \mathrm{~km} \mathrm{~s}^{-1}\right.$, consulte la Tabla 4.4) al este de NGC 7418A, compensada con la velocidad sistémica, con una masa de $\mathrm{H}$ I de $1,5 \times 10^{8} \mathrm{M}_{\odot}$.

- NGC 7418 (HIPASS J2256-37) $\left(v_{\text {sys }}=1450 \mathrm{~km} \mathrm{~s}^{-1}\right)$ es una galaxia espiral brillante ubicada a 15!5 al sur de NGC 7418A, en las afueras del campo que se muestra en la Fig. 4.1. Serra et al. [2015a] encontraron que el disco de H I presenta una rotación regular con un tamaño similar al de la componente estelar y una nube de $\mathrm{H}$ I asociada a la galaxia, sin estrellas, de masa $M_{\mathrm{HI}} \sim 6 \times 10^{8} \mathrm{M}_{\odot}$ ) en la región noroeste de la misma. Ryder et al. [1997] detectó en NGC 7418 a partir de las observaciones realizadas con ATCA en $21 \mathrm{~cm}$ signos de alabeo en dirección a la galaxia NGC 7421 .

- Todavía más al sur, se encuentra la galaxia espiral barrada NGC 7421 (HI- 
PASS J2257-37) con $v_{\text {sys }}=1793 \mathrm{~km} \mathrm{~s}^{-1}$, la cual fue detectada recientemente con ASKAP [Serra et al., 2015a]. La galaxia posee un disco estelar de bajo brillo superficial, corrido del centro de la galaxia, con formación estelar en la región oeste de la misma. Observaciones de alta sensibilidad realizadas con ATCA del H I por Ryder et al. [1997] revelaron una envoltura de H I $\left(\sim 7^{\prime} \times 5^{\prime}\right)$, alrededor de tres veces más grande que el tamaño del disco estelar, una estructura de bow shock y velocidades peculiares. Ryder et al. consideraron al proceso de presión cinética intragrupo como uno de los posibles mecanismos causantes de estas estructuras peculiares observadas.

\subsection{Discusión}

En la región interna del grupo de galaxias IC 1459 se observaron escombros de H I los cuales se extienden sobre $\sim 250 \mathrm{kpc}$ con una masa total de $\mathrm{H} \mathrm{I}$ de $\sim 10^{9} \mathrm{M}_{\odot}$. La presencia de este gas indica fuertemente que interacciones entre los miembros del grupo dentro del potencial gravitatorio del mismo se están llevando a cabo.

Se han observado escombros con esta morfología irregular en numerosos sistemas de galaxias. Por ejemplo, una cola de $\sim 300 \mathrm{kpc}$ de longitud, que consta de numerosas nubes, se detectó cerca del grupo compacto de Hickson 44 [Serra et al., 2013] con una masa de $\mathrm{H}$ I de al menos $5 \times 10^{8} \mathrm{M}_{\odot}$. Un enorme complejo de escombros de $\mathrm{H} \mathrm{I}$ conocido como el "Vela Cloud", con al menos $3 \times 10^{9} \mathrm{M}_{\odot}$ fue identificado por English et al. [2010] cerca de NGC 3263 en el grupo NGC 3256. Filamentos extendidos de H I también se observan en el grupo de Ursa Major [Serra et al., 2012] cerca de las galaxias lenticulares NGC 4026 y NGC 4011.

Las simulaciones hidrodinámicas realizadas por Bekki et al. [2005a,b] demostraron que el campo de marea grupal puede ser responsable de la extracción de H i del disco exterior de galaxias ricas en gas y de bajo brillo superficial, mientras que tiene poco efecto en sus discos estelares. Este escenario se exploró en detalle para explicar el origen de la nube masiva H i (HIPASS J0731-69) descubierta cerca de NGC 2442 por Ryder et al. [2001]. Se considera que la separación del gas es más eficiente en el pericentro de la órbita. En nuestro caso, asumiendo que las galaxias IC 5264 y NGC 7418A son galaxias de bajo brillo superficial, es posible que ambas galaxias mencionadas haya sido despojada de su disco externo de H I durante su acercamiento a IC 1459.

Usando las relaciones de escala por Dénes et al. [2014] encontramos que IC 5264 es deficiente en Hi, lo que soporta este escenario. Además, los mapas de ASKAP de H i presentados por Serra et al. [2015a] muestran que el H I en IC 5264 está desfasado con respecto al disco estelar hacia el sureste. También hay indicios de interacciones de marea entre NGC 7418A e IC 1459, dados por la presencia de una cola de gas en la parte noroeste de NGC 7418A, que se vincula con el complejo de nubes de H I cerca de IC 1459. Su separación proyectada de 19.5 corresponde a $165 \mathrm{kpc}$ a la distancia de grupo adoptada de $29 \mathrm{Mpc}$. La diferencia en sus velocidades sistémicas $\left(\sim 400 \mathrm{~km} \mathrm{~s}^{-1}\right)$ probablemente se deba a movimientos peculiares dentro del grupo. La existencia de la emisión de rayos X intragrupo, así como las características peculiares de IC 1459 (por 
ejemplo, cáscaras estelares y un anillo de rotación en sentido contrario) respaldan aún más el escenario de interacción sugerido.

La detección de una línea de absorción H I en $~ 1714$ km s${ }^{-1}$ hacia PKS 2254-367 implica la presencia de grupos de hidrógeno fríos frente a IC 1459, parte probable del complejo de escombros detectado en la emisión H i. Esta también es compatible con la detección de emisiones de CO (1-0) en $1782 \mathrm{~km} \mathrm{~s}^{-1}$ hacia IC 1459 por Bettoni et al. [2001].

Además, observamos que IC 5269B e IC 1459, separadas por 14'.5 (122 kpc), son las únicas dos galaxias brillantes en el grupo con velocidades sistémicas en el rango de velocidad de los residuos de H i. No hay signos de interacción de mareas en IC 5269B. Los escombros de $\mathrm{H}$ I presentados en este Capítulo así como las nubes de $\mathrm{H}$ I detectadas cerca de las galaxias IC 5270 y NGC 7418 por Serra et al. [2015a], son indicadores de que procesos continuos de extracción de gas en escalas pequeñas y grandes están están ocurriendo.

\subsection{Resumen}

Observaciones previas de la galaxia IC 1459 y sus alrededores ya habían sido publicadas por Walsh et al. [1990], quien detectó a tres miembros del grupo (IC 5269B, NGC 7418A e IC 5264) utilizando datos del VLA, y por Oosterloo et al. [1999] quien también detectó parte de los escombros de H i en los alrededores de IC 1459, utilizando datos de ATCA.

En nuestro trabajo recopilamos del archivo del Telescope Compact Array de Australia todas las observaciones de la línea $21 \mathrm{~cm}$, realizadas sobre la región central del grupo de galaxias IC 1459. La sensibilidad resultante de la combinación de todos estos datos, nos permitió encontrar un gran complejo de nubes de H i cerca de la galaxia elíptica IC 1459 y una línea de absorción en dirección a la fuente intensa de continuo PKS 2254-367. Las nubes H I detectadas abarcan $\sim 250 \mathrm{kpc}$ y tienen una masa H i total de $\sim 10^{9} \mathrm{M}_{\odot}$. La mayoría de los escombros de H i se detectan al este de la pequeña espiral IC 5264.

Basados en las simulaciones de Bekki et al. [2005b], sugerimos que el campo de marea grupal de IC 1459 es responsable de remover el H I del disco externo de IC 5264, que es notablemente deficiente en H I, y NGC 7418A durante su primer acercamiento al grupo. La actividad de formación de estrellas en el lado occidental de NGC 5264, evidentes en las imágenes GALEX $U V$, puede haber sido causado por las interacciones de las mareas. No se detectan signos de actividad de formación de estrellas en ninguna de las nubes identificadas de H I. Imágenes de la distribución de gas molecular dentro del complejo H i nos permitirían rastrear las posibles regiones de formación estelar.

La línea espectral de $21 \mathrm{~cm}$ del $\mathrm{H}$ i es un excelente trazador de interacciones entre galaxias, proporcionando información tanto espacial como cinemática del gas en y entre galaxias. También nos permite derivar distribuciones totales de la masa de H i en 
galaxias y grupos.

Aunque se espera que los fenómenos relacionados con las interacciones de galaxias en grupos y agrupaciones sean relativamente comunes [eg, Verdes-Montenegro et al., 2001, Bekki et al., 2005b,a, Chung et al., 2009, English et al., 2010, Serra et al., 2012, Wolfinger et al., 2013, Serra et al., 2015a] la necesidad de una sensibilidad alta para mapear las estructuras extendidas, una buena resolución angular y en velocidad, hacen que sean difíciles de detectar y estudiar en detalle. Futuras observaciones en H I con ASKAP, Apertif y MeerKat [ver Koribalski, 2015] permitirá la obtención de imágenes H I profundas de muchos grupos de galaxias y agrupaciones cercanas y lejanas. Sobre la base de los primeros resultados de ASKAP presentados en [Serra et al., 2015a], esperamos el descubrimiento de muchos filamentos, plumas y nubes cerca de galaxias interactuantes, proporcionando información nueva y valiosa sobre la evolución. de los grupos de galaxias. 


\section{Capítulo 5}

\section{KK 69, una galaxia enana en transición}

En este capítulo, presentamos el trabajo detallado realizado sobre la galaxia enana KK 69. Mientras que las imágenes ópticas de KK 69 sugieren que es una galaxia enana esferoidal muy débil, los mapas que obtuvimos utilizando el Giant Metrewave Radiotelescope (GMRT) con alta resolución angular y una sensibilidad casi 1.4 veces mayor que las publicadas previamente por otros autores, revelan la presencia de una considerable cantidad de H I desfasada de la componente estelar. Esto indica que puede ser una galaxia enana en transición. Las interacciones de marea entre KK 69 y la galaxia espiral cercana NGC 2683, así como el proceso de barrido por presión cinética, se investigan como los mecanismos responsables de este desfasaje. Además, pudimos, por primera vez en esta galaxia, separar las fases fría y tibia del H i del medio interestelar mediante un método de descomposición gaussiana y una rutina de apilamiento (stacking). A lo largo de este capítulo, discutiremos nuestros resultados teniendo en cuenta la relación entre el medio interestelar y la actividad de formación de estrellas en la galaxia, el papel desempeñado por el medio ambiente y la influencia de estos fenómenos en la evolución de la galaxia.

Los resultados presentados en este capítulo son parte del aporte titulado "New H I observations of KK 69, a dwarf galaxy in transition" by J. Saponara, B. S. Koribalski, N. N. Patra, P. Benaglia., enviado a MNRAS.

\subsection{KK 69 y el ambiente donde se encuentra}

KK 69, junto con KK 70, AGC 182595, N2683dw1 y N2683dw2, son galaxias enanas compañeras de la galaxia espiral NGC 2683 [Karachentsev et al., 2015b, Vollmer et al., 2016]. Todos los miembros del grupo se muestran en la Fig. 5.1, excepto AGC 182595 debido a su distancia a la galaxia principal. Resumimos las propiedades ópticas de las galaxias en la Tabla 5.1. Karachentsev et al. [2015b] determinó que la distancia para KK 69 es de 9,28 $\pm 0,28 \mathrm{Mpc}$, utilizando el método del extremo de la rama de las gigantes rojas (TRGB, por sus siglas en inglés). De aquí en adelante, 9,28 Mpc es la distancia adoptada para el grupo; a esta distancia, $1^{\prime}$ es equivalente a $2,7 \mathrm{kpc}$. 

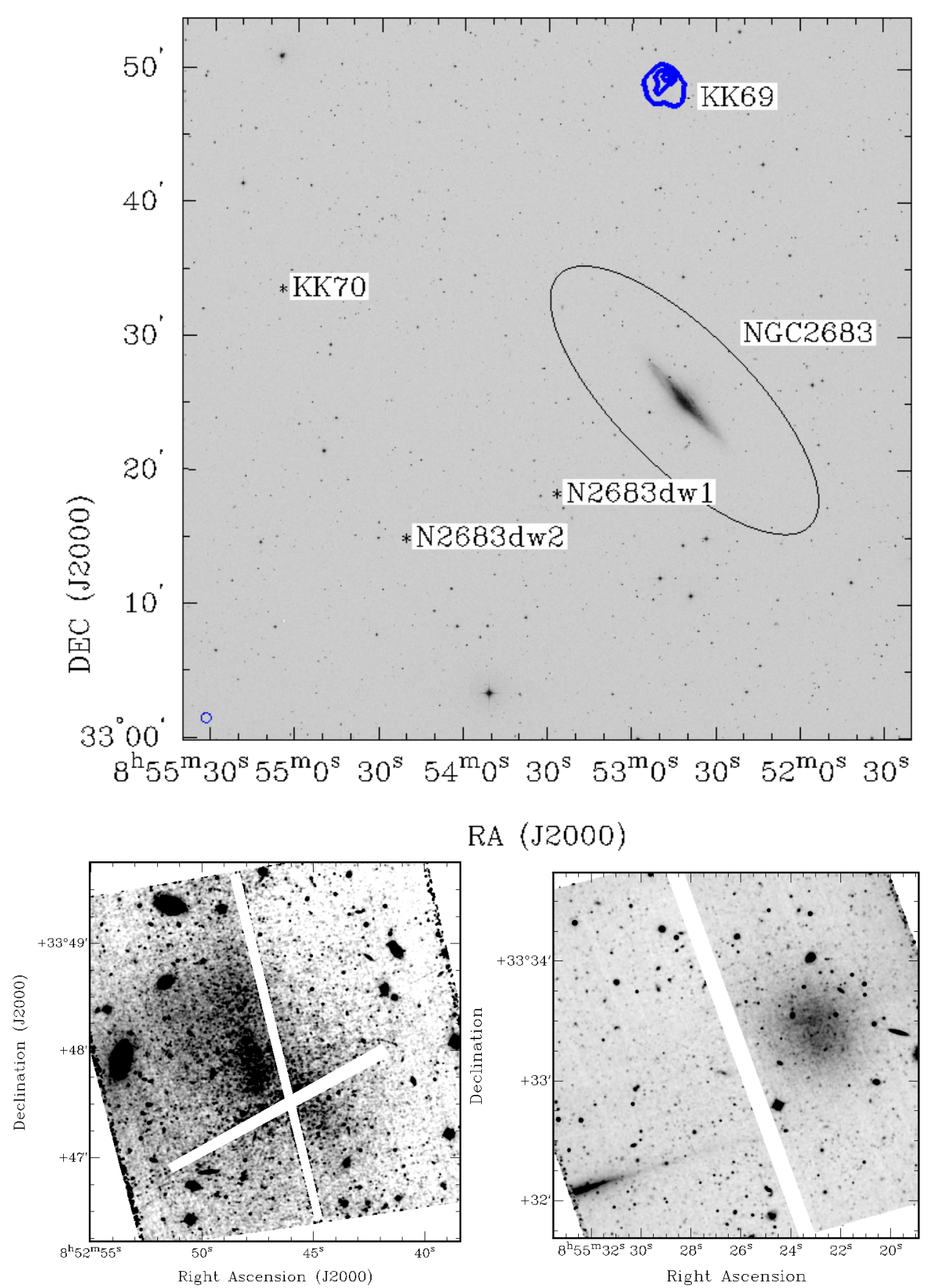

RA (J2000)

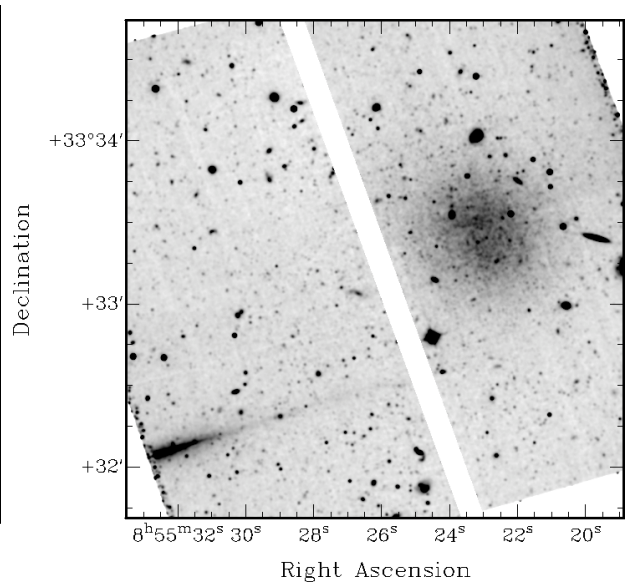

Figura 5.1: Panel superior: La galaxia espiral NGC 2683 y sus galaxias compañeras están etiquetadas. El mapa de intensidad de H I (contornos azules) se superpone en la imagen de magnitud de banda B del DSS (escala de grises). Los niveles de contorno son 6,$7 ; 16 ; 27 \times 10^{20}$ átomos $\mathrm{cm}^{-2}$. La elipse negra representa la extensión del gas H I de NGC 2683. Panel inferior izquierdo: KK 69 imagen del Telescopio Espacial Hubble (HST) (filtro F606W). Panel inferior derecho: KK imagen de KK 70 HST (filtro F814W). 
Tabla 5.1: Propiedades ópticas de KK 69 y de las galaxias que forman parte del grupo.

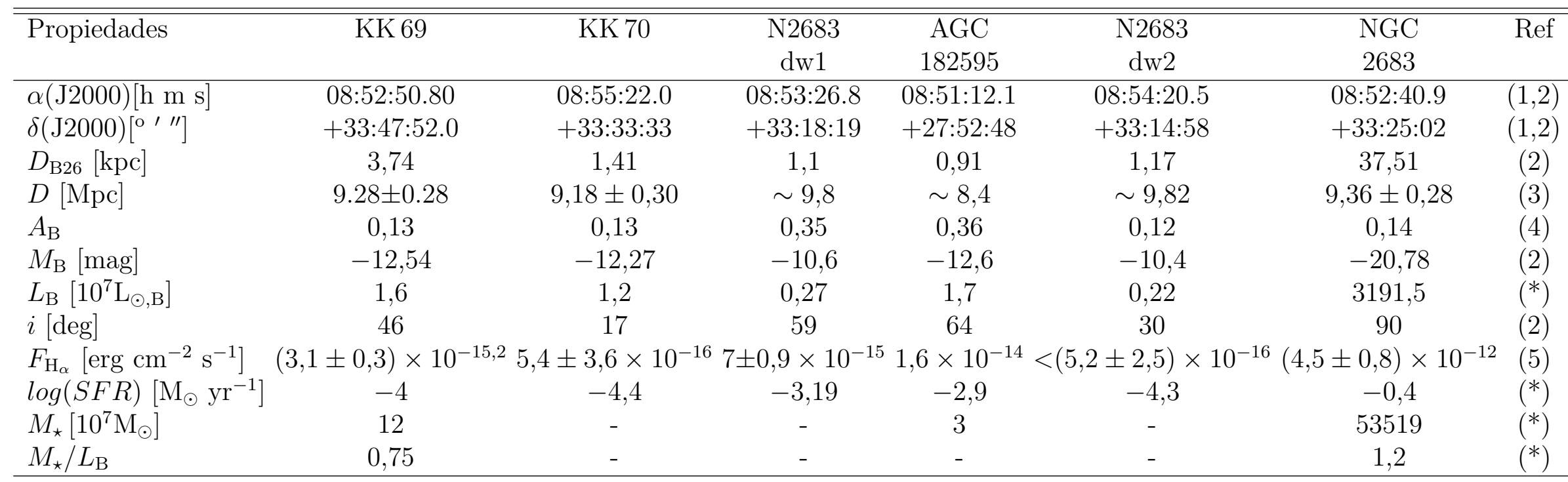

Referencias: (1) Whiting et al. [2007], Evans et al. [2010]; (2) [Karachentsev et al., 2013]; (3) Karachentsev et al. [2015b]; (4) Schlegel et al. [1998]; (5) Kennicutt et al. [2008], Karachentsev and Kaisina [2013], Kaisin and Karachentsev [2014], Karachentsev et al. [2015a]; (*) este trabajo, utilizando la fórmula presente en Roberts and Haynes [1994]. 
En los siguientes párrafos describimos cada una de las galaxias mencionadas.

- KK 69 también se conoce como LEDA 166095 (ver Fig. 5.1). La galaxia se observó con el radio telescopio de $100 \mathrm{~m}$ Effelsberg, su flujo integrado es de $F_{\mathrm{HI}}=$ 2,8 $\mathrm{Jy} \mathrm{km} \mathrm{s}^{-1}$ [Huchtmeier et al., 2003]. Forma parte del relevamiento realizado con GMRT de galaxias irregulares débiles donde el flujo total integrado en $\mathrm{H}$ I es de $3,0 \pm 0,3 \mathrm{Jy} \mathrm{km} \mathrm{s}{ }^{-1}$ y su velocidad sistémica es $v_{\text {sys }}=462,04 \mathrm{~km} \mathrm{~s}^{-1}$ [Begum et al., 2008]. Sobre la base de su apariencia óptica, KK 69 fue catalogada inicialmente como una posible galaxia dSph por Karachentseva and Karachentsev [1998], pero más tarde, se la propuso como una galaxia dIrr debido a la detección en H I [Begum et al., 2008, Karachentsev et al., 2013]. La magnitud absoluta en la banda $\mathrm{B}$ es $M_{\mathrm{B}}=-12,54 \mathrm{mag}$, lo que significa que esta galaxia es la más brillante del grupo. El diámetro del eje mayor calculado usando la isofota de Holmberg $\left(D_{\mathrm{B} 26}\right)$ es de $3,74 \mathrm{kpc}$ y su distancia proyectada de NGC 2683 es de $23^{\prime}$ o $\sim 62 \mathrm{kpc}$. Derivamos una velocidad de Grupo Local, $v_{\mathrm{LG}}=430 \mathrm{~km} \mathrm{~s}^{-1}$, que corresponde a una distancia de Hubble de 5,9 Mpc, basada en una constante de Hubble de $H_{0} \sim 73 \mathrm{~km} \mathrm{~s}^{-1} \mathrm{Mpc}^{1}$. La gran diferencia entre la distancia determinada usando TRGB y el 'flujo de Hubble' nos permite derivar una velocidad peculiar para KK 69 de $-247 \mathrm{~km} \mathrm{~s}^{-1}$ (ver también Karachentsev et al. [2015b]). La velocidad peculiar negativa implica que el movimiento se dirige hacia nosotros.

- KK 70, también conocida como LEDA 166096 (ver Fig. 5.1), es una galaxia dSph. Esta galaxia se encuentra a una distancia de $D_{\mathrm{TRGB}}=9,18 \pm 0,30 \mathrm{Mpc}[\mathrm{Ka}-$ rachentsev et al., 2015b]. La magnitud absoluta de la banda B es de $-12,27$ mag y el diámetro del eje mayor, usando la isofota de Holemberg, es de $1.4 \mathrm{kpc}$; menos de la mitad del valor del semieje mayor de KK 69. La distancia proyectada a NGC 2683 es de 30' o 82 kpc. Karachentsev et al. [2014] ha estimado un límite superior del flujo de $\mathrm{H} \mathrm{I}_{\mathrm{HI}}=0,48 \mathrm{Jy} \mathrm{km} \mathrm{s}^{-1}$ y un límite superior de masa total de Hi de $M_{\mathrm{HI}}=10^{7} \mathrm{M}_{\odot}$.

- AGC 182595 es una galaxia enana compacta azul la cual forma parte del estudio en H I de enanas de muy baja masa realizado por [Cannon et al., 2011]. La galaxia se encuentra ubicada a una distancia de $D_{\mathrm{TRGB}}=8,47 \pm 0,14 \mathrm{Mpc}$ [Karachentsev et al., 2015b]. La magnitud absoluta de la banda B es $-12,6$ mag, valor que es similar al de KK 69. El diámetro del eje principal calculado usando la isofota de Holmberg es de 0,91 kpc y su distancia proyectada de NGC 2683 es de $333^{\prime}$ o $\sim 123 \mathrm{kpc}$. El $F_{\mathrm{HI}}$ es $0,54 \mathrm{Jy} \mathrm{km} \mathrm{s}^{-1}$, el ancho de línea a $50 \%$ de la densidad de flujo es $w_{50}=20 \mathrm{~km} \mathrm{~s}^{-1}$ y la velocidad sistémica es $v_{\text {sys }}=398 \mathrm{~km} \mathrm{~s}^{-1}$ (ver Cannon et al. [2011]). Usando la distancia estimada por Karachentsev et al. [2015b] derivamos la masa de $\mathrm{H}$ I de la galaxia de $18 \mathrm{C} 95, M_{\mathrm{HI}}=9,1 \times 10^{6} \mathrm{M}_{\odot}$.

- N2683dw1 y N2683dw2 son galaxias dIrr y dSph ubicadas a una distancia de $\sim 9,8 \mathrm{Mpc}$, asumiendo que las galaxias están en el grupo de galaxias NGC 2683 [Karachentsev et al., 2015b]. Sus $M_{\mathrm{B}}$ y $D_{\mathrm{B} 26}$ implican que son los miembros más débiles y pequeños del grupo, de acuerdo a la Tabla 5.1. La galaxia N2683dw1 
está a una distancia proyectada de $\sim 7^{\prime}$ o $\sim 19 \mathrm{kpc}$, mientras que N2683dw2 está a una distancia proyectada de $\sim 13^{\prime}$ o $\sim 35 \mathrm{kpc}$ de la galaxia espiral. No hay detección H I relacionada con ninguno de ellos. Teniendo en cuenta los r.m.s. de $1 \mathrm{mJy} \mathrm{haz}{ }^{-1}$ en $5 \mathrm{~km} \mathrm{~s}^{-1}$ por canal en Vollmer et al. [2016] y asumiendo un ancho de línea de $\sim 30 \mathrm{kms}^{-1}$, estimamos un $\mathrm{H}$ i límite superior de flujo de $F_{\mathrm{HI}}=0,09 \mathrm{Jy} \mathrm{km} \mathrm{s}^{-1}$.

- NGC 2683 es una galaxia espiral vista de canto que se encuentra a una distancia de 9,82 $\pm 0,28 \mathrm{Mpc}$. Es la galaxia más masiva de este grupo. El $F_{\mathrm{HI}}$ es 101,4 $\mathrm{Jy} \mathrm{km} \mathrm{s}^{-1}$, los anchos de línea a $20 \%$ y 50 \% de la densidad de flujo son $w_{20}=450 \mathrm{~km} \mathrm{~s}^{-1}$ y $w_{50}=426 \mathrm{~km} \mathrm{~s}^{-1}$ [Vollmer et al., 2016]. Usando la distancia de grupo, la masa total de $\mathrm{H}$ I resulta ser $M_{\mathrm{HI}}=2,3 \times 10^{9} \mathrm{M}_{\odot}$. Derivamos la velocidad respecto al Grupo Local, $v_{\mathrm{LG}}=376 \mathrm{~km} \mathrm{~s}^{-1}$, que corresponde a una distancia de Hubble de $\sim 5 \mathrm{Mpc}$, basada en una constante de Hubble de $H_{0} \sim 73 \mathrm{~km} \mathrm{~s}^{-1} \mathrm{Mpc}^{1}$. La gran diferencia entre la distancia determinada usando TRGB y el 'flujo de Hubble' nos permite derivar una velocidad peculiar de NGC 2683 de $-340 \mathrm{~km} \mathrm{~s}^{-1}$ (ver también Karachentsev et al. [2015b]). La velocidad peculiar negativa implica que el movimiento se dirige hacia nosotros. Karachentsev and Kaisin [2010] ha estimado el flujo de $\mathrm{H}$ de $F_{\mathrm{H}_{\alpha}}=4,5 \times 10^{-12} \mathrm{erg}$ $\mathrm{cm}^{-2} \mathrm{~s}^{-1} \mathrm{y}$, a partir de esta información, estimamos la tasa de formación estelar, $S F R=10^{-0,1} \mathrm{M}_{\odot} \mathrm{yr}^{-1}$.

La luminosidad en la banda azul se estimó usando la expresión:

$$
L_{\mathrm{B}}=D^{2} 10^{10-0,4\left(m_{\mathrm{B}}-A_{\mathrm{B}}-M_{\mathrm{B}, \odot}\right)},
$$

donde $D$ es la distancia, $m_{\mathrm{B}}$ es la magnitud aparente, $A_{\mathrm{B}}$ la extinción galáctica y $M_{\mathrm{B}, \odot}$ es la magnitud absoluta de el Sol. SFR fue determinada para cada galaxia utilizando la relación: $\operatorname{SFR}\left[\mathrm{M}_{\odot} \mathrm{yr}^{-1}\right]=0,945 \times 10^{9} F_{\mathrm{H} \alpha} D^{2}$ [Kennicutt, 1998].

\subsection{Observaciones y reducción de los datos}

Observamos la galaxia KK69 con GMRT en la banda L durante un tiempo total de 12 horas. Las observaciones se realizaron durante noviembre de 2015 en el modo de zoom espectral con el backend GMRT-Software. Utilizamos un ancho de banda total de $\sim 4 \mathrm{MHz}$ con 512 canales, lo que resulta en una resolución espectral de $\sim 8,13 \mathrm{kHz}$, equivalente a $1.7 \mathrm{~km} \mathrm{~s}^{-1}$ por canal. Los calibradores de flujo 3C286 y 3C147 se observaron al principio y al final de la ejecución durante $\sim 15$ min cada uno. La fuente $0741+312$ se utilizó como calibrador de fase y se observó durante $\sim 5$ min entre las observaciones de KK 69 que fueron de $\sim 45$ min (ver la Tabla 5.2 para más detalles).

Llevamos a cabo los procesos de calibración utilizando dos métodos diferentes: el método estándar, que consiste en marcar los datos erróneos, realizar la calibración de flujo, la calibración de fase y la calibración de pasa banda utilizando las tareas AIPS adecuadas, y de otra manera que fue utilizando un pipeline llamado "Una tubería 
Tabla 5.2: Parámetros de observación de GMRT.

\begin{tabular}{|c|c|}
\hline Fecha de las observaciones & Noviembre 2015 \\
\hline Tiempo de observación (solo fuente) [h] & 12 \\
\hline \multicolumn{2}{|l|}{ Centro de apuntado } \\
\hline$\alpha(\mathrm{J} 2000)[\mathrm{h} \mathrm{m} \mathrm{s}]$ & $8: 52: 50.7$ \\
\hline 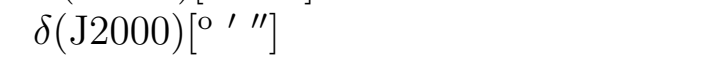 & $+33: 47: 51.9$ \\
\hline Calibradora de flujo 3C147 [Jy] & $22,3 \pm 0,3$ \\
\hline Calibradora de flujo 3C286 [Jy] & $15,1 \pm 0,2$ \\
\hline Calibradora pasabanda $741+312[\mathrm{Jy}]$ & $2,2 \pm 0,03$ \\
\hline Frecuencia central $[\mathrm{MHz}]$ & 1420,435712 \\
\hline Ancho de banda $[\mathrm{MHz}]$ & 4,166 \\
\hline Nro de canales & 512 \\
\hline Ancho de los canales $[\mathrm{MHz}]$ & 0,008138 \\
\hline Resolución en velocidad $\left[\mathrm{km} \mathrm{s}^{-1}\right]$ & 1,7 \\
\hline
\end{tabular}

Tabla 5.3: Flujos de las calibradoras.

\begin{tabular}{lccc}
\hline \hline Name & $\begin{array}{c}\text { VLA } \\
(20 \mathrm{~cm})\end{array}$ & $\begin{array}{c}\text { Este trabajo } \\
(21 \mathrm{~cm})\end{array}$ \\
& & date $15 / 11$ & $17 / 11$ \\
\hline 3C147 & 22,5 & $22,2 \pm 0,3$ & $22,4 \pm 0,3$ \\
$741+312$ & 2 & $2,1 \pm 0,03$ & $2,3 \pm 0,03$ \\
$3 \mathrm{C} 286$ & 15 & $15 \pm 0,2$ & $15,2 \pm 0,2$ \\
\hline
\end{tabular}
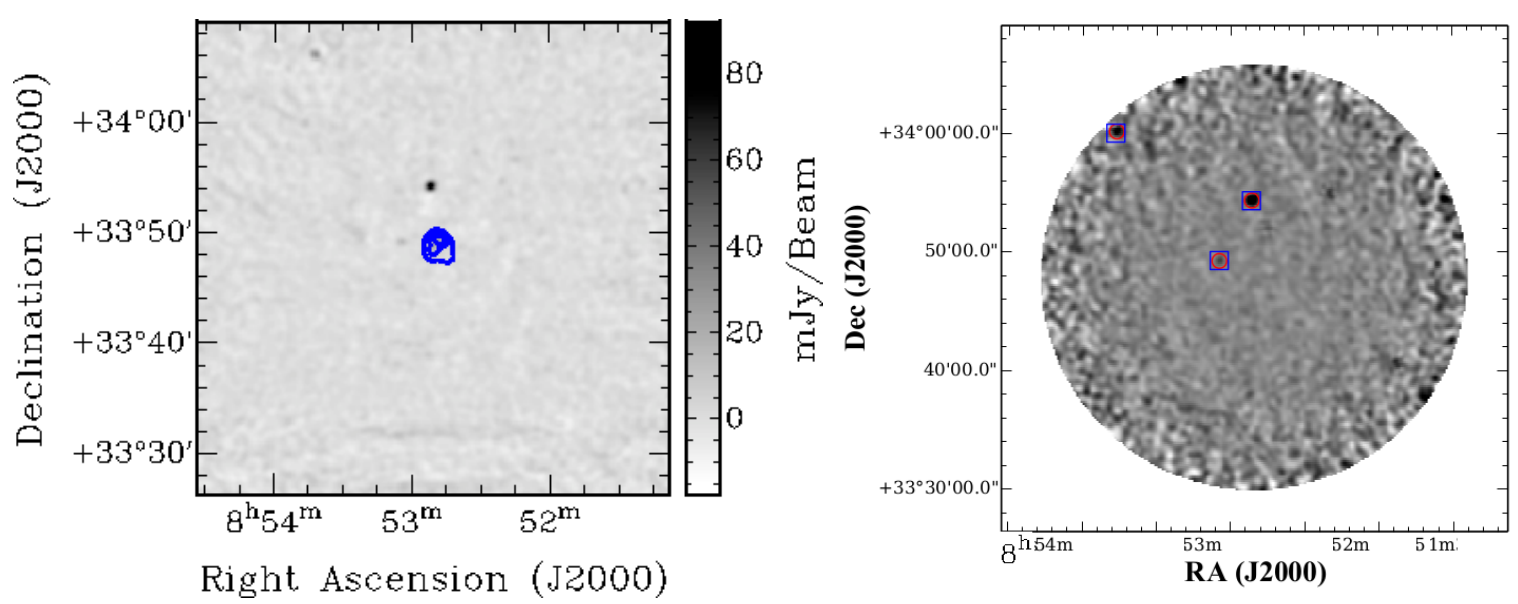

Figura 5.2: Panel izquierdo: Imagen sin la resta del continuo. Los contornos son los mismos de la Fig. 5.1. Panel derecho: Los círculos rojos indican las fuentes presentes en el relevamiento NVSS mientras que el azul encuadra las detectadas con GMRT. La imagen está corregida por haz primario. 
(pipeline) de señalización y calibración para datos GMRT " (FLGCAL, por sus siglas en inglés), Prasad and Chengalur [2011]. El r.m.s. logrado en el cubo de imagen final usando el 'pipeline' fue mejor que el r.m.s. obtenido a través del procedimiento estándar. Por lo tanto, decidimos trabajar con los datos marcados y calibrados por FLGCAL. Hemos corroborado el proceso de calibración mediante la obtención de imágenes de todas las calibradoras y la estimación de sus flujos. Encontramos que el valor de los flujos está de acuerdo con los esperados para cada fuente (consulte la Tabla 5.3). Antes de la construcción de las imágenes es necesario restar la emisión continua. Este paso es especialmente necesario cuando la emisión continua es fuerte o comparable con la línea espectral y se desea un cubo de imagen final con una buena relación senãl-ruido (SNR). La imagen sin la sustracción continua se muestra en la Fig. 5.2. Generalmente se recomienda restar el continuo en el dominio uv (task UVSUB, UVLIN) en lugar de en el plano de la imagen (task IMLIN).

El proceso de construcción del cubo imagen se llevó a cabo con AIPS. Además, utilizamos para análisis adicionales, visualización y generación de imágenes de longitud de onda múltiple, los software MIRIAD y KVIS el cual es parte del paquete KARMA. Para probar la estructura del H I en varias escalas espaciales, creamos cubos de imagenes con diferentes resoluciones espaciales. Sin embargo, dado que la galaxia es muy débil, para todos los propósitos prácticos del estudio actual, utilizamos el cubo de imágenes con una resolución espacial baja; cubo de imagen creado con la tarea IMAGR considerando los datos obtanidos hasta $5 \mathrm{k} \lambda$ de línea de base. La resta del continuo se realizó con la tarea IMLIN, y APCLN se utilizó para producir el cubo final. El haz sintetizado del mapa de H I empleando una ponderación natural fue de $45^{\prime \prime}$. $11 \times 42^{\prime \prime}$.77 y medimos un r.m.s. de $\sim 1,4 \mathrm{mJy} \mathrm{haz}^{-1}$ por $1,7 \mathrm{~km} \mathrm{~s}^{-1}$ por canal en el centro del

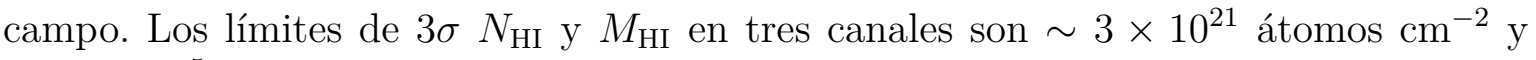
$\sim 4,3 \times 10^{5} \quad \mathrm{M}_{\odot}($ asumiendo que el gas llena el haz).

\subsection{Resultados}

La Figura 5.3 muestra el espectro global H i de KK 69. La emisión del H i se detecta desde $\sim 440$ a $490 \mathrm{~km} \mathrm{~s}^{-1}$ con un flujo de línea integrado de $F_{\mathrm{HI}}=2,2 \pm 0,2 \mathrm{Jy} \mathrm{km} \mathrm{s}^{-1}$; el flujo H i total (calculado a partir del cubo corregido de haz primario) es $26 \%$ más bajo que el valor obtenido por Begum et al. [2008] y es $21 \%$ más bajo que el flujo detectado con la antena de disco simple por Huchtmeier et al. [2003]. Para una distancia de 9,2 Mpc, nuestro valor medido corresponde a una masa $\mathrm{H}$ I total de $M_{\mathrm{HI}}=4,4 \times 10^{7} \mathrm{M}_{\odot}$. Los anchos de línea a $20 \%$ y $50 \%$ de la densidad de flujo pico son $w_{20}=32,6 \mathrm{~km} \mathrm{~s}^{-1}$ y $w_{50}=13,6 \mathrm{~km} \mathrm{~s}^{-1}$ con una velocidad sistémica de $463,8 \pm 0,3 \mathrm{~km} \mathrm{~s}^{-1}$. Estas estimaciones se realizaron utilizando la tarea MBSPECT en MIRIAD. Enumeramos las propiedades H I de KK 69 extraídas de las observaciones GMRT en la Tabla 5.4.

\subsubsection{Distribución y cinemática del $\mathrm{H}$ I}

La distribución del H i de KK 69 se observa desplazado hacia el norte del cuerpo estelar y levemente hacia el oeste como se muestra en nuestras Figs. 5.4 y 5.5, 

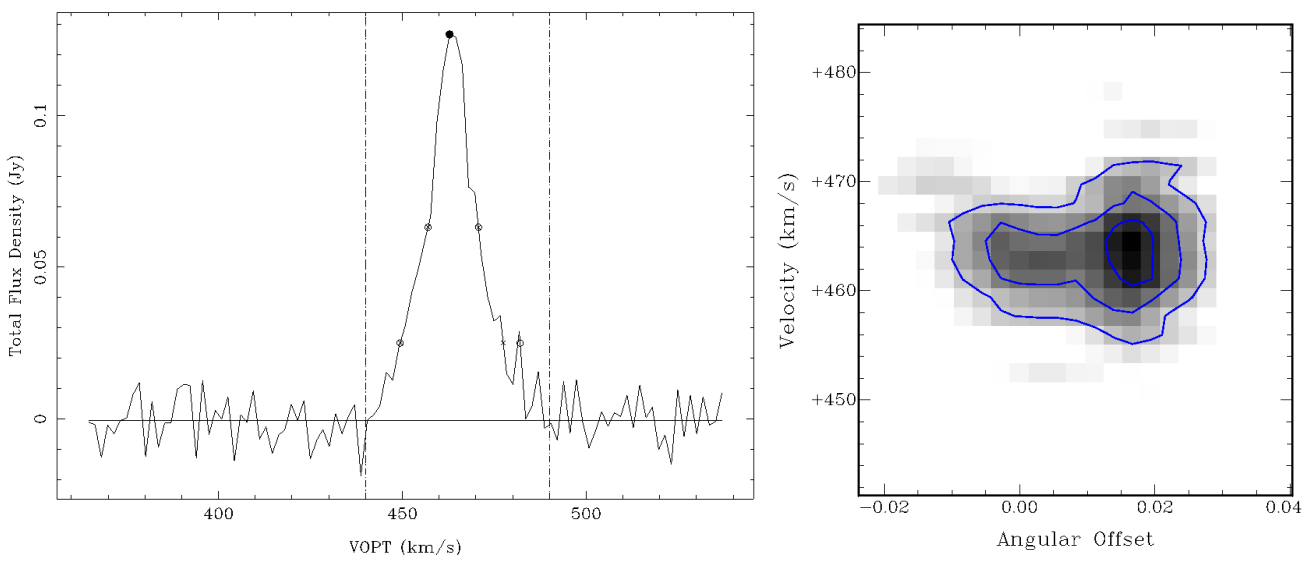

Figura 5.3: Panel izquierdo: Flujo integrado del espectro de H I de la galaxia KK 69. Se marcan el pico de flujo y los puntos donde se estimaron los anchos de línea en $50 \%$ y 20 \%. Las líneas verticales indican el rango de velocidades de la detección de emisiones H I desde $\sim 440$ a $490 \mathrm{~km} \mathrm{~s}^{-1}$. Panel derecho: El diagrama posición velocidad $(p v)$ del área mostrada en la Figura 5.6. Los niveles de contorno son 11; $18 ; 24 \mathrm{mJy} \mathrm{haz}^{-1}$.

mientras que en el sur, la emisión del H i es más extendida y difusa. La posición del pico de emisión del H I es $\alpha, \delta(\mathrm{J} 2000)=08^{\mathrm{h}} 52^{\mathrm{m}} 47,49^{\mathrm{s}},+33^{\mathrm{o}} 49^{\prime} 21,98^{\prime \prime}$. La medida del desplazamiento entre la región estelar de alta densidad y la región del gas de alta densidad es de $\sim 1,6^{\prime}$ o $\sim 4,3 \mathrm{kpc}$, asumiendo que la distancia es de 9,28 Mpc. Corroboramos que el desplazamiento no es debido a un problema en el sistema de coordenadas. El mismo se observa tanto en la imagen HST así como en la imagen DSS (Fig. 5.5 y 5.6).

La extensión de H i de la galaxia es de $\sim 3,3^{\prime}(\sim 9 \mathrm{kpc})$; los valores son cercanos a los determinados por Begum et al. [2008] (ver la Tabla 5.4). Utilizando la tarea de MIRIAD IMFIT ajustamos una gaussiana considerando el contorno de H I más externo de KK 69, que corresponde a una emisión de $3 \sigma\left(\sim 6,7 \times 10^{20}\right.$ átomos $\left.\mathrm{cm}^{-2}\right)$. El mejor ajuste corresponde a una elipse centrada en $\alpha, \delta(\mathrm{J} 2000)=08^{\mathrm{h}} 52^{\mathrm{m}} 48,80^{\mathrm{s}}, 33^{\circ} \quad 49^{\prime} \quad 04,44^{\prime \prime}$, con ejes mayor y menor de 1'.95 \pm 0 ’.04, 1'.6 \pm 0 ’03 respectivamente y con un ángulo de posición de $-19 \pm 4$ grados. Esto lleva a $D_{\mathrm{HI}} / D_{\mathrm{B} 26} \sim 2,1$ que es similar al valor encontrado por Begum et al. [2008]. Nuestros mapas de canales de la galaxia KK 69, suavizados a $5.1 \mathrm{kms}^{-1}$ (r.m.s. de $\sim 1 \mathrm{mJy} \mathrm{haz}^{-1}$ por $3,4 \mathrm{~km} \mathrm{~s}^{-1}$ canal), se muestran en la Fig. 5.4.

El tamaño H I de KK 69 es de casi tres veces el valor del haz sintetizado (ver Fig. 5.6). El campo de velocidad revela un pequeño gradiente de velocidad de $460 \mathrm{~km} \mathrm{~s}^{-1}$ a $470 \mathrm{~km} \mathrm{~s}^{-1}$ así como también lo hace el diagrama de posición-velocidad ( $p v$ ) (consulte las Figs. 5.6 y 5.3). Se necesitan una resolución de alta velocidad y una resolución angular alta para distinguir un patrón de rotación claro. La dispersión de la velocidad ponderada de flujo (momento dos) muestra que la dispersión de alta velocidad tiene lugar en la región H I de alta densidad (ver Fig. 5.6). 

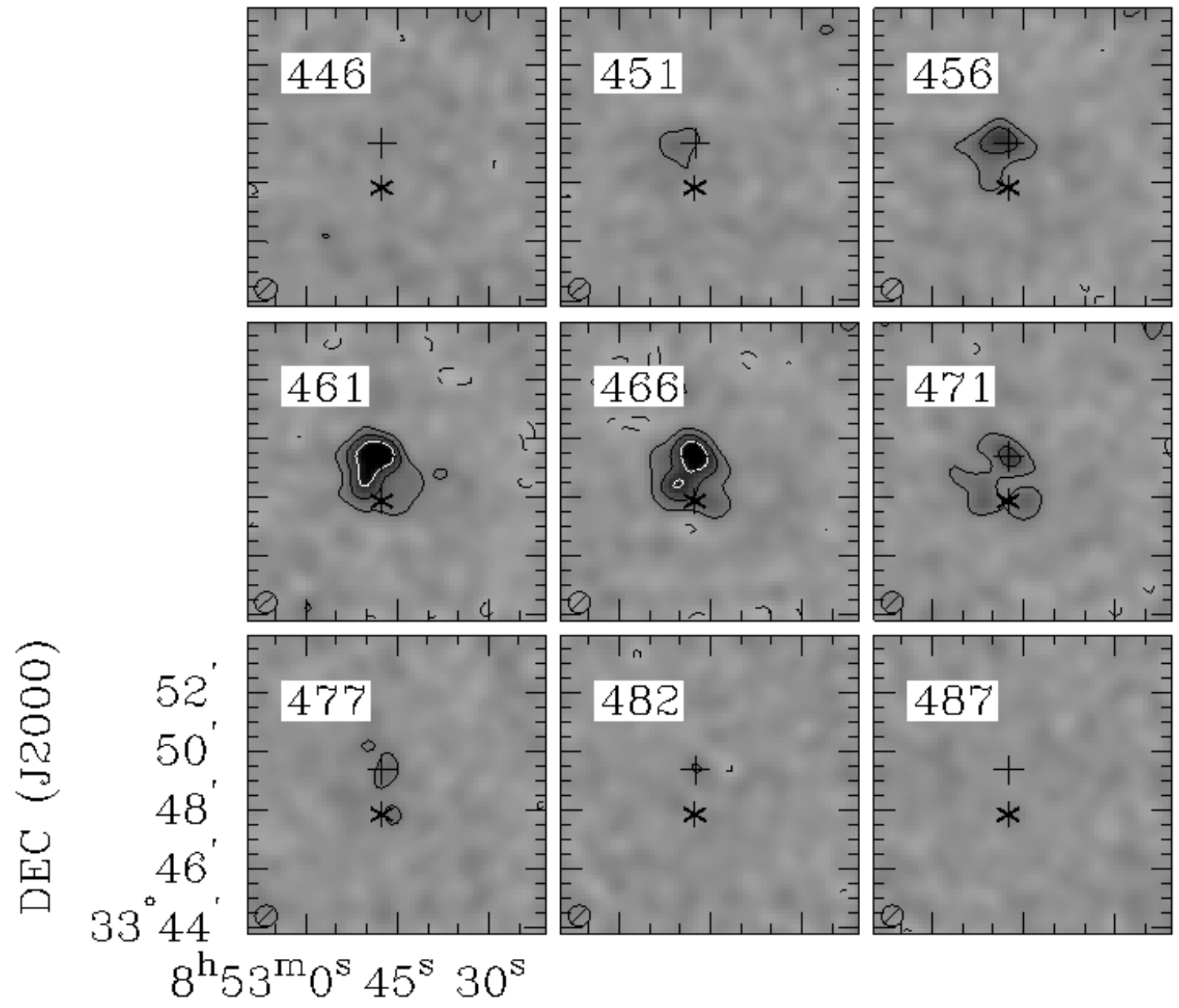

\section{RA (J2000)}

Figura 5.4: Mapa de H i por canales de velocidad de la galaxia KK 69. El H I máximo de emisión (cruz) y la alta densidad estelar (estrella) están marcados. Los niveles de contorno son $\pm 3,5 ; 9 ; 16 ; 27 \mathrm{mJy} \mathrm{haz}^{-1}$. Las velocidades centrales del canal se muestran en la esquina superior izquierda (las unidades son $\mathrm{kms}^{-1}$ ) y el haz sintetizado en la esquina inferior izquierda de cada mapa. 


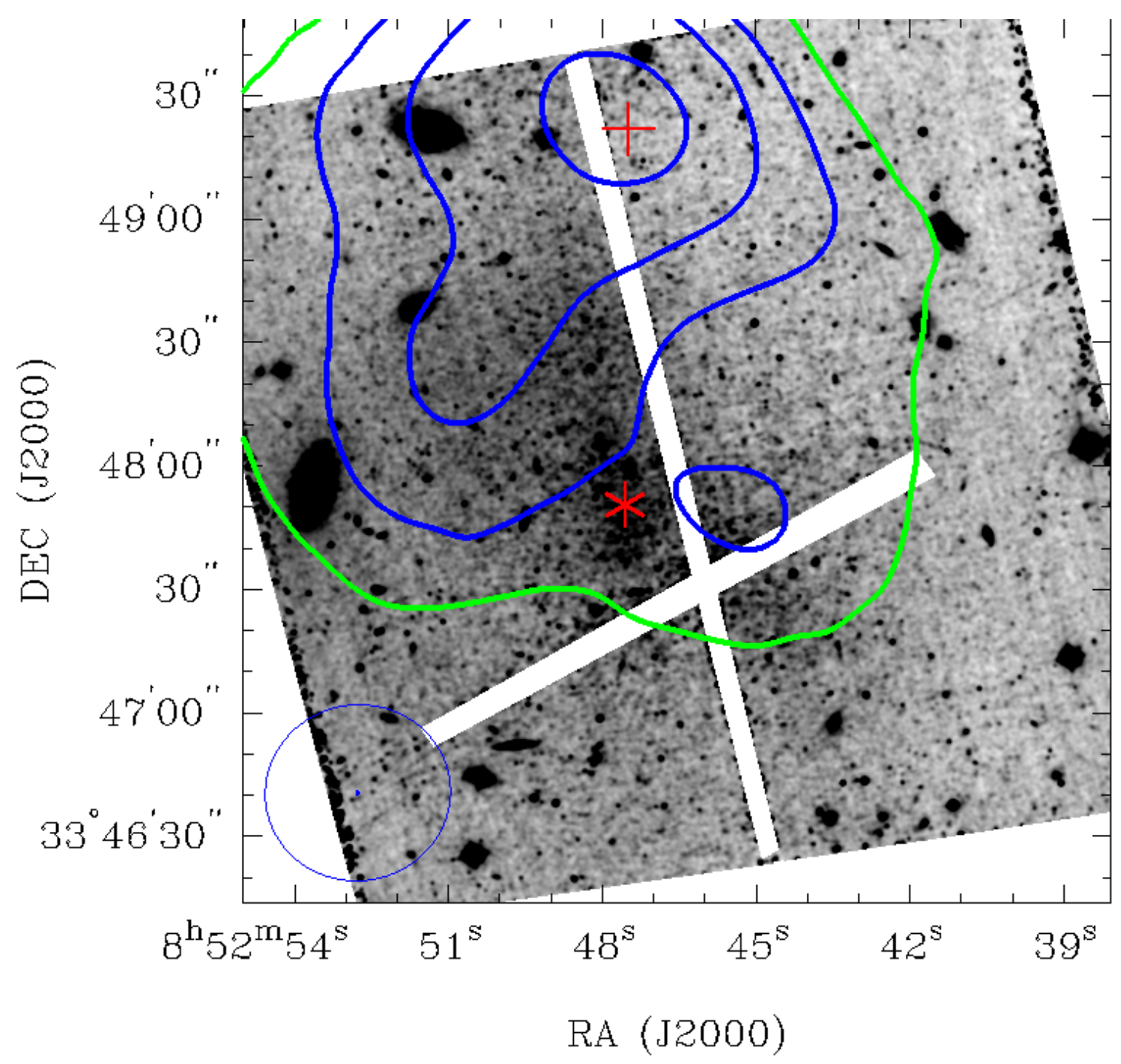

Figura 5.5: La galaxia enana KK 69. El mapa de intensidad de H I de KK 69 se superpone a la imagen de la banda F606W del Telescopio Espacial Hubble (escala de grises). Los niveles de contorno de H I son 0,039; 0,093; 0,16; 0,27 Jy haz ${ }^{-1} \mathrm{~km} \mathrm{~s}^{-1}$ $\left(6,7 ; 16 ; 27 ; 46 \times 10^{20}\right.$ átomos $\left.\mathrm{cm}^{-2}\right)$. El centro de la distribución estelar (símbolo de estrella) y el pico del gas (símbolo más) no son coincidentes; el desplazamiento entre los dos es $\sim 1,6^{\prime}$ o $\sim 4,3 \mathrm{kpc}$ para una distancia de $D=9,28 \mathrm{Mpc}$. 

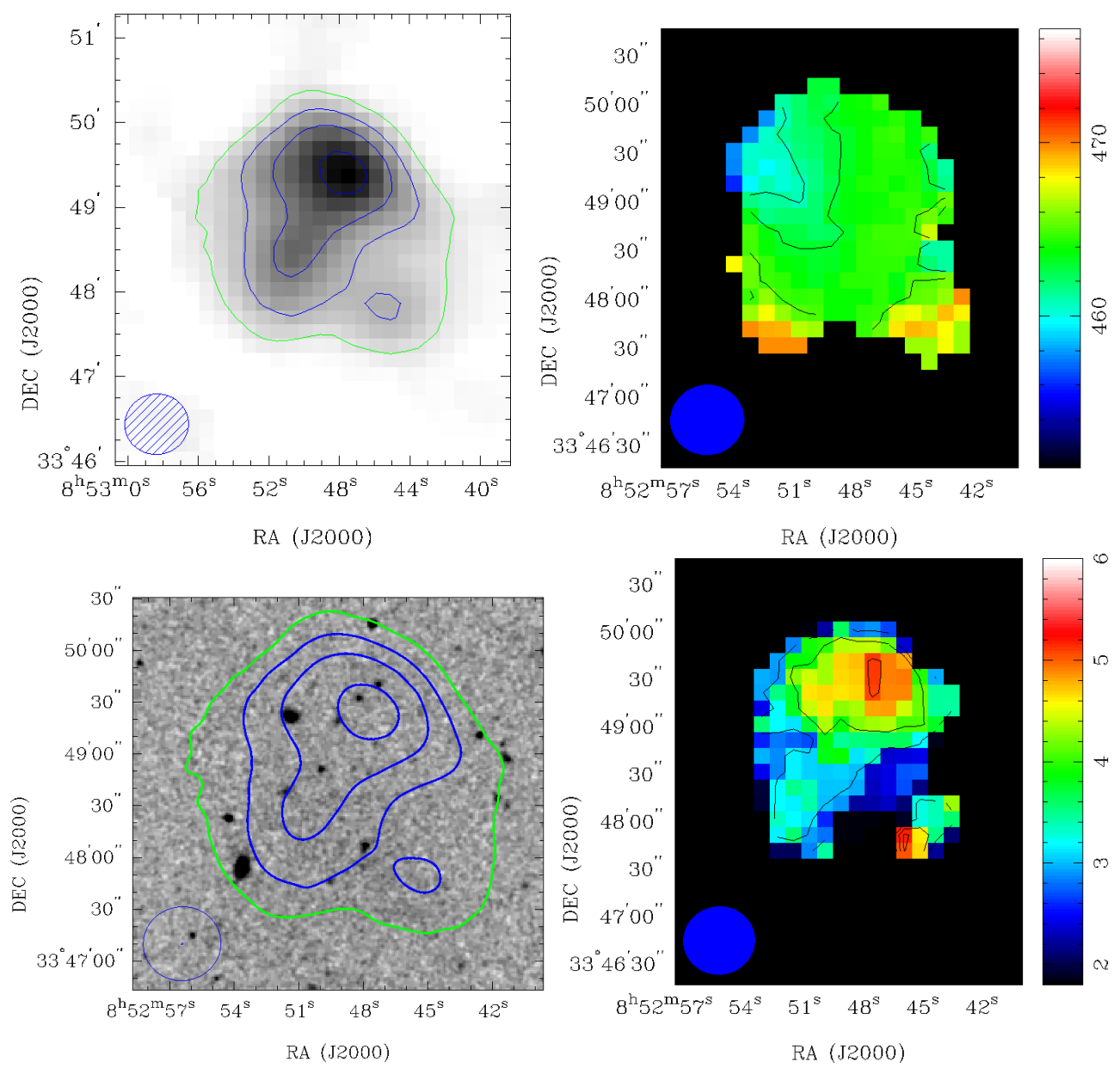

Figura 5.6: Mapas de momento de H I de la galaxia enana KK 69 en el rango de velocidad de 440 a $490 \mathrm{~km} \mathrm{~s}^{-1}$. Panel superior izquierdo: distribución del H I, los niveles de contorno son 0,039; 0,093; 0,16; 0,27 Jy haz ${ }^{-1} \mathrm{~km} \mathrm{~s}^{-1}\left(6,7 ; 16 ; 27 ; 46 \times 10^{20}\right.$ átomos cm $\left.{ }^{-2}\right)$. Panel inferior izquierdo: Distribución del H i (los mismos contornos) superpuestos en la imagen de banda R DSS2. Panel superior derecho: campo de velocidades de H I los niveles de contorno son 461, 463, $465 \mathrm{~km} \mathrm{~s}^{-1}$. Panel inferior derecho: dispersión de velocidades del H I Los niveles de contorno son 2, 4, $6 \mathrm{~km} \mathrm{~s}^{-1}$. El haz sintetizado $\left(45^{\prime \prime} .11 \times 42^{\prime \prime} .77\right)$ se muestra en la esquina inferior izquierda de cada panel. 
Tabla 5.4: Propiedades en H I de KK 69 y del resto de las galaxias del grupo.

\begin{tabular}{lccc}
\hline \hline Propiedades & $\begin{array}{c}\text { KK 69 } \\
(*)\end{array}$ & $\begin{array}{c}\text { AGC 182595 } \\
(1)\end{array}$ & $\begin{array}{c}\text { NGC 2683 } \\
(2)\end{array}$ \\
\hline H I pico & & & \\
$\alpha(\mathrm{J} 2000)[\mathrm{h} \mathrm{m} \mathrm{s}]$ & $08: 52: 47.49$ & $08: 51: 12.1$ & $08: 52: 40.9$ \\
$\delta(\mathrm{J} 2000)\left[{ }^{\circ} \prime^{\prime \prime}\right]$ & $33: 49: 21.98$ & $27: 52: 48$ & $+33: 25: 02$ \\
$F_{\mathrm{HI}}\left[\mathrm{Jy} \mathrm{km} \mathrm{s}^{-1}\right]$ & $2,2 \pm 0,3$ & 0,54 & 101,4 \\
$M_{\mathrm{HI}}\left[10^{7} \mathrm{M}_{\odot}\right]$ & 4,4 & $0,9^{*}$ & $152^{*}$ \\
$M_{\mathrm{HI}} / L_{\mathrm{B}}\left[\mathrm{M}_{\odot}\right]$ & 2 & $0,5^{*}$ & $0,05^{*}$ \\
$D_{\mathrm{HI}}[\mathrm{arcmin}]$ & 3,3 & 0,6 & $26,5 \times 5$ \\
$D_{\mathrm{HI}}[\mathrm{kpc}]$ & 9 & $1,4^{*}$ & $60^{*} \times 13^{*}$ \\
$i[\mathrm{deg}]$ & $-32 \pm 15$ & 64 & 83 \\
$v_{\text {sys }}\left[\mathrm{km} \mathrm{s}^{-1}\right]$ & $463,8 \pm 0,3$ & 398 & 411 \\
$w_{50}\left[\mathrm{~km} \mathrm{~s}^{-1}\right]$ & 13,6 & 20 & 426 \\
$w_{20}\left[\mathrm{~km} \mathrm{~s}^{-1}\right]$ & 32,6 & & 450 \\
$v_{\mathrm{LG}}\left[\mathrm{km} \mathrm{s}^{-1}\right]$ & 430 & $500^{*}$ & $376^{*}$ \\
$v_{\mathrm{pec}}\left[\mathrm{km} \mathrm{s}^{-1}\right]$ & -247 & $-113 *$ & $-340 *$ \\
$M_{\mathrm{dyn}}\left[10^{8} \mathrm{M}_{\odot}\right]$ & $\sim 1,1$ & & \\
\hline
\end{tabular}

Referencias: (1) Cannon et al. [2011], (2) Vollmer et al. [2016], (*) este trabajo.

\subsubsection{Identificación de la component fría y tibia del medio interestelar de la galaxia KK 69}

En muchos trabajos se ha podido identificar la presencia de la fase fría y tibia del MIE. Young and Lo [1996] descompuso, para el caso de varias galaxias enanas, los espectros de emisión de la línea de H I en múltiples componentes gaussianas y encontró evidencia de la existencia de dos componentes, una con un ancho de $\sim 8-12 \mathrm{~km} \mathrm{~s}^{-1}$ y la otra con un ancho relativamente estrecho, menor a $6 \mathrm{kms}^{-1}$. Los anchos que encuentran corresponden a temperaturas cinéticas mucho más altas que las esperadas en los modelos teóricos [Wolfire et al., 1995, 2003]. Ellos atribuyen este ensachamiento a la contribución de procesos de turbulencia. Más tarde, en otros trabajos [por ejemplo Stilp et al., 2013, Patra et al., 2016, etc.] también llegaron a la misma conclusión sobre las fases del MIE. Por lo tanto, se espera que mediante la descomposición gaussiana del espectro de emisión del H i se logren identificar la fases frías y tibias del MIE.

Adoptando el mismo enfoque, descompusimos los espectros de línea del H I de KK 69 para identificar las diferentes fases de su MIE. Para ello, utilizamos la rutina multigauss de Patra et al. [2016]. La descomposición se llevó a cabo considerando diferentes valores máximos de SNR. El valor más bajo de SNR fue 5. La rutina fue capaz de identificar la fase fría y tibia (ver Fig. 5.7). El gas frío cubre casi dos veces el tamaños de haz de la galaxia y por eso su detección es confiable. Pero el gas caliente fue detectado en unos pocos pixeles; la resolución angular no es lo suficientemente buena como para hacer creíble este resultado.

Como se sugirió en Patra et al. [2016] los resultados son confiables si sólo descompo- 

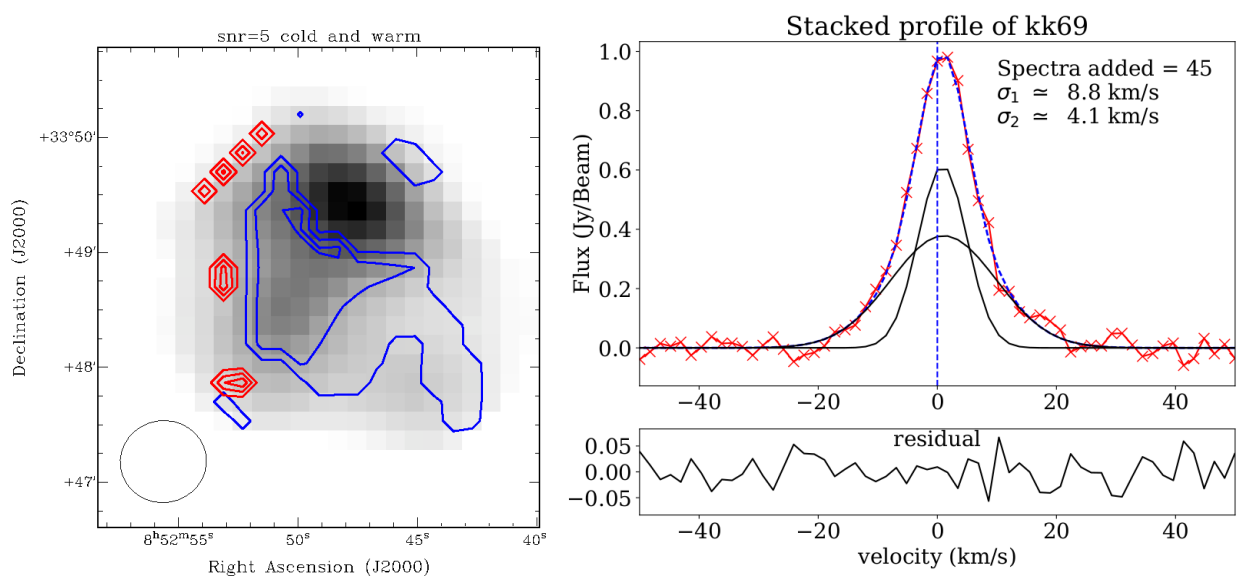

Figura 5.7: Panel izquierdo: Componente fría y tibia del H I en KK 69 detectado por el método de descomposición gaussiana considerando una SNR de 5. En escala de grises se muestra la distribución total de H I. Los contornos azules indican donde fue detectada la componente fría mientras que los rojos, donde fue detectada la componente tibia. El haz sintetizado se muentra en la parte inferior izquierda de cada figura. Los niveles de contorno son $9,17,37 \times 10^{19}$ átomos $\mathrm{cm}^{-2}$ para la componente fría del H I y $6 \times 10^{19}$ átomos $\mathrm{cm}^{-2}$ para la componente tibia del H I. Panel derecho: Espectro resultante debido al stacking de H I considerando una SNR de 10. Las cruces rojas representan el espectro apilado y la línea a trozos, en color azul, indica el ajuste realizado al espectro mediante dos gaussianas. La curva negra indica la componente angosta, correspondiente a la gaussiana que identifica la componente fría, mientras que la curva negra, con un trazo más grueso, respresenta el ajuste gaussiano de la componente tibia del H I. La línea azul a trozos indica la velocidad central del CNM $\left(0,88 \pm 0,08 \mathrm{~km} \mathrm{~s}^{-1}\right)$ y la del WNM $\left(1,06 \pm 0,19 \mathrm{~km} \mathrm{~s}^{-1}\right)$. Panel inferior derecho: Residuos del ajuste utilizando dos gaussianas. 

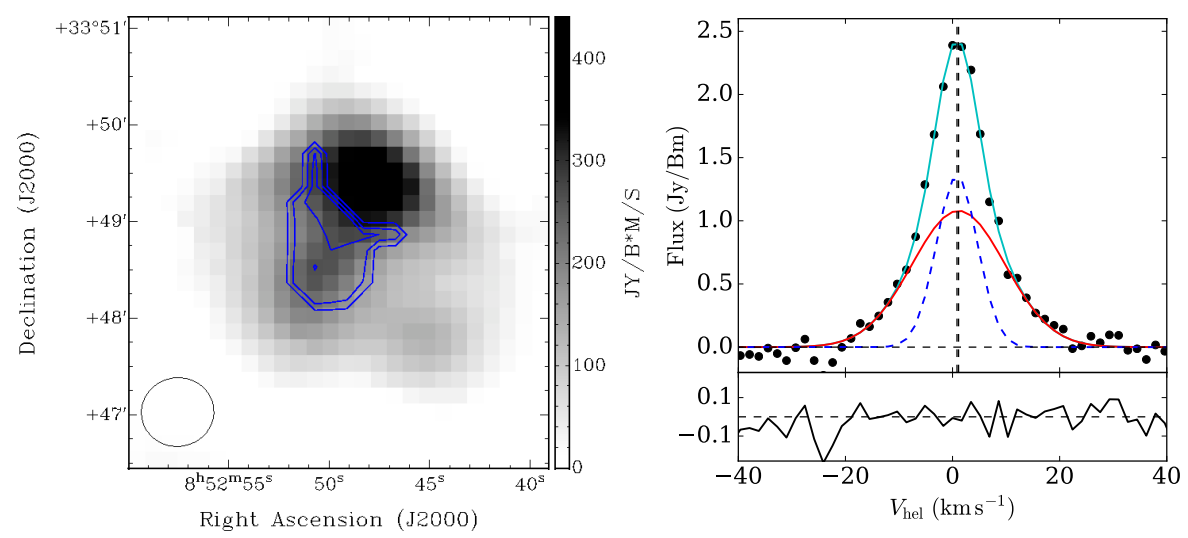

Figura 5.8: Panel izquierdo: Componente fría del H i en KK 69, según lo detectado por el método de descomposición gaussiana. En escala de grises se muestra la distribución total de H I mientras que los contornos representan donde fue detectada la componente fría. El haz sintetizado se muestra en la esquina inferior izquierda de la figura. Los niveles de contorno son 26, 33, $43 \times 10^{20}$ átomos $\mathrm{cm}^{-2}$. Panel derecho: El espectro resultante debido al stacking del H I se muestra con puntos negros y la línea cian sólida indica un ajuste utilizando dos gaussianas. La línea discontinua azul representa la componente gaussiana estrecha (CNM), mientras que la línea roja continua representa la componente gaussiana ancha (WNM). Las líneas discontinuas negras verticales indican las velocidades centrales de los componentes CNM $\left(0,8 \pm 0,07 \mathrm{~km} \mathrm{~s}^{-1}\right)$ y WNM $\left(1,1 \pm 0,1 \mathrm{~km} \mathrm{~s}^{-1}\right)$. Panel inferior derecho: residuos del ajuste utilizando dos gaussianas. 
nemos los espectros que tienen una SNR mayor que 10. Además, optamos por utilizar un nivel de confianza del $95 \%$ para F-test ${ }^{1}$ en la rutina multigauss para evitar cualquier falso positivo. Para KK 69, encontramos que sólo una componente gaussiana se ajusta mejor a todos los espectros con $\sigma_{\mathrm{HI}} \leq 6 \mathrm{~km} \mathrm{~s}^{-1}$. Esto es muy interesante, ya que señala la presencia de gas frío en todas las líneas inspeccionadas. Con este método detectamos $\sim 8,45 \pm 0,09 \times 10^{6} \mathrm{M}_{\odot}$ de gas frío en KK 69. En la Fig. 5.8 mostramos la ubicación del gas frío detectado (contornos azules) superpuesto sobre el mapa de densidad de la columna de gas total (escala de grises). Como se puede ver en la figura, el gas frío detectado utilizando el método de descomposición gaussiana se encuentra desfasado de la región de mayor concentración de H I y de la componente estelar de la galaxia. Esto se atribuye a la presencia de un alto nivel de turbulencia en las regiones centrales de alta densidad de columna que ensancha artificialmente los espectros observados del H i [por ejemplo, Stilp et al., 2013, Patra et al., 2016]. En el caso de KK 69, el método se aplicó a una región menor a 2 veces el área de haz sintetizado. Para KK 69, también notamos que en ninguna línea de visión detectamos $\mathrm{H}$ i con $\sigma_{\mathrm{HI}} \geq 6$. Esto indica una presencia mínima de WNM que no se recupera en nuestro método de descomposición gaussiana debido a la baja SNR.

Por lo tanto, para superar este problema, apilamos los espectros de línea de visión H I en KK 69. Adoptando un enfoque similar al descrito en Stilp et al. [2013], ajustamos el espectro de $\mathrm{H}$ i en la dirección de la línea de la visual con un polinomio de Hermite para localizar el centroide de espectros individuales. Luego usamos la información de los centroides para alinear todos los espectros a una velocidad común y los apilamos para producir un espectro con una alta SNR. Se requiere una SNR mínima de 5 para producir un ajuste significativo de los espectros [de Blok et al., 2008b]. También hemos implementado una SNR mínima de 9 en la rutina de apilamiento para corroborar la cantidad de gas frío encontrado con la rutina que sólo ajusta (ver párrafo anterior). Como se esperaba, los resultados de ambos métodos están de acuerdo.

En la Fig. 5.8 trazamos los espectros apilados resultantes para KK 69. A continuación, descompusimos este espectro apilado usando dos gaussianas para identificar el CNM y el WNM. En la Fig. 5.8, panel derecho, trazamos los componentes resultantes, es decir, una componente más angosta y otra más ancha con un $\sigma_{C N M}$ de $3,8 \pm 0,3 \mathrm{~km} \mathrm{~s}^{-1}$ y un $\sigma_{W N M}$ de $8,6 \pm 0,5 \mathrm{~km} \mathrm{~s}^{-1}$ respectivamente. Estos componentes representan el CNM y el WNM en KK69. Se obtuvieron valores similares considerando una SNR diferente (ver Fig: 5.7). En el panel inferior derecho, mostramos el residuo del ajuste. Encontramos un total de $(1,2 \pm 0,02) \times 10^{7} \mathrm{M}_{\odot}$ de gas en la fase $\mathrm{CNM}$, mientras que $(2,1 \pm 0,04) \times 10^{7} \mathrm{M}_{\odot}$ está en la fase WNM. Esto lleva a que $\sim 36 \%$ del gas detectado (con SNR > 5) se encuentra en la fase CNM, y $\sim 64 \%$ en la fase WNM.

El ajuste gaussiano y los métodos de apilamiento permitieron encontrar una masa de gas frío similar. Sin embargo, la fase neutra cálida solo fue expuesta por el procedimiento de apilamiento.

\footnotetext{
${ }^{1}$ El F-test se explica en la Sección 3.1 del documento Patra et al. [2016].
} 
Tabla 5.5: Propiedades de las fases CNM y WNM en la galaxia KK 69.

\begin{tabular}{lc}
\hline \hline Método/Parámetro & Resultado \\
\hline Descomposición Gaussiana & \\
$M_{\mathrm{CNM}}\left[\mathrm{M}_{\odot}\right]$ & $8,4 \pm 0,09 \times 10^{6}$ \\
Stacking & $3,8 \pm 0,3$ \\
$\sigma_{\mathrm{CNM}}\left[\mathrm{km} \mathrm{s}^{-1}\right]$ & $8,6 \pm 0,5$ \\
$\sigma_{\mathrm{WNM}}\left[\mathrm{km} \mathrm{s}^{-1}\right]$ & $1,2 \pm 0,02 \times 10^{7}$ \\
$M_{\mathrm{CNM}}\left[\mathrm{M}_{\odot}\right]$ & $2,1 \pm 0,04 \times 10^{7}$ \\
$M_{\mathrm{WNM}}\left[\mathrm{M}_{\odot}\right]$ & \\
\hline
\end{tabular}

\subsection{Discusión}

El bajo pozo de potencial de las galaxias enanas hace que su medio interestelar (MIE) sea susceptible a las perturbaciones producidas por los efectos ambientales y por los procesos internos. Los eventos de supernovas por ejemplo, son causa interna de desajuste y pérdida de masa en galaxias enanas [Larson, 1974, Vader, 1986, Dekel and Silk, 1986], mientras que el proceso de barrido por presión cinética y las interacciones de mareas son los principales mecanismos externos de eliminación de gas. La eficiencia del proceso de barrido por presión cinética depende de la densidad del medio intragrupo y de la velocidad de la galaxia a través del medio [Gunn and Gott, 1972]; es común observar una característica de cola en la dirección opuesta a la del movimiento de la galaxia [Chung et al., 2007]. La interacción de las mareas depende de la masa, la velocidad de la galaxia y las órbitas de las galaxias que interactúan. El gas eliminado se puede encontrar como filamentos e incluso puentes de estrellas y gas [Higdon, 1996, Koribalski et al., 2003, Koribalski and Dickey, 2004, English et al., 2010]. Estas estructuras extendidas de H I pueden ser difíciles de detectar, debido a su baja emisión de brillo superficial [Yun et al., 2000].

Los mecanismos internos y externos mencionados no sólo son la causa de cambios estructurales/morfológicos, sino que también pueden influir en la futura actividad de formación de estrellas en las galaxias. Adams and Oosterloo [2018] han encontrado que casi $10 \%$ de la masa total de Leo T está en la fase fría y lo extraño es que la galaxia no está formando estrellas intensivamente. Los autores atribuyeron la presencia de una gran cantidad de gas en la fase fría como el resultado de la interacción de Leo T con el medio circumgaláctico de la Vía Láctea.

\subsubsection{El medio interestelar de la galaxia KK 69}

Para caracterizar en detalle el MIE de KK 69, utilizamos un código de descomposición multi-gaussiano y una rutina de apilamiento. Desde el primer método, encontramos un valor sobresaliente para la masa de la componente fría del H I. En promedio, la cantidad de CNM en galaxias enanas ricas en gas es inferior a $5 \%$ de su masa total de $\mathrm{H} \mathrm{I}$ [ver, por ejemplo, los resultados en decenas de galaxias de Warren et al., 2012, Patra et al., 2016]. Sin embargo, en KK 69, el CNM detectado es casi 19 \% de su masa total de H I, una característica compartida con la galaxia enana Leo T (consulte Adams and 
Oosterloo [2018]). Por medio del método de stacking, determinamos una proporción de gas frío de $\mathrm{H}$ I frente a cálido de $\mathrm{H}$ I igual a 0,6 , valor que es similar a resultados anteriores encontrados para otras galaxias. La fase WNM suele ser dominante en la fase CNM [Warren et al., 2012].

La densidad columnar del CNM $N_{\mathrm{HI}}$ es de $\sim 4 \times 10^{21}$ átomos $\mathrm{cm}^{-2}$. Si corregimos este valor por la abundancia del He obtenemos que $N_{\text {gas }}=1,33 \times N_{\mathrm{HI}} \approx 5,3 \times 10^{21}$ átomos $\mathrm{cm}^{-2}$. Este valor es mayor que el valor umbral para la formación de hidrógeno molecular en la fase CNM, $N_{\mathrm{HI}}=3 \times 10^{20}$ átomos $\mathrm{cm}^{-2}$ [Schaye, 2004]. Sin embargo, no se observa una contraparte en el ultravioleta (chequeamos la base de datos de GALEX) , que se asocia comúnmente con los escenarios de formación estelar. Considerando la tasa de formación estelar de KK 69 determinada por nosotros $10^{-3,8} \mathrm{M}_{\odot} \mathrm{yr}^{-1}$, se puede determinar la escala de tiempo de agotamiento del gas $\tau_{\text {gas }}{ }^{2}$ ) considerando que la SFR permanece constante. $\tau_{\text {gas }} \sim 86,4$ Gyr, Por ende, la galaxia necesitará seis veces la edad del universo para transformar todo el gas en estrellas. Este valor no es tan alto como el que se encuentra en las galaxias UGCA 365 ( $\tau_{\text {gas }}=1250$ Gyr) y UKS 1424-460 $\left(\tau_{\text {gas }}=534\right.$ Gyr $)$ [Côté et al., 2009], pero sigue siendo alto en comparación con el $\tau_{\text {gas }}$ estimado para galaxias que forman estrellas más activamente [Grebel et al., 2003].

\subsubsection{Clasificando morfológicamente a KK 69}

Hasta la fecha, las galaxias con morfologías mixtas dIrr/dSph y con un contenido de H I de unas pocas veces $10^{6} \mathrm{M}_{\odot}$, se han identificado como galaxias enanas en transición. Mateo [1998], Skillman et al. [2003] y Grebel et al. [2003] propusieron, además, que deben detectarse en $\mathrm{H}$, sin o con un flujo extremadamente débil $\mathrm{H}_{\alpha}$ y con una escala de tiempo de agotamiento de gas $\left(\tau_{\text {gas }}\right)$ superior a 100 Gyr. Algunos ejemplos son Pegasus ( $\tau_{\text {gas }}=3220$ Gyr), Phoenix, DD0 210, LGS 3, Antlia y KKR 25, en las cercanías de la Vía Láctea. ESO 471-G06, ESO 348-G09, SC 18 y SC 24 pertenecientes al grupo de Sculptor [Skillman et al., 2003] mientras que ESO 269-G58, UCGA 365 $\left(\tau_{\text {gas }}=1250\right.$ Gyr $)$, ESO 384-G016, y UKS 1424-460 ( $\tau_{\text {gas }}=534$ Gyr $)$ están en el grupo de Centaurus A [Côté et al., 2009]. Otras dos galaxias bajo sospecha de ser galaxias enanas de transición son AM 19-662 y UGC 438 [Koribalski et al., 2018b].

Si bien, KK 69 se asemeja a una galaxia enana irregular débil, ya que $F_{\mathrm{HI}}=2,2 \mathrm{Jy}$ $\mathrm{km} \mathrm{s}^{-1}, D_{\mathrm{HI}} / D_{\mathrm{B} 26} \sim 2,1$ y $M_{\mathrm{HI}}=4,4 \times 10^{7} \mathrm{M}_{\odot}$ (ver valores característicos para dIrr en Begum et al. [2008] y Grebel et al. [2003]) la luminosidad de KK 69 es la esperada para una galaxia dSph y, además, un resultado notable que surge de nuestros datos es el desfasaje de $\sim 4,2 \mathrm{kpc}$ entre la región de alta densidad estelar y la región donde se encuentra la mayor concentración de gas H i. Este desfasaje también se observa en algunas galaxias enanas de transición [Oosterloo et al., 1996, Blitz and Robishaw, 2000, Young et al., 2007, Koribalski et al., 2018b]. Este fenómeno podría ser producido por procesos internos así como por efectos ambientales.

Debido al bajo potencial de las galaxias enanas, los eventos de supernovas son los procesos internos primarios que contribuyen a los cambios estructurales. Un ejemplo

\footnotetext{
${ }^{2} \tau_{\text {gas }}=1,32 \times M_{H I} / S F R$; el factor 1,32 se agrega para considerar la presencia de He.
} 
interesante es la galaxia de transición enana Phoenix [Young and Lo, 1997, Mateo, 1998, St-Germain et al., 1999]. Esta galaxia, a una distancia proyectada de $445 \mathrm{kpc}$ de la Vía Láctea, muestra un desfasaje entre el gas H I y las estrellas de 0,6 kpc. Los autores atribuyeron esto a los recientes eventos de formación de estrellas ocurridos a lo sumo hace 100 Myr [Young et al., 2007]. En KK 69, el desplazamiento entre las regiones de alta densidad de H y y las regiones de alta densidad estelar es un orden de magnitud más alto que el que se encuentra en Phoenix.

Aunque la interacción de las mareas puede modificar las regiones externas de una galaxia, también puede permitir que se pierda el momento angular de la dIrr y dar a la turbulencia la oportunidad de desempeñar un papel activo en la cinemática de la galaxia [Grebel et al., 2003]. Eso podría implicar que el proceso de interacción de las mareas desempeña un papel importante en el origen de las galaxias de tipo de transición. En el entorno de la Vía Láctea [Mateo, 1998], así como en el grupo de Sculptor [Skillman et al., 2003] y el grupo Centaurus A [Côté et al., 2009], las galaxias dE y dSph predominan a distancias cercanas a la galaxia principal, mientras que las galaxias dSph/dIrr están a distancias intermedias y las dIrr son distantes. NGC 2683 es la principal galaxia perturbadora del grupo estudiado aquí y muestra evidencia de reciente acumulación de gas externo [Vollmer et al., 2016]. La interacción de marea entre KK 69 y la cercana galaxia espiral NGC 2683 también puede ser responsable del desplazamiento observado entre la región de alta densidad estelar y la región de alta densidad del H I.

Teniendo en cuenta todo lo anterior, probablemente, KK 69 sea una galaxia enana de transición, pero hasta ahora, la información necesaria para discutir este tema en detalle no es suficiente.

\subsection{Resumen}

De las observaciones de H I de la galaxia enana KK 69 obtenidas con GMRT encontramos que la mayor parte del gas se encuentra desplazado a $\sim 4,3 \mathrm{kpc}$ del cuerpo estelar de la galaxia. Si bien existe un pequeño gradiente de velocidad, los movimientos turbulentos parecen tener una amplitud similar. KK $69\left(M_{\mathrm{HI}}=4,4 \times 10^{7} \mathrm{M}_{\odot}\right)$ es probablemente una galaxia enana de transición, en el proceso de transformación de una irregular rica en gas a una esferoidal pobre en gas. Su galaxia vecina más importante es la galaxia espiral NGC $2683\left(M_{\mathrm{HI}}=1,5 \times 10^{9} \mathrm{M}_{\odot}\right)$ con signos de reciente acumulación externa de gas. Encontramos que la galaxia enana KK 69 parece estar moviéndose hacia NGC 2683, arrastrando el medio intergaláctico con ella. Consideramos que tanto el barrido de presión cinemática como las interacciones de las mareas son las responsables del desplazamiento observado entre la región estelar de alta densidad y la región de alta densidad del H I.

Usando un código de descomposición multi-gaussiano, encontramos una cantidad considerable de gas frío H I $\left(M_{\mathrm{CNM}}=8,4 \pm 0,09 \times 10^{6} \mathrm{M}_{\odot}\right)$. Los datos nos permitieron apilar los espectros H i para incluir más regiones y así mejorar la SNR para nuestro análisis de medio interestelar. Hemos detectado dos fases del MIE, el WNM y el CNM, donde WMN es el predominante como se espera. Sin embargo, al menos $19 \%$ del gas 
total está en la fase CNM.

Mediciones de las velocidades de la componente estelar podrían confirmar si el gas H I está efectivamente asociado a la componente estelar observada. Futuras observaciones de rayos $\mathrm{X}$ podrían aportar información sobre la existencia de gas caliente intragrupo y contribuir al estudio de la relación entre la presencia de gas caliente y el estado evolutivo del grupo de galaxias [Desjardins et al., 2013]. 
5. KK 69, una galaxia enana en transición 


\section{Capítulo 6}

\section{La galaxia Fourcade-Figueroa}

En este capítulo, presentamos el estudio de la galaxia Fourcade-Figueroa (FF). La combinación de nuevas observaciones en H I (GMRT) con datos previos (ATCA) fue una excelente oportunidad para aprender más en detalle sobre la técnica de síntesis de apertura. La distribución del H I y los mapas de velocidades de la galaxia FF muestran un pequeña asimetría respecto del semieje mayor en la componente noroeste del disco de la galaxia. Dado que FF está ubicada detrás del lóbulo sur de Cen A (NGC 5128) y su velocidad relativa a NGC $5128\left(\sim 285 \mathrm{~km} \mathrm{~s}^{-1}\right)$ es demasiado alta para estar vinculada al grupo, las perturbaciones pueden haber sido originadas por una galaxia compañera enana o por eventos de formación de estrellas/supernovas. Derivamos la curva de rotación de FF con una resolución lineal de $\sim 916$ pc. El modelado de distribución de masa que mejor ajusta a la curva de rotación observada es el ajuste utilizando el modelo de distribución de materia oscura propuesto por Navarro, Frenk y White.

\subsection{Introducción}

Las simulaciones cosmológicas de halos de materia oscura (DM, por sus siglas en inglés) en galaxias predicen una distribución de densidad de masa que aumenta rápidamente hacia el centro o "cúspide", $\rho(r) \propto r^{-1}$, y que cae como $\rho(r) \propto r^{-3}$ en las partes externas [Navarro et al., 1996]. Sin embargo, la distribución de DM obtenida a través de las observaciones parece indicar que en la parte interna de las galaxias, la distribución de densidad de la DM está representada por un núcleo constante $\left(\rho(r) \propto r^{0}\right)$ [de Blok and Bosma, 2002, de Blok et al., 2008a]. Esta diferencia entre las simulaciones cosmológicas y las observaciones se conoce como "la discrepancia entre el núcleo y la cúspide" (consultar, por ejemplo, van Eymeren et al. [2009], de Blok [2007]).

Algunas galaxias de bajo brillo superficial (LSB, por sus siglas en inglés) son ricas en gas y sin actividad aparente de formación estelar significativa [de Blok, 2006]. Estas galaxias carecen de un bulbo masivo, lo que significa que es probable que las dinámicas centrales estén dominadas por la materia oscura en lugar de por las estrellas [de Blok and McGaugh, 1997]. Las curvas de rotación planas observadas en la parte exterior de las LSB son uno de los indicios observacionales de la existencia de DM [Rubin et al., 1978, McGaugh and de Blok, 1998, Banerjee et al., 2010]. Los estudios de la cinemática estelar y del H i en galaxias enanas o LSB son importantes para derivar restricciones 


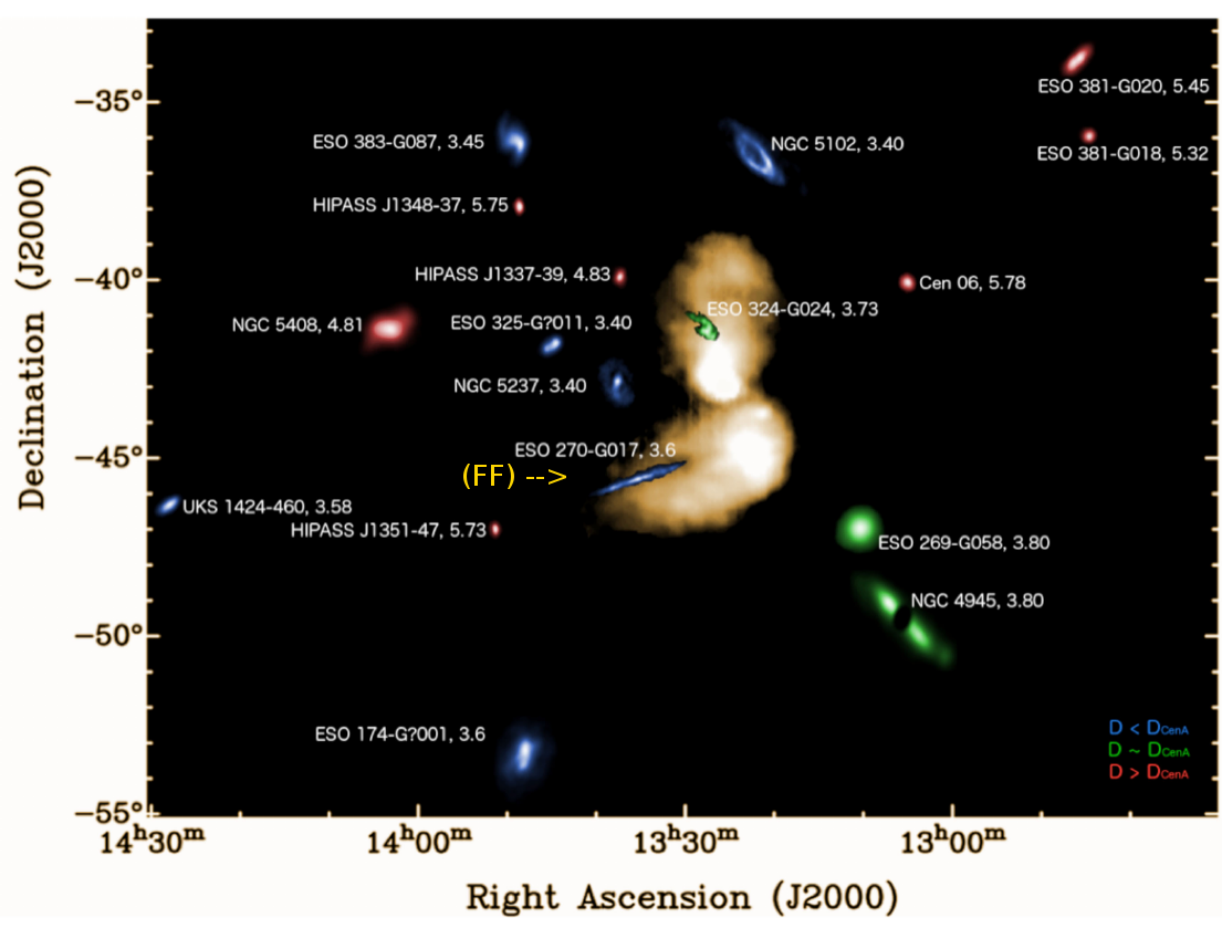

Figura 6.1: El grupo de galaxias Cen A por Johnson et al. [2015]. En este trabajo, los autores consideran que la distancia a la galaxia $\mathrm{FF}$ es de $\sim 4 \mathrm{Mpc}$.

en la distribución de DM.

\subsubsection{La galaxia Fourcade-Figueroa}

La galaxia ESO 270-G017, también conocida como FF (ver Fig. 6.1 y 6.2), fue descubierta en 1971 [Fourcade, 1971] como un objeto alargado y difuso ubicado aproximadamente a $2^{\circ} 32^{\prime}$ al sureste de la radio galaxia Centaurus A (NGC 5128). Ocho años más tarde, Graham [1978] observó la galaxia utilizando el telescopio de 4 m $\mathrm{CTIO}^{1}$ y concluyó que FF es una galaxia de tipo tardío, vista de canto.

Hasta el año 2013, se consideraba que la distancia de la galaxia FF era de $\sim 4 \mathrm{Mpc}$, determinada mediante la relación empírica de Tully-Fisher (TF); dicho valor es similar a la distancia de NGC 5128 (3,8 \pm 0,34 Mpc, ver Sérsic [1960]). Por lo tanto, Colomb et al. [1984] y Thomson [1992] atribuyeron la asimetría observada en la parte noroeste de la galaxia FF como el resultado de la interacción gravitacional entre FF y la galaxia NGC 5128. En un trabajo más reciente, se determinó una nueva distancia utilizando el TRGB, posicionándola en el fondo sin vecinos conocidos a 6,94 Mpc [Tully et al., 2013]. La velocidad de FF relativa a NGC $5128\left(285 \mathrm{~km} \mathrm{~s}^{-1}\right)$ podría ser demasiado alta para estar vinculada al Grupo Centaurus.

Usando la distancia TRGB calculamos la magnitud azul integrada de FF, obtenien-

${ }^{1}$ IIIa-J emulsión, filtro GG385, tiempo de exposición de 45 minutos. 
Tabla 6.1: Propiedades ópticas de la galaxia Fourcade-Figueroa.

\begin{tabular}{|c|c|c|}
\hline \multicolumn{2}{|l|}{ Parameters } & Ref \\
\hline Tipo morfológico & $\mathrm{SB}(\mathrm{s}) \mathrm{m}$ & (1) \\
\hline Ascención recta (J2000) [h m s] & $13: 34: 47.3$ & \\
\hline Declinación (J2000) [ $\left[\begin{array}{lll}0 & \prime & \prime \prime\end{array}\right]$ & $-45: 32: 51$ & \\
\hline$D[\mathrm{Mpc}]$ & 6,9 & $(2)$ \\
\hline$m_{\mathrm{B}}$ & 11,7 & (3) \\
\hline$D_{\mathrm{B} 25}[\mathrm{kpc}]$ & 15,12 & (3) \\
\hline$A_{\mathrm{B}}$ & 0,48 & (4) \\
\hline$M_{\mathrm{B}}[\mathrm{mag}]$ & -18 & $(*)$ \\
\hline$L_{\mathrm{B}}\left[10^{9} \mathrm{~L}_{\odot, \mathrm{B}}\right]$ & 2,4 & $(*)$ \\
\hline$r_{\text {eff WISE }}[\operatorname{arcsec}]$ & 231,2 & (5) \\
\hline$\mu_{\text {eff WISE }}\left[\mathrm{mag} \operatorname{arcsec}^{-2}\right]$ & 20,2 & (5) \\
\hline$P A[\mathrm{deg}]$ & 118 & (3) \\
\hline$i[\mathrm{deg}]$ & 83 & (3) \\
\hline
\end{tabular}

Referencias: (1) de Vaucouleurs et al. [1991], (2) Tully et al. [2013], (3) ESO LV [Lauberts and Valentijn, 1989], (4) Schlegel et al. [1998], (5)Wang et al. [2017], (*) calculadas en esta tesis.

do un valor de $-17,9$ mag. De las imágenes ópticas se encuentra que el cociente entre la longitud del semieje mayor con el menor es de 8,5. El valor obtenido de la magnitud azul integrada, junto con el valor de la relación del semieje mayor con el menor, nos hace pensar que, tal vez, FF es una galaxia de bajo brillo superficial sin la presencia de bulbo masivo, en donde las dinámicas centrales probablemente estén dominadas por la materia oscura en lugar de las estrellas Colomb et al. [1984], de Blok and McGaugh [1997]. De todos modos, es necesario realizar un trabajo exhaustivo para poder asegurar la hipótesis propuesta. Esto quedará como trabajo a futuro.

La galaxia $\mathrm{FF}$ es una galaxia vista de canto con una inclinación de casi $90^{\circ}$ a la cual se le puede determinar la curva de rotación utilizando la distribución del H i, así como también determinar la escala de altura (ver otros trabajos afines [Begum and Chengalur, 2004, Banerjee et al., 2010, Banerjee and Jog, 2008, 2011]).

\subsection{Observaciones y reducción de los datos}

La galaxia FF se observó a $1420 \mathrm{MHz}$ con el ATCA en 1993 y 2008 con diferentes configuraciones de antenas $^{2}$. A pesar de la existencia de observaciones previas, nuevas observaciones se llevaron a cabo en la misma frecuencia con GMRT durante el 2015. El GMRT proporciona una resolución angular y en velocidad mucho mejor que la de ATCA; los nuevos datos tomados con GMRT lograron una resolución lineal de $\sim 440$ pc (a la distancia considerada) y una resolución en velocidad de $1,7 \mathrm{~km} \mathrm{~s}^{-1}$. Como se puede ver en la Fig. 6.2, el plano uv está mejor cubierto usando ambos instrumentos.

\footnotetext{
${ }^{2}$ https://atoa.atnf.csiro.au/
} 

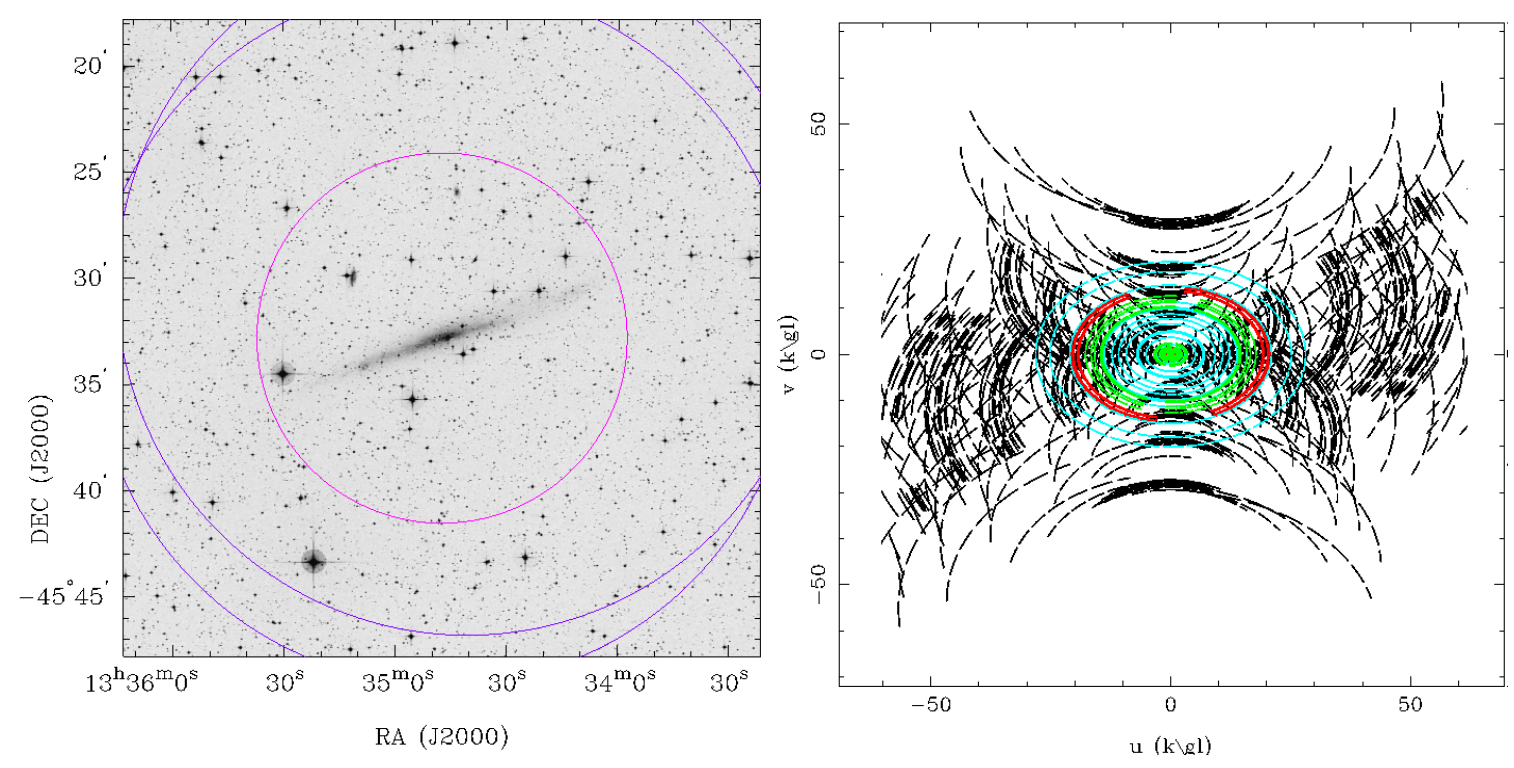

Figura 6.2: Panel izquierdo: Los haces primarios de ATCA (círculos violeta) y GMRT (círculo magenta) se superponen en la imagen DSS en la banda B. Panel derecho: La cobertura plana $u v$ de los interferómetros ATCA (colores) y GMRT (negro).

Tabla 6.2: Parámetros de las observaciones realizadas con ATCA y GMRT.

\begin{tabular}{|c|c|c|c|c|}
\hline & \multicolumn{3}{|c|}{ ATCA configuración } & \multirow[t]{2}{*}{ GMRT } \\
\hline & $750 \mathrm{~A}$ & $6 \mathrm{~A}$ & EW367 & \\
\hline Proyecto & $\overline{\mathrm{C} 245}$ & $\overline{\mathrm{C} 245}$ & C1341 & $28 \_069$ \\
\hline \multirow[t]{4}{*}{ Día } & $28-01-93$ & $28-06-93$ & $15-11-08$ & $29-06-15$ \\
\hline & $29-01-93$ & $16-07-93$ & & From $04-07-15$ \\
\hline & & & & to $07-07-15$ \\
\hline & & & & 26-01-16 \\
\hline \multirow[t]{3}{*}{ Tiempo en la fuente [min.] } & 474,9 & 588 & 597,0 & 195 \\
\hline & & 544 & & 501 \\
\hline & & & & 196 \\
\hline Frecuencia central $[\mathrm{MHz}]$ & 1417 & 1417 & 1417 & 1414 \\
\hline Ancho de banda $[\mathrm{MHz}]$ & 8 & 8 & 8 & 4,16 \\
\hline Nro. de canales & 512 & 512 & 512 & 512 \\
\hline$\Delta \mathrm{S}\left[\mathrm{mJy} \mathrm{haz}^{-1}\right]$ & 2,8 & 1,5 & 2,5 & 1,1 \\
\hline Ancho de canales $\left[\mathrm{km} \mathrm{s}^{-1}\right]$ & 3,3 & 3,3 & 3,3 & 1,8 \\
\hline Resolución en velocidad $\left[\mathrm{km} \mathrm{s}^{-1}\right]$ & 4 & 4 & 4 & 1,8 \\
\hline HPBW ['] & & 33 & & 26,6 \\
\hline
\end{tabular}


Tabla 6.3: Calibradoras - valores coincidentes con un error del $10 \%$.

\begin{tabular}{|r|c|c|}
\hline Fuente & VLA flujo de referencia [Jy] & Nuestras calibraciones [Jy] \\
\hline \hline GMRT & 15 & \\
\hline \hline Calibradora de flujo 3C286 & $3 \pm 2 \times 10^{-3}$ & $14,8 \pm 2 \times 10^{-4}$ \\
Calibradora de fase 1323-448 & $2,8 \pm 2 \times 10^{-4}$ \\
\hline \hline ATCA & ATCA flujo de referencia [Jy] & \\
\hline \hline 750 & $14,46 \pm 7 \times 10^{-3}$ & $15,5 \pm 3 \times 10^{-3}$ \\
Calibradora de flujo 0407-658 & $3,0 \pm 9 \times 10^{-3}$ & $3,1 \pm 3 \times 10^{-3}$ \\
Calibradora de fase 1320-446 & & $15,5 \pm 1 \times 10^{-2}$ \\
\hline $6 \mathrm{~A}$ & & $3,2 \pm 1 \times 10^{-2}$ \\
Calibradora de flujo 0407-658 & & $15,5 \pm 1 \times 10^{-2}$ \\
Calibradora de fase 1320-446 & & $3,0 \pm 1 \times 10^{-3}$ \\
Calibradora de flujo 0407-658 & & $14,8 \pm 3 \times 10^{-3}$ \\
Calibradora de fase 1320-446 & & $8 \pm 2 \times 10^{-2}$ \\
\hline EW367 & & \\
Calibradora de flujo 1934-638 & $14,8 \pm 2 \times 10^{-3}$ & \\
Calibradora de fase 1421-490 & $8,3 \pm 3 \times 10^{-2}$ & \\
\hline
\end{tabular}

\subsubsection{Datos de archivo del "Australia Telescope Compact Array"}

Las observaciones con ATCA a $1420 \mathrm{MHz}$ se llevaron a cabo en Enero de 1993, Junio y Julio de 1993 y Noviembre de 2008 utilizando las siguientes configuraciones de antenas: 750, 6A y EW367, respectivamente. El tiempo total de integración en la fuente fue de 27,75 horas. El ancho de banda de $8 \mathrm{MHz}$ dividido en 512 canales resulta en una resolución espectral de $15,6 \mathrm{kHz}$, equivalente a $4 \mathrm{~km} \mathrm{~s}^{-1}$ por canal. Los datos obtenidos con la configuración EW367 dieron lugar al "Local Volume H i Survey (LVHIS)" [Koribalski et al., 2018a]. El calibrador de flujo se observó al principio y al final mientras que el calibrador de fase se observó entre las observaciones de la galaxia FF (ver Tablas 6.2 y 6.3 para más detalles).

La reducción de los datos y el análisis de los mismos se realizaron con el software MIRIAD mediante procedimientos estándar. Cada conjunto de datos fue calibrado por separado utilizando a la fuente PKS 0407-658 (arreglo 750/6A) y a la fuente PKS 1934638 (arreglo EW367) como calibradores de flujo primario y de pasabanda, respectivamente. PKS 1320-446 (arreglo 750/6A) y PKS 1421-490 (arreglo EW367) sirvieron como calibradores de fase. Las densidades de flujo medidas concuerdan dentro del $10 \%$ del error y se muestran en la Tabla 6.3. Utilizamos la tarea de MIRIAD UVLIN para restar el continuo. Con un ancho de banda de $8 \mathrm{MHz}$ (consulte la Tabla 6.2), pudimos seleccionar los canales sin línea en ambos lados de la emisión del H I detectado. Las imágenes se realizaron considerando una ponderación natural y robusta. Dado que nuestro objetivo era combinar los datos de ATCA con los datos GMRT, presentamos en esta subsección los mapas de momentos así como los mapas de canales de tres cubos de imágenes diferentes, que serán importantes en el proceso de combinación. Para el primer cubo, con la resolución más baja, se excluyeron las líneas de base más largas de la antena CA06 y se utilizó la ponderación natural, con el fin de mejorar la sensibili- 

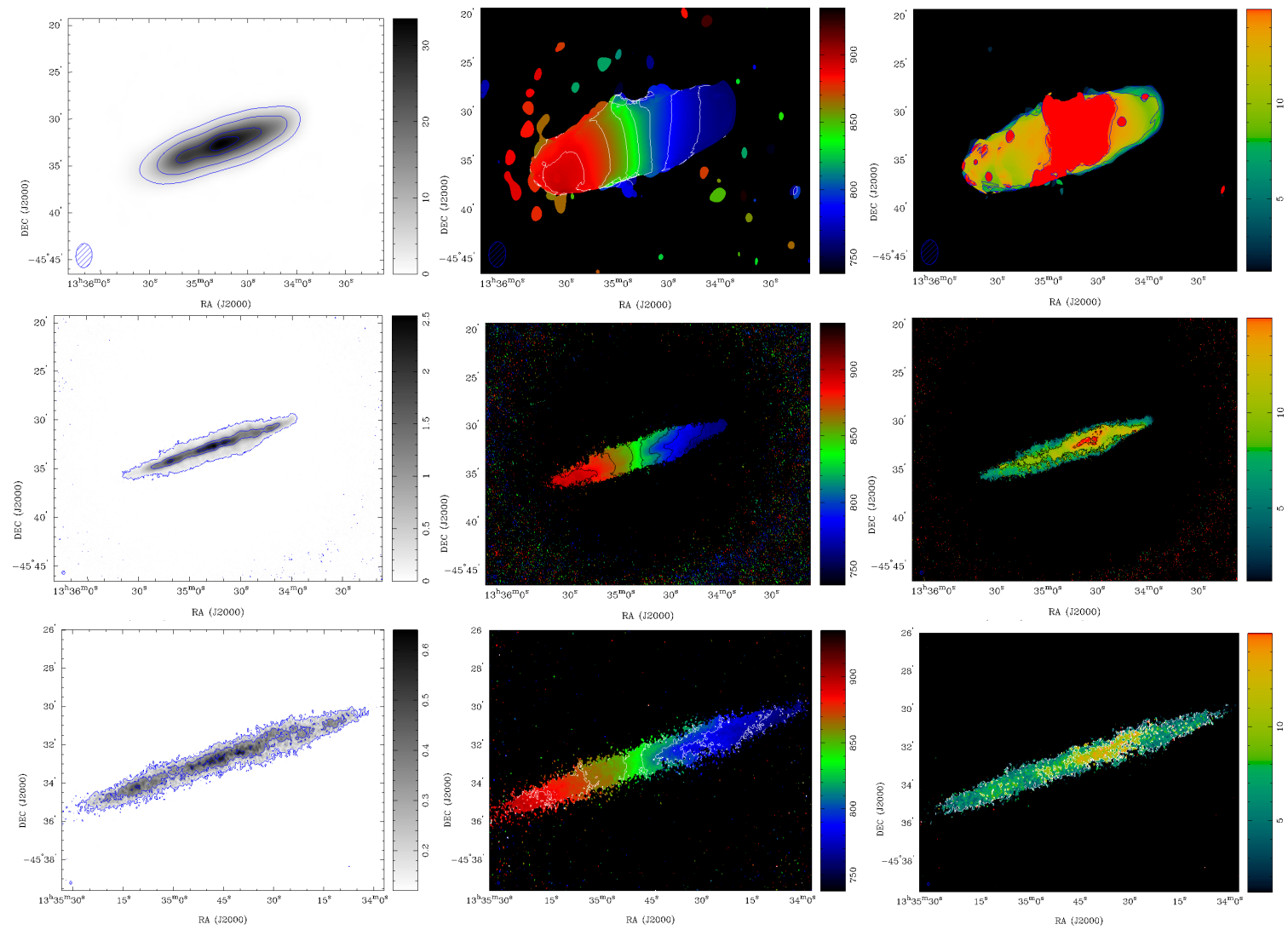

Figura 6.3: Mapas de momentos ATCA con diferentes resoluciones angulares de la galaxia Fourcade-Figueroa. Primer fila: imágenes de baja resolución realizadas usando una ponderación natural sin la antena 6 de ATCA (CA06). El haz sintetizado de $154^{\prime \prime} .8 \times 103^{\prime \prime} .9$ se muestra en la esquina inferior izquierda de cada panel. Panel izquierdo: distribución del HI; los niveles de contorno son 0,072; 0,024;0,055;0,072 $\mathrm{Jy} \mathrm{haz}^{-1}$; Panel central: campo de velocidad; los niveles de contorno son 768; 788; 808; 828; 848; 868; $888 \mathrm{~km} \mathrm{~s}^{-1}$; Panel derecho: dispersión de velocidad; los niveles de contorno son $3 ; 8,9 ; 14,53 \mathrm{~km} \mathrm{~s}^{-1}$. Segunda fila, usando ponderación natural con CA06; el haz sintetizado de $20^{\prime \prime} .5 \times 18^{\prime \prime} .7$ se muestra en la esquina inferior izquierda de cada panel. Panel izquierdo: distribución H I; los niveles de contorno son 0,$069 ; 1,0 ; 1,8 \mathrm{Jy} \mathrm{haz}^{-1}$. Panel central: campo de velocidad; los niveles de contorno son 768; 788; 808; 828; 848; 868; $888 \mathrm{~km} \mathrm{~s}^{-1}$; Panel derecho: dispersión de velocidad; los niveles de contorno son $3 ; 8,9 ; 14,53 \mathrm{~km} \mathrm{~s}^{-1}$. Tercera fila: imágenes con una alta resolución angular realizadas utilizando una ponderación robusta incluyendo la antena 6; el haz sintetizado de 9.'8 $\times 6$ 6.'8 se muestra en la esquina inferior izquierda de cada panel. Panel izquierdo: distribución del H I; los niveles de contorno son 0,15; 0,3;0,5 Jy haz ${ }^{-1}$. Panel central: campo de velocidad; los niveles de contorno son $768 ; 788 ; 808 ; 828 ; 848 ; 868 ; 888 \mathrm{~km} \mathrm{~s}^{-1}$. Panel derecho: dispersión de velocidad; los niveles de contorno son $3 ; 8,9 ; 14,53 \mathrm{~km} \mathrm{~s}^{-1}$. 


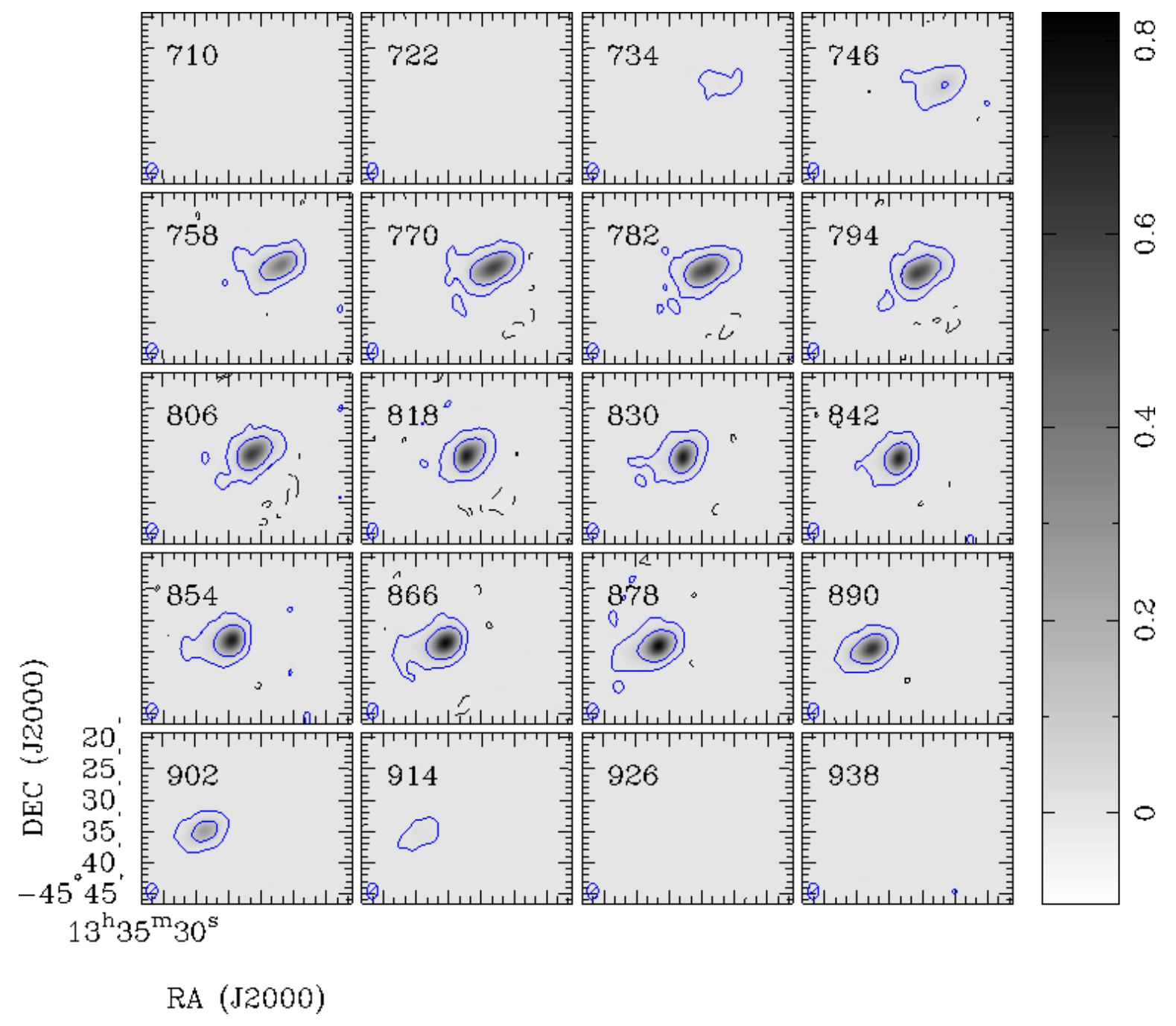

Figura 6.4: Mapas de H i por canales de baja resolución de la galaxia Fourcade-Figueroa. La velocidad del canal se muestra en la esquina superior izquierda (en $\mathrm{km} \mathrm{s}^{-1}$ ) y el haz sintetizado, en la esquina inferior izquierda de cada panel. Los niveles de contorno son $\pm 6,9 ; 11,5$ mJy haz $^{-1}$. 


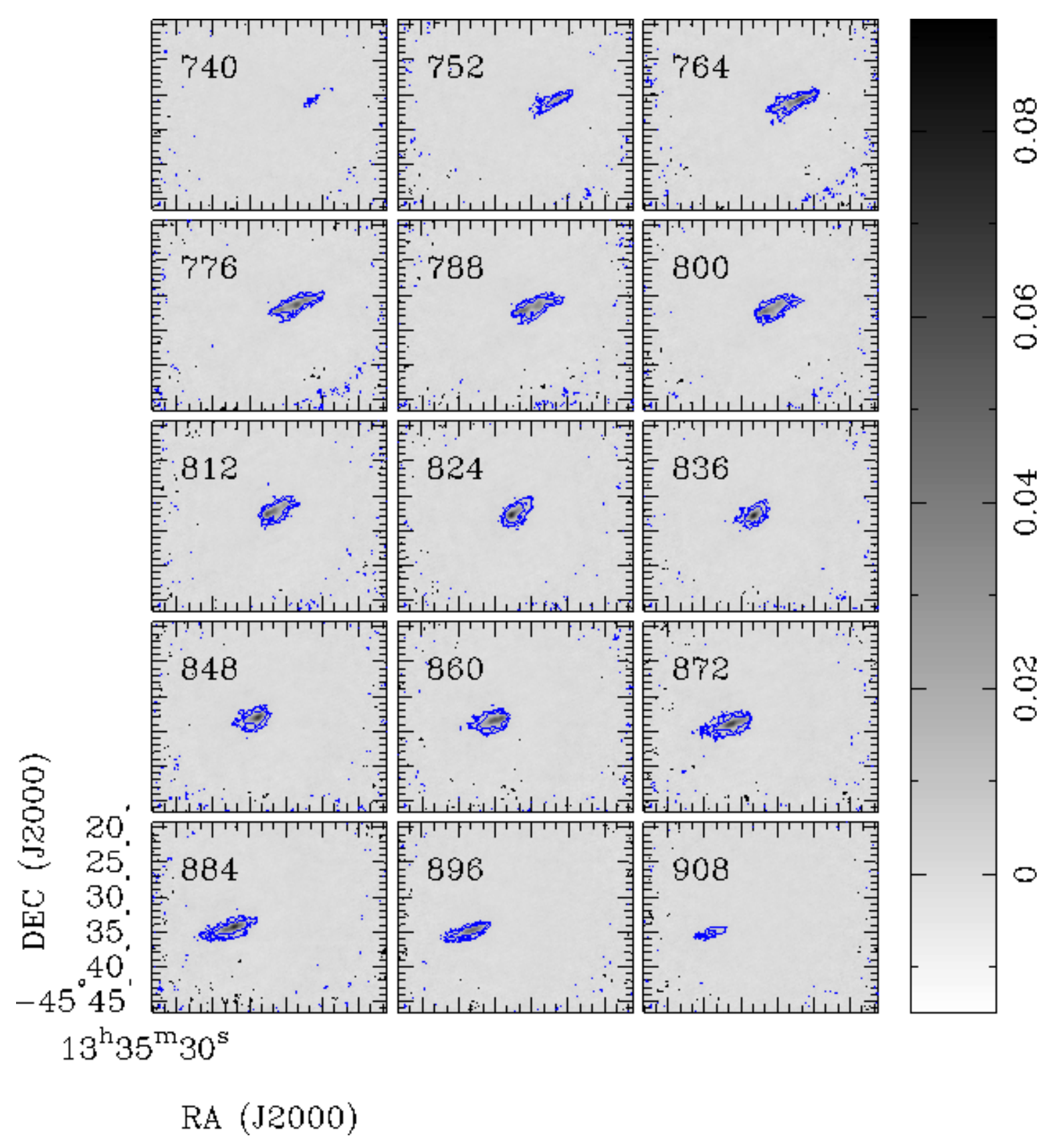

Figura 6.5: Mapas de H I por canales con una resolución angular intermedia de la galaxia Fourcade-Figueroa. La velocidad del canal se muestra en la esquina superior izquierda (en $\mathrm{km} \mathrm{s}^{-1}$ ) de cada panel. Los niveles de contorno son $\pm 3,75 ; 9 \mathrm{mJy} \mathrm{haz}^{-1}$. 


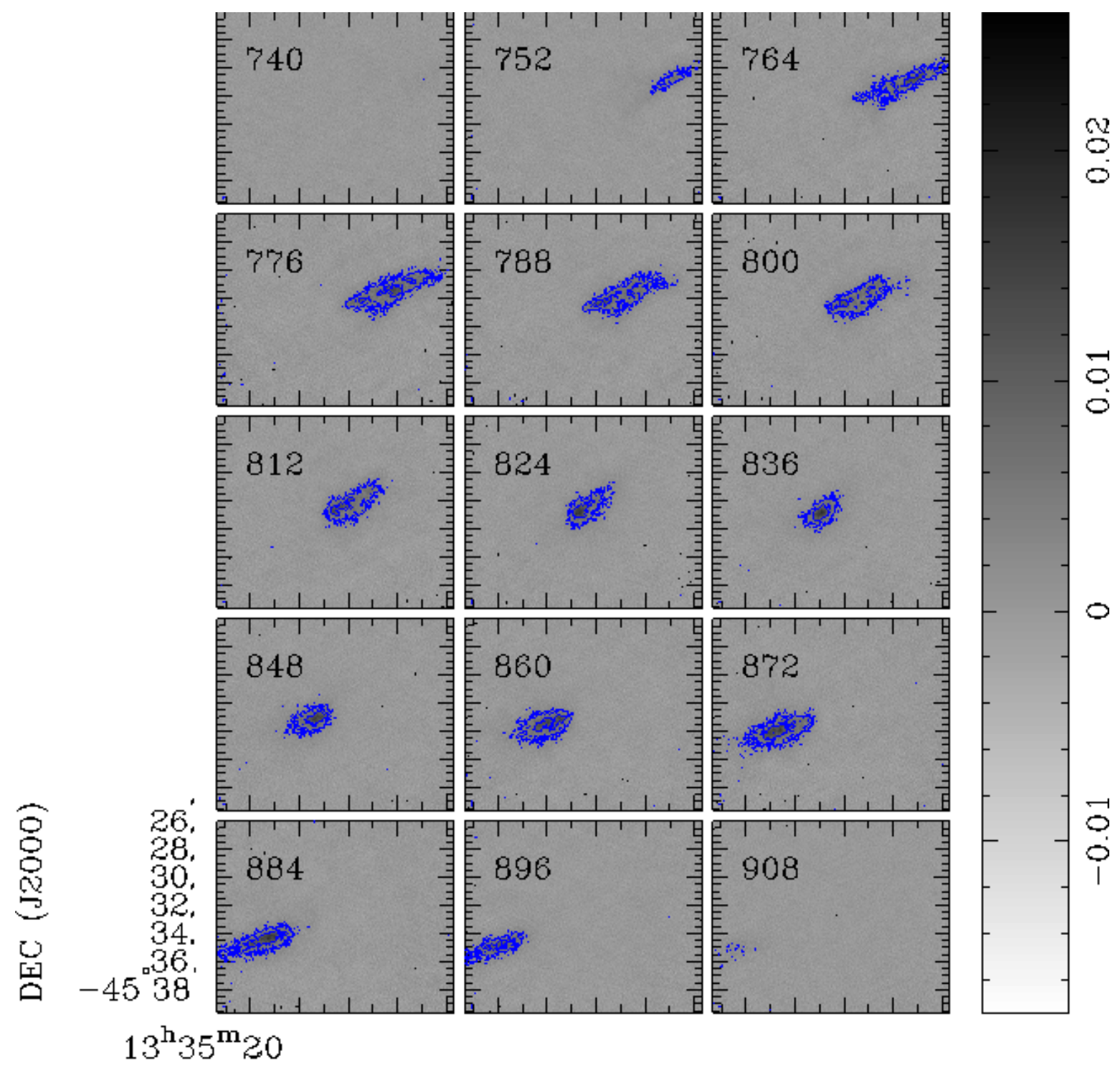

RA (J2000)

Figura 6.6: Mapas de H i por canales de alta resolución de la galaxia Fourcade-Figueroa. La velocidad del canal se muestra en la esquina superior izquierda (en $\mathrm{km} \mathrm{s}^{-1}$ ) de cada panel. Los niveles de contorno son $\pm 3,75 ; 9 \mathrm{mJy} \mathrm{haz}^{-1}$. 
dad y detectar la emisión difusa extendida del H I. El haz sintetizado resultante fue de $154^{\prime \prime} .8 \times 103^{\prime \prime} .9$ y medimos un r.m.s. de $2,8 \times 10^{-3}$ mJy haz $^{-1}$ por canal (ver Figs. 6.3 y 6.4 ). En la segunda, no se excluyó la antena CA06 y se implementó una ponderación natural. El haz sintetizado fue de $20^{\prime \prime} .5 \times 18^{\prime \prime} .7$ con un un r.m.s. de $2,3 \times 10^{-3} \mathrm{mJy} \mathrm{haz}^{-1}$ por canal (ver Figs. 6.3 y 6.5). En el tercero, se utilizaron todas las líneas de base y se realizó la ponderación uniforme. El haz sintetizado es de 9!.8 $\times 66^{\prime \prime} 8$ con un r.m.s. de $2,3 \times 10^{-3} \mathrm{mJy} \mathrm{haz}^{-1}$ (ver Figs. 6.3 y 6.6). Como los conjuntos de datos tienen dos centros de observaciones diferentes, marcados en la Fig. 6.2, se produjo una imagen de mosaico.

\subsubsection{Datos obtenidos con el "Giant Metrewave Radio Teles- cope"}

Observamos la galaxia FF con GMRT a $1420 \mathrm{MHz}$ durante un tiempo total de 11,5 horas. Las observaciones se llevaron a cabo durante el mes de noviembre 2015 en el modo de zoom espectral con el software GMRT backend. Utilizamos un ancho de banda de $4,16 \mathrm{MHz}$ con 512 canales, lo que resulta en una resolución espectral de $8,13 \mathrm{kHz}$, equivalente a $1,7 \mathrm{~km} \mathrm{~s}^{-1}$ por canal. El calibrador de flujo $3 \mathrm{C} 286 \mathrm{se}$ observó al principio y al final. La fuente 1323-448 se utilizó como calibrador de fase y se observó entre las observaciones de la galaxia FF (ver la Tabla 6.2 para más detalles).

Los datos se calibraron utilizando el "pipeline" FLGCAL. Además, utilizamos para análisis adicionales, visualización y creación de imágenes de longitud de onda múltiple los paquetes del software MIRIAD y de kvis, parte del paquete karma. Para verificar el proceso de calibración, se tomaron imágenes de todas las fuentes del calibrador. Los flujos medidos se muestran en la Tabla 6.3. GMRT no hace correciones Doppler durante las observaciones. Por lo tanto, la tarea CVEL se implementó para aplicar esas correcciones. Todos los conjuntos de datos se combinaron utilizando la tarea de AIPS DBCON.

La configuración GMRT genera información tanto en escalas angulares grandes como pequeñas. Para probar la estructura $\mathrm{H}$ i en varias escalas espaciales, creamos una imagen del cubo de visibilidad utilizando ponderaciones diferentes (natural y robusta) y a diferentes resoluciones espaciales estableciendo los límites de reducción de forma adecuada. En esta subsección, presentamos las imágenes de baja y alta resolución $\mathrm{H} \mathrm{I}$, realizadas en rangos de $0-5 \mathrm{k} \lambda$ con ponderación natural y $0-15 \mathrm{k} \lambda$ con ponderación uniforme. Los cubos de imágenes se produjeron utilizando la tarea AIPS IMAGR, y los canales individuales se inspeccionaron utilizando la tarea TVMOVIE para identificar los canales con emisión del H i. Utilizamos la tarea AIPS IMLIN para restar el continuo. Ejecutamos APCLN para producir el cubo final de imágenes.

La función de visibilidad definida como una transformada de Fourier 2D es correcta en el caso de un arreglo este-oeste (por ejemplo, ATCA). Sin embargo, dado que las matrices de configuración están diseñadas para maximizar la cobertura de $u v$, se implementa la configuración en forma de 'Y' de las antenas, y con ello, aparece el problema de líneas de base no coplanares. 

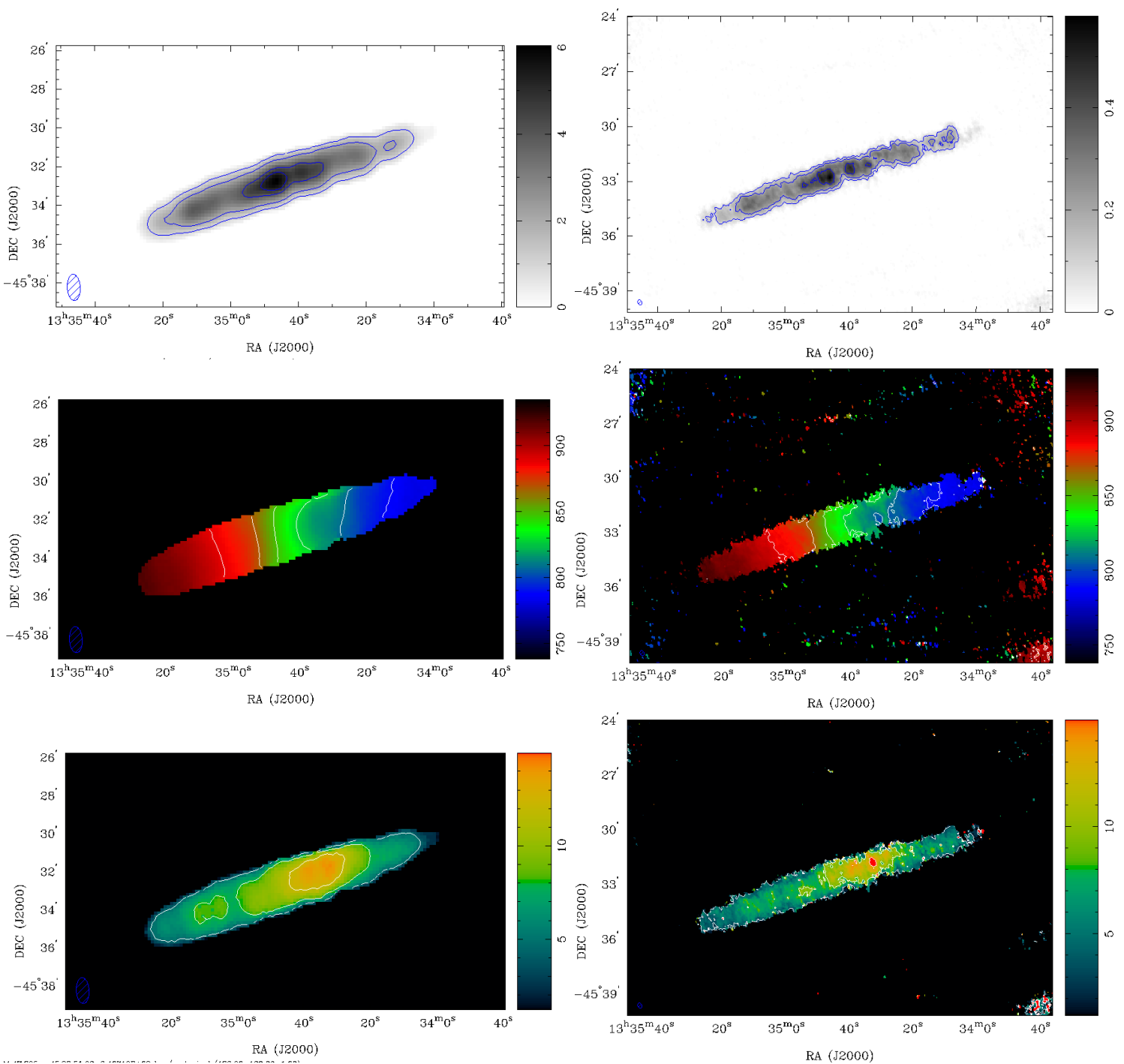

Figura 6.7: Mapas de momento de $\mathrm{H}$ I realizadas con diferentes resoluciones angulares de la galaxia Fourcade-Figueroa (datos GMRT). Primera columna: imágenes con baja resolución angular realizados con una ponderación natural (hasta $5 \mathrm{k} \lambda$ ). El haz sintetizado de $81^{\prime \prime} .49 \times 40^{\prime \prime} .35$ se muestra en la esquina inferior izquierda de cada panel. Primera fila: Distribución del H I; los niveles de contorno son 1;2; 4; $5 \mathrm{Jy} \mathrm{haz}^{-1}$. Fila central: campo de velocidad; los niveles de contorno son $768 ; 788 ; 808 ; 828 ; 848 ; 868$; $888 \mathrm{~km} \mathrm{~s}^{-1}$. Tercera fila: dispersión de velocidad; los niveles de contorno son 4.5, 8, $12 \mathrm{~km} \mathrm{~s}^{-1}$. Segunda columna: imágenes con alta resolución, con una ponderación natural (hasta $15 \mathrm{k} \lambda$ ); el haz sintetizado de $17^{\prime \prime} .31 \times 13^{\prime \prime} .34$ se muestra en la parte inferior izquierda de cada panel. Primera fila: H I distribución; los niveles de contorno son 0,1;0,2;0,4 $\mathrm{Jy} \mathrm{haz}^{-1}$. Fila central: campo de velocidad; los niveles de contorno son $768 ; 788 ; 808 ; 828 ; 848 ; 868 ; 888 \mathrm{~km} \mathrm{~s}^{-1}$. Tercera fila: dispersión de velocidad; los niveles de contorno son $3 ; 8,9 ; 14,5 \mathrm{~km} \mathrm{~s}^{-1}$. 


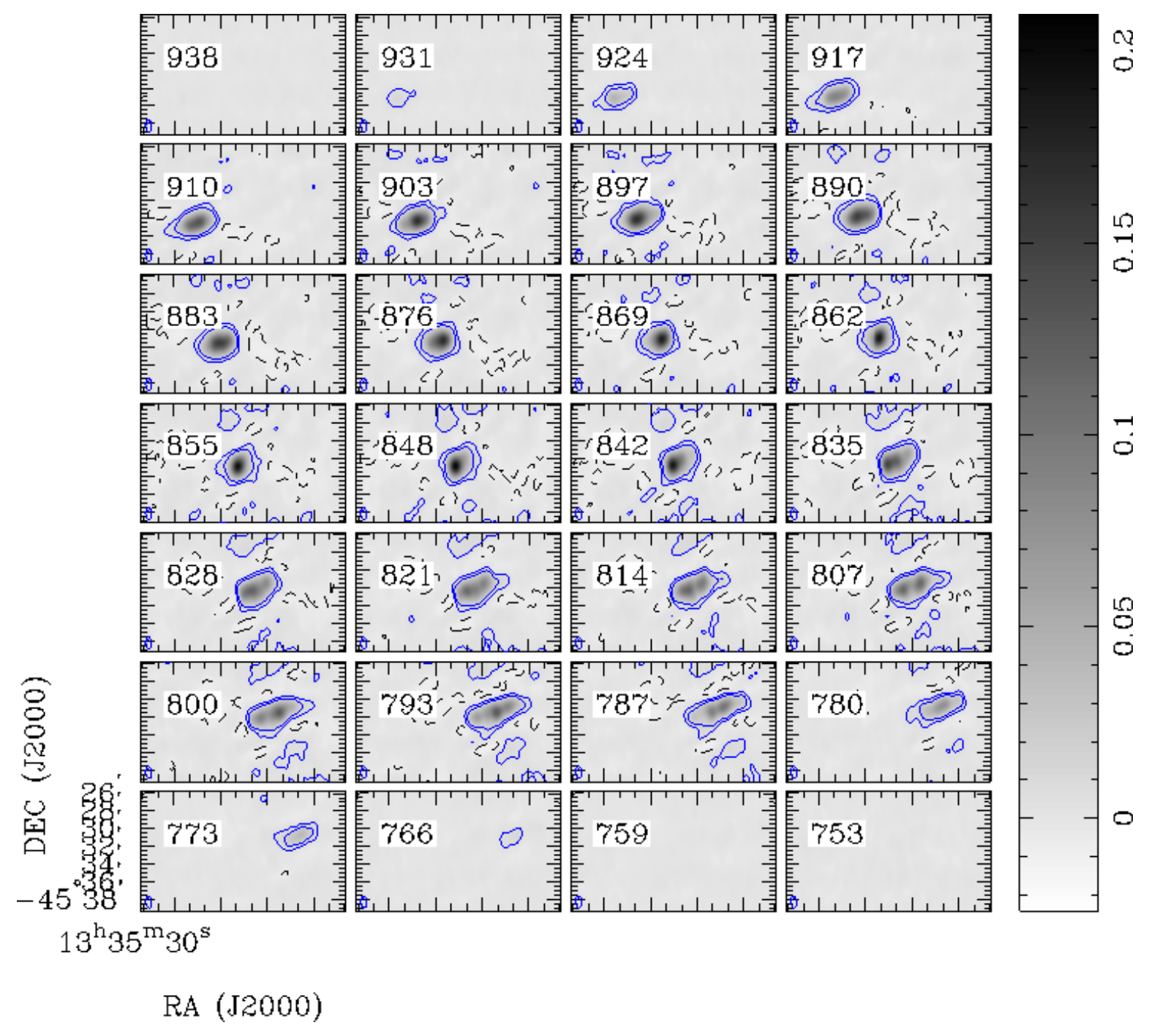

Figura 6.8: Mapas de H i por canales de baja resolución de la galaxia Fourcade-Figueroa. La velocidad del canal se muestra en la esquina superior izquierda (en $\mathrm{km} \mathrm{s}^{-1}$ ) y el haz sintetizado en la esquina inferior izquierda de cada panel. Los niveles de contorno son $\pm 10 ; 45$ mJy haz ${ }^{-1}$. 


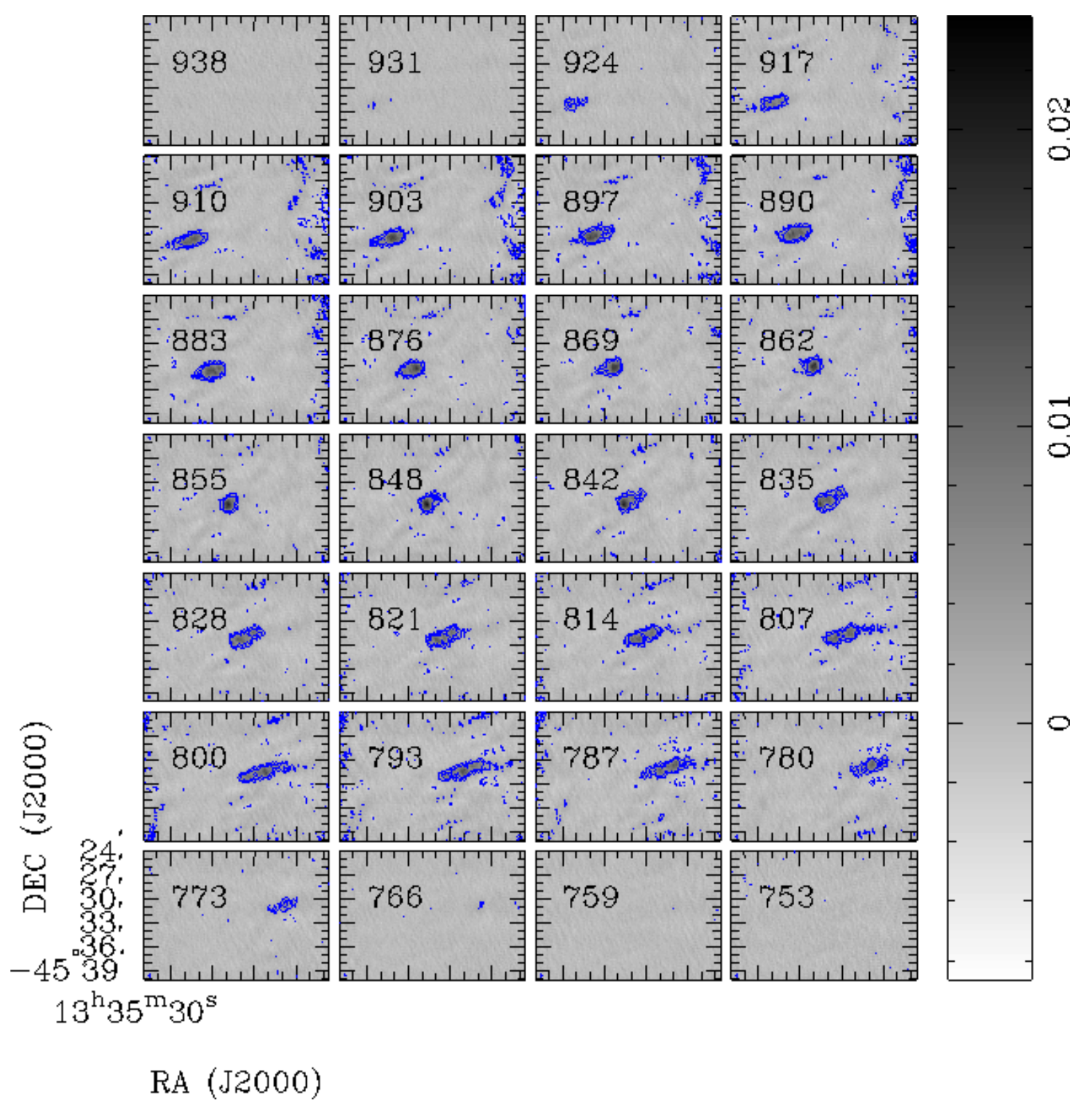

Figura 6.9: Mapas de H i por canales de alta resolución de la galaxia Fourcade-Figueroa. La velocidad del canal se muestra en la esquina superior izquierda (en $\mathrm{km} \mathrm{s}^{-1}$ ) y el haz sintetizado en la esquina inferior izquierda de cada panel. Los niveles de contorno son $\pm 10 ; 45$ mJy haz ${ }^{-1}$. 
Este efecto también se conoce como el problema "w-term" y causa un cambio en la posición de una fuente en el plano de la imagen. La distorsión es más considerable si la fuente está ubicada a una distancia significativa del centro del campo; el cambio se puede determinar usando las fórmulas presentes en Taylor et al. [1999]. Se estimó un cambio de 2".25 para la observación de 12 con el GMRT; esta corrección no es extremadamente importante cuando se tiene un haz de $30^{\prime \prime}$, pero es crucial para un haz de $5^{\prime \prime}$.

Se han desarrollado diferentes algoritmos para resolver este problema y algunos de ellos forman parte de los programas CASA y AIPS. En AIPS, esta corrección se puede implementar haciendo el proceso de autocalibración y usando la tarea FACETS. Desafortunadamente, no pudimos realizar el proceso de autocalibración debido a la falta de fuentes continuas en el campo. Llegamos a la conclusión de que este problema no afectará a los cubos de imagen si solo usamos las visibilidades hasta 40k $\lambda$.

El haz sintetizado con baja resolución angular de los mapas de H i es de $81^{\prime \prime} .49 \times 40^{\prime \prime} .35$ con un ángulo de posición de $3,4^{\circ}$. Medimos un r.m.s. de $4.3 \times 10^{-3} \mathrm{mJy} \mathrm{haz}^{-1}$ por canal (ver la Fig. 6.8). El haz sintetizado en los mapas H I de alta resolución fue de 17 ". $31 \times 13^{\prime \prime} .34$ con un ángulo de posición de $27,9^{\circ}$. El correspondiente r.m.s. es $1.6 \times 10^{-3} \mathrm{mJy} \mathrm{haz}^{-1}$ por canal (ver la Fig. 6.9).

\subsection{Combinación de los datos de ATCA con los de GMRT.}

Las observaciones realizadas preponderando las líneas de base largas dan como resultado cubos de imagen con resolución angular alta. Sin embargo, la falta de líneas de base cortas hace que se pierda la baja emisión de brillo de la superficie H i y, por lo tanto, se subestimen sus flujos y su alcance. Aunque los pozos negativos observados en la Fig. 6.8 son un efecto común del problema mencionado, este no es el caso. Aquí, los pozos negativos son el resultado del problema de interpolación originado por la falta de datos en el muestreo del plano $u v$. Los beneficios del complemento GMRT con datos ATCA son las mejoras en el valor de la SNR en un $~ 15 \%$ y una mejor cobertura del plano $u v$ que implica una mejora en la calidad de las imágenes finales. De esta manera, sacaremos el máximo provecho de las observaciones pudiendo mapear las estructuras extendidas con una buena resolución angular.

El proceso de combinación se puede realizar en el dominio de la imagen o en el plano $u v$. En el plano $u v$, funciona mejor cuando los conjuntos de datos individuales tienen una sensibilidad similar, que es el caso si combinamos los datos utilizando todas las líneas de base ATCA (consulte la Tabla 6.4). Para evitar el problema de proyección a introducido por el "w-term" introducido por el arreglo de GMRT decidimos utilizar datos de hasta $28 \mathrm{k} \lambda$ (equivalente a $6 \mathrm{~km}$ ).

Decidimos llevar a cabo la combinación de datos en el dominio uv usando el software MIRIAD. Ambos conjuntos de datos deben tener la misma referencia del sistema de velocidad y el incremento del canal organizados de la misma manera; las tareas CVEL, SPLIT y BLOAT del software AIPS se utilizaron para resolver los problemas 


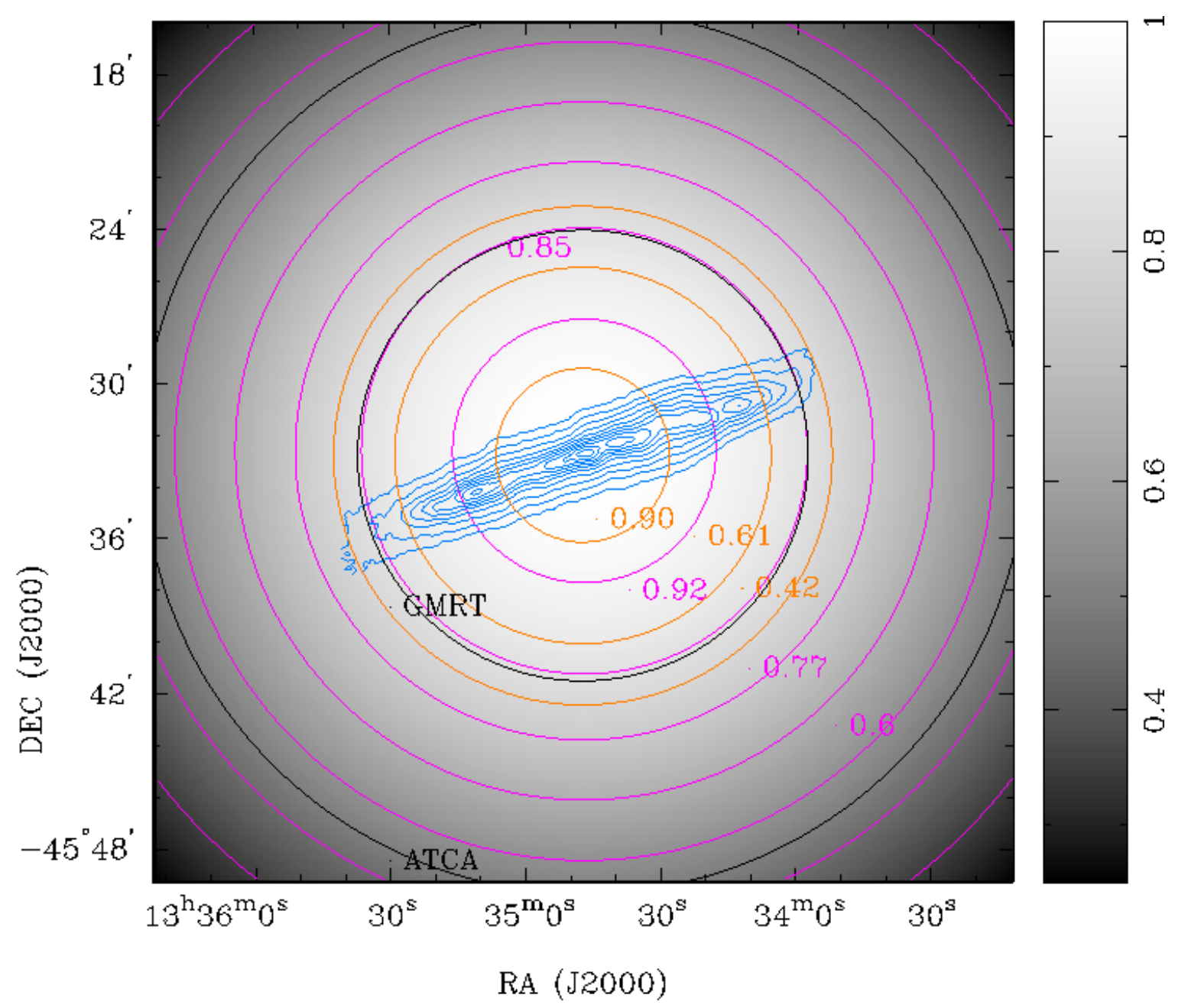

Figura 6.10: Comparación de las correcciones de haz primario (PB). A la frecuencia de $1420 \mathrm{MHz}$, el ATCA-PB es 34,21' y el GMRT-PB es 17,46’. Ambos están representados con círculos y etiquetados usando color negro. Los contornos naranjas muestran la corrección realizada a cada distancia para el GMRT-PB, mientras que los contornos rosados muestran el ATCA-PB. El mapa de intensidad H i (contornos azules) se superpone a la distribución de ganancia de ATCA-PB (escala de grises). 
Tabla 6.4: Resumen de las propiedades de los cubos de imagen obtenidos con los datos de ATCA y de GMRT.

\begin{tabular}{|c|c|c|}
\hline ATCA haz & GMRT haz & $\begin{array}{c}\text { r.m.s. } \\
\mathrm{Jy} \mathrm{haz}^{-1}\end{array}$ \\
\hline \hline $\begin{array}{c}\text { ponderación natural - CA06 } \\
154 " \times 103 "\end{array}$ & & $2,8 \times 10^{-3}$ \\
\hline & $\begin{array}{c}\text { poneración natural } \\
81 " \times 40 "\end{array}$ & $4,3 \times 10^{-3}$ \\
\hline $\begin{array}{c}\text { ponderación natural + CA06 } \\
20 " \times 18 "\end{array}$ & $\begin{array}{c}\text { ponderación uniforme } \\
17^{\prime \prime} \times 13 "\end{array}$ & $2,3 \times 10^{-3}$ \\
\hline & & $2,3 \times 10^{-3}$ \\
\hline $\begin{array}{c}\text { ponderación uniforme } \\
9 " \times 6 "\end{array}$ & & $2 \times 10^{-3}$ \\
\hline
\end{tabular}

Notas: El ancho del canal de ATCA es $4 \mathrm{~km} \mathrm{~s}^{-1} \mathrm{y}$ para GMRT es 1,8 $\mathrm{km} \mathrm{s}^{-1}$; esto significa que el ancho de GMRT es menor a dos veces el de ATCA. El r.m.s será entonces $\sim \sqrt{2}$ veces mejor.

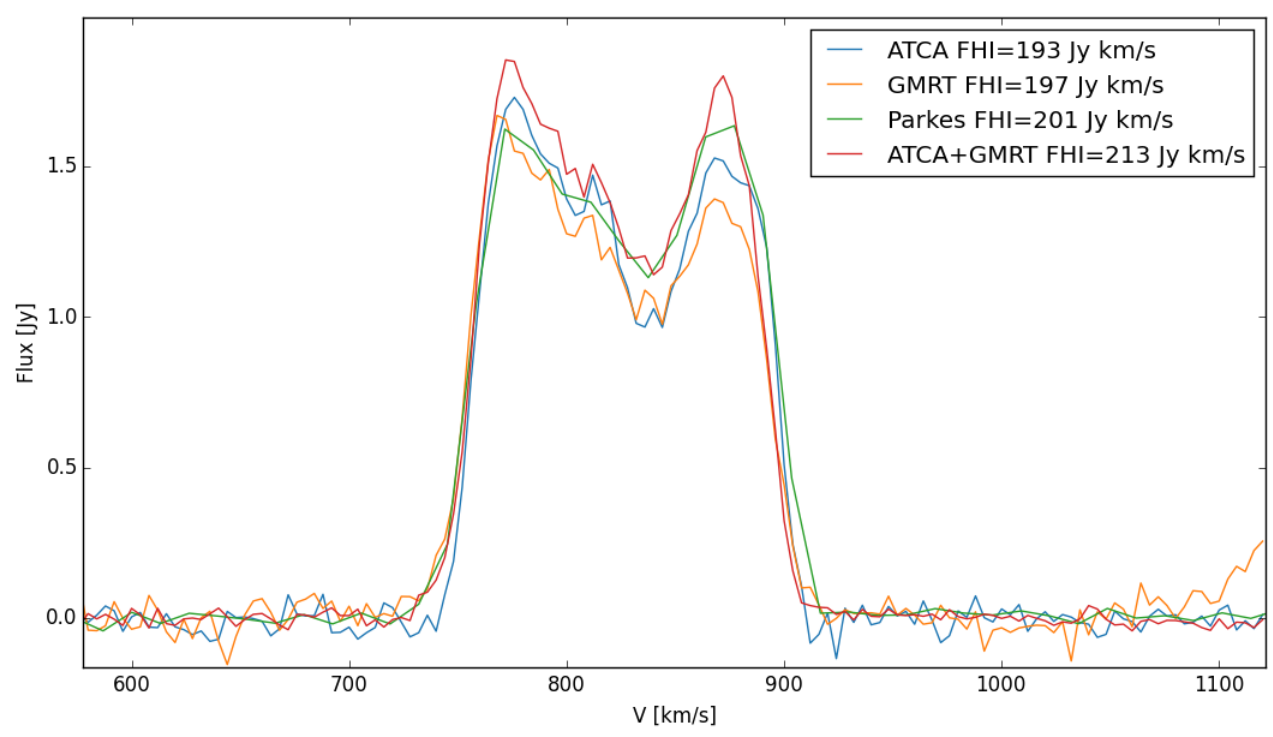

Figura 6.11: Comparaciónn del perfil global de H I de la galaxia FF obtenido con los distintos intrumentos. El flujo total obtenido utilizando datos ATCA (azul claro), datos GMRT (naranja), Parkes (verde, descargado de la base de datos NED) y la resultante de la combinación de datos ATCA y GMRT (rojo). Los flujos mostrados se estimaron utilizando el método de integración de Simpson; los consideramos como valores aproximados debido a la falta de estimaciones de error en la rutina implementada. 
mencionados.

Implementamos la rutina INVERT para realizar un mosaico de los datos GMRT y ATCA de $21 \mathrm{~cm}$. La tarea INVERT optimiza la SNR utilizando la temperatura del sistema. Para eso, una vez cargados los conjuntos de datos GMRT en MIRIAD tuvimos que agregar el valor de la temperatura del sistema en el encabezado. El valor fue tomado de la página web de GMRT. Después de convertir las mediciones de polarización circular ATCA lineal y GMRT a los parámetros de Stokes, la rutina toma las imágenes de los dos telescopios por separado y luego las combina. La deconvolución de la imagen en mosaico de $21 \mathrm{~cm}$ se realizó mediante la rutina MOSSDI. Utilizamos el software SoFiA [Serra et al., 2015b] para crear una máscara y mejorar el proceso de limpieza. El haz final sintetizado se creó utilizando la tarea MOsspsF y se aplicó durante la restauración.

El último paso a tener en cuenta es la corrección del haz primario. Como puede verse en la Fig. 6.10, el patrón del haz es diferente para cada interferómetro, y por lo tanto, la corrección aplicada. La tarea MossDi lee del encabezado, del primer conjunto de datos, el nombre del telescopio y lo utiliza para realizar la corrección del haz primario. Para corroborar la bondad de esta corrección hecha por la rutina de MIRIAD, creamos los cubos de imagen configurando primero los datos ATCA y en segundo lugar los datos GMRT y al revés. Si bien se espera que a medida que nos alejamos del centro de la imagen el problema sea más grande (o sea próximos al borde del haz primario), inspeccionamos los dos cubos de imagen canal por canal y encontramos un acuerdo entre los flujos obtenidos en cada caso. Además, el flujo H i integrado obtenido del cubo de imagen combinado es similar al valor obtenido con el plato único de Parkes de $64 \mathrm{~m}$ (ver Fig. 6.11). Esto sugiere que la corrección del haz primario se realizó con éxito.

El cubo H i de baja resolución angular se obtuvo considerando las líneas de hasta $10 \mathrm{k} \lambda$ y una ponderación uniforme. El haz sintetizado es $27^{\prime \prime} \cdot 71 \times 19^{\prime \prime} \cdot 21$, lo que resulta en un resolución física de $912 \mathrm{pc} \times 644 \mathrm{pc}$ a la distancia dada. El r.m.s. medido es de 1,6 mJy haz ${ }^{-1}$ por canal; los mapas de canales se muestran en la Fig. 6.12. El cubo de imágenes con alta resolución angular se hizo considerando líneas de base de hasta $28 \mathrm{k} \lambda$, con una ponderación uniforme. El haz sintetizado es $15^{\prime \prime} .9 \times 11^{\prime \prime}$. 3 , lo que resulta en una resolución física de 509 pc $\times 373$ pc a la distancia dada. El correspondiente r.m.s. es de $1 \mathrm{mJy} \mathrm{haz}^{-1}$ por canal.

\subsection{Resultados y Discusión}

El perfil global H I de la galaxia Fourcade-Figueroa se muestra en la Fig. 6.11. La emisión H i se detectó en el rango de velocidades entre $720 \mathrm{~km} \mathrm{~s}^{-1}$ y $920 \mathrm{~km} \mathrm{~s}^{-1}$. El flujo total de $\mathrm{H}$ I obtenido del cubo de imágenes combinado es $F_{\mathrm{HI}}=226 \pm 0,5 \mathrm{Jy} \mathrm{km} \mathrm{s}{ }^{-1}$, que está de acuerdo con el valor presente en HIPASS, $F_{\mathrm{HI}}=199 \pm 15,1 \mathrm{Jy} \mathrm{km} \mathrm{s}{ }^{-1}$ [Koribalski et al., 2004]. Es importante tener en cuenta que HIPASS sufre una calibración de pasabanda inexacta que resulta en una serie de errores en las imágenes en las proximidades a fuentes brillantes extendidas, por lo que el flujo total de FF podría ser algo mayor. A una distancia de $\sim 7 \mathrm{Mpc}$, esto corresponde a una masa $\mathrm{H}$ i total de $M_{\mathrm{HI}}=2,6 \times 10^{9} \mathrm{M}_{\odot}$. La velocidad sistémica de FF es $828 \mathrm{~km} \mathrm{~s}^{-1}$. El ancho del perfil a los niveles del $20 \%$ y $50 \%$, son $145 \mathrm{~km} \mathrm{~s}^{-1}$ y $130 \mathrm{~km} \mathrm{~s}^{-1}$ respectivamente. Estas estimaciones se realizaron utilizando la tarea MBSPECT en MIRIAD. 


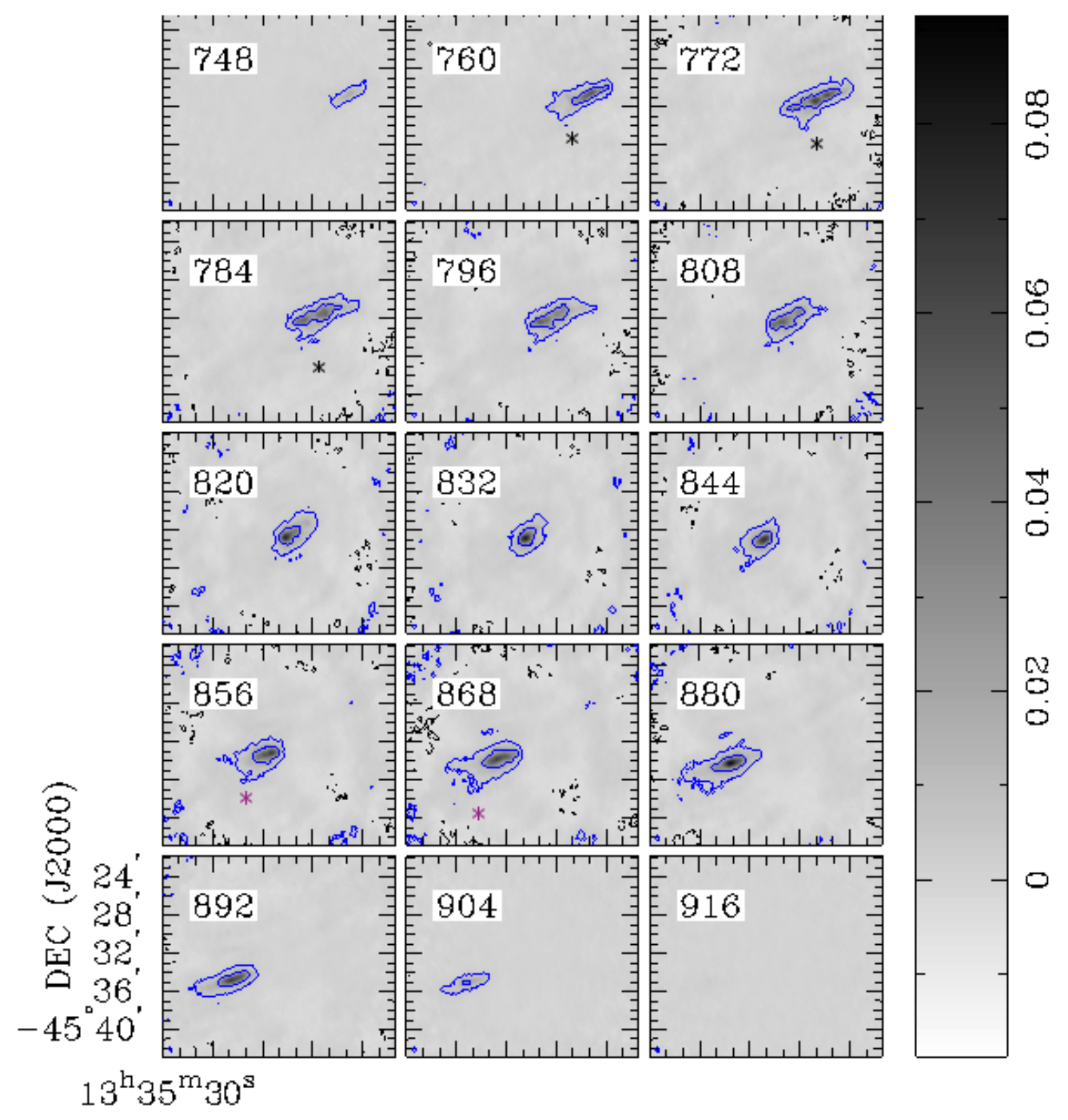

\section{RA (J2000)}

Figura 6.12: ATCA + GMRT mapas de H i por canales de alta resolución de la galaxia Fourcade-Figueroa. La velocidad del canal se muestra en la esquina superior izquierda (en $\left.\mathrm{km} \mathrm{s}^{-1}\right)$ y el haz sintetizado en la esquina inferior izquierda de cada panel $\left(15^{\prime \prime} 9 \times\right.$ $11^{\prime \prime}$.3). Los niveles de contorno son $\pm 4,5 ; 20 \mathrm{mJy} \mathrm{haz}^{-1}$. Las estrellas negras y magentas indican las posiciones de las manchas. 

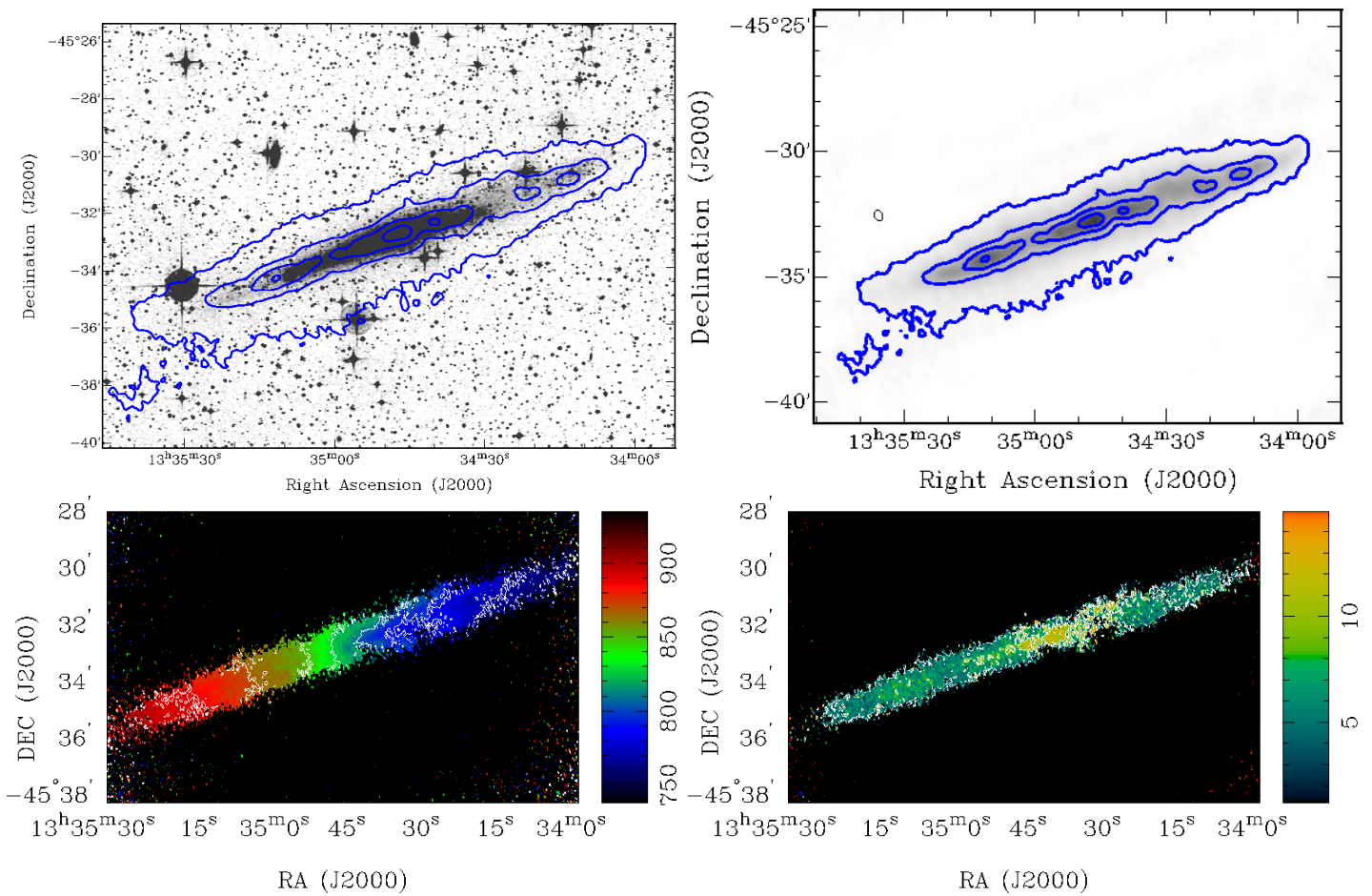

Figura 6.13: ATCA + GMRT mapas de momentos de H I de la galaxia FourcadeFigueroa. Panel superior izquierdo: distribución del H I superpuesta en la imagen de la banda I del DSS2. Los niveles de contorno H I son 0,$24 ; 0,9 ; 1,7 ; 2,1 \mathrm{Jy} \mathrm{haz}^{-1} \mathrm{~km} \mathrm{~s}^{-1}$. Panel superior derecho: distribución del H I (mismos contornos). Panel inferior izquierdo: campo de velocidad; los niveles de contorno son $768 ; 788 ; 808 ; 828 ; 848 ; 868$; $888 \mathrm{~km} \mathrm{~s}^{-1}$. Panel inferior derecho: dispersión de velocidad; los niveles de contorno son 4,$5 ; 8 ; 12 \mathrm{~km} \mathrm{~s}^{-1}$. Los mapas de distribución H I se realizaron utilizando el cubo de baja resolución con un haz sintetizado de $27^{\prime \prime} .71 \times 19^{\prime \prime} .21$ mientras que los campos de dispersión de velocidad y velocidad se realizaron utilizando el cubo de alta resolución, que corresponde a un haz sintetizado de $15^{\prime \prime} 9 \times 11^{\prime \prime} .3$. 

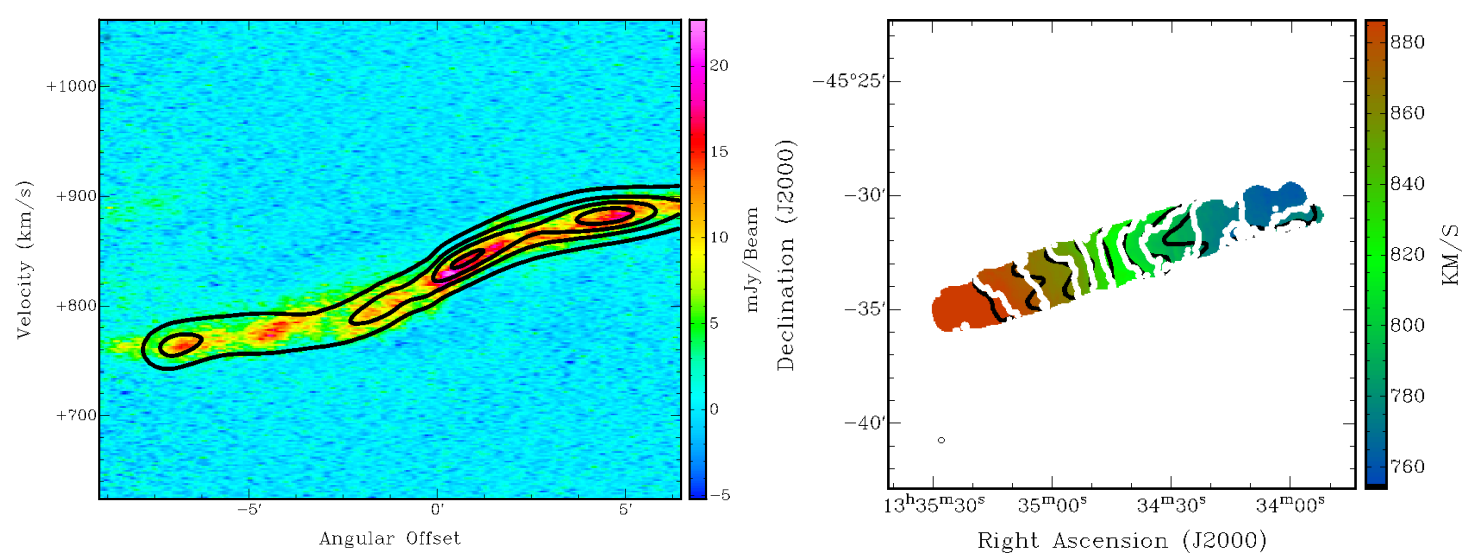

Figura 6.14: Panel izquierdo: El diagrama posición-velocidad del H i $(p v)$ a lo largo del eje mayor se muestra en colores, mientras que los niveles de contorno de $17 ; 14 ; 11$; 8; 4 mJy haz ${ }^{-1}$ representan el $p v$ de la galaxia modelada. Panel derecho: El campo de velocidad de la galaxia. Los contornos blancos son las velocidades medidas, mientras que los contornos negros son los modelados.

\subsubsection{Distribución del HI}

La distribución de Hi de la galaxia FF se presenta en la Fig. 6.13. El hidrógeno atómico se distribuye abarcando $\sim 17^{\prime}$, casi 2 veces el diámetro óptico $\left(10^{\prime}\right)$. La distribución observada se corresponde con la de un disco en rotación. El disco parece estar conformado por una componente interna más delgada de gas de H I con zonas de grumos (posiblemente los brazos espirales), abarcando $\sim 10^{\prime}$ de diámetro a lo largo del eje principal y una estructura vertical más extendida.

El disco parece significativamente deformado en la región noroeste a $\sim 4^{\prime}$ desde el centro de la galaxia, mientras que la parte sureste del disco de gas no se altera. Próximo al borde del disco gaseoso, en la parte oeste a $\sim 5^{\prime}$ de distancia al centro, se observan dos pequeñas globos de gas (ver la Fig. 6.12). Probablemente, la galaxia FF tiene un halo extendido de $\mathrm{H}$ i el cual puede haber sido originado por explosiones de supernovas [Shapiro and Field, 1976, Bregman, 1980].

\subsubsection{Cinemática, modelado $3 \mathrm{D}$ de la curva de rotación uti- lizando FAT}

La curva de rotación se derivó utilizando el código de ajuste de anillos inclinados automatizado [Kamphuis et al., 2015, FAT]. FAT se construyó sobre el código de ajuste de anillos inclinados 3D [TiRiFic, Józsa et al., 2012], un programa de computadora desarrollado para construir simulaciones espectrales astronómicas en 3D (cubos de datos) de modelos cinemáticos y morfológicos simples de discos galácticos. FAT analiza los cubos de imágenes $\mathrm{H}$ I de forma automatizada utilizando TiRiFic. Los requisitos para la implementación de FAT son que la extensión de la galaxia debe estar representada por al menos ocho haces a través del eje principal y que la inclinación debe ser mayor a $20^{\circ}$; cuanto más cerca esté de una inclinación de $90^{\circ}$, más difícil será obtener una curva de rotación precisa. 


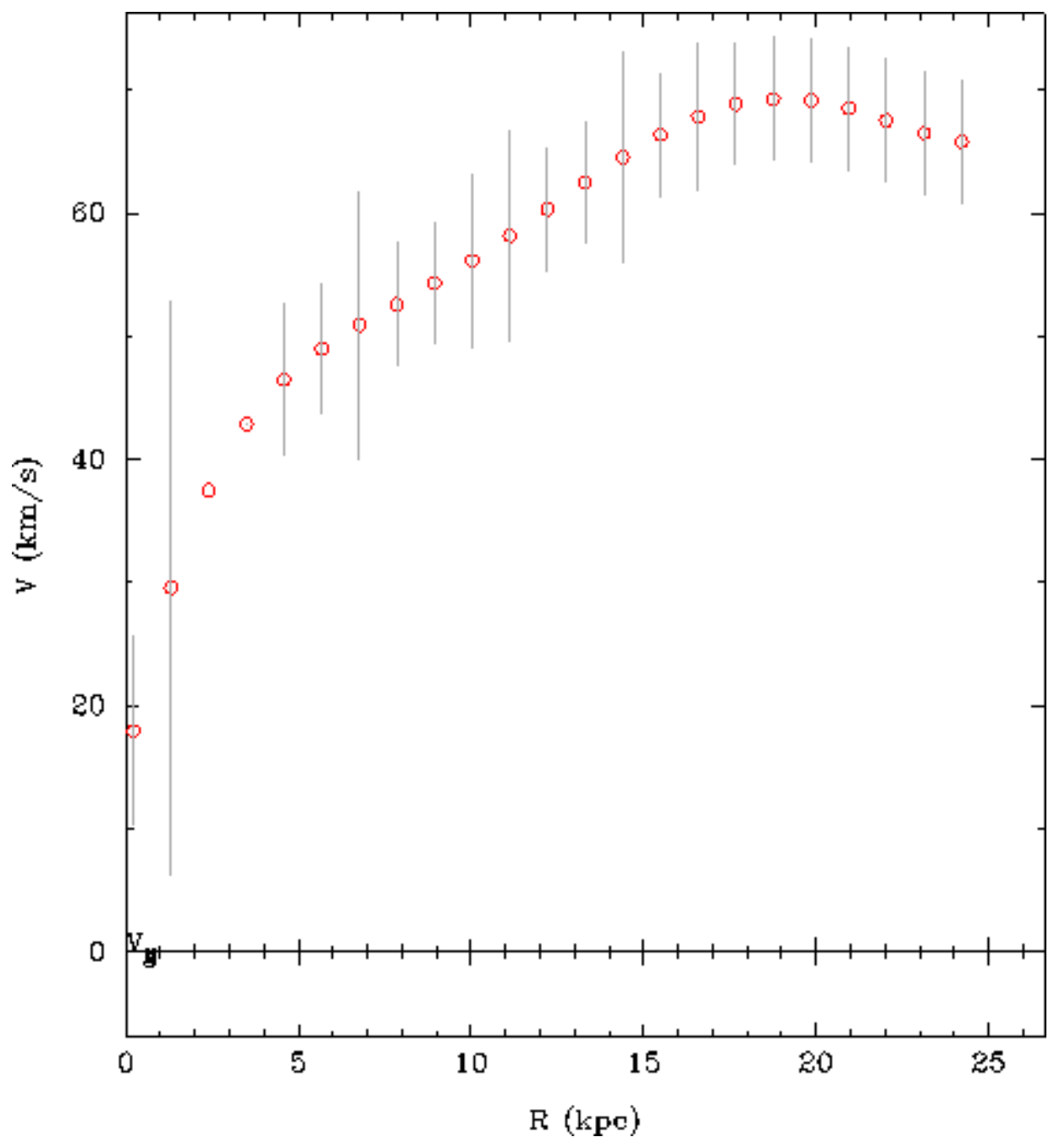

Figura 6.15: La curva de rotación de la galaxia Fourcade-Figueroa obtenida utilizando FAT. A una distancia de $\sim 7 \mathrm{Mpc}, 1^{\prime \prime}$ es equivalente a $\sim 34 \mathrm{pc}$.

A pesar de que nuestros cubos de imágenes nos permiten derivar una curva de rotación con una resolución lineal de $\sim 438$ pc, la complejidad de los mismos hace que el algoritmo FAT tenga problemas para encontrar soluciones significativas. En particular, el ángulo de inclinación era un parámetro difícil de ajustar en el proceso del modelo de galaxia, especialmente en el lado que se aproxima a nosotros, donde la galaxia está deformada. Después de varios intentos, encontramos una curva de rotación bien representativa para la galaxia FF utilizando el cubo de imagen obtenido con datos GMRT. Para verificar la validez del modelo FAT, se realizaron comparaciones entre los datos y el modelo 3D, como el mapa de canales por mapa de canales, el campo de velocidad y el diagrama de velocidad de posición $(p v)$ paralelos al eje principal. Los últimos dos se muestran en la Fig. 6.14 donde se usó el cubo en la resolución angular máxima. 


\subsubsection{Distribución de luminosidad de la galaxia FF}

La distribución de luminosidad de la galaxia FF se obtuvo utilizando el algoritmo GALFIT [Peng et al., 2002]. GALFIT le permite al usuario ajustar modelos simples, como un modelo elipsoidal, pero también puede adaptarse a situaciones más complicadas como puede ser la presencia de brazos, estructuras irregulares o espiral. Algunos parámetros fundamentales deben estar presentes en los encabezados de imagen de FITS: exposure time, instrumental gain, readnoise y la cantidad de imágenes combinadas para generar los datos (ncombine); todos ellos deben estar en las unidades correctas. Si una imagen tiene unidades de flujo (cuenta $\mathrm{s}^{-1}$ ), el valor del parámetro exptime debe ser de 1 segundo. GALFIT convierte las imágenes $\mathrm{ADU}^{3}$ en electrones usando el parámetro gain de tal manera que, en cada píxel: $\mathrm{ADU} \times$ gain $=$ electrones por píxel. Por lo tanto, si la ADU tiene unidades de [cuentas], entonces gain tiene que tener una unidad de $\left[\mathrm{e}^{-} \mathrm{ADU} \mathrm{U}^{-1}\right]$. Afortunadamente, utilizamos una imagen obtenida con el Telescopio Espacial Hubble donde todas las consideraciones mencionadas ya están implementadas en el encabezado de la imagen FIT. La imagen fue tomada con el filtro F814 por la cámara ACS WFC1. Usamos esta imagen porque mapea la población estelar más vieja y porque no se encontraron datos en bandas infrarrojas; se trató de trabajar de manera similar a los trabajos realizados por Banerjee and Jog [2008, 2011].

Para mejorar el resultado, es de vital importancia enmascarar los objetos astronómicos más brillantes en los alrededores de la fuente principal. Para esto, usamos DS9, la aplicación de visualización de imágenes y datos astronómicos ${ }^{4}$, y también dos rutinas disponibles en la página web de GALFIT. Estas rutinas son ds9poly y fillpoly.

Dado que la galaxia Fourcade-Figueroa es una galaxia vista de canto, se espera que la distribución de luminosidad esté bien descrita por

- disco visto de canto donde la función está definida como:

$$
\Sigma(r, h)=\Sigma_{0}\left(\frac{r}{r_{s}}\right) K_{1}\left(\frac{r}{r_{s}}\right) \operatorname{sech}^{2}\left(\frac{h}{h_{s}}\right),
$$

en el que el parámetro $\Sigma_{0}$ es el brillo superficial central en $\mathrm{ADU} / \mathrm{s}, r_{s}$ es la longitud de la escala y $h_{s}$ es la altura de la escala. En el caso de una galaxia de disco exponencial, la longitud de la escala es la distancia desde el centro a la cual la intensidad cae 1/e veces, y se mide a lo largo del eje mayor. La altura de la escala es la misma medida tomada a lo largo del eje menor de la galaxia. La función $K_{1}\left(r / r_{s}\right)$ es una función de Bessel modificada del segundo tipo, con respecto a $r / r_{s}$. El brillo superficial central de la galaxia, $\Sigma_{0}$, se encontró mediante el uso de la fórmula:

$$
\mu_{0}=-2,5 \log _{10}\left(\frac{\Sigma_{0}}{t_{\exp } \Delta x \Delta y}\right)+\operatorname{mag}_{z p t}
$$

donde $\mu_{0}$ es el parámetro de brillo superficial central ajustado por GALFIT, $t_{\exp }$ es el tiempo de exposición, $\Delta x$ y $\Delta y$ son la escala de la placa, y $\operatorname{mag}_{z p t}$ es la magnitud

\footnotetext{
${ }^{3}$ Analog Digital Unit.

${ }^{4}$ ds9.si.edu/site/
} 
Tabla 6.5: Comparación de los resultados obtenidos utilizando los diferentes modelos.

\begin{tabular}{|c|c|c|}
\hline Parámetros & Vista de canto & $\begin{array}{c}\text { Sérsic + Disco exponencial } \\
\text { considerando centros diferentes }\end{array}$ \\
\hline Centro (RA) & $13: 34: 47.2$ & $13: 34: 47.2 \quad 13: 34: 46$ \\
\hline Centro (DEC) & $-45: 32: 49.8$ & $-45: 32: 49.8-45: 32: 49.4$ \\
\hline escala de altura ["] & 14 & \\
\hline escala en ancho ["] & 39,7 & $-\quad 42$ \\
\hline$r_{e}\left[{ }^{\prime \prime}\right]$ & & $0,071-$ \\
\hline PA [grados] & -38 & $2,0-38,3$ \\
\hline Cociente de los ejes & & $0,8 \quad 0,2$ \\
\hline Índice de Sérsic (n) & & $0,6 \quad 1,0$ \\
\hline$\mu_{o}\left[\mathrm{mag} / \operatorname{arcsec}^{2}\right]$ & 22,05 & \\
\hline$\Sigma_{e}\left[\mathrm{mag} / \operatorname{arcsec}^{2}\right]$ & & $2,9 \quad 13,16$ \\
\hline$\chi^{2} / \nu$ & 0,9 & 3,5 \\
\hline
\end{tabular}

Notes: $\mu_{o}$ es el brillo superficial central mientras que $\Sigma_{e}$ es el brillo superficial en un radio efectivo $r_{e}$.

del punto cero. La magnitud del punto cero se define como la magnitud de un objeto astrofísico que produciría un flujo de 1 ADU por segundo cuando se ve directamente sobre el Zenit. Según la página del HST, el valor es de 26.78 para el filtro utilizado.

- Alternativamente, la distribución de la luz se puede representar mediante una combinación de dos perfiles Sérsic: uno que representa el bulbo y otro que representa el disco. La expresión del perfil Sersic es

$$
\Sigma(r)=\Sigma_{e} \exp \left[-k\left(\left(\frac{r}{r_{e}}\right)^{1 / n}-1\right)\right]
$$

$\Sigma_{e}$ es el brillo de la superficie de píxeles en radio efectivo, $r_{e}$. El radio efectivo se define como el radio tal que la mitad del flujo total de la galaxia está dentro de $r_{e}$. El parámetro $n$ es el índice de Sérsic.

El parámetro $k$ está relacionado con $n$; se aproxima por $k \sim 2 n-1+O(n)$, donde $O(n)$ representa las contribuciones de los términos de orden superior de $n$.

Ambas expresiones que describen la distribución de luminosidad fueron exraídas de Peng et al. [2002].

El $\chi^{2} / \nu$ es un parámetro estadístico que utiliza GALFIT para medir la bondad del ajuste $\left(\chi^{2} / \nu \sim 1\right)$ (ver los resultados en la Tabla 6.5). El modelo realizado teniendo en cuenta la presencia de un bulbo más un disco falla cuando intenta ajustar el índice de Sérsic y deben fijarse algunos parámetros para obtener resultados significativos. El modelo que mejor ajusta es el disco visto de canto. 

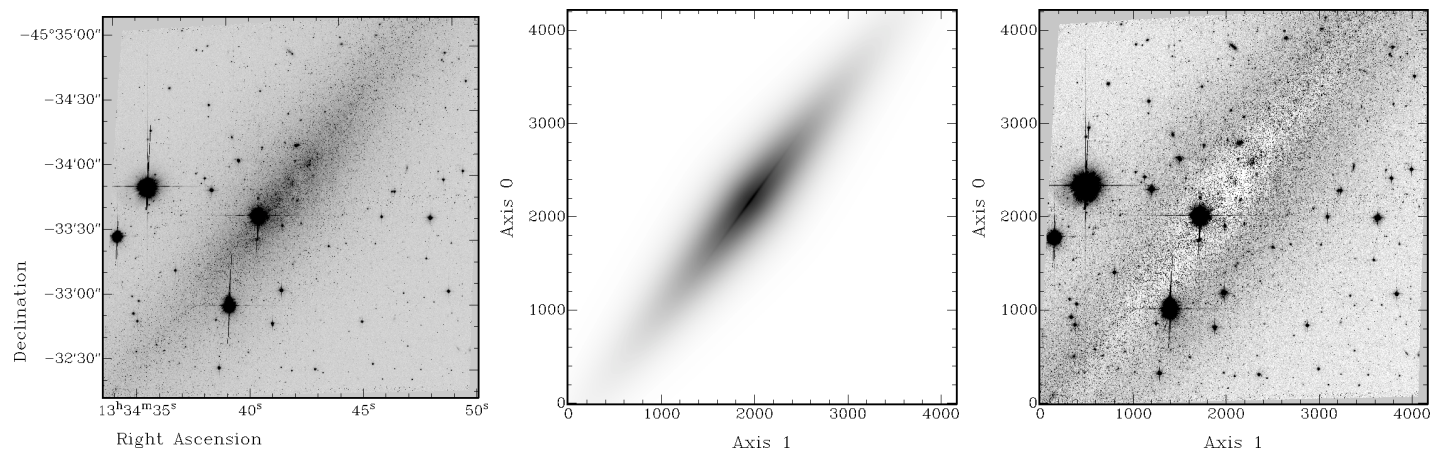

Figura 6.16: Distribución de luminosidad de FF obtenida considerando el modelo de un disco visto de canto. Panel izquierdo: imagen tomada con el HST en el filtro F814. Panel central: el modelo de disco visto de canto. Panel derecho: Resta entre la imagen y lo modelado.

\subsection{Modelado de la distribución de masa}

La contribución de los discos estelares y gaseosos a la curva de rotación ( $\left.V_{\text {gas }}\right)$ se derivaron utilizando la tarea ROTMOD del sistema de procesamiento de imágenes de Groningen (GIPSY) [van der Hulst et al., 1992]. Para la contribución estelar usamos el perfil de densidad de superficie derivado en la Sección 6.4.3 y también asumimos la distribución vertical como

$$
D_{*}(z)=\frac{\operatorname{sech}\left(\frac{z}{z_{0}}\right)^{2}}{z_{0}},
$$

donde $z_{0}$ es la altura de la escala del disco, y en este caso, se estableció en 0,7 kpc. Esta distribución del disco estelar está motivada por los estudios de galaxia espiral de borde por van der Kruit and Searle [1981]. Para el disco gaseoso se consideró una distribución de densidad vertical dada por la ley exponencial

$$
D_{\text {gas }}(z)=\frac{-\exp \left(\frac{\mathrm{z}}{\mathrm{z}_{0}}\right)}{z_{0}},
$$

donde $z_{0}$ para este caso es $2 \mathrm{kpc}$. La distribución de la densidad de la superficie del gas H i se multiplicó por un factor de 1,4 para dar cuenta del helio primordial, pero no consideramos la presencia de $\mathrm{H}_{2}$ molecular en nuestros modelos.

Hicimos uso de Rotmas, un subprograma de GIPSY que permite el modelado interactivo de curvas de rotación, con opciones para la adición de la contribución del halo de materia oscura. La velocidad de rotación neta $V_{r}$ en un radio $r$ se obtiene sumando en cuadratura la velocidad de rotación debida al potencial gravitatorio de las estrellas, el gas y los componentes de DM:

$$
(V(r))^{2}=f_{\star}\left(v_{\star}(r)\right)^{2}+f_{\text {gas }}\left(v_{\text {gas }}(r)\right)^{2}+\left(v_{D M}(r)\right)^{2},
$$

donde $f_{*}$ y $f_{\text {gas }}$ son factores de escala de la componente estelar y gaseosa del disco respectivamente. 


\subsubsection{Halo de materia oscura}

Utilizamos los modelos de distribución de materia oscura dados por el modelo de halo pseudo-isotérmico (PI) y el modelo de Navarro, Frenk y White (NFW).

- El modelo más simple es el modelo de un halo pseudo-isotérmico (PI) [Begeman et al., 1991], donde el perfil de densidad está dado por:

$$
\rho_{P I}(R)=\frac{\rho_{0}}{1+\left(\frac{R}{R_{c}}\right)^{2}}
$$

Aquí $\rho_{0}$ es la densidad central y $R_{c}$ es el radio del núcleo de halo. La velocidad de rotación para cualquier radio $r$ debido a un halo pseudo-isotérmico está dada por la siguiente expresión:

$$
V_{D M}(R)=V_{\text {inf }} \sqrt{1-\left(\frac{R_{c}}{R} \arctan \left(\frac{R}{R_{c}}\right)\right)}
$$

donde la velocidad asintótica $V_{\text {inf }}$ está definida como:

$$
V_{\text {inf }}=\sqrt{4 \pi G \rho_{0}\left(R_{C}\right)^{2}} .
$$

- Basándose en simulaciones numéricas de halos de materia oscura, Navarro, Frenk y White (NFW)[Navarro et al., 1996] describen al perfil de distribución de materia oscura de la siguiente manera:

$$
\begin{gathered}
\frac{\rho_{N F W}}{\rho_{\text {crit }}}=\frac{\delta_{c}}{\frac{R}{R_{s}}\left(1+\frac{R}{R_{s}}\right)^{2}} \\
\delta_{c}=\frac{200 c^{3}}{3 \ln (1+c)-\frac{c}{1+c}} \\
c=\frac{R_{200}}{R s} \\
V_{D M}(R)=V_{200} \sqrt{\frac{\ln (1+c x)-\frac{c x}{1+c x}}{x \ln (1+c)-\frac{c}{1+c}}} \\
x=\frac{R}{R_{200}} \\
V_{200}=0,73 R_{200} .
\end{gathered}
$$

$R_{s}$ es el radio característico del halo, $\rho_{\text {crit }}$ es la densidad crítica del universo y $c$ es el parámetro de concentración. $R_{200}$ es el radio donde el promedio de la densidad del halo es $200 \rho_{\text {crit }}$. 

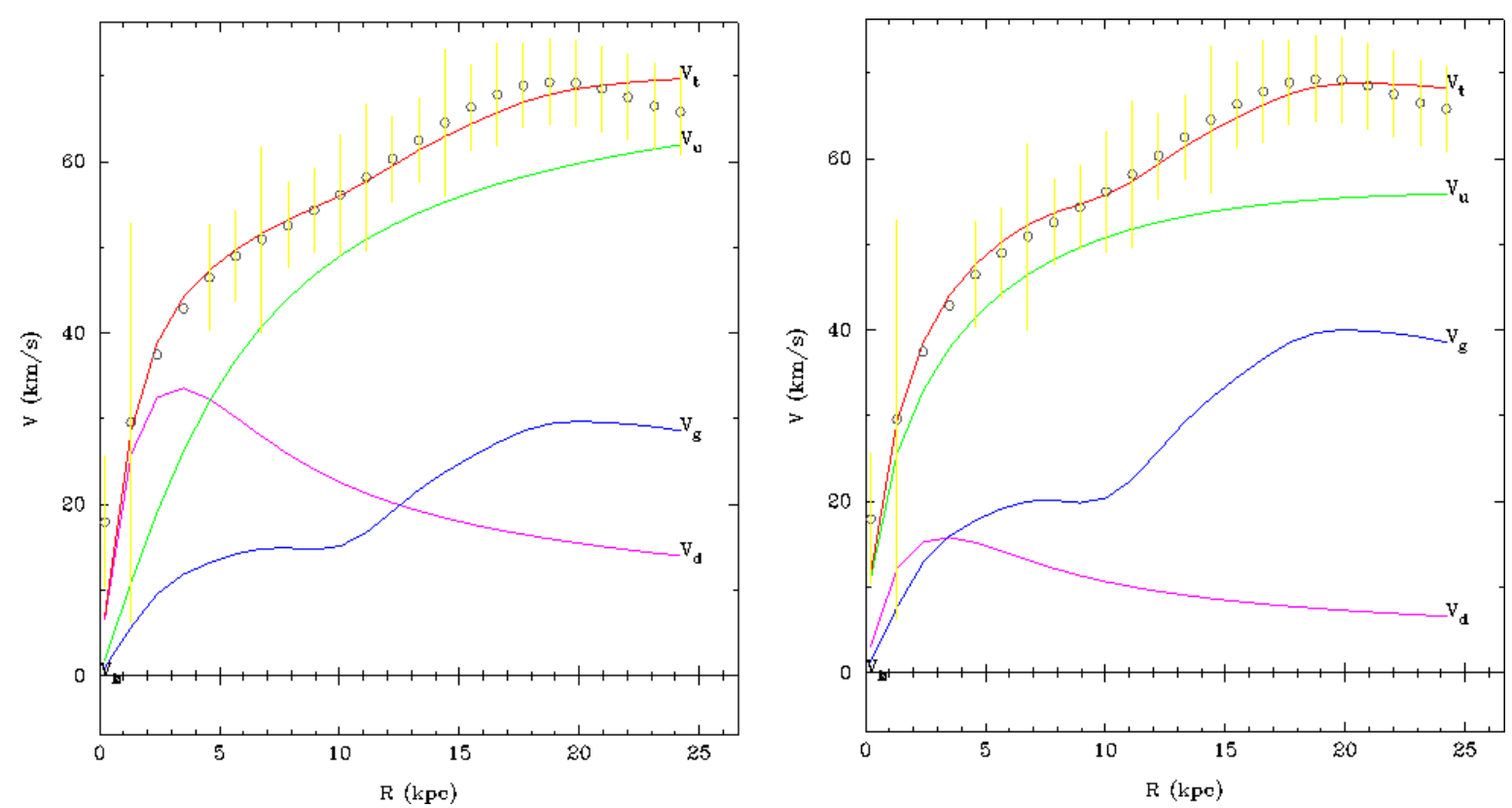

Figura 6.17: Modelado de la curva de rotación de la galaxia Fourcade-Figueroa utilizando los datos de $\mathrm{H}$ I(círculos abiertos). Panel izquierdo: ajuste de curva de rotación utilizando el halo pseudo-isotérmico (parámetros libres, $\chi^{2}=9$ ). Panel derecho: ajuste de curva de rotación utilizando el halo NFW (parámetros fijos, $\chi^{2}=3,4$ ). En ambos paneles, la curva azul indica la curva de rotación debida a la componente gaseosa, la curva rosada es la contribución debido a la componente estelar, la curva verde es debida al halo de materia oscura y en color rojo, la curva de rotación del modelo que mejor ajusta a las observaciones.

Tabla 6.6: Resultados del modelado de distribución de masa utilizando los perfiles de halo de materia oscura pseudo-isotérmica $(\mathrm{PI})$ y NFW. $f_{*}$ y $f_{\text {gas }}$ son los factores de escala de masa para el disco estelar y gaseoso, respectivamente.

\begin{tabular}{lcccccc}
\hline Modelo & $f_{*}$ & $f_{\text {gas }}$ & $\begin{array}{c}r_{c} \\
{[\mathrm{kpc}]}\end{array}$ & $\begin{array}{c}\rho_{0} \\
{\left[10^{-3}\right.} \\
\left.\mathrm{M}_{\odot} \mathrm{pc}^{-3}\right]\end{array}$ & $\chi^{2}$ & \\
\hline \hline PI (fijo) & 4,6 & 1,0 & $4,9 \pm 0,5$ & $3,9 \pm 0,6$ & 8,3 & \\
PI (gas fijo) & 4,6 & $1,0 \pm 0,8$ & $4,9 \pm 0,8$ & $3,9 \pm 0,6$ & 8,7 & \\
PI (libre) & $4,6 \pm 1,18$ & $1,0 \pm 1,15$ & $4,9 \pm 1,7$ & $3,9 \pm 1,5$ & 9 & \\
& $f_{*}$ & $f_{\text {gas }}$ & $c$ & $R_{200}$ & $\chi^{2}$ & $v_{200}$ \\
& & & {$[\mathrm{kpc}]$} & {$[\mathrm{kpc}]$} & & {$\left[\mathrm{km} \mathrm{s}^{-1}\right]$} \\
NFW (fijo) & 1 & 2 & $3,1 \pm 0,2$ & $40,2 \pm 0,8$ & 3,4 & $\sim 30$ \\
NFW (gas libre) & 1 & $2 \pm 0,5$ & $3,1 \pm 0,3$ & $40,2 \pm 0,3$ & 3,6 & \\
\hline
\end{tabular}



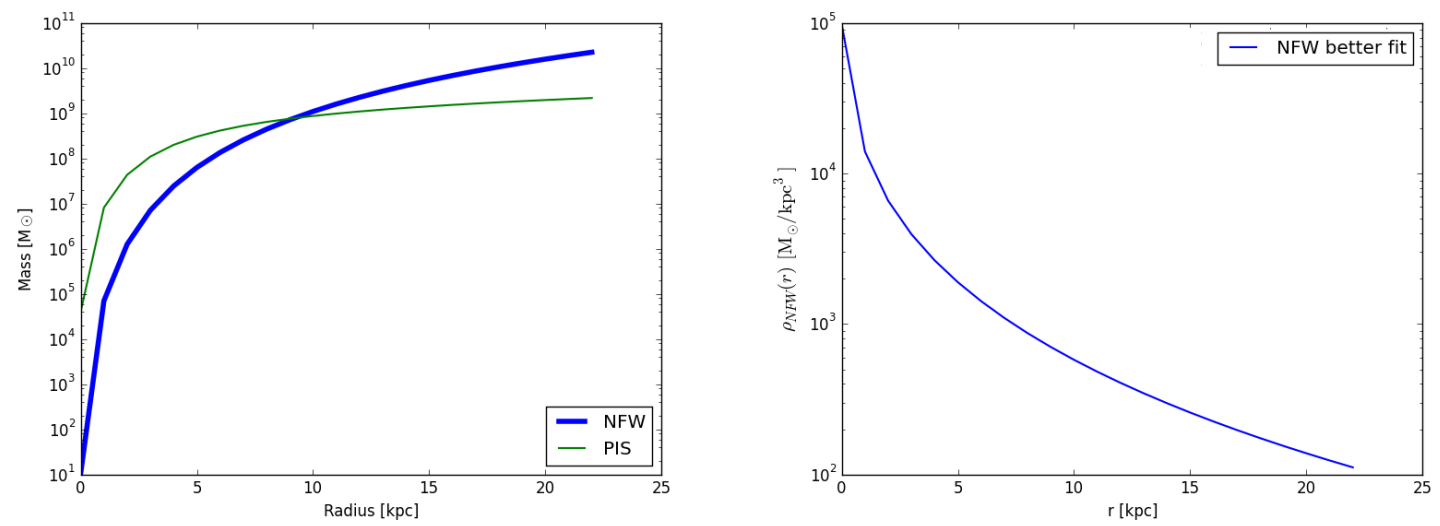

Figura 6.18: Panel izquierdo: Perfil de distribución de masa utilizando el halo pseudoisotérmico y el de NFW. Panel derecho: Perfil de densidad que mejor ajustó (NFW).

En la Fig. 6.17 se muestra el modelado de distribución de masa implementados para la galaxia Fourcade-Figueroa utiliando en un caso el perfil de densidad de materia oscura PI (parámetros libres, $\chi^{2}=9$ ) y en otro caso el de NFW (parámetros fijos, $\chi^{2}$ =3.4). En cada gráfico se indica la descomposición de la curva de rotación, es decir, la contribución de las estrellas, el gas y del halo de materia oscura. Los parámetros ajustados se muestran en la Tabla 6.6; el ajuste utilizando NFW con los parámetros libres produjo masas estelares negativas y, por lo tanto, no se proporciona el resultado. Tanto el modelo utilizando NFW como PI ajustaron bien a la curva de rotación observada, excepto por los desajustes leves entre 20 y $25 \mathrm{kpc}$ y una subestimación de los valores observados en $\sim 16-17$ kpc. La Fig. 6.18 muestra que la masa central del perfil PI es mayor que la del NFW.

El perfil utilizando el halo PI converge a una masa de $10^{9} \mathrm{M}_{\odot}$, mientras que el de NFW parece converger a una masa de $10^{10} \mathrm{M}_{\odot}$. El parámetro $\chi^{2}$ reducido se usó para determinar la bondad de los ajustes. Estos valores son 9.1 para el perfil PI y 3.6 para NFW, por lo que el perfil NFW proporciona un mejor ajuste.

\subsection{Resumen}

Hemos combinado los datos obtenidos con ATCA y GMRT para estudiar la galaxia Fourcade-Figueroa. La combinación de conjuntos de datos de diferentes interferómetros rara vez se lleva a cabo. Su procesamiento no está estandarizado, por lo que representa un desafío tanto desde el punto de vista computacional como en la interpretación de los resultados.

Encontramos que el hidrógeno atómico se distribuye en extensión casi dos veces más que la componente estelar. La parte noreste del disco está deformado. Teniendo en cuenta que la galaxia FF está detrás de Cen A, las características mencionadas podrían vincularse a mecanismos internos como eventos de supernova o la interacción entre la FF y una galaxia enana. Pudimos determinar la curva de rotación de la galaxia, con 
una resolución lineal de $\sim 916$ pc y realizamos el modelado en masa implementando la rutina ROTMAS del software GIPSY; el mejor ajuste corresponde al halo de materia oscura de NFW.

Se necesita un análisis adicional utilizando los datos de $\mathrm{H}_{\alpha}$ para confirmar o descartar el escenario propuesto de mecanismos internos que conducen a la deformación observada en la región noroeste del disco de la galaxia FF. Con el fin de contribuir a la comprensión de la distribución de materia oscura en las galaxias vistas de canto y probar la correlación entre las observaciones y los resultados obtenidos utilizando modelos de distribución de DM, la curva de rotación debe tener una mejor resolución de velocidad en la parte interior de la galaxia. Consideramos que valdrá la pena intentar usar la técnica desarrollada por Kregel and van der Kruit [2004], que consiste en modelar con un conjunto de anillos el diagrama de posición-velocidad. 


\section{Capítulo 7}

\section{Conclusiones generales}

En esta tesis presento nuevas observaciones radio interferométricas de gran calidad de 3 galaxias de baja luminosidad, en diferentes entornos. Los resultados de esta tesis son relevantes en particular para el estudio del efecto del entorno de las galaxias tanto en sus propiedades globales como locales; como por ejemplo, el contenido de gas, la cinemática y la tasa de formación estelar. Por lo tanto, los estudios de la naturaleza de las interacciones así como también la frecuencia con la que estas ocurren son esenciales para comprender la formación y evolución de las galaxias.

En particular, hemos encontrado un gran complejo de nubes de H I cerca de la galaxia elíptica IC 1459 usando imágenes de $21 \mathrm{~cm}$ del Australia Telescope Compact Array (ATCA). Las nubes de H I detectadas abarcan $\sim 250 \mathrm{kpc}$, tienen una H I masa total de $\sim 10^{9} \mathrm{M}_{\odot}$ y la mayoría de estos escombros de $\mathrm{H}$ I se identifican al este de la galaxia espiral IC 5264. Las interacciones de marea del grupo IC 1459 son responsables de la pérdida de $\mathrm{H}$ I perteneciente a la componente más externa del disco gaseoso de IC 5264 y NGC 7418A (ambas deficientes en Hi). La formación de estrellas en el lado oeste de NGC 5264, evidente en las imágenes GALEX UV, puede haber sido desencadenada por las interacciones de las mareas. A pesar de que los escombros de H i proporcionan combustible para la formación de nuevas galaxias enanas, no se detectan signos de actividad de formación de estrellas en ninguna de las nubes de H I identificadas.

Aún en entornos de baja densidad, como es el grupo NGC 2683 cerca de "Leo-Gemini void", la evolución de la galaxia enana KK 69 parece estar mayormente influenciada por su entorno. De las observaciones de H I de GMRT hemos encontrado que la mayor parte del gas H i se encuentra desplazado a $\sim 4.3 \mathrm{kpc}$ del cuerpo estelar. KK 69 es probablemente una galaxia enana de transición, en el proceso de transformación de una irregular rica en gas a una esferoidal pobre en gas. La distribución del gas H I de KK 69 muestra una forma cometaria, lo que indicaría que la galaxia enana se mueve hacia NGC 2683, arrastrando el medio intergaláctico con ella. Probablemente, el barrido de presión dinámica y las interacciones de las mareas con NGC 2683 son los mecanismos responsables del desplazamiento observado entre las regiones de alta densidad estelar y las regiones de alta densidad del gas.

Por último, estudiamos la galaxia Fourcade-Figueroa, la cual es una galaxia vista 
de canto, que presenta asimetrías en la componente noroeste del disco gaseoso cuyo origen todavía no se encuentra del todo claro. En particular, el hecho que esté de canto la convierte en el laboratorio ideal para estudiar el contenido de materia oscura y los problemas relacionados como la discrepancia entre el núcleo y la cúspide. Los primeros resultados, indican que el modelo de distribución de materia oscura que mejor ajusta a nuestro modelado de la distribución de masa, es el modelo de NFW.

Futuras observaciones con ASKAP, Apertif y MeerKat permitirán obtener imágenes H I con buena resolución angular y sensibilidad de muchos grupos de galaxias ya sean cercanos como lejanos. Sobre la base de los primeros resultados de HI de campo amplio de ASKAP, esperamos el descubrimiento de muchos filamentos, plumas y nubes cerca de galaxias que interactúan, proporcionando información nueva y valiosa sobre la evolución de los grupos de galaxias. Es importante que, tarde o temprano, Argentina pueda hacer uso de esto. 


\section{Apéndice A}

\section{Catálogo de Parámetros del HI en galaxias (CHIPA)}

Como complemento de mi trabajo de tesis he construído el Catálogo de parámetros del H i en galaxias (CHIPA) que tiene como objetivo facilitar las búsquedas de datos públicos de relevamientos de $\mathrm{H}$ I a través de una base de datos pública (NOVA y UNLP), Saponara et al. [2015]. La base de datos se creó utilizando "mysql" (sql, Structured Query Language, un sistema de gestión de base de datos relacional de código abierto), mientras que la página web se creó utilizando " html" (Hypertext Markup Language) y "php" (Preprocesador de hipertexto). Actualmente se está migrando la interfaz de CHIPA de java (Nova) a Web based (euridice.fcaglp.unlp.edu.ar).

La información proporcionada en esta base de datos se recopiló de varios relevamientos que estuvieron disponibles hasta el año 2015. Entre ellos: THINGS, VLA-ANGST, Little THINGS, FIGGS y WHISP. En el catálogo se pueden encontrar algunos datos básicos como el diámetro óptico, la magnitud azul, la distancia, el tipo morfológico, la extensión H I de la galaxia, la velocidad sistémica, la resolución en la velocidad de las observaciones realizadas en radio, etc. Además, proporcionamos los mapas de distribución de $\mathrm{HI}$, distribución de velocidades y dispersión de velocidades, en los casos que fuera posible.

\section{A.1. Introducción}

Las técnicas de observación en radio han ido mejorando desde la primera detección de la línea de H i que se realizó con la bocina de Ewen y Purcell (1951), contando hoy en día con los receptores multibeam utilizados por ASKAP. Aunque el primer interferómetro de radio se probó en 1946, hasta los años setenta u ochenta los datos se observaron principalmente con discos simples. Martin [1998a,b] publicó un catálogo completo teniendo en cuenta la información obtenida por antenas simples entre 1953 y 1995. En las últimas décadas, los instrumentos interferométricos recopilan datos sobre objetos individuales y relevamientos con una resolución angular y en velocidad mucho mejor a la existente 20 años atrás.

Las observaciones de la línea de $21 \mathrm{~cm}$ de Hidrógeno atómico han demostrado ser cruciales para nuestra comprensión del proceso que conduce a la formación de estrellas, 


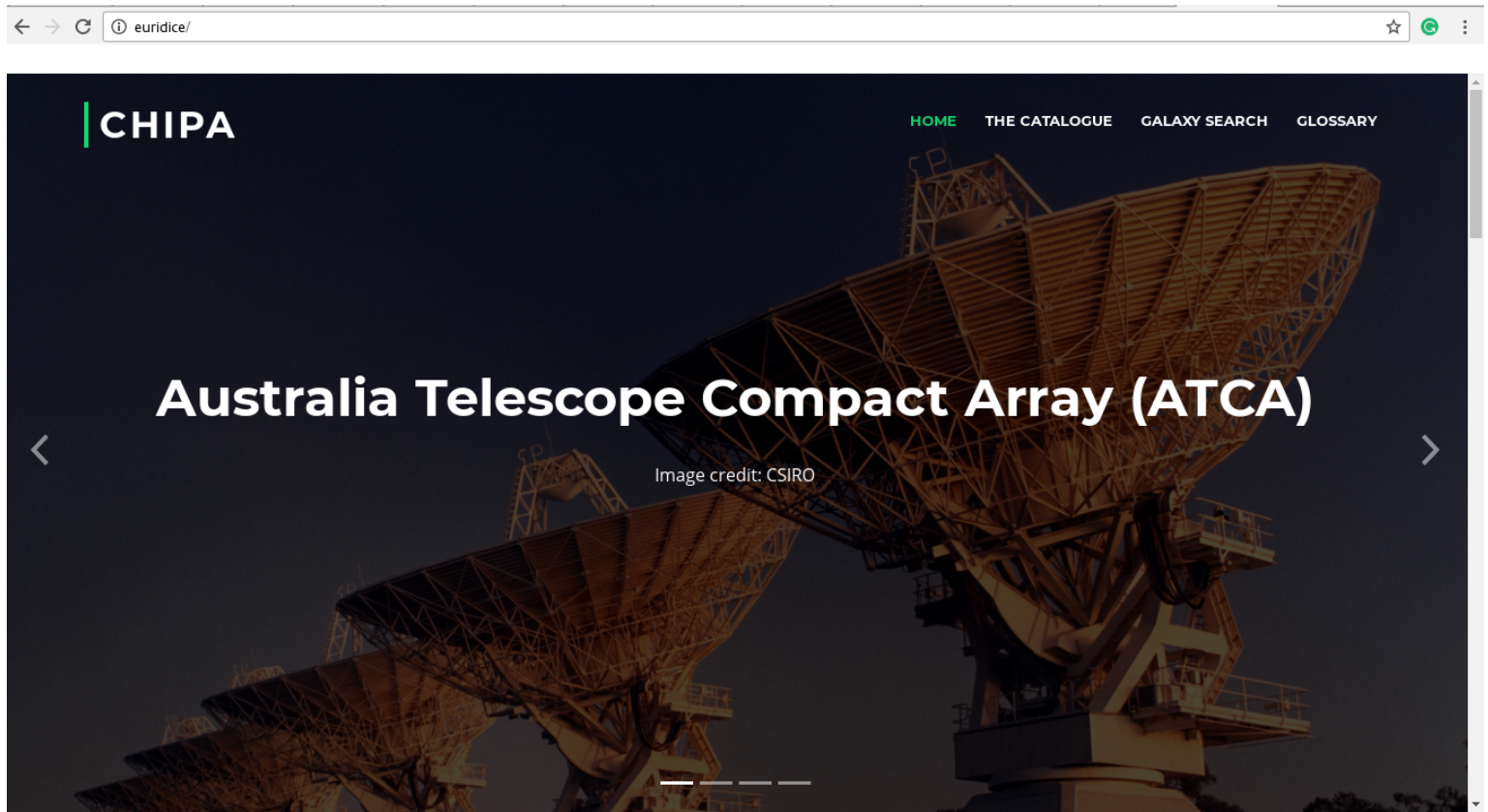

Figura A.1: Página web

la dinámica y la estructura del medio interestelar (MIE) y la distribución de materia oscura en las galaxias, todas relacionadas con la evolución de las mismas.

En la actualidad, muchos relevamientos se centran en estos temas de investigación. Por ejemplo, "The HI nearby galaxy survey" (THINGS ${ }^{1}$ ), es un relevamiento realizado con una alta resolución espectral y espacial de la emisión de H I de galaxias cercanas obtenidas con el interferómetro Very Large Array (VLA). THINGS produjo mapas de H I integrados, mapas de campo de velocidad, mapas de dispersión de velocidades y mapas de canales para cada galaxia. " El estudio Westerbork HI de galaxias irregulares y en espiral " (WHISP ${ }^{2}$ ) también estudió la estructura y la cinemática del H I en galaxias y la dinámica de las galaxias utilizando al H i como trazador.

Los relevamientos de tipo morfológico más restrictivas han hecho énfasis en las galaxias enanas: VLA-ANGST ${ }^{3}$ y FIGGS [Begum et al., 2008] son algunos de ellos. Los estudios de galaxias enanas son importantes porque, en los modelos jerárquicos de formación de galaxias, serían, en cierto modo, los bloques primordiales para la formación de galaxias más grandes.

Nuestro objetivo principal era reunir, en una base de datos, los parámetros más importantes derivados de las observaciones interferométricas de galaxias de la lína de $21 \mathrm{~cm}$. En este momento, la base de datos contiene la información recopilada de los relevamientos: THINGS, VLA-ANGST, Little THINGS, FIGGS y WHISP.

\footnotetext{
${ }^{1}$ www.mpia-hd.mpg.de/THINGS/Overview.html

${ }^{2}$ www.astron.nl/wow/testcode.php?project $=3$

${ }^{3}$ science.nrao.edu/science/surveys/vla-angst
} 


\section{A.2. Breve descripción de los relevamientos}

- The H I nearby galaxy survey (THINGS, Walter et al. 2008) comprende 34 objetos a distancias de hasta $15 \mathrm{Mpc}$ (que resultan en resoluciones lineales de $\sim 100$ a $\sim 500 \mathrm{pc}$ ), tasas de formación estelar $\sim 10^{-3}$ a $6 \mathrm{M}_{\odot}$ año ${ }^{-1}$, masas H I totales $\mathrm{M}_{\mathrm{HI}}=14 \times 10^{9} \mathrm{M}_{\odot}$, magnitudes azules absolutas entre $-11,5$ mag y $-21,7$ mag, y metalicidades de 7,5 a 9,2 en unidades de $12+\log [\mathrm{O} / \mathrm{H}]$.

- The Local Irregulars That Trace Luminosity Extremes, The H i Nearby Galaxy Survey (Little-THINGS, Hunter et al. 2012) contiene galaxias enanas que están relativamente cerca, hasta 10,3 Mpc.

- The Westerbork H I survey of irregular and spiral galaxies (WHISP, van der Hulst et al. 2001). Su muestra de galaxias se seleccionó del Catálogo General de Uppsala (UGC)(Nilson 1973), y contiene galaxias con $\delta>20^{\circ}$ y tamaños mayores que $1,2^{\prime}$.

- The Faint Irregular Galaxies GMRT Survey (FIGGS, Begum et al. 2008) es un relevamiento que contiene galaxias enanas irregulares de masas extremadamente baja, con $\mathrm{M}_{\mathrm{B}}>-14,5 \mathrm{mag}$, masas de $\mathrm{H}$ I de $\sim 3 \times 10^{7} \mathrm{M}_{\odot}$, flujo total de $\mathrm{H} \mathrm{I}$ $>1 \mathrm{Jy} \mathrm{km}^{-1}$ y diámetros ópticos $>1,0^{\prime}$.

- El estudio en H i de alta resolución, de galaxias enanas cercanas, (VLA-ANGST, Ott et al. 2012) se centró en una muestra completa de 69 galaxias. Las galaxias observadas están comprendidas en la región limitada por: una latitud galáctica | $b \mid>20^{\circ}$, galaxias fuera del grupo local pero dentro de $3,5 \mathrm{Mpc}$ y con observaciones adicionales, a $4 \mathrm{Mpc}$, en las direcciones de los grupos M81 y Sculptor.

\section{A.3. Parámetros disponibles}

La primera versión de CHIPA proporciona dos criterios de búsqueda: por nombre del relevamiento y por coordenadas (ver Fig. A.2). Presentamos datos sobre las propiedades ópticas y HI básicas de las galaxias, en particular el diámetro óptico, la magnitud azul, la distancia, el tipo morfológico, la extensión angular H i la masa HI, la velocidad sistémica y algunas configuraciones de observación (el interferómetro utilizado, la resolución angular y de velocidad, etc). Además, CHIPA contiene la distribución de H I, la distribución de velocidad, los mapas de dispersión de velocidad y el perfil de HI global cuando esté disponible. 
$\leftarrow \rightarrow$ C (i) euridice/

\section{CHIPA}

\section{SEARCH GALAXY BY:}

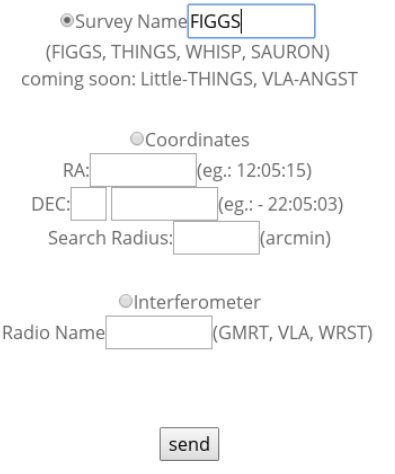

\section{Results}

You find 46 galaxies

\begin{tabular}{|c|c|c|c|}
\hline \multicolumn{3}{|c|}{ Survey G. Name Right A. } & \multirow{2}{*}{$\begin{array}{l}\text { Dec. } \\
\text { o:':": }\end{array}$} \\
\hline & & h:m:s & \\
\hline FIGGS & DDO 226 & 6:43:3.00 & $22: 15: 1.00$ \\
\hline FIGGS & DDO 6 & $0: 49: 49.00$ & 21:0:8.00 \\
\hline FIGGS & ugc 685 & 1:7:22.00 & $16: 41: 2.00$ \\
\hline FIGGS & KKH 6 & 1:34:51.00 & $52: 5: 30.00$ \\
\hline FIGGS & KK 14 & 1:44:42.00 & $27: 17: 16.00$ \\
\hline FIGGS & KKH 11 & $2: 24: 35.00$ & $56: 0: 42.00$ \\
\hline FIGGS & KKH 12 & $2: 27: 27.00$ & $57: 29: 16.00$ \\
\hline FIGGS & KK 41 & $4: 25: 15.00$ & $72: 48: 21.00$ \\
\hline FIGGS & KKH 34 & $5: 59: 41.00$ & $73: 25: 39.00$ \\
\hline FIGGS & E490-17 & $6: 37: 56.00$ & $25: 59: 59.00$ \\
\hline FIGGS & ugc 3755 & 7:13:51.00 & $10: 31: 19.00$ \\
\hline FIGGS & DDO 43 & $7: 28: 17.00$ & $40: 46: 13.00$ \\
\hline FIGGS & KK 65 & $7: 42: 31.00$ & $16: 33: 40.00$ \\
\hline FIGGS & ugc 4115 & 7:57:1.00 & $14: 23: 27.00$ \\
\hline FIGGS & KK 69 & $8: 52: 50.00$ & $33: 47: 52.00$ \\
\hline FIGGS & ugc $51 \varepsilon$ & 5 9:42:59.00 & $33: 15: 52.00$ \\
\hline FIGGS & ugc 5209 & 9:45:4.00 & $32: 14: 18.00$ \\
\hline
\end{tabular}

Figura A.2: Ejemplo de búsqueda 


\section{Apéndice B}

\section{Tutoriales}

En el directorio jota@crux/Public se dejan:

- Tutoriales de AIPS.

- Scripts en bash de MIRIAD, para llevar a cabo los procesos de calibración y construcción de cubo de imágenes.

- Como corregir por el efecto Doppler en AIPS.

- Un set de datos correspondiente la galaxia KK 69 para practicar. 
B. Tutoriales 


\section{Bibliografía}

M. Aaronson, J. A. Dawe, R. J. Dickens, J. R. Mould, and J. B. Murray. The Fornax and Grus clusters and the local infall velocity. , 195:1P-8P, April 1981. doi: 10.1093/ mnras/195.1.1P.

E. A. K. Adams and T. A. Oosterloo. Deep neutral hydrogen observations of Leo T with the Westerbork Synthesis Radio Telescope. , 612:A26, April 2018. doi: 10.1051/0004-6361/201732017.

A. Banerjee and C. J. Jog. The Flattened Dark Matter Halo of M31 as Deduced from the Observed H I Scale Heights. , 685:254-260, September 2008. doi: 10.1086/591223.

Arunima Banerjee and Chanda J. Jog. Progressively More Prolate Dark Matter Halo in the Outer Galaxy as Traced by Flaring H I Gas. , 732(1):L8, May 2011. doi: 10.1088/2041-8205/732/1/L8.

Arunima Banerjee, Lynn D. Matthews, and Chanda J. Jog. Dark matter dominance at all radii in the superthin galaxy UGC 7321. , 15:89-95, January 2010. doi: 10.1016/j.newast.2009.05.015.

K. G. Begeman, A. H. Broeils, and R. H. Sanders. Extended rotation curves of spiral galaxies - Dark haloes and modified dynamics. , 249:523-537, April 1991. doi: $10.1093 / \mathrm{mnras} / 249.3 .523$.

A. Begum and J. N. Chengalur. Kinematics of the faintest gas-rich galaxy in the Local Group: DDO210. , 413:525-534, Jan 2004. doi: 10.1051/0004-6361:20031549.

A. Begum, J. N. Chengalur, I. D. Karachentsev, M. E. Sharina, and S. S. Kaisin. FIGGS: Faint Irregular Galaxies GMRT Survey - overview, observations and first results. , 386:1667-1682, May 2008. doi: 10.1111/j.1365-2966.2008.13150.x.

K. Bekki, B. S. Koribalski, and V. A. Kilborn. Dark galaxies or tidal debris? Kinematical clues to the origin of massive isolated HI clouds. , 363:L21-L25, October 2005a. doi: $10.1111 /$ j.1745-3933.2005.00076.x.

K. Bekki, B. S. Koribalski, S. D. Ryder, and W. J. Couch. Massive HI clouds with no optical counterparts as high-density regions of intragroup HI rings and arcs. , 357: L21-L25, February 2005b. doi: 10.1111/j.1745-3933.2005.08625.x.

D. Bettoni, G. Galletta, S. García-Burillo, and A. Rodríguez-Franco. The gas content of peculiar galaxies: Counterrotators and polar rings. , 374:421-434, August 2001. doi: 10.1051/0004-6361:20010717. 


\section{BIBLIOGRAFÍA}

J. P. Blakeslee, J. R. Lucey, B. J. Barris, M. J. Hudson, and J. L. Tonry. A synthesis of data from fundamental plane and surface brightness fluctuation surveys. , 327: 1004-1020, November 2001. doi: 10.1046/j.1365-8711.2001.04800.x.

Leo Blitz and Timothy Robishaw. Gas-Rich Dwarf Spheroidals. , 541:675-687, October 2000. doi: 10.1086/309457.

G. R. Blumenthal, S. M. Faber, J. R. Primack, and M. J. Rees. Formation of galaxies and large-scale structure with cold dark matter. , 311:517-525, October 1984. doi: $10.1038 / 311517 \mathrm{a} 0$.

A. Boselli and G. Gavazzi. Environmental Effects on Late-Type Galaxies in Nearby Clusters. , 118:517-559, April 2006. doi: 10.1086/500691.

J. N. Bregman. The galactic fountain of high-velocity clouds. , 236:577-591, March 1980. doi: 10.1086/157776.

S. Brough, D. A. Forbes, V. A. Kilborn, and W. Couch. Southern GEMS groups - I. Dynamical properties. , 370:1223-1246, August 2006. doi: 10.1111/j.1365-2966.2006. 10542.x.

V. Buat, T. T. Takeuchi, J. Iglesias-Páramo, C. K. Xu, D. Burgarella, A. Boselli, T. Barlow, L. Bianchi, J. Donas, K. Forster, P. G. Friedman, T. M. Heckman, Y.W. Lee, B. F. Madore, D. C. Martin, B. Milliard, P. Morissey, S. Neff, M. Rich, D. Schiminovich, M. Seibert, T. Small, A. S. Szalay, B. Welsh, T. Wyder, and S. K. Yi. The Local Universe as Seen in the Far-Infrared and Far-Ultraviolet: A Global Point of View of the Local Recent Star Formation. , 173:404-414, December 2007. doi: $10.1086 / 516645$.

John M. Cannon, Riccardo Giovanelli, Martha P. Haynes, Steven Janowiecki, Angela Parker, John J. Salzer, Elizabeth A. K. Adams, Eric Engstrom, Shan Huang, Kristen B. W. McQuinn, JÃijrgen Ott, AmÃllie Saintonge, Evan D. Skillman, John Allan, Grace Erny, Palmer Fliss, and AnnaLeigh Smith. The survey of h i in extremely low-mass dwarfs (shield). The Astrophysical Journal Letters, 739(1):L22, 2011. URL http://stacks.iop.org/2041-8205/739/i=1/a=L22.

Sergio A. Cellone and Alberto Buzzoni. The low-luminosity galaxy population in the NGC5044 Group., 356:41-53, January 2005. doi: 10.1111/j.1365-2966.2004.08422.x.

Philip I. Choi, Puragra Guhathakurta, and Kathryn V. Johnston. Tidal Interaction of M32 and NGC 205 with M31: Surface Photometry and Numerical Simulations. , 124(1):310-331, Jul 2002. doi: 10.1086/341041.

A. Chung, J. H. van Gorkom, J. D. P. Kenney, H. Crowl, and B. Vollmer. VLA Imaging of Virgo Spirals in Atomic Gas (VIVA). I. The Atlas and the H I Properties. , 138: 1741-1816, December 2009. doi: 10.1088/0004-6256/138/6/1741.

Aeree Chung, J. H. van Gorkom, Jeffrey D. P. Kenney, and Bernd Vollmer. Virgo Galaxies with Long One-sided H I Tails. , 659:L115-L119, April 2007. doi: 10.1086/ 518034. 
F. R. Colomb, N. Loiseau, and J. C. Testori. Neutral hydrogen in the Fourcade-Figueroa galaxy (A 1332 - 45). , 24:139-147, 1984.

J. J. Condon. Radio emission from normal galaxies. Annual Review of Astronomy and Astrophysics, 30:575-611, January 1992. doi: 10.1146/annurev.aa.30.090192.003043.

Stéphanie Côté, Adam Draginda, Evan D. Skillman, and Bryan W. Miller. Star Formation in Dwarf Galaxies of the Nearby Centaurus a Group. , 138:1037-1061, October 2009. doi: 10.1088/0004-6256/138/4/1037.

L. N. da Costa, P. S. Pellegrini, M. Davis, A. Meiksin, W. L. W. Sargent, and J. L. Tonry. Southern Sky Redshift Survey - The catalog. , 75:935-964, April 1991. doi: $10.1086 / 191555$.

W. J. G. de Blok. Low Surface Brightness Galaxies. Encyclopedia of Astronomy and Astrophysics, Murdin P., ed. IoP Publishing, Bristol, p. 1, 2006.

W. J. G. de Blok. Halo Mass Profiles of Low Surface Brightness Galaxies. Astrophysics and Space Science Proceedings, 3:89, January 2007. doi: 10.1007/ 978-1-4020-5573-7_13.

W. J. G. de Blok and A. Bosma. High-resolution rotation curves of low surface brightness galaxies. , 385:816-846, Apr 2002. doi: 10.1051/0004-6361:20020080.

W. J. G. de Blok and S. S. McGaugh. The dark and visible matter content of low surface brightness disc galaxies. , 290:533-552, September 1997. doi: 10.1093/mnras/290.3. 533.

W. J. G. de Blok, F. Walter, E. Brinks, C. Trachternach, S. H. Oh, and Jr. Kennicutt, R. C. High-Resolution Rotation Curves and Galaxy Mass Models from THINGS. 136(6):2648-2719, Dec 2008a. doi: 10.1088/0004-6256/136/6/2648.

W. J. G. de Blok, F. Walter, E. Brinks, C. Trachternach, S.-H. Oh, and R. C. Kennicutt, Jr. High-Resolution Rotation Curves and Galaxy Mass Models from THINGS. , 136: 2648, December 2008b. doi: 10.1088/0004-6256/136/6/2648.

G. de Vaucouleurs, A. de Vaucouleurs, H. G. Corwin, Jr., Buta R. J., G. Paturel, and P. Fouque. Third Reference Catalogue of Bright Galaxies, volume 3 of 1 . SpringerVerlag, Berlin Heidelberg New York, 1991.

Avishai Dekel and Joseph Silk. The Origin of Dwarf Galaxies, Cold Dark Matter, and Biased Galaxy Formation. , 303:39, April 1986. doi: 10.1086/164050.

H. Dénes, V. A. Kilborn, and B. S. Koribalski. New H I scaling relations to probe the H I content of galaxies via global H I-deficiency maps. , 444:667-681, October 2014. doi: 10.1093/mnras/stu1337.

Tyler D. Desjardins, Sarah C. Gallagher, Panayiotis Tzanavaris, John S. Mulchaey, William N. Brand t, Jane C. Charlton, Gordon P. Garmire, Caryl Gronwall, Ann E. Hornschemeier, and Kelsey E. Johnson. Intragroup and Galaxy-linked Diffuse XRay Emission in Hickson Compact Groups. , 763(2):121, Feb 2013. doi: 10.1088/ 0004-637X/763/2/121. 


\section{BIBLIOGRAFÍA}

J. M. Dickey, E. E. Salpeter, and Y. Terzian. Galactic neutral hydrogen emissionabsorption observations from Arecibo. , 36:77-114, January 1978. doi: 10.1086/ 190492.

P.-A. Duc and I. F. Mirabel. Tidal Dwarf Galaxies. In J. E. Barnes and D. B. Sanders, editors, Galaxy Interactions at Low and High Redshift, volume 186 of IAU Symposium, page 61, 1999.

P.-A. Duc, E. Brinks, V. Springel, B. Pichardo, P. Weilbacher, and I. F. Mirabel. Formation of a Tidal Dwarf Galaxy in the Interacting System Arp 245 (NGC 2992/93). , 120:1238-1264, September 2000. doi: 10.1086/301516.

P.-A. Duc, F. Bournaud, and F. Masset. A top-down scenario for the formation of massive Tidal Dwarf Galaxies. , 427:803-814, December 2004. doi: 10.1051/0004-6361: 20041410 .

J. English, B. Koribalski, J. Bland-Hawthorn, K. C. Freeman, and C. F. McCain. The Vela Cloud: A Giant H I Anomaly in the NGC 3256 GROUP. , 139:102-119, January 2010. doi: 10.1088/0004-6256/139/1/102.

Ian N. Evans, Francis A. Primini, Kenny J. Glotfelty, Craig S. Anderson, Nina R. Bonaventura, Judy C. Chen, John E. Davis, Stephen M. Doe, Janet D. Evans, Giuseppina Fabbiano, Elizabeth C. Galle, II Gibbs, Danny G., John D. Grier, Roger M. Hain, Diane M. Hall, Peter N. Harbo, Xiangqun Helen He, John C. Houck, Margarita Karovska, Vinay L. Kashyap, Jennifer Lauer, Michael L. McCollough, Jonathan C. McDowell, Joseph B. Miller, Arik W. Mitschang, Douglas L. Morgan, Amy E. Mossman, Joy S. Nichols, Michael A. Nowak, David A. Plummer, Brian L. Refsdal, Arnold H. Rots, Aneta Siemiginowska, Beth A. Sundheim, Michael S. Tibbetts, David W. Van Stone, Sherry L. Winkelman, and Panagoula Zografou. The Chandra Source Catalog. The Astrophysical Journal Supplement Series, 189:37-82, July 2010. doi: 10.1088/0067-0049/189/1/37.

H. I. Ewen and E. M. Purcell. Observation of a Line in the Galactic Radio Spectrum: Radiation from Galactic Hydrogen at 1,420 Mc./sec. , 168:356, September 1951. doi: 10.1038/168356a0.

G. B. Field, D. W. Goldsmith, and H. J. Habing. Cosmic-Ray Heating of the Interstellar Gas. , 155:L149, March 1969. doi: 10.1086/180324.

D. A. Forbes, D. B. Reitzel, and G. M. Williger. Shell colors in the peculiar elliptical galaxy IC 1459. , 109:1576-1581, April 1995. doi: 10.1086/117386.

C.R Fourcade. . Bol. Asoc. Argentina de Astron, 16:10, 1971.

M. Franx and G. D. Illingworth. A counterrotating core in IC 1459. , 327:L55-L59, April 1988. doi: 10.1086/185139.

M. Franx, G. Illingworth, and T. Heckman. Major and minor axis kinematics of 22 ellipticals. , 344:613-636, September 1989. doi: 10.1086/167830. 
R. Gooch. Karma: a Visualization Test-Bed. In G. H. Jacoby and J. Barnes, editors, Astronomical Data Analysis Software and Systems V, volume 101 of Astronomical Society of the Pacific Conference Series, page 80, 1996.

S. Gordon, B. Koribalski, and K. Jones. H i observations of interacting galaxy pair NGC 4038/9. , 326:578-596, September 2001. doi: 10.1046/j.1365-8711.2001.04588.x.

S. Gordon, B. Koribalski, and K. Jones. Australia Telescope Compact Array H I observations of the NGC 6845 galaxy group. , 342:939-950, July 2003. doi: 10.1046/ j.1365-8711.2003.06606.x.

P. Goudfrooij, T. de Jong, H. U. Norgaard-Nielsen, L. Hansen, and H. E. Jorgensen. An extended disk of ionized gas in IC 1459. , 228:L9-L12, February 1990.

C.R Graham. . Pub. astr. Soc. Pacific, 90:273, 1978.

Jana Grcevich and Mary E. Putman. H I in Local Group Dwarf Galaxies and Stripping by the Galactic Halo. , 696:385-395, May 2009. doi: 10.1088/0004-637X/696/1/385.

Eva K. Grebel, III Gallagher, John S., and Daniel Harbeck. The Progenitors of Dwarf Spheroidal Galaxies. , 125:1926-1939, April 2003. doi: 10.1086/368363.

James E. Gunn and III Gott, J. Richard. On the Infall of Matter Into Clusters of Galaxies and Some Effects on Their Evolution. , 176:1, August 1972. doi: 10.1086/ 151605 .

Martha P. Haynes, Ricardo Giovanelli, and Guido L. Chincarini. The Influence of Envirionment on the H I Content of Galaxies. Annual Review of Astronomy and Astrophysics, 22:445-470, January 1984. doi: 10.1146/annurev.aa.22.090184.002305.

C. Heiles and T. H. Troland. The Millennium Arecibo 21 Centimeter Absorption-Line Survey. I. Techniques and Gaussian Fits. , 145:329-354, April 2003. doi: 10.1086/ 367785 .

P. Hickson. Systematic properties of compact groups of galaxies. , 255:382-391, April 1982. doi: $10.1086 / 159838$.

J. L. Higdon. Wheels of Fire. II. Neutral Hydrogen in the Cartwheel Ring Galaxy. , 467:241, August 1996. doi: 10.1086/177599.

J. P. Huchra and M. J. Geller. Groups of galaxies. I - Nearby groups. , 257:423-437, June 1982. doi: 10.1086/160000.

W. K. Huchtmeier, I. D. Karachentsev, and V. E. Karachentseva. HI observations of nearby galaxies V. Narrow (HI) line galaxies. , 401:483-489, April 2003. doi: 10.1051/0004-6361:20030138.

D. A. Hunter, D. Ficut-Vicas, T. Ashley, E. Brinks, P. Cigan, B. G. Elmegreen, V. Heesen, K. A. Herrmann, M. Johnson, S.-H. Oh, M. P. Rupen, A. Schruba, C. E. Simpson, F. Walter, D. J. Westpfahl, L. M. Young, and H.-X. Zhang. Little Things. , 144:134, November 2012. doi: 10.1088/0004-6256/144/5/134. 


\section{BIBLIOGRAFÍA}

M. C. Johnson, P. Kamphuis, B. S. Koribalski, J. Wang, S.-H. Oh, A. S. Hill, S. O'Sullivan, S. Haan, and P. Serra. Blasting away a dwarf galaxy: the 'tail' of ESO 324-G024. , 451:3192-3209, August 2015. doi: 10.1093/mnras/stv1180.

Gyula I. G. Józsa, Franz Kenn, Thomas A. Oosterloo, and Ulrich Klein. TiRiFiC: Tilted Ring Fitting Code, August 2012.

S. S. Kaisin and I. D. Karachentsev. New H $\alpha$ flux measurements in nearby dwarf galaxies. Astrophysical Bulletin, 69:390-408, October 2014. doi: 10.1134/ S1990341314040038.

P. Kamphuis, G. I. G. Józsa, S. . H. Oh, K. Spekkens, N. Urbancic, P. Serra, B. S. Koribalski, and R. J. Dettmar. FAT: Fully Automated TiRiFiC, July 2015.

I. D. Karachentsev and S. S. Kaisin. More Galaxies in the Local Volume Imaged in H $\alpha$. , 140:1241-1253, November 2010. doi: 10.1088/0004-6256/140/5/1241.

I. D. Karachentsev and E. I. Kaisina. Star Formation Properties in the Local Volume Galaxies via $\mathrm{H} \alpha$ and Far-ultraviolet Fluxes. , 146:46, September 2013. doi: 10.1088/ 0004-6256/146/3/46.

I. D. Karachentsev, D. I. Makarov, and E. I. Kaisina. Updated Nearby Galaxy Catalog. , 145:101, April 2013. doi: 10.1088/0004-6256/145/4/101.

I. D. Karachentsev, S. S. Kaisin, and E. I. Kaisina. Extending the H $\alpha$ Survey for the Local Volume Galaxies. Astrophysics, 58:453-470, December 2015a. doi: 10.1007/ s10511-015-9399-0.

I. D. Karachentsev, R. B. Tully, L. N. Makarova, D. I. Makarov, and L. Rizzi. Peculiar Velocities of Galaxies in the Leo Spur. , 805:144, June 2015b. doi: 10.1088/0004-637X/805/2/144.

Igor D. Karachentsev, Valentina E. Karachentseva, Walter K. Huchtmeier, and Dmitry I. Makarov. A Catalog of Neighboring Galaxies. , 127:2031-2068, April 2004. doi: $10.1086 / 382905$.

Igor D. Karachentsev, Elena I. Kaisina, and Dmitry I. Makarov. Suites of Dwarfs around nearby Giant Galaxies. , 147:13, January 2014. doi: 10.1088/0004-6256/147/ $1 / 13$.

V. E. Karachentseva and I. D. Karachentsev. A list of new nearby dwarf galaxy candidates. , 127:409-419, February 1998. doi: 10.1051/aas:1998109.

R. C. Kennicutt, Jr. Star Formation in Galaxies Along the Hubble Sequence. , 36: 189-232, 1998. doi: 10.1146/annurev.astro.36.1.189.

R. C. Kennicutt, Jr., J. C. Lee, J. G. Funes, S. J., S. Sakai, and S. Akiyama. An H $\alpha$ Imaging Survey of Galaxies in the Local 11 Mpc Volume. , 178:247-279, October 2008. doi: 10.1086/590058. 
V. A. Kilborn, D. A. Forbes, D. G. Barnes, B. S. Koribalski, S. Brough, and K. Kern. Southern GEMS groups - II. HI distribution, mass functions and HI deficient galaxies. , 400:1962-1985, December 2009. doi: 10.1111/j.1365-2966.2009.15587.x.

B. Koribalski and J. M. Dickey. Neutral hydrogen gas in interacting galaxies: the NGC 6221/6215 galaxy group. , 348:1255-1274, March 2004. doi: 10.1111/j.1365-2966. 2004.07444.x.

B. Koribalski, S. Gordon, and K. Jones. ATCA HI observations of the peculiar galaxy IC 2554. , 339:1203-1222, March 2003. doi: 10.1046/j.1365-8711.2003.06277.x.

B. S. Koribalski. The Local Universe: Galaxies in 3D. In B. L. Ziegler, F. Combes, H. Dannerbauer, and M. Verdugo, editors, Galaxies in 3D across the Universe, volume 309 of IAU Symposium, pages 39-46, February 2015. doi: 10.1017/ S1743921314009272.

B. S. Koribalski and Á. R. López-Sánchez. Gas dynamics and star formation in the galaxy pair NGC1512/1510. , 400:1749-1767, December 2009. doi: 10.1111/j.1365-2966. 2009.15610.x.

B. S. Koribalski, L. Staveley-Smith, V. A. Kilborn, S. D. Ryder, R. C. Kraan-Korteweg, E. V. Ryan-Weber, R. D. Ekers, H. Jerjen, P. A. Henning, M. E. Putman, M. A. Zwaan, W. J. G. de Blok, M. R. Calabretta, M. J. Disney, R. F. Minchin, R. Bhathal, P. J. Boyce, M. J. Drinkwater, K. C. Freeman, B. K. Gibson, A. J. Green, R. F. Haynes, S. Juraszek, M. J. Kesteven, P. M. Knezek, S. Mader, M. Marquarding, M. Meyer, J. R. Mould, T. Oosterloo, J. O'Brien, R. M. Price, E. M. Sadler, A. Schröder, I. M. Stewart, F. Stootman, M. Waugh, B. E. Warren, R. L. Webster, and A. E. Wright. The 1000 Brightest HIPASS Galaxies: H I Properties. , 128:16-46, July 2004. doi: 10.1086/421744.

B. S. Koribalski, J. Wang, P. Kamphuis, T. Westmeier, L. Staveley-Smith, S.-H. Oh, Á. R. López-Sánchez, O. I. Wong, J. Ott, W. J. G. de Blok, and L. Shao. The Local Volume H I Survey (LVHIS). , 478:1611-1648, August 2018a. doi: 10.1093/mnras/ sty 479 .

Bärbel S. Koribalski, Jing Wang, P. Kamphuis, T. Westmeier, L. Staveley-Smith, S. Oh, Á. R. López-Sánchez, O. I. Wong, J. Ott, W. J. G. de Blok, and L. Shao. The Local Volume HI Survey (LVHIS). , page 467, February 2018b. doi: 10.1093/mnras/sty 479.

J. Kormendy and R. Bender. A Revised Parallel-sequence Morphological Classification of Galaxies: Structure and Formation of S0 and Spheroidal Galaxies. , 198:2, January 2012. doi: 10.1088/0067-0049/198/1/2.

M. Kregel and P. C. van der Kruit. Structure and kinematics of edge-on galaxy discs - III. The rotation curves in the gas. , 352:787-803, August 2004. doi: 10.1111/j. 1365-2966.2004.07978.x.

Richard B. Larson. Effects of supernovae on the early evolution of galaxies. , 169: 229-246, November 1974. doi: 10.1093/mnras/169.2.229. 
A. Lauberts and E. A. Valentijn. The surface photometry catalogue of the ESO-Uppsala galaxies. 1989.

K. Lee-Waddell, K. Spekkens, P. Chandra, N. Patra, J.-C. Cuillandre, J. Wang, M. P. Haynes, J. Cannon, S. Stierwalt, J. Sick, and R. Giovanelli. The frequency and properties of young tidal dwarf galaxies in nearby gas-rich groups. , 460:2945-2961, August 2016. doi: 10.1093/mnras/stw1162.

D.F. Malin. New Aspects of Galaxy Photometry: Proceedings of the Specialized Meeting of the Eigh page 272. Lecture Notes in Physics. Springer-Verlag, 1985. ISBN 9783540156574. URL https://books . google.com.ar/books?id=mYzvAAAAMAAJ.

M. C. Martin. Catalogue of HI maps of galaxies. I. , 131:73-75, July 1998a. doi: 10.1051/aas:1998252.

M. C. Martin. Catalogue of HI maps of galaxies. II. Analysis of the data. , 131:77-87, July 1998b. doi: 10.1051/aas:1998422.

Mario L. Mateo. Dwarf Galaxies of the Local Group. Annual Review of Astronomy and Astrophysics, 36:435-506, January 1998. doi: 10.1146/annurev.astro.36.1.435.

Stacy S. McGaugh and W. J. G. de Blok. Testing the Dark Matter Hypothesis with Low Surface Brightness Galaxies and Other Evidence. , 499:41-65, May 1998. doi: $10.1086 / 305612$.

C. F. McKee and J. P. Ostriker. A theory of the interstellar medium - Three components regulated by supernova explosions in an inhomogeneous substrate. , 218:148-169, November 1977. doi: 10.1086/155667.

M. J. Meyer, M. A. Zwaan, R. L. Webster, L. Staveley-Smith, E. Ryan-Weber, M. J. Drinkwater, D. G. Barnes, M. Howlett, V. A. Kilborn, J. Stevens, M. Waugh, M. J. Pierce, R. Bhathal, W. J. G. de Blok, M. J. Disney, R. D. Ekers, K. C. Freeman, D. A. Garcia, B. K. Gibson, J. Harnett, P. A. Henning, H. Jerjen, M. J. Kesteven, P. M. Knezek, B. S. Koribalski, S. Mader, M. Marquarding, R. F. Minchin, J. O'Brien, T. Oosterloo, R. M. Price, M. E. Putman, S. D. Ryder, E. M. Sadler, I. M. Stewart, F. Stootman, and A. E. Wright. The HIPASS catalogue - I. Data presentation. , 350:1195-1209, June 2004. doi: 10.1111/j.1365-2966.2004.07710.x.

M. Milgrom. A modification of the Newtonian dynamics as a possible alternative to the hidden mass hypothesis. , 270:365-370, July 1983. doi: 10.1086/161130.

H. Mo, F. van den Bosch, and S. White. Galaxy Formation and Evolution. 2010.

C. A. Muller and J. H. Oort. Observation of a Line in the Galactic Radio Spectrum: The Interstellar Hydrogen Line at 1,420 Mc./sec., and an Estimate of Galactic Rotation. , 168:357-358, September 1951. doi: 10.1038/168357a0.

Julio F. Navarro, Carlos S. Frenk, and Simon D. M. White. The Structure of Cold Dark Matter Halos. , 462:563, May 1996. doi: 10.1086/177173.

P. Nilson. Uppsala general catalogue of galaxies. 1973. 
T. Oosterloo and J. van Gorkom. A large H I cloud near the centre of the Virgo cluster. , 437:L19-L22, July 2005. doi: 10.1051/0004-6361:200500127.

T. Oosterloo, G. S. Da Costa, and L. Staveley-Smith. HI Observations of the Tucana Dwarf Elliptical Galaxy. , 112:1969, November 1996. doi: 10.1086/118155.

T. Oosterloo, R. Morganti, and E. M. Sadler. HI in Low-Luminosity Early-Type Galaxies. In P. Carral and J. Cepa, editors, Star Formation in Early Type Galaxies, volume 163 of Astronomical Society of the Pacific Conference Series, page 72, 1999.

J. P. F. Osmond and T. J. Ponman. The GEMS project: X-ray analysis and statistical properties of the group sample. , 350:1511-1535, June 2004. doi: 10.1111/j.1365-2966. 2004.07742.x.

J. Ott, A. M. Stilp, S. R. Warren, E. D. Skillman, J. J. Dalcanton, F. Walter, W. J. G. de Blok, B. Koribalski, and A. A. West. VLA-ANGST: A High-resolution H I Survey of Nearby Dwarf Galaxies. , 144:123, October 2012. doi: 10.1088/0004-6256/144/4/123.

N. N. Patra, J. N. Chengalur, I. D. Karachentsev, S. S. Kaisin, and A. Begum. Cold H I in faint dwarf galaxies. , 456:2467-2485, March 2016. doi: 10.1093/mnras/stv2789.

H. E. Payne, E. E. Salpeter, and Y. Terzian. Interpretation of neutral hydrogen spin temperature measurements. , 272:540-550, September 1983. doi: 10.1086/161318.

Chien Y. Peng, Luis C. Ho, Chris D. Impey, and Hans-Walter Rix. Detailed Structural Decomposition of Galaxy Images. , 124:266-293, July 2002. doi: 10.1086/340952.

D. J. Pisano, D. G. Barnes, L. Staveley-Smith, B. K. Gibson, V. A. Kilborn, and K. C. Freeman. An H I Survey of Six Local Group Analogs. II. H I Properties of Group Galaxies. , 197:28, December 2011. doi: 10.1088/0067-0049/197/2/28.

J. Prasad and J. Chengalur. FLAGCAL: FLAGging and CALlibration Pipeline for GMRT Data. Astrophysics Source Code Library, December 2011.

M. E. Putman, B. K. Gibson, L. Staveley-Smith, G. Banks, D. G. Barnes, R. Bhatal, M. J. Disney, R. D. Ekers, K. C. Freeman, R. F. Haynes, P. Henning, H. Jerjen, V. Kilborn, B. Koribalski, P. Knezek, D. F. Malin, J. R. Mould, T. Oosterloo, R. M. Price, S. D. Ryder, E. M. Sadler, I. Stewart, F. Stootman, R. A. Vaile, R. L. Webster, and A. E. Wright. Tidal disruption of the Magellanic Clouds by the Milky Way. , 394:752-754, August 1998. doi: 10.1038/29466.

M. S. Roberts and M. Haynes. Global Properties Along the Morphological Sequence from Im to Sa. In European Southern Observatory Conference and Workshop Proceedings, volume 49, page 197, January 1994.

D. H. Rogstad, I. A. Lockhart, and M. C. H. Wright. Aperture-synthesis observations of $\mathrm{H}$ I in the galaxy M83. , 193:309-319, October 1974. doi: 10.1086/153164.

N. Roy, J. N. Chengalur, and R. Srianand. A multiwavelength investigation of the temperature of the cold neutral medium. , 365:L1-L5, January 2006. doi: 10.1111/ j.1745-3933.2005.00114.x. 
V. C. Rubin, Jr. Ford, W. K., and N. Thonnard. Extended rotation curves of highluminosity spiral galaxies. IV. Systematic dynamical properties, Sa -\&gt; Sc. , 225: L107-L111, November 1978. doi: 10.1086/182804.

S. D. Ryder, G. Purcell, D. Davis, and V. Andersen. NGC 7421: Surfing the Intracluster Medium? , 14:81-84, April 1997. doi: 10.1071/AS97081.

S. D. Ryder, B. Koribalski, L. Staveley-Smith, V. A. Kilborn, D. F. Malin, G. D. Banks, D. G. Barnes, R. Bhatal, W. J. G. de Blok, P. J. Boyce, M. J. Disney, M. J. Drinkwater, R. D. Ekers, K. C. Freeman, B. K. Gibson, P. A. Henning, H. Jerjen, P. M. Knezek, M. Marquarding, R. F. Minchin, J. R. Mould, T. Oosterloo, R. M. Price, M. E. Putman, E. M. Sadler, I. Stewart, F. Stootman, R. L. Webster, and A. E. Wright. HIPASS Detection of an Intergalactic Gas Cloud in the NGC 2442 Group. , 555:232-239, July 2001. doi: 10.1086/321453.

J. Saponara, P. Benaglia, B. Koribalski, and I. Andruchow. Catalogue of HI PArameters (CHIPA). Boletin de la Asociacion Argentina de Astronomia La Plata Argentina, 57:16-18, Aug 2015.

Juliana Saponara, Bärbel S. Koribalski, Paula Benaglia, and Manuel Fernández López. H I debris in the IC 1459 galaxy group. , 473(3):3358-3366, Jan 2018. doi: 10.1093/ mnras/stx2475.

R. J. Sault, P. J. Teuben, and M. C. H. Wright. A Retrospective View of MIRIAD. In R. A. Shaw, H. E. Payne, and J. J. E. Hayes, editors, Astronomical Data Analysis Software and Systems IV, volume 77 of Astronomical Society of the Pacific Conference Series, page 433, 1995.

J. Schaye. Star Formation Thresholds and Galaxy Edges: Why and Where. , 609: 667-682, July 2004. doi: 10.1086/421232.

D. J. Schlegel, D. P. Finkbeiner, and M. Davis. Maps of Dust Infrared Emission for Use in Estimation of Reddening and Cosmic Microwave Background Radiation Foregrounds. , 500:525-553, June 1998. doi: 10.1086/305772.

S. E. Schneider. Neutral hydrogen in the M96 group - The galaxies and the intergalactic ring. , 343:94-106, August 1989. doi: 10.1086/167687.

C. Sengupta, R. Balasubramanyam, and K. S. Dwarakanath. HI imaging of galaxies in X-ray bright groups. , 378:137-147, June 2007. doi: 10.1111/j.1365-2966.2007.11748. $\mathrm{x}$.

C. Sengupta, T. C. Scott, S. Paudel, D. J. Saikia, K. S. Dwarakanath, and B. W. Sohn. Arp 65 interaction debris: massive H I displacement and star formation. , 584:A114, December 2015. doi: 10.1051/0004-6361/201425149.

P. Serra, T. Oosterloo, R. Morganti, K. Alatalo, L. Blitz, M. Bois, F. Bournaud, M. Bureau, M. Cappellari, A. F. Crocker, R. L. Davies, T. A. Davis, P. T. de Zeeuw, P.-A. Duc, E. Emsellem, S. Khochfar, D. Krajnović, H. Kuntschner, P.-Y. Lablanche, R. M. McDermid, T. Naab, M. Sarzi, N. Scott, S. C. Trager, A.-M. Weijmans, 
and L. M. Young. The ATLAS ${ }^{3 D}$ project - XIII. Mass and morphology of H I in early-type galaxies as a function of environment. , 422:1835-1862, May 2012. doi: 10.1111/j.1365-2966.2012.20219.x.

P. Serra, B. Koribalski, P.-A. Duc, T. Oosterloo, R. M. McDermid, L. Michel-Dansac, E. Emsellem, J.-C. Cuillandre, K. Alatalo, L. Blitz, M. Bois, F. Bournaud, M. Bureau, M. Cappellari, A. F. Crocker, R. L. Davies, T. A. Davis, P. T. de Zeeuw, S. Khochfar, D. Krajnović, H. Kuntschner, P.-Y. Lablanche, R. Morganti, T. Naab, M. Sarzi, N. Scott, A.-M. Weijmans, and L. M. Young. Discovery of a giant HI tail in the galaxy group HCG 44. , 428:370-380, January 2013. doi: 10.1093/mnras/sts033.

P. Serra, B. Koribalski, V. Kilborn, J. R. Allison, S. W. Amy, L. Ball, K. Bannister, M. E. Bell, D. C.-J. Bock, R. Bolton, M. Bowen, B. Boyle, S. Broadhurst, D. Brodrick, M. Brothers, J. D. Bunton, J. Chapman, W. Cheng, A. P. Chippendale, Y. Chung, F. Cooray, T. Cornwell, D. DeBoer, P. Diamond, R. Forsyth, R. Gough, N. Gupta, G. A. Hampson, L. Harvey-Smith, S. Hay, D. B. Hayman, I. Heywood, A. W. Hotan, S. Hoyle, B. Humphreys, B. Indermuehle, C. Jacka, C. A. Jackson, S. Jackson, K. Jeganathan, S. Johnston, J. Joseph, P. Kamphuis, M. Leach, E. Lenc, E. Lensson, S. Mackay, M. Marquarding, J. Marvil, N. McClure-Griffiths, D. McConnell, M. Meyer, P. Mirtschin, S. Neuhold, A. Ng, R. P. Norris, J. O’Sullivan, J. Pathikulangara, S. Pearce, C. Phillips, A. Popping, R. Y. Qiao, J. E. Reynolds, P. Roberts, R. J. Sault, A. E. T. Schinckel, R. Shaw, T. W. Shimwell, L. Staveley-Smith, M. Storey, A. W. Sweetnam, E. Troup, A. Tzioumis, M. A. Voronkov, T. Westmeier, M. Whiting, C. Wilson, O. I. Wong, and X. Wu. ASKAP H I imaging of the galaxy group IC 1459. , 452:2680-2691, September 2015a. doi: 10.1093/mnras/stv1326.

P. Serra, T. Westmeier, N. Giese, R. Jurek, L. Flöer, A. Popping, B. Winkel, T. van der Hulst, M. Meyer, B. S. Koribalski, L. Staveley-Smith, and H. Courtois. SOFIA: a flexible source finder for 3D spectral line data. , 448:1922-1929, April 2015b. doi: 10.1093/mnras/stv079.

J. L. Sérsic. Short Communications. The Distance of NGC 5128. With 1 Figure in the Text. , 51:64, 1960.

Paul R. Shapiro and George B. Field. Consequences of a New Hot Component of the Interstellar Medium. , 205:762-765, May 1976. doi: 10.1086/154332.

Evan D. Skillman, Stéphanie Côté, and Bryan W. Miller. Star Formation in Sculptor Group Dwarf Irregular Galaxies and the Nature of "Transition" Galaxies. , 125: 593-609, February 2003. doi: 10.1086/345964.

L. s. Sparke and J. S. Gallagher. Galaxies in the Universe. 2007.

Julie St-Germain, Claude Carignan, Stéphanie Côte, and Tom Oosterloo. H I in the Field of the Dwarf Spheroidal/Irregular Galaxy PHOENIX. , 118:1235-1244, September 1999. doi: 10.1086/301021.

L. Staveley-Smith, R. D. Davies, and T. D. Kinman. H I and optical observations of dwarf galaxies. , 258:334-346, September 1992. doi: 10.1093/mnras/258.2.334. 
A. M. Stilp, J. J. Dalcanton, E. Skillman, S. R. Warren, J. Ott, and B. Koribalski. Drivers of H I Turbulence in Dwarf Galaxies. , 773:88, August 2013. doi: 10.1088/ 0004-637X/773/2/88.

C. Struve, T. A. Oosterloo, R. Morganti, and L. Saripalli. Centaurus A: morphology and kinematics of the atomic hydrogen. , 515:A67, June 2010. doi: 10.1051/0004-6361/ 201014355 .

G. A. Tammann. A Survey of Dwarf Galaxies. In Massimo Tarenghi and Kurt Kjaer, editors, ESA Workshop on Dwarf Galaxies, page 3, Jan 1980.

G. A. Tammann. Dwarf Galaxies in the Past. In European Southern Observatory Conference and Workshop Proceedings, volume 49, page 3, Jan 1994.

G. B. Taylor, C. L. Carilli, and R. A. Perley, editors. Synthesis Imaging in Radio Astronomy II, volume 180 of Astronomical Society of the Pacific Conference Series, 1999.

D. A. Thilker, L. Bianchi, G. Meurer, A. Gil de Paz, S. Boissier, B. F. Madore, A. Boselli, A. M. N. Ferguson, J. C. Muñoz-Mateos, G. J. Madsen, S. Hameed, R. A. Overzier, K. Forster, P. G. Friedman, D. C. Martin, P. Morrissey, S. G. Neff, D. Schiminovich, M. Seibert, T. Small, T. K. Wyder, J. Donas, T. M. Heckman, Y.-W. Lee, B. Milliard, R. M. Rich, A. S. Szalay, B. Y. Welsh, and S. K. Yi. A Search for Extended Ultraviolet Disk (XUV-Disk) Galaxies in the Local Universe. , 173:538-571, December 2007. doi: 10.1086/523853.

R. C. Thomson. Galaxy shredding. I - Centaurus A, NGC 5237, and the FourcadeFigueroa shred. , 257:689-698, August 1992. doi: 10.1093/mnras/257.4.689.

S. J. Tingay and P. G. Edwards. The multifrequency parsec-scale structure of PKS 2254-367 (IC 1459): a luminosity-dependent break in morphology for the precursors of radio galaxies? , 448:252-257, March 2015. doi: 10.1093/mnras/stu2756.

Eline Tolstoy, Vanessa Hill, and Monica Tosi. Star-Formation Histories, Abundances, and Kinematics of Dwarf Galaxies in the Local Group. Annual Review of Astronomy and Astrophysics, 47:371-425, September 2009. doi: 10.1146/ annurev-astro-082708-101650.

J. L. Tonry, A. Dressler, J. P. Blakeslee, E. A. Ajhar, A. B. Fletcher, G. A. Luppino, M. R. Metzger, and C. B. Moore. The SBF Survey of Galaxy Distances. IV. SBF Magnitudes, Colors, and Distances. , 546:681-693, January 2001. doi: 10.1086/ 318301.

R. B. Tully, H. M. Courtois, A. E. Dolphin, J. R. Fisher, P. Héraudeau, B. A. Jacobs, I. D. Karachentsev, D. Makarov, L. Makarova, S. Mitronova, L. Rizzi, E. J. Shaya, J. G. Sorce, and P.-F. Wu. Cosmicflows-2: The Data. , 146:86, October 2013. doi: 10.1088/0004-6256/146/4/86.

J. P. Vader and B. Chaboyer. The RSA survey of dwarf galaxies, 1: Optical photometry. , 108:1209-1243, October 1994. doi: 10.1086/117149. 
J. Patricia Vader. Metal-Enhanced Galactic Winds. I. , 305:669, June 1986. doi: 10.1086/164281.

S. van den Bergh. A new classification system for galaxies. , 206:883-887, June 1976. doi: 10.1086/154452.

J. M. van der Hulst, J. P. Terlouw, K. G. Begeman, W. Zwitser, and P. R. Roelfsema. The Groningen Image Processing SYstem, GIPSY. In Diana M. Worrall, Chris Biemesderfer, and Jeannette Barnes, editors, Astronomical Data Analysis Software and Systems I, volume 25 of Astronomical Society of the Pacific Conference Series, page 131, January 1992.

J. M. van der Hulst, T. S. van Albada, and R. Sancisi. The Westerbork HI Survey of Irregular and Spiral Galaxies, WHISP. In J. E. Hibbard, M. Rupen, and J. H. van Gorkom, editors, Gas and Galaxy Evolution, volume 240 of Astronomical Society of the Pacific Conference Series, page 451, 2001.

P. C. van der Kruit and L. Searle. Surface photometry of edge-on spiral galaxies. I - A model for the three-dimensional distribution of light in galactic disks. , 95:105-115, February 1981.

J. van Eymeren, C. Trachternach, B. S. Koribalski, and R. J. Dettmar. Non-circular motions and the cusp-core discrepancy in dwarf galaxies. , 505:1-20, October 2009. doi: 10.1051/0004-6361/200912119.

L. Verdes-Montenegro, M. S. Yun, B. A. Williams, W. K. Huchtmeier, A. Del Olmo, and J. Perea. Where is the neutral atomic gas in Hickson groups? , 377:812-826, October 2001. doi: 10.1051/0004-6361:20011127.

G. A. Verdoes Kleijn, R. P. van der Marel, C. M. Carollo, and P. T. de Zeeuw. The Black Hole in IC 1459 from Hubble Space Telescope Observations of the Ionized Gas Disk. , 120:1221-1237, September 2000. doi: 10.1086/301524.

M. A. W. Verheijen and M. Zwaan. HI in the Three Largest LEnticulars in the Ursa Major Cluster. In J. E. Hibbard, M. Rupen, and J. H. van Gorkom, editors, Gas and Galaxy Evolution, volume 240 of Astronomical Society of the Pacific Conference Series, page $867,2001$.

G. L. Verschuur and K. I. Kellermann. Galactic and extra-galactic radio astronomy. 1988.

B. Vollmer, F. Nehlig, and R. Ibata. The flaring Hi disk of the nearby spiral galaxy NGC 2683. , 586:A98, February 2016. doi: 10.1051/0004-6361/201322899.

D. E. P. Walsh, J. H. van Gorkom, W. E. Bies, N. Katz, G. R. Knapp, and S. Wallington. H I observations of three IRAS detected elliptical galaxies. , 352:532-543, April 1990. doi: $10.1086 / 168556$.

F. Walter, E. Brinks, W. J. G. de Blok, F. Bigiel, R. C. Kennicutt, Jr., M. D. Thornley, and A. Leroy. THINGS: The H I Nearby Galaxy Survey. , 136:2563, December 2008. doi: 10.1088/0004-6256/136/6/2563. 
Jing Wang, Bärbel S. Koribalski, Tom H. Jarrett, Peter Kamphuis, Zhao-Yu Li, Luis C. Ho, Tobias Westmeier, Li Shao, Claudia del P. Lagos, Oiwei Ivy Wong, Paolo Serra, Lister Staveley-Smith, Gyula Józsa, Thijs van der Hulst, and Á. R. López-Sánchez. The Local Volume H I Survey: star formation properties. , 472:3029-3057, December 2017. doi: 10.1093/mnras/stx2073.

S. R. Warren, E. D. Skillman, A. M. Stilp, J. J. Dalcanton, J. Ott, F. Walter, E. A. Petersen, B. Koribalski, and A. A. West. Tracing Cold H I Gas in nearby, Low-mass Galaxies. , 757:84, September 2012. doi: 10.1088/0004-637X/757/1/84.

A. B. Whiting, G. K. T. Hau, M. Irwin, and M. Verdugo. An Observational Limit on the Dwarf Galaxy Population of the Local Group. , 133:715-733, February 2007. doi: $10.1086 / 510309$.

T. B. Williams and M. Schwarzschild. A photometric determination of twists in three early-type galaxies. , 227:56-63, January 1979. doi: 10.1086/156703.

Warwick E. Wilson, R. H. Ferris, P. Axtens, A. Brown, E. Davis, G. Hampson, M. Leach, P. Roberts, S. Saunders, B. S. Koribalski, J. L. Caswell, E. Lenc, J. Stevens, M. A. Voronkov, M. H. Wieringa, K. Brooks, P. G. Edwards, R. D. Ekers, B. Emonts, L. Hindson, S. Johnston, S. T. Maddison, E. K. Mahony, S. S. Malu, M. Massardi, M. Y. Mao, D. McConnell, R. P. Norris, D. Schnitzeler, R. Subrahmanyan, J. S. Urquhart, M. A. Thompson, and R. M. Wark. The Australia Telescope Compact Array Broad-band Backend: description and first results. , 416:832-856, September 2011. doi: 10.1111/j.1365-2966.2011.19054.x.

K. Wolfinger, V. A. Kilborn, B. S. Koribalski, R. F. Minchin, P. J. Boyce, M. J. Disney, R. H. Lang, and C. A. Jordan. A blind HI survey in the Ursa Major region. , 428: 1790-1817, January 2013. doi: 10.1093/mnras/sts160.

M. G. Wolfire, D. Hollenbach, C. F. McKee, A. G. G. M. Tielens, and E. L. O. Bakes. The neutral atomic phases of the interstellar medium. , 443:152-168, April 1995. doi: $10.1086 / 175510$.

M. G. Wolfire, C. F. McKee, D. Hollenbach, and A. G. G. M. Tielens. Neutral Atomic Phases of the Interstellar Medium in the Galaxy. , 587:278-311, April 2003. doi: $10.1086 / 368016$.

L. M. Young and K. Y. Lo. The Neutral Interstellar Medium in Nearby Dwarf Galaxies. I. Leo A. , 462:203, May 1996. doi: 10.1086/177141.

L. M. Young and K. Y. Lo. The Neutral Interstellar Medium in Nearby Dwarf Galaxies. III. Sagittarius DIG, LGS 3, and Phoenix. , 490:710-728, December 1997. doi: $10.1086 / 304909$.

Lisa M. Young, Evan D. Skillman, Daniel R. Weisz, and Andrew E. Dolphin. The Aptly Named Phoenix Dwarf Galaxy. , 659:331-338, April 2007. doi: 10.1086/512153.

M. S. Yun, P. T. P. Ho, and K. Y. Lo. New 24 Field VLA Mosaic Imaging of HI in the M81 Group. In Jeffrey G. Mangum and Simon J. E. Radford, editors, Imaging at Radio through Submillimeter Wavelengths, volume 217, page 374, January 2000. 